\title{
Proceedings of the International Congress of the Research Center in Sports Sciences, Health Sciences \& Human Development (2016)
}

\section{INTERNATIONAL CONGRESS EXERCISE AND HEALTH, SPORTS AND HUMAN DEVELOPMENT}

ÉVORA UNIVERSITY $11 \& 12$ NOVEMBER 2016
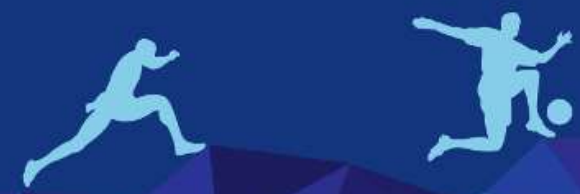

Victor Reis

António Silva

Nuno Batalha

Francisco Saavedra

Catarina Abrantes

Aldo Costa

Pedro Esteves

Ana Teresa Conceição

Tiago Barbosa

Armando Raimundo

\section{SCIENTIFIC COMMITTEE}

Mário Marques

Daniel Marinho

Bruno Travassos

Ana Pereira

Carolina Vila-Chã

Mário Costa

Hugo Louro

Luís Cid

Vitor Lopes

José Parraça

Jorge Bravo
Susana Póvoas

Catarina Pereira

José Marmeleira

Borja Sanudo Corrales

Guilhermo Olcina

Marcus Maynar

Jesus del Pozo

Rafael Timon

Hugo Folgado

Jorge Bravo

Pablo Carús

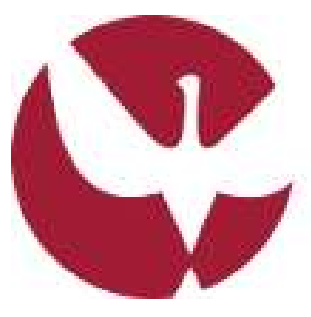

UNIVERSIDADE DE ÉVORA ESCOLA DE CIÊNCIAS E TECNOLOGIA DEPARTAMENTO DE DESPORTOESAÚDE
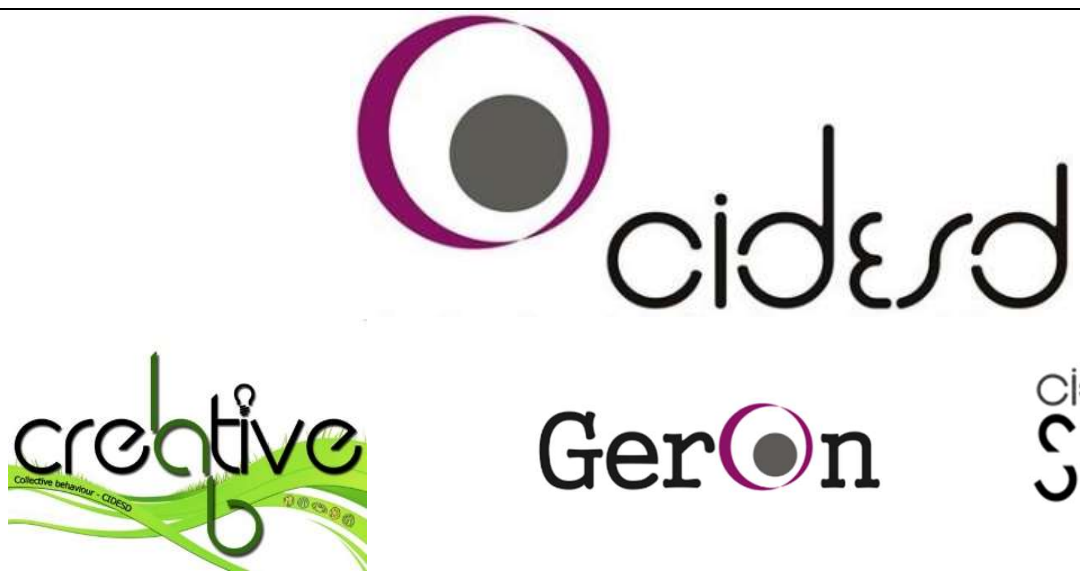

Ger(On

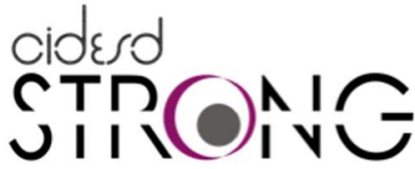

Nan॰Stima 
The papers published in this book of abstracts / proceedings were submitted to the Scientific Commission of the International Congress of Research Center in Sports Sciences, Health Sciences \& Human Development, held on 11 and 12 November 2016, at the University of Évora, Évora, Portugal, under the topic of Exercise and Health, Sports and Human Development. The content of the abstracts is solely and exclusively of its authors responsibility. The editors and the Scientific Committee of the International Congress of Research Center in Sports Sciences, Health Sciences \& Human Development do not assume any responsibility for the opinions and statements expressed by the authors. Partial reproduction of the texts and their use without commercial purposes is allowed, provided the source / reference is duly mentioned.

$\begin{array}{cl} & \text { Abstracts } \\ 101 & \text { Strong group } \\ 153 & \text { Geron group } \\ 191 & \text { Creative Lab group } \\ 228 & \text { Nanostima }\end{array}$




\section{Comparison of kinematics and joint kinetics between seated-down and standing positions in water cycling.}

Mário J. Costa1,5, Carolina Vila-Chã ${ }^{1,5}$, Inês Martins ${ }^{1}$, Marco Branco², Nuno D. Garrido3,5, Tiago M. Barbosa 4,5

1. Polytechnic Institute of Guarda, Portugal; mario.costa@ipg.pt; 2. Polytechnic Institute of Santarém, Portugal; 3. University of Trás-os-Montes and Alto Douro, Portugal; 4. Nanyang Technological University, Singapore; 5. Research Centre in Sport Sciences, Health Sciences and Human Development, CIDESD, Portugal

\section{INTRODUCTION}

Water cycling is a fairly recent water programme in comparison to head-out aquatic programmes. As far as our understanding goes, there are only a few reports on the acute physiological response exercising in different bikes (Giacomini et al., 2009), changing water temperature (Yazigi et al., 2013) or using different training methods (Brasil et al., 2011). However, evidence on the biomechanical adaptations are nonexistent yet. The aim of this study was to compare the angular kinematics and joint forces between different pedalling positions in water cycling.

\section{METHODS}

Seventeen young women $(21.6 \pm 1.6$ years, $58.5 \pm 7.9 \mathrm{~kg}$ of body mass and $1.60 \pm 0.06 \mathrm{~m}$ of height) were recruited to ride a stationary underwater bike during one minute at the cadence of 149 bpm in two randomly assigned conditions: (i) standing and; (ii) seateddown. Kinematic analysis of three full revolutions were performed by a motion capture system (APAS). Kinetic characteristics were estimated by $2 \mathrm{D}$ inverse dynamics. The maximum and minimum angles, range of motion, angular velocity peak, maximal horizontal force, maximal vertical force and torque peak for both knee and ankle joints, were analysed.

\section{RESULTS}

Higher values of maximum $\left(168 \pm 9^{\circ}\right)$, minimum angles $\left(89 \pm 8^{\circ}\right)$, range of motion $\left(79 \pm 6^{\circ}\right)$ and angular velocity peak $\left(352 \pm 4^{\circ} / \mathrm{s}\right)$ were noted in the knee joint for the standing position. Whereas, for the ankle joint, higher values were obtained in the seated-down condition just for the maximum $\left(139 \pm 9^{\circ}\right)$ and minimum $\left(100 \pm 9^{\circ}\right)$. No differences between exercise conditions were found in forces acting in the knee. However, ankle showed a higher maximal horizontal force $(51 \pm 11 \mathrm{~N})$ and torque peak $(21 \pm 7 \mathrm{~N} . \mathrm{m})$ while seated-down.

\section{CONCLUSIONS}

It can be concluded that angular kinematics are changed when assuming different pedalling positions in water cycling. The higher joint forces occur in the most distal joint (i.e. the ankle) pedalling seated-down.

\section{REFERENCES}

Brasil, R. M., Barreto, A. C., Nogueira, L., Santos, E., Novaes, J. S., \& Reis, V. M. (2011). Comparison of Physiological and Perceptual Responses Between Continuous and Intermittent Cycling. Journal of Human Kinetics, 29A, 59-68. https://doi.org/10.2478/v10078-011-0060-7

Giacomini, F., Ditroilo, M., Lucertini, F., De Vito, G., Gatta, G., \& Benelli, P. (2009). The cardiovascular response to underwater pedaling at different intensities: a comparison of 4 different water stationary bikes. The Journal of Sports Medicine and Physical Fitness, 49(4), 432439.

Yazigi, F., Pinto, S., Colado, J., Escalante, Y., Armadada-Silva, P. A. S., Brasil, R., \& Alves, F. (2013). The cadence and water temperature effect on physiological responses during water cycling. European Journal of Sport Science, 13(6), 659-665. https://doi.org/10.1080/17461391.2013.77092 4 


\section{Shoulder rotator water training program effects on strength and muscular balance. Comparison with a conventional dry-land program: a pilot study.}

Sónia Dias ${ }^{1}$, Jorge Bravo ${ }^{1}$, Nuno Batalha ${ }^{1,2}$

1. Departamento de Desporto e Saúde, Escola de Ciência e Tecnologia, Universidade de Évora, Portugal; soniaisabela@gmail.com; 2. Research Centre of Sports, Health and Human Development, CIDESD, STRONG Research Community.

\section{INTRODUCTION}

Some studies (Wanivenhaus et al., 2012) have documented that the swimming propulsive forces responsible for total body displacement are mainly produced by the upper limbs, through arm adduction and shoulder internal rotation, which may lead to an agonistantagonist muscular imbalance, resulting in an injury process. Regarding this issue, some researchers (Swanik et al. 2002) looked for ways to prevent injuries with dry-land strength training programs. However, from our knowledge, there are no studies with water specific strength training programs. This pilot study aims to compare the effects of two training programs on shoulder rotator cuff muscles strength and balance in young swimmers.

\section{METHODS}

A total of 21 male swimmers were assessed and randomly divided in two groups: the land group $(\mathrm{n}=11 ; 13.18 \pm$ 0.98 years old; $49.85 \pm 5.77 \mathrm{Kg} ; 163.18$ $\pm 9.46 \mathrm{~cm}$ of height; $5.70 \pm 0.67$ sessions per week) that performed only a dry-land training program, and the water group $(\mathrm{n}=10 ; 13.00 \pm 1.05$ years old; $49.82 \pm$ $8.03 \mathrm{Kg} ; 160.11 \pm 5.88 \mathrm{~cm}$ of height; $6.09 \pm 0.30$ sessions per week) which performed a training program with exercises exclusively in the water. Both groups were evaluated in the beginning of the season and after 10 weeks. The peak torque of the shoulder internal rotator (IR), external rotator (ER) and unilateral ratios (ER/IR) were evaluated in concentric actions at $60 \%$ and at $180^{\circ} / \mathrm{s}$, performing 3 and 20 repetitions respectively, on an isokinetic dynamometer (Biodex System 3 - Biodex Corp., Shirley, NY, USA).

\section{Intra-group analysis showed} significant increases in strength only for the shoulder IR of the land group. For the protocol at $60^{\circ} \% \mathrm{~s}$, there was a trend to increase strength on the shoulder ER of the land group. Regarding the IR values, differences arose between groups, with higher strength gains with the dry-land training. The land group increased the unilateral ratios significantly when compared to the water group.

\section{CONCLUSIONS}

The dry-land training program proved to be more effective than the one conducted in the water, reducing the shoulder rotator muscle imbalances and increasing the IR strength in young swimmers.

\section{REFERENCES}

Swanik, K. A., Swanik, C. B., Lephart, S. M., \& Huxel, K. (2002). The effect of functional training on the incidence of shoulder pain and strength in intercollegiate swimmers. Journal of Sport Rehabilitation, 11(2), 140-154.

Wanivenhaus, F., Fox, A. J., Chaudhury, S., \& Rodeo, S. A. (2012). Epidemiology of injuries and prevention strategies in competitive swimmers. Sports Health: A Multidisciplinary Approach, 4(3), 246-251. 


\section{Re warm-up prior to football matches: is it beneficial for physical performance?}

Eduardo Abade ${ }^{1,2}$, Jaime Sampaio ${ }^{1,3}$, Bruno Gonçalves ${ }^{1,3}$, Jorge Baptista ${ }^{2}$, Alberto Alves ${ }^{1,2}$, João Viana ${ }^{1,2}$

1. Research Center in Sports Sciences, Health Sciences and Human Development, CIDESD; eabade@ismai.pt; 2. University Institute of Maia; 3. University of Trás-os-Montes e Alto Douro

\section{INTRODUCTION}

Warm-up (WU) routines are widely explored and commonly accepted for optimizing performance and preventing injury. However, official international pre-match protocols may require players to passively rest for approximately 15 minutes in the time-course between WU and the beginning of the match. Therefore, the aim of this study was to assess the contribution of different re warm-up (re-WU) strategies on the physical performance of football players.

\section{METHODS}

Twenty-Two Portuguese elite under19 football players participated in the study conducted during the competitive season. 4 protocols (WU + re-WU) were tested in 4 consecutive days. The protocols differed only in the re-WU strategy applied after the standardized WU: without re-WU (CON), eccentric re-WU (ECC), plyometric re-WU (PLY) and repeated changes of direction re-WU (RCOD). Vertical jump (counter movement, CMJ; and abalakov, $\mathrm{AJ}$ ) and Sprint capacity (10-m and 20-m) were tested immediately after WU and 12 minutes after WU. The re-WU strategies were performed 6 minutes after WU. Magnitude-based inferences and precision of estimation were employed in data analysis.

\section{RESULTS}

Both CMJ and AJ performances presented a likely/very likely improvement after PLY intervention $(\sim 3.8 \%$ in $\mathrm{CMJ}$ and $\sim 4.8 \%$ in $\mathrm{AJ})$ when compared to CON. PLY also showed a moderate very likely beneficial effect in 10-m (Cohen d; $\pm 90 \%$ CL, $-0.7 ; \pm 0.3$ ) and a moderate most likely beneficial effect in 20-m (ES=-0.9; \pm 0.3 ) performances. The RCOD presented a likely/possible beneficial effect to CMJ and AJ, and a moderate likely/most likely beneficial effect to 10-m and 20-m sprint performances. Different practical implications may be taken from the ECC since there was a $-5.1 \pm 5.6 \%$ decrease in CMJ height from post-WU to re-WU which suggests a possible harmful effect when compared to CON.

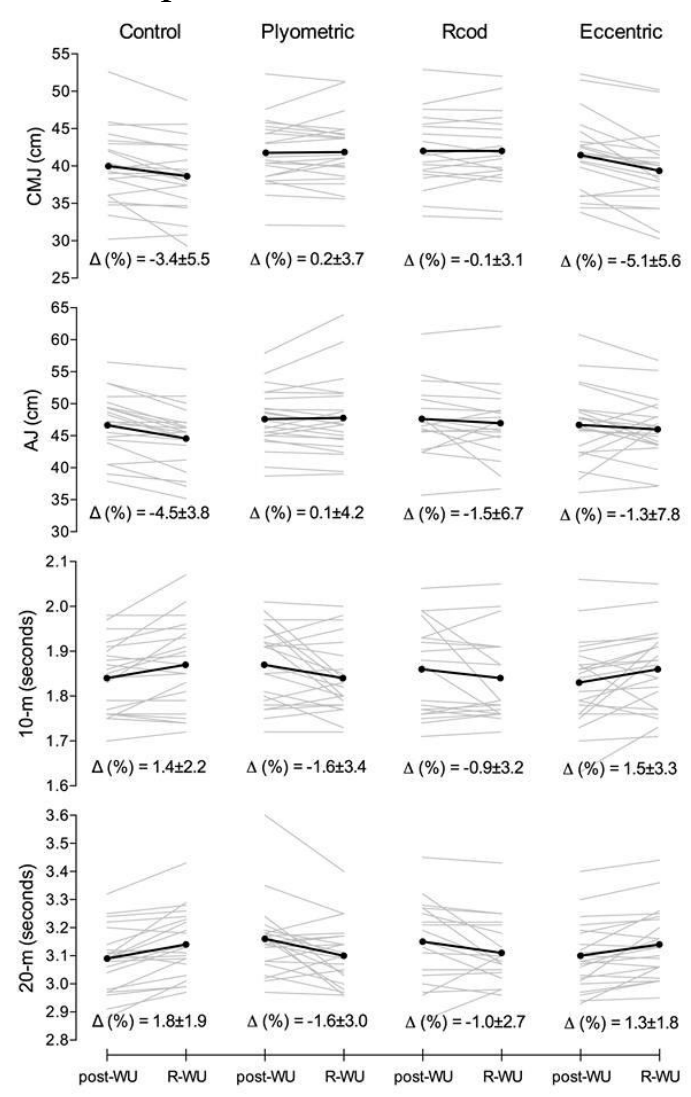

Figure 1. Individual and mean changes from postWU to R-WU in considered performance measures. 


\section{CONCLUSIONS}

The absence of re-WU activities in the time-course between the WU and the beginning of the match may be detrimental to players' physical performance. However, the inclusion of re-WU exercises prior to match is a very delicate issue, since the manipulation of volume, intensity and recovery may positively or negatively affect the subsequent performance (Robbins, 2005). In fact, our research shows that eccentric exercise prior a football match may be harmful for physical performance. However, plyometric and repeated changes of direction exercises seem to be efficient active strategies to attenuate losses in vertical jump and sprint capacity after WU.

\section{REFERENCES}

Robbins, D. W. (2005). Postactivation potentiation and its practical applicability: a brief review. Journal of Strength and Conditioning Research, 19(2), 453-458. https://doi.org/10.1519/R-14653.1

\section{Physical fitness in youth basketball players in pre and post season under a strength program effect.}

Pedro Forte ${ }^{1,2}$, Raul Bartolomeu ${ }^{2,4}$, António M. Monteiro ${ }^{2,3}$, Tiago M Barbosa ${ }^{2,5}$

1. University of Beira Interior, Covilhã, Portugal; pedromiguelforte@gmail.com; 2. Research Center in Sports, Health and Human Development, Vila Real, Portugal; 3. Polytechnic Institute of Bragança, Bragança, Portugal; 4. University of Trás-os-Montes and Alto Douro, Vila Real, Portugal; 5. Nanyang Technological University, Singapure

\section{INTRODUCTION}

Basketball it's an acyclic modality characterized by an intermittent effort, direction changes and a hypersolicitation of upper and lower limbs. Thus, it depends of a physical excellence to individual or collective performance improvement. The aim of this study was to evaluate the physical fitness in youth basketball players in pre-season and post-season under a strength program.

\section{METHODS}

The sample were composed by 12 male basketball players (under-18), with participation in Regional and Nacional Competitions. For physical fitness the following variables were evaluated: Mass (kg); Height (m); upper limbs (pushups/30s) and lower limbs strength (horizontal jump without preparatory race); coordination (dribbling barriers and lay up finalization in seconds); Speed (20 meters sprint in seconds); Flexibility ("seat and reach" and "up the back" in $\mathrm{cm}$ ). The evaluation two moments occurred in September 2015 and January 2016. The strength program was characterized by: $5 \mathrm{~min}$ of crisscross; 4 sets of 10 pus-ups, curl ups, back extensions, vertical jumps and burpees. The training session was divided in three moments, the warming up followed by the strength program, fundamental part (technic and tactic training) and the final one (stretching). Kruskal-Wallis allowed to check statistical differences between the moments.

Table 1

Means and standard deviations in the first and second evaluation moment.

\begin{tabular}{lccc}
\multicolumn{1}{c}{ Variables } & Moment 1 & Moment 2 & F Test \\
\hline Age & $15.83 \pm .55$ & $16.42 \pm 0.64$ & $4.441 ; \mathrm{p}=0.035^{*}$ \\
Mass & $73.67 \pm .58$ & $74.25 \pm 8.42$ & $0.13 ; \mathrm{p}=0.908$ \\
Height & $1.84 \pm 0.08$ & $1.86 \pm 0.06$ & $0.371 ; \mathrm{p}=0.542$ \\
Wingspan & $1.86 \pm .08$ & $1.87 \pm 0.07$ & $0.068 ; \mathrm{p}=0.794$ \\
ULS & $31.58 \pm .49$ & $37.73 \pm 6.12$ & $4.278 ; \mathrm{p}=0.039^{*}$ \\
LLS & $2.33 \pm 0.21$ & $2.36 \pm 0.16$ & $0.459 ; \mathrm{p}=0.498$ \\
Coordination & $13.16 \pm 0.27$ & $6.86 \pm 0.62$ & $6.367 ; \mathrm{p}=0.012^{*}$ \\
Speed & $2.94 \pm 0.08$ & $2.91 \pm 0.11$ & $0.547 ; \mathrm{p}=0.459$ \\
Seat and Reach & $10.25 \pm 8.28$ & $9.42 \pm 9.57$ & $0.191 ; \mathrm{p}=0.662$ \\
Up the Back & $-13 \pm 9.52$ & $13.45 \pm 8.45$ & $13.677 ; \mathrm{p}<0.001^{*}$ \\
\hline Legend: $1-$ ULS: Upper Limbs Strength; LLS: Lower Limbs \\
Strength; ${ }^{*} \mathrm{p}<0.05 ;$
\end{tabular}

\section{RESULTS}

Improvements in all variables were observed in exception of the seat and 
reach test. Statistical differences were observed in age, upper limbs strength, coordination and up to back test. Table 1 presents results in means and standard deviations in the two evaluation moments.

\section{CONCLUSION}

Despite all variables improvement in exception of seat and reach test, it seems that the statistical differences comes from strength program. The upper limbs strength might become from burpees and push-ups exercises. The coordination improvement should be related with the upper limbs strength effect, once strength levels increase leads to sportive technic improvement.

\section{REFERENCES}

Figueiredo, T., Espada, M., \& Pereira, A. (2015). Análise da aptidão física entre jogadores masculinos juvenis de futsal e de basquetebol. Medi@ções, 3(2), $16-27$.

\section{Acute effects of a shoulder rotators strength training session in young swimmers}

Carlos Paixão ${ }^{1}$, Armando Raimundo ${ }^{2,4}$, António J. Silva ${ }^{3,4}$, Nuno Batalha ${ }^{2,4}$

1. Sub-Dep. de Desporto, Escola Superior de Educação, Instituto Politécnico de Beja, Portugal; cfpaixao@hotmail.com; 2. Dep. de Desporto e Saúde, Escola de Ciência e Tecnologia, Universidade de Évora, Portugal; 3. University of Trás-os-Montes and Alto Douro, Vila Real, Portugal; 4. Research Centre of Sports, Health and Human Development, CIDESD, Portugal.

\section{INTRODUCTION}

Competitive swimming usually carries large volumes of daily training, in which the propulsive force is obtained mainly by the upper limbs. Therefore, there may be an overload on the shoulder joint, which can promote muscle imbalances. Some studies showed that shoulder rotators injury prevention training programs are essential (Batalha et al., 2015), and the majority of them are performed before the swim practice. This study aims to analyse the acute effects of an injury prevention training session on shoulder rotators strength, endurance and muscle balance.

\section{METHODS}

A group of 23 young swimmers (13.43 \pm 1.38 years old; $58.97 \pm 7.75 \mathrm{Kg} ; 168.61 \pm$ $7.91 \mathrm{~cm}$ of height) were evaluated. The peak torques (PT) of shoulder internal (IR) and external rotators (ER) were assessed before and after one session of a compensatory strength training program. The ER/IR ratios and the fatigue index (FI) were also assessed.
The measurements were obtained with concentric actions at $60 \% \mathrm{~s} \mathrm{(3} \mathrm{reps)} \mathrm{and} \mathrm{at}$ $180 \%$ s (20 reps), using an isokinetic dynamometer (Biodex System 3 - Biodex Corp., Shirley, NY, USA). The T-Student test for paired samples was used to compare the results.

\section{RESULTS}

Despite a decrease in the ER and IR strength values after the conducted training, there were no significant differences between pre and post assessment, on both shoulders at $60^{\circ} \%$ s. Likewise there were no statistical differences in the ER/IR ratios.

At the angular speed of $180^{\circ} / \mathrm{s}$ in the dominant shoulder, the compensatory strength training session does not induce any significant acute effect in the same variables ER-PT $(p=0.264)$, IR-PT $(\mathrm{p}=0.138)$ and $\mathrm{ER} / \mathrm{IR}$ ratios $(\mathrm{p}=0.750)$. Also for the ER-FI and IR-FI, statistical differences weren't observed $(p=0.910$ and $\mathrm{p}=0.102$ respectively). Regarding the non-dominant shoulder, at the same angular velocity $\left(180^{\circ} / \mathrm{s}\right)$, results were 
similar to the ones obtained in the dominant shoulder.

\section{CONCLUSIONS}

The realization of an injury prevention program does not have a significant acute effect on strength, endurance and muscle balance of rotators of the shoulder in young swimmers. Performing a shoulder rotators strength training program before the aquatic training it seems appropriate.

\section{REFERENCES}

Batalha, N., Raimundo, A., Tomas-Carus, P., Paulo, J., Simão, R., \& Silva, A. J. (2015). Does a landbased compensatory strength-training programme influences the rotator cuff balance of young competitive swimmers? European Journal of Sport Science, 15(8), 764-772. https://doi.org/10.1080/17461391.2015.10511 32

\section{Players' body weight / hip strength ratio as a measure to predict groin injuries in football}

António Calado1 ${ }^{1}$ Bruno Travassos 2,3 , Ricardo Monteiro ${ }^{1}$, Victor Moreno-Pérez ${ }^{4}$, António Dias.

1. Rio Ave Rendimento, Rio Ave FC, Vila do Conde, Portugal; 2. Sports Sciences Department, University of Beira Interior, Covilhã, Portugal; bfrt@ubi.pt; 3. CreativeLab, Research Center in Sports Sciences, Health Sciences and Human Development, CIDESD, Vila Real, Portugal; 4. Sports Research Centre, Miguel Hernandez University of Elche, Elche, Alicante, Spain.

\section{INTRODUCTION}

Groin injuries are among the most common injuries in football players (Arnason et al., 2004), with the adductor muscle weakness has been considered a risk factor. These injuries usually result from sudden changes in direction, and repetitive kicking (Kibler \& Safran, 2005). In this prospective study we investigated the players' body weight / hip strength ratio as a measure to predict groin and adductor injures in football players.

\section{METHODS}

A total of 71 junior and senior players (21.07 \pm 4.73 yr. old) from a Portuguese elite football club integrated the study. Hip strength was assessed with a handheld dynamometer. The body weight were registered using a digital weight measurement balance. Also, a questionnaire on groin pain and injured symptoms was registered during the following weeks. Differences on players body weight / hip strength ratio between injured (IP) and non-injured players
(NIP) were assessed independently via standardized differences with pooled variance, derived from the mean and standard deviation of each variable, with 90\% Confidence Intervals (90\% CI). Thresholds for effect sizes (ES) statistics were 0.2 , trivial; 0.6 , small; 1.2 , moderate; 2.0 , large; and 2.0, very large.

\section{RESULTS}

The mean value of hip strength was $53.20 \pm 10 \mathrm{Kg}$. The mean value of players' weight was $75.25 \pm 8.04 \mathrm{Kg}$. The mean value for the overall body weight / hip strength ratio was $56.25 \pm$ $31.02 \%$. The comparison between IP and NIP players revealed a very large effect on the weight / hip strength ratio with higher values for NIP players in comparison with IP players (2.93, [2.49, 3.33], 53\% possible) (see Fig.1). In general, values below $60 \%$ of body weight / hip strength ratio can be associated to a higher probability of hip adductor and groin injury. 


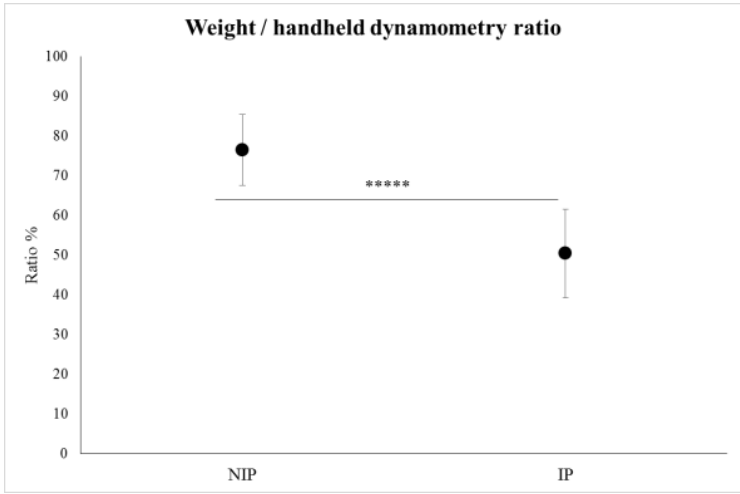

Figure 1. Mean value and standard deviation of the body weight / hip strength ratio for NIP and IP. ${ }^{* * * *}$ very large effect size.

\section{CONCLUSIONS}

Our results revealed that players' body weight / hip strength ratio could be a reliable method to predict groin and adductor injures in football players.

\section{REFERENCES}

Arnason, A., Sigurdsson, S. B., Gudmundsson, A., Holme, I., Engebretsen, L., \& Bahr, R. (2004). Risk factors for injuries in football. The American Journal of Sports Medicine, 32 (1 sup), 5S-16S.

Kibler, W., \& Safran. (2005). Tennis injuries. Em D. J. Caine \& N. Maffulli (Eds.), Epidemiology of Pediatric Sports Injuries: Team Sports (Vol. 48, pp. 120-137). Basel: Karger Medical and Scientific Publishers.

\section{Muscle mechanical properties changes after an Ultra-Trail competition assessed through Tensiomyography}

Pedro Bezerra ${ }^{1,3}$, Bruno Silva1 ${ }^{1}$ Oscar García-García², José M. Cancela-Carral ${ }^{2}$

1. Polytechnic Institute of Viana do Castelo, Portugal; pbezerra@esdl.ipvc.pt; 2. Faculty of Education and Sport Sciences, University of Vigo, Pontevedra, Spain; 3. Research Center in Sports Sciences, Health and Human Development, CIDESD, Portugal

\section{INTRODUCTION}

Ultramarathons and trail running events are increasing in popularity and in number of participant in the last years. Trail running can be defined as off-road endurance run, covering distances from 15 to over $90 \mathrm{~km}$ (ultra-trails) and lasting for over 5 hours on unsurfaced mountain trail involving extensive vertical displacement. Trail running competition affect different functions such cardiac function, muscle soreness, oxidative stress and maximal voluntary contractions (Easthope et al., 2010). However, to our knowledge, the impact on peripheral factors such as skeletal muscle contractile properties after a trail running event were little investigated. Thus, the aim of this study was to analyse the effects of trail running induced fatigue in lower limbs power and muscle contractile properties, accessed through Tensiomyography (TMG).

\section{METHODS}

Seven ultra-trail athletes (2 female) participated in the study $(40.0 \pm 6.5 \mathrm{y}$; $67.9 \pm 13.5 \mathrm{~kg} ; 170.0 \pm 10.9 \mathrm{~cm})$ and were tested on anthropometrics (Tanita BC-418), jump performance (Ergojump Bosco System) and TMG of the rectus femoris (RF) and the biceps femoris (BF) (Maximal Radial Displacement or deformation of muscle belly (Dm); Contraction Time (Tc); Delay Time (Td); Sustain Time (Ts) and Relaxation Time (Tr) ms).

\section{RESULTS}

When related the results before and after the race, is observed a significant decrease in jump performance (Fly Time and Height $p=0.05$, Power $p=0.02$ and Initial Velocity $p=0.04$ ) and anthropometrics (weight, percentage of fat and fat mass $p=0.00$ ). However, the TMG results (table 1) concerning mechanical characteristics and the contractile capacity of the muscles RF 
and $\mathrm{BF}$, only $\mathrm{Td}(\mathrm{p}=0.009)$ of the $\mathrm{RF}$ presents a significant alteration after the $274 \mathrm{~km}$ trail-run. In contrast total body water presents better indicators after the end of all stages $(p=0.048)$.

Table 1

Differences between physical parameters analysis before first stages and after last stage (1 - first assessment; 2 - second assessment)

\begin{tabular}{|c|c|c|c|c|c|c|}
\hline$T M G$ & $\begin{array}{c}\text { Biceps femoris Mean } \\
\text { (Standard Deviation) }\end{array}$ & $\begin{array}{l}\text { Rectus femoris Mean } \\
\text { (Standard Deviation) }\end{array}$ & Tanita 418 & $\begin{array}{c}\text { Mean } \\
\text { (Standard Deviation) } \\
\end{array}$ & Squat Jump & $\begin{array}{c}\text { Mean } \\
\text { (Standard Deviation) }\end{array}$ \\
\hline Tc 1 & $32.0(6.9)$ & $31.7(6.9)$ & Weight 1 & $67.86(13.55)$ & Fly Time 1 & $0.45(0.05)$ \\
\hline Tc 2 & $41.8(22.9)$ & $35.6(12.9)$ & Weight 2 & $66.19(13.55)$ & Fly Time 2 & $0.44(0.05)^{*}$ \\
\hline Dm 1 & $6.8(2.8)$ & $6.7(2.0)$ & Percentage of Fat 1 & $15.86(4.74)$ & Height 1 & $25.80(5.96)$ \\
\hline $\operatorname{Dm} 2$ & $6.4(2.5)$ & $6.1(1.4)$ & Percentage of Fat 2 & $13.10(5.34)^{*}$ & Height 2 & $23.52(5.12)^{*}$ \\
\hline Td 1 & $22.8(2.1)$ & $23.2(1.4)$ & Fat Mass 1 & $10.80(3.99)$ & Power 1 & $743.43(181.37)$ \\
\hline Td 2 & $23.8(3.3)$ & $25.5(1.8)^{*}$ & Fat Mass 2 & $8.8(4.42)^{*}$ & Power 2 & $710.45(170.82)^{*}$ \\
\hline Ts 1 & $215.8(30.4)$ & $106.3(44.2)$ & Fat Free Mass 1 & $57.11(11.74)$ & Initial Velocity 1 & $2.23(0.27)$ \\
\hline Ts 2 & $205.4(20.9)$ & $114.3(37.5)$ & Fat Free Mass 2 & $57.39(11.62)$ & Initial Velocity 2 & $2.14(0.24)^{*}$ \\
\hline $\operatorname{Tr} 1$ & $72.0(48.3)$ & $61.4(37.7)$ & Total Body Water & $37.14(7.78)$ & & \\
\hline $\operatorname{Tr} 2$ & $74.0(62.4)$ & $65.1(36.1)$ & Total Body Water & $39.23(8.48)^{*}$ & & \\
\hline Vc 1 & $0.22(0.10)$ & $0.23(0.10)$ & & & & \\
\hline Vc 2 & $0.18(0.08)$ & $0.19(0.07)$ & & & & \\
\hline
\end{tabular}

\section{CONCLUSION}

An $274 \mathrm{~km}$ ultra-trail running event divided in eight consecutive competition days significantly decreases the power of the lower limbs and induce weight lost attributed to reduction in body fat. Although, the data from TMG evidence the presence of fatigue (Tc, Td and $\mathrm{Dm}$ ), but only significant in Td from RF. It seems that this format of race, do not have an extreme impact on RF and $\mathrm{BF}$ muscle contractile capacity.

\section{REFERENCES}

Easthope, C. S., Hausswirth, C., Louis, J., Lepers, R., Vercruyssen, F., \& Brisswalter, J. (2010). Effects of a trail running competition on muscular performance and efficiency in well-trained young and master athletes. European Journal of Applied Physiology, 110(6), 1107-1116. https://doi.org/10.1007/s00421-010-15971

\section{Swimming performance and tethered swimming in male age group swimmers}

Nuno Amaro1, Daniel A. Marinho ${ }^{2,4}$, Mário C. Marques ${ }^{2,4}$, Nuno Batalha ${ }^{3,4}$, Pedro G. Morouço ${ }^{1}$

1. Polythecnic Institute of Leiria, Leiria, Portugal; nuno.amaro@ipleiria.pt; 2. University of Beira Interior, Covilhã, Portugal; 3. Departamento de Desporto e Saúde, Escola de Ciência e Tecnologia, Universidade de Évora, Portugal; 4. Research Centre of Sports, Health and Human Development, CIDESD, STRONG Research Community

\section{INTRODUCTION}

In competitive swimming, the ability to apply force in the water is crucial, particularly in short distances. Tethered swimming is a reliable methodology to measure force applied by swimmers (Morouço et al., 2014). Therefore, the aim of this study was to determine the correlation between tethered swimming measures and swimming performance.

\section{METHODS}

Twenty-one male prepubescent swimmers (12.7 \pm 0.7 years; $47.7 \pm 9.6$ $\mathrm{Kg} ; 1.56 \pm 0.78 \mathrm{~m}$ ) were recruited for this research. Experiments were conducted during the competitive period of the spring training, thus ensuring that the subjects were in a prime training period cycle. After an $800 \mathrm{~m}$ moderate 
intensity warm-up, a maximal intensity front crawl tethered swimming was conducted to measure force produced in the water. The duration of the exercise was $40 \mathrm{~s}$ with an initial phase of $10 \mathrm{~s}$ with moderate intensity and $30 \mathrm{~s}$ at maximum intensity. Values of mean force (MF), maximum force (MAX) and mechanical impulse (IMP) were obtained. Swimming performance tests were executed after an $800 \mathrm{~m}$ moderate intensity warm-up in a $25 \mathrm{~m}$ indoor swimming pool. All subjects completed one maximal test of $50 \mathrm{~m}$ and $15 \mathrm{~m}$ (to exclude the influence of start) in front crawl in order to access their best time in each test (t50 and t15). Spearman correlation coefficients were calculated between in water and dry land parameters assessed. Significance was accepted at the $\mathrm{p}<0.05$ level.

Table 1

Correlation values $(\rho)$ between tethered swimming values (MF; MAX and IMP) and swimming performance (15 and $50 \mathrm{~m})$.

\begin{tabular}{cccc}
\hline & MF & MAX & IMP \\
\hline t15 & $-0.77^{*}$ & $-0.69^{*}$ & $-0.76^{*}$ \\
$\mathrm{t} 50$ & $-0.79^{*}$ & $-0.69^{*}$ & $-0.78^{*}$ \\
\hline${ }^{*} \mathrm{p}<0.01$ & & &
\end{tabular}

\section{RESULTS}

Correlations obtained between swimming performance and tethered swimming values were strong for $\mathrm{MF}$ and IMP, and moderate for MAX (table $1)$. Mean values ( \pm sd) obtained for tethered swimming were: $59.82 \pm 14.26$ $\mathrm{N}(\mathrm{MF}) ; 70.57 \pm 20.38$ N.s (IMP) and $149.99 \pm 42.96 \mathrm{~N}$ (MAX). Swimming performance mean values ( \pm sd) were $10.63 \pm 0.51 \mathrm{~s}$ for $15 \mathrm{~m}$ trial and 33.70 $\pm 2.46 \mathrm{~s}$ for $50 \mathrm{~m}$ trial.

\section{CONCLUSION}

As in elite swimmers, tethered swimming values showed a strong correlation with swimming performance, in age group swimmers. Therefore, tethered swimming seems to be a methodology with strong association with swimming performance also in lower competitive levels.

\section{REFERENCES}

Morouço, P, Marinho, DA, Keskinen, K, Badillo, J, and Marques, MC (2014). Tethered swimming can be used to evaluate force contribution for shortdistance swimming performance. Journal of Strength and Conditioning Research, 28(11), 30933099

\section{Are stretching routines harmful for sprint performance when added to warm-up?}

Henrique P. Neiva1,2, Maria H. Gil ${ }^{1,2}$, Mário C. Marques ${ }^{1,2}$, Tiago M. Barbosa ${ }^{2,3}$, António B. Sousa ${ }^{1,2}$, Fausto Veríssimo ${ }^{1}$, Daniel A. Marinho ${ }^{1,2}$

1. University of Beira Interior, Department of Sport Sciences, Portugal; henriquepn@gmail.com; 2. Research Centre in Sport Sciences, Health Sciences and Human Development, CIDESD, Portugal; 3. National Institute of Education, Nanyang Technological University, Singapore

\section{INTRODUCTION}

Stretching, static (SS) or dynamic (DS), are generally considered as an essential component of training programs and also as part of the warmup routines (McGowan \& Pyne, 2015). Although recent studies have challenged some of these beliefs, coaches and athletes continue to include these routines in their preparation activities to optimize performance and to prevent from injuries (McGowan \& Pyne, 2015). In fact, several limitations have been pointed out to those studies that discourage the use of stretching during warm-up and it is unknown the effect of SS or DS in maximal efforts and repeated sprint ability performances (Kay \& 
Blazevich, 2012). Therefore, our purpose was to examine the effects of using SS or DS added to the warm-up common routine, in short running performance and repeated sprint ability performance.

\section{METHODS}

On three different occasions (separated by $48 \mathrm{~h}), 16$ college-age men $(n=10)$ and women $(n=6)$ performed one of three warm-ups followed by a $2 \times 60 \mathrm{~m}$ sprint-test (5min interval) in a counterbalanced design. The control warm-up consisted of $10 \mathrm{~min}$ of lightintensity running, and the two experimental warm-ups consisted on adding a SS or a DS routine to the control warm-up. Performance and physiological variables were evaluated during procedures.

\section{RESULTS}

In the first sprint of $60 \mathrm{~m}$ there were no differences between the three warmups tested $(F=0.21, \mathrm{p}=0.73)$, as opposed to that observed in the second $60 \mathrm{~m}$ repetition $(F=7.04, \mathrm{p}<0.01)$. The participants were $1.70 \%$ faster after the SS warm-up compared with the control warm-up. The sum of the time performed in the two sprints emphasizes these results, with better performances in the SS warm-up instead of the control $(1.01 \%)$ and of the DS warm-up (0.80\%).

\section{CONCLUSIONS}

These results suggest that including a SS routine or a DS routine during warmup may be viable choices to optimize sprinting performance. The better performance in the second sprint after the warm-up including SS suggests that this particular stretching method could positively influence the repeated sprint ability.

\section{REFERENCES}

Kay, A.D., \& Blazevich, A.J. (2012). Effect of acute static stretch on maximal muscle performance: a systematic review. Medicine and Science in Sport and Exercise, 44(1), 154-164.

McGowan, C. J., Pyne, D. B., Thompson, K. G., \& Rattray, B. (2015). Warm-up strategies for sport and exercise: Mechanisms and applications. Sports Medicine, 45(11), 1523-1546.

\section{Effects of order and sequence of resistance and endurance training on body fat in Prepubescent girls}

Ana Alves ${ }^{1}$, Carlos Marta ${ }^{2,4}$, Mário C. Marques ${ }^{1,3}$

1. University of Beira Interior. Department of Sport Sciences, Covilhã, Portugal; anasofiaruivoalves@gmail.com; 2. Polytechnique Institute of Guarda, Department of Sport Sciences, Guarda, Portugal; 3. Research Center in Sport Sciences, Health Sciences and Human Development, CIDESD, Portugal; 4. Research Unit for Inland Development, UDI, Guarda, Portugal

\section{INTRODUCTION}

There is a large number of studies reporting the efficacy of school-based programs to increase physical activity and improve the body composition among young people (Kriemler et al., 2003). Strength-only or endurance-only training vs. combined strength and endurance training are usually used for fat mass and weight loss programs (Akbarpour et al., 2011; Santos et al., 2012). However, there are some doubts on the best program to use. The aim of the current study was to investigate the effect of different methods of training on body fat percentage in prepubescent girls.

\section{METHODS}

One hundred twenty-six girls (10.95 \pm 0.48 years) were randomly assigned into five experimental groups to perform different training protocols per week for 8 weeks: Resistance-only (R), 
endurance-only (E), concurrent distinct endurance-resistance (CDER), concurrent parallel endurance-resistance (CPER), concurrent parallel resistanceendurance (CPRE), and a control group (C).

\section{RESULTS}

Body fat percentage significantly decreases from pre- to the post-training only in the CPRE $(p<0.001)$ and CPER $(p<0.05)$ groups. There was an increase in the control group.

\section{CONCLUSIONS}

Performing concurrent resistance and endurance training in the same session is more helpful than endurance or resistance training alone or combined resistance and endurance training in separate sessions for reducing body fat percentage of prepubescent girls. Also, the order of concurrent parallel resistance and endurance training did not influence the body fat percentage. These results have a meaningful interest to optimized school-based fat loss exercise programs in childhood.

\section{REFERENCES}

Akbarpour, M. B., Assarzadeh, M. \& Sadeghian, H. (2011). The Effect of Combined StrengthEndurance Training on the Improvement of Cardiovascular Disease Risk Factors of Obese Middle-aged Men. Annals of Biological Research, 2(6), 123-129.

Kriemler, S., Zahner, L., Schindler, C., Meyer, U., Hartmann, T., Hebestreit, H., ... Puder, J. J. (2010). Effect of school based physical activity programme (KISS) on fitness and adiposity in primary schoolchildren: cluster randomised controlled trial. BMJ (Clinical Research Ed.), 340, c785.

Santos, A. P., Marinho, D. A., Costa, A. M., Izquierdo, M., \& Marques, M. C. (2012). The effects of concurrent resistance and endurance training follow a detraining period in elementary school students. Journal of Strength and Conditioning Research, 26(6), 1708-1716. https://doi.org/10.1519/JSC.0b013e318234e87 2

\section{Performance and physiological changes after an Olympic distance triathlon under thermal stress conditions}

Guillermo Olcina ${ }^{1}$, Rafael Timón ${ }^{1}$, Javier Brazo-Sayavera ${ }^{1}$, Ismael Martínez-Guardado¹, Marta Marcos-Serrano ${ }^{1}$, Carmen Crespo ${ }^{1}$

1. Sport Sciences Faculty, University of Extremadura, Cáceres, Spain; golcina@unex.es

\section{INTRODUCTION}

Triathlon is classified as an endurance sport which involves three consecutive efforts: swimming, cycling and running. Most part of triathlon races are scheduled in summer. The aim of this study was to evaluate the acute effects on some physiological parameters and performance after the completion of an Olympic distance triathlon in a hot environment.

\section{METHODS}

Twenty three triathletes, who participated in a triathlon qualifier for the National Spanish Championship, were recruited. Average temperature during the race was $31^{\circ} \mathrm{C}$. Before and after the race, body composition, CMJ jump test and perceived exertion through the use of the BORG and VAS scales were assessed. As well, blood analysis were performed analysing the following parameters: Lactate $(\mathrm{mmol} / \mathrm{L})$, Haematocrit (\%), Glucose $(\mathrm{mg} / \mathrm{dL})$, Total protein $(\mathrm{mg} / \mathrm{dL})$, Triglycerides $(\mathrm{mg} / \mathrm{dL}), \quad$ Bilirubin (mg/dL), GOT (IU/L), GPT (IU/L), LDH (IU/L), BUN (mg/dL), CPK (IU/L). RESULTS: The results showed an increase $(p<0.001)$ in the different markers of metabolic stress and 
muscular damage following the triathlon in a range between 13 and $21 \%$, but always within a normal range, with the exception of CPK (IU/L) (PRE $149.33 \pm$ 108.16 vs POST $290.10 \pm 102.48)$. CMJ decreased $3.24 \% \quad(p>0.001)$, body weight decreased $1.7 \%(\mathrm{p}<0.001)$, no reporting changes on haematocrit.

\section{CONCLUSIONS}

It seems that competing in an Olympic-distance triathlon under heat conditions does not pose health risks for trained triathletes if fluid loss is under a low rate. However due to CPK changes; short term recovery should be studied.

\begin{abstract}
Aknowledgments:
This paper was supported by 226ERS (research agreement 179/15) and by the Council of Extremadura (Aid for research groups GR 15020) for funding the research.
\end{abstract}

\section{REFERENCES}

Aragón-Vargas, L. F., Wilk, B., Timmons, B. W., \& Bar-Or, O. (2013). Body weight changes in child and adolescent athletes during a triathlon competition. European Journal of Applied Physiology, 113(1), 233-239. https://doi.org/10.1007/s00421-012-2431-8

Long, D., Blake, M., McNaughton, L., \& Angle, B. (1990). Hematological and biochemical changes during a short triathlon competition in novice triathletes. European Journal of Applied Physiology and Occupational Physiology, 61 (1-2), 93-99.

Suzuki, K., Peake, J., Nosaka, K., Okutsu, M., Abbiss, C. R., Surriano, R., ... Laursen, P. B. (2006). Changes in markers of muscle damage, inflammation and HSP70 after an Ironman Triathlon race. European Journal of Applied Physiology, 98(6), 525-534. https://doi.org/10.1007/s00421-006-0296-4

\section{Concurrent strength and aerobic training followed by a detraining period: does strength training intensity matters?}

António Sousa ${ }^{1,2}$, Daniel A. Marinho1,2, Maria H. Gill, ${ }^{1,2}$ Henrique Neiva ${ }^{1,2}$, Mário C. Marques ${ }^{1,2}$

1. Department of Sport Sciences, University of Beira Interior, Covilhã, Portugal; antonio carlossousa@hotmail.com; 2. Research Centre in Sports Sciences, Health Sciences and Human Development, Portugal

\section{INTRODUCTION}

Concurrent training (combination of strength and aerobic regimens) has become a contemporary topic for researchers due to the controversial results claimed by different studies (Cadore et al., 2014; García-Pallarés \& Izquierdo, 2011). Additionally, interruptions in training because of illness, injury, post-season breaks or other factors are normal in any sport. Therefore, this study aimed to examine the effects of different combinations of strength training intensities with an aerobic regimen followed by a detraining period (DT) on explosive strength and maximal oxygen uptake $\left(\mathrm{VO}_{2} \max \right)$.

\section{METHODS}

26 young athletes of distinct explosive sports (age: 20.6 \pm 1.7 years; weight: $69.1 \pm 7.3 \mathrm{~kg}$, height: $1.80 \pm 0.1 \mathrm{~m}$ ) participated on study. They were allocated into 3 homogenous squat training groups: i) a high-load (70-85\% $1 \mathrm{RM})$ group (GHL $\mathrm{n}=9)$; ii) a moderateload (55-70\% 1RM) group (GML $n=9)$; iii) and a light-load (40-55\% 1RM) group (GLL $n=8$ ); in addition, all subjects performed a countermovement vertical jump set (CMVJ). Each experimental group performed the same aerobic training protocol based on shuttle run test ( $70 \%$ of the established maximum volume achieve on a previous test). The total volume of training was 
the same regardless of the intensity of the load of each group.

\section{RESULTS}

After 8 weeks of training, there was improvement in the $10 \mathrm{~m}$ sprint for the GHL $(3.5 \%)$ and in the $20 \mathrm{~m}$ sprint for the GLL (1.4\%). It was noticed gains in the CMVJ, full squat (FS) and VO2max for the GHL (12.5\%, $11.6 \%$ and $12.3 \%$, respectively), GML (14.4\%, 10.2\% and $12.4 \%$, respectively) and GLL ( $11.7 \%$, $14.2 \%$ and $15.4 \%$ respectively). After 4 weeks of DT, there was an important loss in the $20 \mathrm{~m}$ sprint performance for the GHL (2.5\%), GML (3.4\%) and GLL $(-2.0 \%)$. It was also observed differences inVO2max for the GHL and GML of $9.1 \%$ and $-14.7 \%$, respectively. The results showed a decrement in the FS for the GLL corresponding to $7.0 \%$ and in the $10 \mathrm{~m}$ sprint for the GHL corresponding to $2.2 \%$.

\section{CONCLUSIONS}

This study suggests that an appropriate combination of different strength training intensities combined with the same aerobic training can be effective in improving both strength and aerobic performances in athletes of different explosive strength modalities. Moreover, a short DT tends to decrease overall performances, except for vertical jump ability.

\section{REFERENCE}

Cadore, E. L., Pinto, R. S., Bottaro, M., \& Izquierdo, M. (2014). Strength and endurance training prescription in healthy and frail elderly. Aging and Disease, 5(3), 183-195. https://doi.org/10.14336/AD.2014.0500183

García-Pallarés, J., \& Izquierdo, M. (2011). Strategies to optimize concurrent training of strength and aerobic fitness for rowing and canoeing. Sports Medicine, 41(4), 329-343. https://doi.org/10.2165/11539690-00000000000000

\section{Association between body composition clinical markers and cardiorespiratory performance in youg non-athlete males}

Diana Filipe ${ }^{1}$, Cristiana Mercê ${ }^{1}$, Maria Fernandes ${ }^{1}$, Filipe N. Gomes ${ }^{1}$, Nuno M. Pimenta ${ }^{1}$

1. Instituto Politécnico de Santarém, Escola Superior Desporto Rio Maior, ESDREM, Rio Maior, Portugal; dianafilipe@msn.com

\section{INTRODUCTION}

Body Composition (BC) is an important health related fitness component (ACSM, 2013). Body fat has been found a limiting factor for performance in sport. To our knowledge it is unknown if and to what extent specific markers of body composition are related to performance in non-athletes young adults (Mooses et al., 2013). The purpose of this study was to investigate if and how specific markers of body composition are associated with cardiorespiratory performance in male non-athletes, yet active, apparently healthy young adults.

\section{METHODS}

We assessed 12 apparently healthy young adult male subjects $(20.9 \pm 0.7$ years). All subjects underwent a maximal treadmill graded exercise test (GXT) using Bruce standard protocol. Cardiorespiratory performance was assessed by test duration. Body composition assessment consisted of anthropometry, specifically: weight, height, waist, hip and calf circumferences, abdominal, thigh and calf skinfolds, and body indexes were calculated as follows: body mass index, waist-to-hip ratio, waist-to-height ratio, body adiposity index, conicity index and abdominal volume index. 


\section{RESULTS}

Cardiorespiratory performance was negatively associated with weight $(\mathrm{r}=$ 0.73; $p=0.021$ ) and hip circumference $(\mathrm{r}=-0.60 ; \mathrm{p}=0.067)$ and was positively associated with waist-to-hip ratio ( $\mathrm{r}=$ 0.65; $\mathrm{p}=0.042$ ) meaning that increased hip circumferences and body masses were predictors of reduced cardiorespiratory performance. The fact that no other no other body composition component showed relation with cardiorespiratory performance seem to indicate that the associations found may reflect more a mechanical influence, with metabolic consequences, rather than a metabolic effect of BC alone.

\section{DISCUSSION}

Markers of body size and mass seem to explain better cardiorespiratory performance them other body composition marques more related with fat accumulation, in active non-athletes apparently healthy young adult male subjects. Future studies should confirm these results.

\section{REFERENCES}

American College of Sport Medicine. (2013). ACSM's Guidelines for Exercise Testing and Prescription ( $9^{\text {th }}$ ed.). Baltimore: Lippincott Williams \& Wilkins.

Mooses, M., Jürimäe, J., Mäestu, J., Purge, P., Mooses, K., \& Jürimäe, T. (2013). Anthropometric and physiological determinants of running performance in middle-and long-distance runners. Kineziologija, 45(2), 154-162.

\section{Is shoulder rotator strength and balance affected by a single swim practice?}

Nuno Batalha1,2, Parraca, J.A.1,2, Hugo Louro ${ }^{2,3}$, Ana Conceição ${ }^{2,3}$, António Silva ${ }^{2,4}$, Daniel A. Marinho $^{2,5}$, Mário J. Costa ${ }^{2,6}$

1. Departamento de Desporto e Saúde, Escola de Ciência e Tecnologia, Universidade de Évora, Portugal; nmpba@uevora.pt; 2. Research Centre of Sports, Health and Human Development, CIDESD, STRONG Research Community; 3. Sport Sciences School of Rio Maior, Portugal; 4. University of Trás-os-Montes and Alto Douro, Vila Real, Portugal; 5. University of Beira Interior, Sports Sciences Department, Covilhã, Portugal; 6 Polytechnic Institute of Guarda, Portugal.

\section{INTRODUCTION}

Dry-land training programs that focus on preventing shoulder rotators injuries are essential for swimmers. Normally, training routines comprise strength programs before (Batalha et al., 2015) or after (Ramsi et al, 2004) the swimming session. However, it is unclear if one swimming session will induce fatigue and impair muscle strength and balance. This study aimed to analyse the acute effects in shoulder rotators strength and balance after a standard swim practice.

\section{METHODS}

Seventy-two male swimmers (16.28 \pm 1.55 years; $63.97 \pm 6.85 \mathrm{Kg} ; 174.1 \pm$ $7.89 \mathrm{~cm}$ ) performed strength tests targeting both shoulders before and after a standardized swim practice (with
$4600 \mathrm{~m}$ of total swimming volume in long course swimming pool: $900 \mathrm{~m}$ of warm-up with low intensity tasks, $800 \mathrm{~m}$ of technical training, $400 \mathrm{~m}$ of velocity training, $1000 \mathrm{~m}$ of aerobic training capacity, $600 \mathrm{~m}$ of aerobic power training, and $900 \mathrm{~m}$ of recovery tasks). A microFET2 hand-held dynamometer (Hoggan Scientific LLC, Utah) was positioned proximal to the ulnar styloid process on the posterior surface of the forearm to assess external (ER) and internal (IR) rotators strength. Maximal isometric strength and ER/IR ratios were assessed in prone position, as previously described (Ramsi et al. 2014). Prior to these tests a test-retest was performed in order to calculate the interclass correlation coefficients (ICC) 
of the IR and ER evaluation. All ICC results were high $(>0.90)$.
No significant differences were found between strength values before and after the swim practice (table 1 ).

\section{RESULTS}

Table1

$E R, I R$ and $E R / I R$ ratios values before and after the swim practice.

\begin{tabular}{ccccc}
\hline & & Dominant shoulder & \\
& $\begin{array}{c}\text { Pre-intervention } \\
(\text { Mean } \pm \text { SD) }\end{array}$ & $\begin{array}{c}\text { Post-intervention } \\
(\text { Mean } \pm \text { SD) }\end{array}$ & $\begin{array}{c}\text { Difference } \\
\text { Mean (95\% CI) }\end{array}$ & $p$ \\
\hline ER-PT (N) & $151.15 \pm 30,54$ & $150.31 \pm 32,99$ & $-0.84(-5.47$ to 7,16) & 0.791 \\
IR-PT (N) & $196.30 \pm 37.54$ & $191.7 \pm 40.61$ & $-4,60(-2.06$ to 11,27) & 0.173 \\
ER/IR ratio (\%) & $77.61 \pm 11.73$ & $79.51 \pm 14.59$ & $1.90(-5.07$ to 1.27) & 0.236 \\
\hline & & Non-dominant shoulder & \\
\hline & Pre-intervention & Post-intervention & Difference & $p$ \\
\hline ER-PT (N) & $($ Mean \pm SD) & (Mean \pm SD) & Mean (95\% CI) & 0.755 \\
IR-PT (N) & $137,73 \pm 23,94$ & $137,05 \pm 24,63$ & $-0,68(-3.67$ to 5,04) & 0.202 \\
ER/IR ratio (\%) & $200,83 \pm 42,88$ & $196,43 \pm 45,19$ & $-4.40(-2,41$ to 11,21$)$ & 0.369 \\
\hline P-p & $70.22 \pm 12.80$ & $71.62 \pm 13.83$ & $1.40(-4,49$ to 1,68$)$ &
\end{tabular}

p-paired sample T-test

\section{CONCLUSION}

The shoulder rotators strength and balance do not seem to be impaired after performing a standard swim session. Our results suggest that coaches can plan a shoulder rotators dry-land strength training program instantly after the swimming session.

\section{REFERENCES}

Batalha, N., Raimundo, A., Tomas-Carus, P., Paulo, J., Simão, R., \& Silva, A. J. (2015). Does a land- based compensatory strength-training programme influences the rotator cuff balance of young competitive swimmers? European Journal of Sport Science, 15(8), 764-772. https://doi.org/10.1080/17461391.2015.10511 32

Ramsi, M., Swanik, K. A., Swanik, C., Straub, S., \& Mattacola, C. (2004). Shoulder-Rotator Strength of High School Swimmers Over the Course of a Competitive Season. Journal of Sport Rehabilitation, 13(1), 9-18. https://doi.org/10.1123/jsr.13.1.9

\section{Body Fat estimation among young football players: DXA versus Bioimpedance}

Miguel Camões ${ }^{1}$, Bruno Silva ${ }^{1}$, Mário Simões ${ }^{1,2}$, Filipe M. Clemente ${ }^{1,3}$, Pedro Bezerra ${ }^{1,4}$

1. Instituto Politécnico de Viana do Castelo, Escola Superior de Desporto e Lazer; joaocamoes@esdl.ipvc.pt; 2. Instituto politécnico da MAIA, Grupo de Investigação para o Desporto, Educação e Saúde, GIDES; 3. Instituto de Telecomunicações, Delegação da Covilhã, Portugal; 4. Research Center in Sports Sciences, Health and Human Development, CIDESD

\section{INTRODUCTION}

Accurate assessment of body composition is an important issue among sports athletes. Different methodologies used in the evaluation of body composition originate controversial results, leading to a deep uncertainty on individual exercise prescription. Thus, this study aims to identify the differences between a widely used method, such as bioelectrical impedance (BIA), and a clinical method, highly accurate, Dual-energy X-ray absorptiometry (DXA), among elite young football players.

\section{METHODS}

Observational study, recruited 38 male Football athletes with mean (sd) age of 16.7 (0.87) years, involved in the Portuguese national competition of U16 $(n=13)$ and U19 $(n=25)$. Study participants were invited to visit the Escola Superior de Desporto e Lazer to be 
evaluated on several sports performance determinants. Objective measures of body composition, muscle strength and football skills, were collected by trained technicians. Body composition was assessed using the electrical bioimpedance (Tanita BC-418, Tanita Corp., Tokyo, Japan), in agreement with all the evaluation premises, in order to reduce the error in the estimation of the different body compartments. Additionally, all athletes were evaluated using the clinical method DXA scanner using a General Electric Hologic Discovery (Hologic Inc., Waltham, MA, USA). Spearman correlation and the mean difference between the two methods used to assess body composition was calculated. The agreement between both methods was illustrated using the Bland and Altman plots.

\section{RESULTS}

Despite the moderate correlation between methods $(r=0.33)$ to estimate the percentage of total fat, the median of the difference between methods (DXA vs BIA) was relevant in clinical terms, $2.9 \%$ and $1.47 \%$ for U16 and U19 athletes respectively. The Bland and
Altman plots, showed a clear tendency in the evaluations using the BIA, namely among athletes with better body composition profile (8-12\% of fat). A clear underestimation of body fat assessment using BIA was observed among $94.5 \%$ of the athletes with less of $12 \%$.

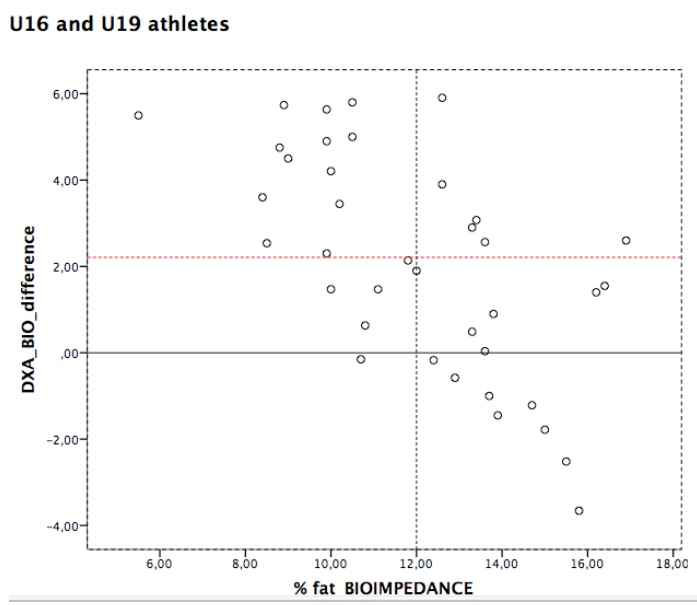

Figure 1. Bland-Altman plots.

\section{CONCLUSION}

Among the evaluated athletes, fat mass is underestimated on average $2.21 \%$, using bioelectrical impedance in comparison with DXA. In addition to the BIA, further data is needed to support the body composition assessments in field context.

\section{How gymnasts perceive context informational variables and regulate action in vaulting?}

Joana Barreto ${ }^{1}$, César Peixoto ${ }^{1}$

1. Faculty of Human Kinetics, Lisbon, Portugal; cpeixoto@fmh.ulisboa.pt

\section{INTRODUCTION}

Gymnastics are one of the most ancient motor activity in the world. It started with acrobatic movements in the Crete-Mycenaean culture, 2500 years BC (Cuk \& Karácsony, 2004). Scientific investigations start to arise in order to understand multiple aspects as expertise performance and interaction between the gymnast and context/environment. The aim of this work is to understand how gymnasts perceive context informational variables, and how they adjust their actions to succeed in vaulting. 


\section{METHODS}

A sample of six male senior elite teamgym gymnasts were selected to participate $(22.17 \pm 3.81$ years old, with at least nine years of practice). We recorded three rounds of six vaulting, measured and analyzed kinematic indicators as: distance (meters), time (seconds), angle (degrees) and speed (meters/second), during six phases of movement: approach run to trampete; hurdle step, 1st flight; vaulting take-off to the highest point of center of gravity (measured in vertical), 2nd flight and approach run to land. We registered the difficulty values for each vaulting. We used SPSS Statistics 21 to analyze the results.

\section{RESULTS}

Results demonstrated: the larger the hurdle step, the higher the horizontal speed in the same phase; the larger the $1^{\text {st }}$ flight, the less the speed in this phase and the lower the difficulty value. For a slower approach run, more time is needed for the $2^{\text {nd }}$ flight and the less the speed in $2^{\text {nd }}$ flight. If the $2^{\text {nd }}$ flight vertical distance are larger, the difficulty value are superior. At last, the longer the $2^{\text {nd }}$ flight (till the highest point of gravity center) the lower the velocity in the same phase and lower the difficulty value.

\section{CONCLUSIONS}

We conclude with this work that gymnasts use spacial-temporal cognition to visually perceive the context (apparatus position, distances to and between apparatus) and constantly adapt their actions. As literature refers, visually perceiving the context guide approach run, position of the feet and hands, but, as we observed, this perception mainly guide the production of velocities that will translate to forces and produce the different phases of the movement.

\section{REFERENCES}

Cuk, I., \& Karácsony, I. (2004). Vault: methods, ideas, curiosities, history. ( $2^{\text {nd }}$ ed.). Slovenia: STD Sangvincki.

UEG. (2009). Seniors and Juniors Code of Points October 2009. Including Revision A (August 2010) and Revision

\section{Shoulder pain according to age, wheelchair use and years of injury in wheelchair basketball players}

Saleky García-Gómez ${ }^{1}$, Javier Pérez-Tejero ${ }^{1}$

1. Technical University of Madrid, Madrid, Spain; saleky@gmail.com

\section{INTRODUCTION}

Wheelchair basketball (WB) is probably the most popular adapted sports, being shoulder pain (SP) a common situation. The aim of the study was to address the relationship between ages, wheelchair use, years of injury and years of sport practice with SP.

\section{METHODS}

Fifty one WB players, aged from 15 to 45 years, were evaluate through the

\begin{tabular}{|c|c|c|c|c|c|}
\hline \multicolumn{6}{|c|}{$\begin{array}{l}\text { Table } 1 \\
\text { Demographic characteristics of the sample. }\end{array}$} \\
\hline $\begin{array}{c}\text { Wheelchair } \\
\text { use }\end{array}$ & Age & $\begin{array}{l}\text { Years since } \\
\text { injury }\end{array}$ & $\begin{array}{c}\text { Years of } \\
\text { wheelchair } \\
\text { use }\end{array}$ & $\begin{array}{c}\text { Years of } \\
\text { federated } \\
\text { sport }\end{array}$ & $\begin{array}{l}\text { Years of } \\
\text { recreative } \\
\text { sport }\end{array}$ \\
\hline ADLs & $25.6 \pm 8.05$ & $0.86 \pm 0.65$ & $0.85 \pm 0.61$ & $0.54 \pm 0.74$ & $0.32 \pm 0.55$ \\
\hline Sport & $22.2 \pm 5.92$ & $1.09 \pm 0.67$ & $0.33 \pm 058$ & $0.26 \pm 054$ & $0.26 \pm 0.45$ \\
\hline
\end{tabular}

"Shoulder Pain Index for WB (SPI-WB)"

(García-Gómez and Pérez-Tejero, 2016). 
This questionnaire was divided into transfers, activities of daily living (ADLs) and sport skills (SS). After descriptive analysis, we applied $\mathrm{U}$ de Mann-Whitney (wheelchair use) and Kruskal-Wallis (age, wheelchair use, years since injury, years of wheelchair use, years of federated sport and years of recreative sport) for determine the statistical difference, after check the normality of the data, indicating the value of effect size. The level of significance was set at $\mathrm{p} \leq 0.05$.

\section{RESULTS}

Twenty seven point five percent of the players reported SP, while $13.7 \%$ of those had pain in their right shoulder. Subjects had more SP between 10 and 20 years of using wheelchair. There was no statistical difference for SP related to specific SS according to age, years since injury, years of wheelchair use and years of federated/recreative sport. However, SP had statistical difference when do rebounding/one-handed long passes according to wheelchair use. The practical significance was from small to large.

\section{CONCLUSIONS}

SP has been reported to increase with advancing age and years of wheelchair use (Curtis et al, 1995). However, in this study subjects with less than 20 years showed increasing index score. In participants that use wheelchair for daily activities, SP is more prevalent in SS such as rebounding/one-handed long passes. Subjects between 10 and 20 years since injury had higher SP in ADLs. Players that had less time doing sport are more predisposed to have SP. It is necessary to promote shoulder health in WB players. In conclusion, SP affect more ADLs than SS in WB players specially related to age, years since injury, years of wheelchair use and years of federated/recreative sport; however SP related to SS had more SP do rebounding/one-handed long passes according to wheelchair use.

\section{REFERENCES}

Curtis, K.A., Roach, K.E., Applegate, E.B. et al. (1995). Reliability and validity of the Wheelchair User's Shoulder Pain Index (WUSPI). Paraplegia, 33(10), 595-601.

García-Gómez, S. and Pérez-Tejero, J. (2016). Validity and Reliability of the Shoulder Pain Index for Wheelchair Basketball Players. Submitted for publication.

\section{The distance-time relationship with aerobic parameters determined in tethered swimming}

Mário Espada ${ }^{1,2}$, Leandro Siqueira ${ }^{3}$, Astor Simionato ${ }^{3}$, Daniel Pestana ${ }^{4}$, André Barreto ${ }^{4}$, Jorge Bombonatti ${ }^{4}$, Luís Imaizum ${ }^{4}$, Wesley Silva ${ }^{4}$, Leonardo Ishizava ${ }^{4}$, Ana Pereira ${ }^{2,5}$, Dalton Pessôa-Filho ${ }^{4}$

1. CIPER, Faculdade de Motricidade Humana, Lisboa, Portugal; mario.espada@ese.ips.pt; 2. Instituto Politécnico Setúbal, Setúbal, Portugal; 3. Instituto de Biociências, PPG-DEHUTE, Unesp, Rio Claro, Brasil; 4. Faculdade de Ciências, Educação Física, Unesp, Bauru, Brasil; 5. Research Centre of Sports, Health and Human Development, CIDESD, Vila Real, Portugal

\section{INTRODUCTION}

Critical velocity $(\mathrm{CV})$ as calculated by the slope of the $d-t_{\text {Lim }}$ relation, has been suggested as a useful tool in the prescription and training load control (Costa et al., 2015). Tethered swimming has been pointed as one of the most specific swimming ergometer, simulating the environment characteristics, stroke mechanics and physiological aspects of swimming (Morouço, 2011). The aim of this study was to analyze the relationship between distance-time indicators and aerobic 
parameters determined in tethered swimming.

\section{METHODS}

Eleven male $(18.0 \pm 4.0$ years of age, $180.2 \pm 6.8 \mathrm{~cm}$ in height and $71.8 \pm 9.5 \mathrm{~kg}$ in body weight) and five female swimmers (16.8 \pm 3.6 years of age, $166.2 \pm 5.5 \mathrm{~cm}$ in height and $61.1 \pm 9.8 \mathrm{~kg}$ in body weight), volunteered for this study. CV was determined from the modeling of the $d-t_{\text {Lim }}$ relationship from maximal performance in 200,400, 800 and $1500 \mathrm{~m}$ freestyle swimming. An incremental tethered swimming test with a conventional load system tied to the swimmer with in increments of $5 \%$ per minute (range $30-100 \%$ of Fmean) was performed. Oxygen uptake was assessed by an automatic and portable system (K4b ${ }^{2}$ Cosmed, Italy) for direct breath-by-breath analysis of pulmonary gas exchange, which was attached to the swimmer by a snorkel with a tridimensional valve (Aquatrainer ${ }^{\circledR}$ ). Critical force $\left(\mathrm{F}_{\mathrm{CRIT}}\right)$, Maximum oxygen uptake $\quad\left(\mathrm{VO}_{2 \max }\right), \quad$ respiratory compensation point (RCP) and gas exchange threshold (GET) were determined, as well as the respective impulses of force $(\mathrm{kg})$. Correlations were analyzed using Pearson's coefficient. In all cases $\rho \leq 0.05$ was adopted.

\section{RESULTS}

$\mathrm{CV}_{200-400-800}\left(1.19 \pm 0.13 \mathrm{~m} . \mathrm{s}^{-1}\right)$ was significantly correlated to iGET $(5.5 \pm 1.3$ kg; $\quad \mathrm{r}=0.51, \quad \mathrm{p}<0.05), \quad \mathrm{RCP}$ $\left(2214.8 \pm 455.0 \quad \mathrm{ml} \cdot \mathrm{min}^{-1} ; \quad \mathrm{r}=0.50\right.$, $\mathrm{p}<0.05), \mathrm{VO}_{2 \max }\left(3423.0 \pm 601.8 \mathrm{ml} . \mathrm{min}^{-}\right.$ $\left.{ }^{1} ; \mathrm{r}=0.52, \mathrm{p}<0.05\right)$ and $\mathrm{F}_{\text {CRIT }}(6.91 \pm 0.94$ kg; $\mathrm{r}=0.52, \quad \mathrm{p}<0.05) . \quad \mathrm{CV}_{400-800}$ $\left(1.18 \pm 0.16 \mathrm{~m} . \mathrm{s}^{-1}\right)$ was also correlated to iGET $(\mathrm{r}=0.55, \mathrm{p}<0.05)$, RCP $(\mathrm{r}=0.53$, $\mathrm{p}<0.05), \mathrm{VO}_{2 \max }(\mathrm{r}=0.54, \mathrm{p}<0.05)$ and $\mathrm{F}_{\text {CRIT }}(\mathrm{r}=0.52, \mathrm{p}<0.05)$. The last, was also correlated to $\mathrm{CV}_{200-400-800-1500}$ $\left(1.22 \pm 0.10 \mathrm{~m} . \mathrm{s}^{-1} ; \mathrm{r}=0.61, \mathrm{p}<0.05\right)$ and $\mathrm{CV}_{400-800-1500}\left(1.22 \pm 0.10 \mathrm{~m} . \mathrm{s}^{-1} ; \mathrm{r}=0.66\right.$, $\mathrm{p}<0.01)$. Conclusions: Tethered swimming is a useful method for training evaluation in swimming. Critical force seems to be related to $\mathrm{CV}$ determined from long distances in swimming, namely, $1.500 \mathrm{~m}$.

\section{REFERENCES}

Costa, A. M. da, Costa, M. J., \& Marinho, D. A. (2015). Velocidade crítica em natação: uma revisão da literatura. Motricidade, 11(3), 158-170. https://doi.org/10.6063/motricidade.2903

Morouço, P., Keskinen, K. L., Vilas-Boas, J. P., \& Fernandes, R. J. (2011). Relationship between tethered forces and the four swimming techniques performance. Journal of Applied Biomechanics, 27(2), 161-169.

\section{Characteristics and incidence of injuries in young football players}

Bruno Grave $^{1}$, António Vicente ${ }^{1}$

1. University of Beira Interior, Covilhã, Portugal; magno.s.bruno@gmail.com

\section{INTRODUCTIONS}

In reviewing the literature on sports injuries, quickly realizes the lack of studies on the characteristics and the incidence of injuries in young football players, and these are mainly for the elite of professional football (Hägglund et al., 2005). This study aims to understand the characteristics and incidences of injuries in young footballers over a season.

\section{METHODS}

On hundred and fifty-four football players aged between 12 and 17 years old participated in this retrospective study. 
The participants were given a questionnaire about the characteristics of the injuries suffered during the last season. The calculation of incidence was expressed by the number of injuries, multiplied by thousand hours of exposure and divide by the time of exposure (Hägglund et al., 2010).

\section{RESULTS}

One hundred and sixty five injuries were identified in the 154 participants over a season. Of these, 115 players (74.7\%) experienced at least one episode of injury. 104 (63\%) contact injuries were recorded and 61 (37\%) of noncontact. The older players (U18) were the group with the highest percentage of injured players $(81.8 \%)$ and the youngest (U13) the less injured (58\%). $73(45 \%)$ injuries were reported from matches context and 92 (55\%) from training sessions. The average incidence for the 154 participants was $24.7( \pm 7.6)$ injuries in game context and $2.5( \pm 0.2)$ injuries in training context. Players suffered more injuries in the dominant member. Foot / ankle with 45 (27.7\%) episodes of injuries, were the most observed location of injuries, followed by the thigh with $34(20.6 \%)$ and the knee with 25 (15.2\%). Contact with the opponent was the most frequent mechanism with occurrences 58 $(35.2 \%)$, followed by the change of direction with $30(18.2 \%)$ and the actions with ball (passing and shooting) with 25 (15.2\%). When advancing in age, clash with opponents and change of direction were the most common mechanisms of injury $(\mathrm{P}<0.05)$. From all injuries identified $41(24.8 \%)$ were of mild severity, 53 (32.1\%) average, 42 (22.5\%) moderate and 29 (17.6\%) severe.

\section{CONCLUSIONS}

It seems to be essential to identify the characteristics and the incidence of injuries in young football players in order to prevent the occurrence of injuries (in game and training context) which may have implications on the future of young practitioners.

\section{REFERENCES}

Hägglund, M., Walden, M., Bahr, R., \& Ekstrand, J. (2005). Methods for epidemiological study of injuries to professional football players: developing the UEFA model. British Journal of Sports Medicine, 39(6), 340-346. https://doi.org/10.1136/bjsm.2005.018267

Hägglund, M., Waldén, M., Til, L., \& Pruna, R. (2010). The importance of epidemiological research in sports medicine. Apunts. Medicina de l'Esport, 45(166), 57-59. https://doi.org/10.1016/j.apunts.2010.02.006

\section{The effects of warm-up on the performance of the 10om sprint}

Maria H. Gil ${ }^{1,2}$, Mário C. Marques ${ }^{1,2}$, Henrique P. Neiva ${ }^{1,2}$, Maris S. Cirilo-Sousa ${ }^{4,5}$, António Sousa ${ }^{1,2}$, Nuno D. Garrido ${ }^{2,3}$, Hidayane G. Silva, H.G.4,5, Gabriel R. Neto ${ }^{4,5}$, Daniel A. Marinho $0^{1,2}$

1. Department of Sport Sciences, University of Beira Interior, Covilhã, Portugal; maria.helena.gil@hotmail.com; 2. Research Centre in Sports Sciences, Health Sciences and Human Development, Portugal; 3. University of Trás-os-Montes and Alto Douro, Vila Real, Portugal; 4. Department of Physical Education, Federal University of Paraíba, João Pessoa, Paraíba, Brazil; 5. Kinanthropometry and Human Development Laboratory, João Pessoa, Paraíba, Brazil

\section{INTRODUCTION}

A well-designed warm-up can help athletes optimize their performance (Swanson, 2006). However warm-up protocols used by athletes may vary often, suggesting to exist a need for more studies to prove the efficacy of different warm-up protocols (Garber et al., 2011). The aim of this study was to understand the effects of two different 
warm-up protocols in performance of the $100 \mathrm{~m}$-sprint.

\section{METHODS}

The sample consisted of 11 physically active male subjects (age: 27.18 \pm 9.67 years; height: $175.67 \pm 8,32 \mathrm{~cm}$; weight: $78.21 \pm 8,59 \mathrm{~kg})$. The subjects underwent two warming protocols: typical warm-up (TW) and warm-up with post-activation potentiation (PAP). After warming-up, the subjects performed a $100 \mathrm{~m}$ sprint and the time was registered by Brower equipment (Wireless System, US Sprint).

\section{RESULTS}

The results showed that the sprint times were identical for both protocols (TW: $14.74 \pm 1.19 s ;$ PAP: $14.66 \pm 1.52 \mathrm{~s}$ ) and there were no significant differences $(p=0.792)$.

\section{CONCLUSIONS}

Although the use of PAP in warm-up has been suggested to provide improvements on explosive efforts (Sale, 2002), there were no differences between the two warm-ups performed. Hence, we suggest that either the used PAP stimulation protocol did not meet the requirements for sufficient power to stimulate the desired neuromuscular effect (Sale, 2002), or the interval after PAP warm-up was not suitable for the optimization of this effect (Requena, Gapeyeva, García \& Pääsuke, 2008). More research is needed.

\section{REFERENCES:}

Garber, C.E, Blissmer, B., Deschenes, M.R, Franklin, B.A., Lamonte, M.J, Lee, I.M., ... Swain, D.P. (2011). American College of Sports Medicine position stand. Quantity and quality of exercise for developing and maintaining cardiorespiratory, musculoskeletal, and neuromotor fitness in apparently healthy adults: guidance for prescribing exercise. Medicine and Science in Sport and Exercise, 43 (7), 1334-1359.

Requena, B, Gapeyeva, H, García, I, Ereline, J. \& Pääsuke, M. (2008). Twitch potentiation after voluntary versus electrically induced isometric contractions in human knee extensor muscles. European Journal of Applied Physiology, 104(3), 463472.

Sale, D.G. (2002). Postactivation potentiation: role in human performance. Exercise Sport Sciences Reviews, 30(3), 138-143.

Swanson, J. (2006). A functional approach to warmup and flexibility. Strength and Conditioning Journal, 28(5), 30-36.

\section{Net heart rate as estimating mean of the energy expenditure in walking/running and stationary bike}

José Bragada1,3, Raúl Bartolomeu ${ }^{2}$, Eric Macias São Pedro ${ }^{1}$

1. Polytechnic Institute of Bragança, Portugal; jbragada@ipb.pt; 2. University of Trás-os-Montes and Alto Douro, Vila Real,
Portugal; 3. Research Centre in Sports, Health and Human Development, CIDESD, Portugal.

\section{INTRODUCTION}

Net heart rate (HRnet) is known as the variation of the heart rate (HR) above the resting value, as a result of physical activity (PA). The positive association between HRnet, the level of $\mathrm{PA}$ and respective energy expenditure (EE) has been previously reported (Bragada et al., 2009; São Pedro et al., 2015). However, a useful and practical way of objectively calculates EE from
HRnet is still needed. Thus, the aim of this study was to find an EE calculation formula based on HRnet measurement, in walking/running and stationary bike.

\section{METHODS}

One hundred and thirty subjects, 77 men and 53 women, aging between 18 and 81 years old, 79 in a treadmill and 53 in a stationary bike underwent an intermittent and progressive protocol of 
$\mathrm{N} \times 6$ minutes. The $\mathrm{VO}_{2}$ and $\mathrm{HR}$ were measured continuously throughout the protocol. An independent sample T-test was used to test the between-group differences, and a Hierarchical Linear Modeling (HLM) was computed to measure the influence of each variable in the HRnet variation magnitude.

\section{RESULTS}

The HRnet mean values, across all the exercise intensities, revealed significant differences when compared by age ($0.58, p=0.005)$, gender $(t=-3.383, p=$ $0.001)$ and exercise type $(t=-5.543$, $p=0.000)$. However, the modeling of the HRnet response revealed that the magnitude of its variation, as the exercise intensity increased, was not influenced by any of those factors. Additionally, the relationship between the HRnet and the EE showed a very high coefficient of determination $\left(\mathrm{R}^{2}=0.897\right)$.

\section{CONCLUSION}

HRnet is an easy and non-invasive method to estimate EE at different PA intensities either in walking/running or stationary bike. Despite the mean values significantly differed from each other when compared by age, gender and exercise type, while the exercise intensity increased, the HRnet increased in the same magnitude for every participant, independently of any variable in study. This novelty provides practitioners of recreational and healthrelated physical activity with an easy and feasible way of calculating a training session EE, simply by using the formula: $\mathrm{EE}(\mathrm{kcal} / \mathrm{kg} / \mathrm{min})=0.0016 \mathrm{x}$ HRnet + 0.0148 .
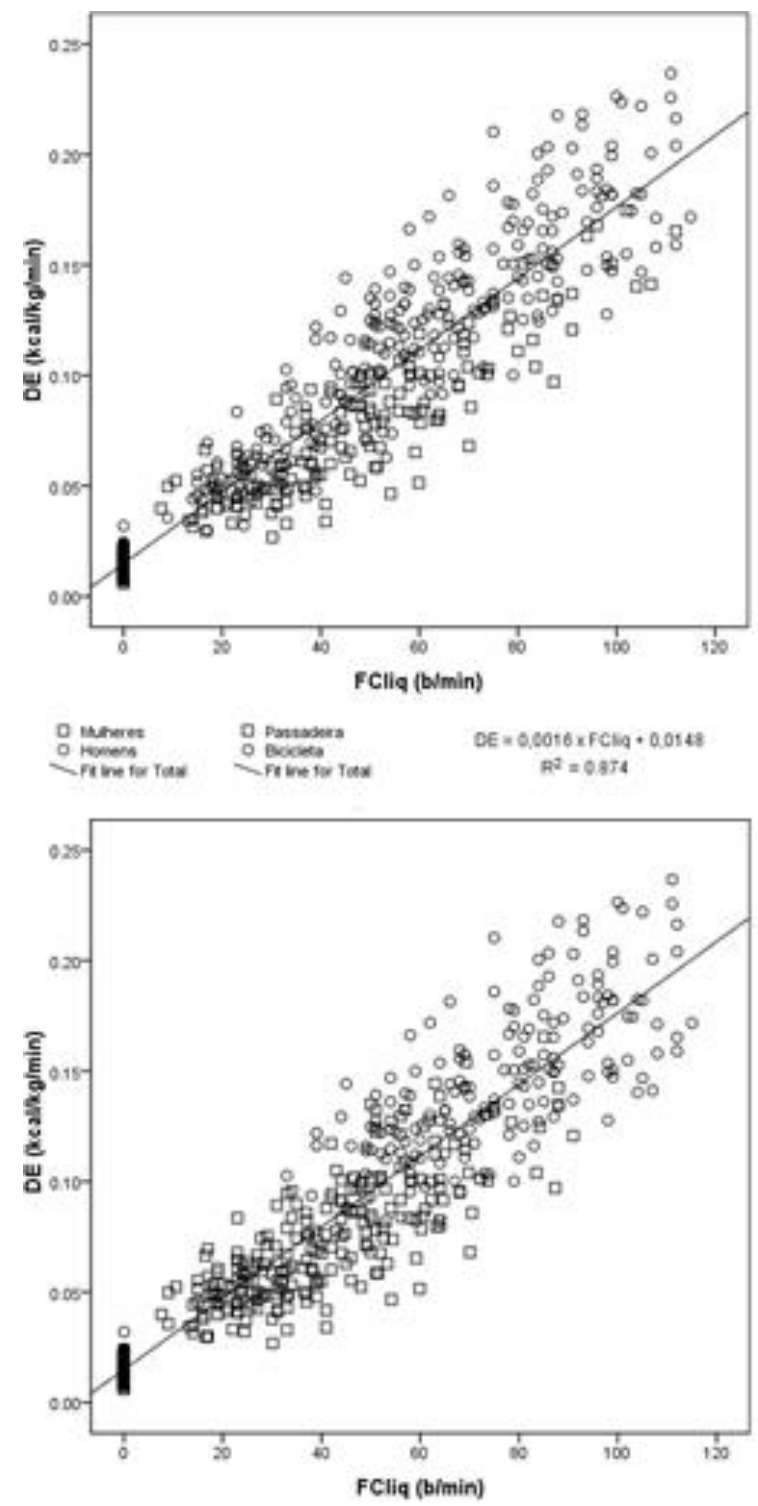

Figure 1. Relationship between the HRnet (FClíq) and the EE (DE), by gender and type of activity.

\section{REFERENCES}

Bragada, J. A., Pedro, P. M., Vasques, C. S., Tiago, M. B., \& Vítor, P. L. (2009). Net Heart Rate to Prescribe Physical Activity in Middle-Aged to Older Active Adults. Journal of Sports Science $\mathcal{E}$ Medicine, 8(4), 616-621.

São Pedro, E. M. (2015). Validação da frequência cardíaca líquida na estimativa do gasto energético e na prescrição da intensidade do exercício em cicloergómetro, em jovens adultos masculinos (Dissertação de Mestrado em Mestrado em Exercício e Saúde). Instituto Politécnico de Bragança, Bragança. 


\section{Dropout in swimming: difference between gender and competitive ranking and intention to return to the competition}

Diogo Monteiro ${ }^{1}$, João Moutão, ${ }^{1,3}$, Daniel A. Marinho', ${ }^{2,3}$, Luís Cid ${ }^{1,3}$

1. Sport Science School of Rio Maior, ESDRM, Polytechnic Institute of Santaré, Santarém, Portugal; diogomonteiro@esdrm.ipsantarem.pt; 2. University of Beira-Interior, Covilhã, Portugal; 3. Research Center in Sport, Health and Human Development, CIDESD, Portugal

\section{INTRODUCTION}

This study's main purpose was to analyse reasons for dropout in competitive swimmers and differences between gender and rankings. Influence of dropout on swimmers intentions to return to competition was also analysed.

\section{METHOD}

This study included 1008 former swimmers (543 male, 465 female) subscribed on Swimming Portuguese Federation (FPN) who dropped out competitive swimming practice within the 2012-2013 and 2013-2014 seasons. The participants had an average age of 16.26 years old $(S D=6.12)$, and their breakdown by FPN category was 148 were cadets, 155 children, 243 juveniles, 203 juniors and 259 seniors. The Portuguese version of Questionnaire of Reasons Attrition was used, to assess the reasons associated with the practice dropout. Descriptive (mean and standard deviation) and inferential (independent sample t-test, one way ANOVA with a tukey and games howell post-hoc and structural equation modelling) techniques were used. The analysis was undertaken using the SPSS 20.0 and AMOS 20.0.

\section{RESULTS}

In general, the main results showed that the most valuable reason for dropout in both gender and rankings was: "dissatisfaction/other priorities". The results also showed that both genders value the same factors similarly, with the exception of the "dissatisfaction/other priorities" and "demands/pressure of modality" factors, which were more valued by the men and women, respectively. Regarding the competitive rankings, the "demands/pressure of modality" factor was revealed to be more valued by seniors, the "technical skills" and "demands/ pressure of modality" factors by cadets and children, the "challenge/competition" and "social recognition rewards" factors by cadets, the "significant others" factor by juveniles and juniors, and the "group environment" factor by juniors. On the other hand, structural model showed that "dissatisfactions/other priorities", "group environment", "challenge/competition and "demands/ pressure of modality" negatively predict the intentions to return. On the other hand, "significant others", "technical skills" and "social recognition rewards", positively predict the intentions to return to competition.

\section{CONCLUSIONS}

This study offers useful guidelines for the training process and the eventual decision call on sports politics to be implemented to fight reduce the dropout. Results can aid coaches and leaders to understand how certain variables work (e.g., demand and pressure of the modality), enabling them to adapt their intervention to the needs and constraints of each group, as well as helping the athletes themselves, enabling them to extend their sports career since the dropout of the organized 
sports practice is increasing. However, is important to widen the evidences to other modalities and implement programs on identified priority areas

based on longitudinal perspectives.

\section{Changes in Functional Movement Screen scores over a 6-month period in surf athletes}

Bruno Silva $^{1}$, Filipe Manuel Clemente ${ }^{1,2}$

1. Instituto Politécnico de Viana do Castelo, Escola Superior de Desporto e Lazer, Portugal; silvabruno@esdl.ipvc.pt; 2. Instituto de Telecomunicações, Delegação da Covilhã, Portugal

\section{INTRODUCTION}

The Functional Movement Screen (FMS) is a tool to measure functional mobility and postural stability and has been proposed as a battery test to simplify the assessment of movement patterns (Kraus, Schutz, Taylor, \& Doyscher, 2014). Nevertheless, research has suggested that over a competitive season, specific movement patterns can decrease (Sprague, Mokha, \& Gatens, 2014). The aim of this study is to ascertain whether FMS scores decreases between preseason and after 6 months and describe the differences between FMS scores of those athletes with and without a regular specific land based physical training.

\section{METHODS}

Thirteen regional competitive surf athletes (8 male) participated in the study $(17.4 \pm 6.4 \mathrm{y} ; 58.9 \pm 8.2 \mathrm{~kg} ; 165$ $\pm 8.3 \mathrm{~cm}$ ) and were tested in the beginning of the preseason and after 6 months. Eight of them (4 male and 4 female) participated in the experimental group and five in the control group. The convenience based on the athletes' schedule was the main criterion. The analysis of variance also confirmed no significant differences between experimental and control groups during the pre-test. An FMS specialist conducted the experiments. The experimental group complied an intervention program twice a week with resistance strength, proprioception and coordination tasks. Upper and lower body tasks were alternately prescribed in a functional training circuit. Comparisons between experimental group and control group were tested.

\section{RESULTS}

A Wilcoxon signed ranks test made per group only revealed statistical improvements (table 1 ) in experimental group after 6-months at deep squat ( $\mathrm{p}=$ $0.025)$, shoulder mobility left side ( $\mathrm{p}=$ $0.02)$, trunk push-up ( $p=0.015)$, rotary stability left and right side $(\mathrm{p}=0.038$ and $\mathrm{p}=0.012$ ) and FMS composite score $(p=0.012)$. Mann-Whitney U test did not revealed differences in FMS scores between both groups in pre- and post-program. 
Table 1

Descriptive statistics (median) of FMS scores for pre- and post-six-months period

\begin{tabular}{|c|c|c|c|c|c|}
\hline & & \multicolumn{2}{|c|}{ Land based physical training (median) } & \multicolumn{2}{|c|}{ Without land based physical training (median) } \\
\hline & & Pre & Post & Pre & Post \\
\hline Deep Squat & & 1.50 & $2.00^{*}$ & 2.00 & 2.00 \\
\hline \multirow{2}{*}{ Hurdle step } & $\mathrm{L}$ & 2.00 & 2.00 & 2.00 & 2.00 \\
\hline & $\mathrm{R}$ & 2.00 & 2.00 & 2.00 & 2.00 \\
\hline \multirow{2}{*}{ Inline Lung } & $\mathrm{L}$ & 2.00 & 2.50 & 2.00 & 3.00 \\
\hline & $\mathrm{R}$ & 2.00 & 3.00 & 2.00 & 2.00 \\
\hline \multirow{2}{*}{ Shoulder mobility } & $\mathrm{L}$ & 1.50 & $2.00 *$ & 2.00 & 2.00 \\
\hline & $\mathrm{R}$ & 2.00 & 3.00 & 1.00 & 3.00 \\
\hline \multirow{2}{*}{ Active straight leg raise } & $\mathrm{L}$ & 2.50 & 3.00 & 2.00 & 3.00 \\
\hline & $\mathrm{R}$ & 2.00 & 3.00 & 2.00 & 2.00 \\
\hline Trunk stability push-up & & 1.00 & $2.00^{*}$ & 2.00 & 3.00 \\
\hline \multirow{2}{*}{ Rotary stability } & $\mathrm{L}$ & 1.00 & $2.00^{*}$ & 1.00 & 2.00 \\
\hline & $\mathrm{R}$ & 1.00 & $2.00^{*}$ & 1.00 & 1.00 \\
\hline Composite FMS score & & 10.00 & 17.00* & 11.00 & 15.00 \\
\hline
\end{tabular}

*significant differences between pre- and post-period

\section{CONCLUSION}

This study has found that functional training program based on resistance strength, proprioception and coordination may help to improve movement patterns. Based on such technique can be possible to optimize training protocols and ultimate performance.

\section{Aknowledgments:}

The authors thank the coaches from Surfing Viana High Performance Centre and participating athletes from Surf Club de Viana.

\section{REFERENCES}

Kraus, K., Schutz, E., Taylor, W. R., \& Doyscher, R. (2014). Efficacy of the functional movement screen: a review. Journal of Strength and Conditioning Research, 28(12), 3571-3584.

Sprague, P. A., Mokha, G. M., \& Gatens, D. R. (2014). Changes in functional movement screen scores over a season in collegiate soccer and volleyball athletes. Journal of Strength and Conditioning Research, 28(11), 3155-3163.

\section{The coach's role in defining the percentage of $1 \mathrm{RM}$ self-selected intensity}

Rhodes Serra ${ }^{1}$, Marcelo Dias2 Roberto Simão ${ }^{1}$, Filipe Matos $^{3,4}$, José Vilaça ${ }^{3,4}$, Francisco Saavedra ${ }^{3,4}$

1. Exercise physiology laboratorie of Granbery Metodista Faculty, Juiz de Fora, MG, Brasil; 2. School of Physical Education and Sports of the Federal University of Rio de Janeiro, Rio de Janeiro, Brasil; 3. University of Trás-os-Montes and Alto Douro, UTAD, Vila Real, Portugal; fmatos@utad.pt; 4. Research Center in Sports Sciences, Health Sciences and Human Development, CIDESD, Vila Real, Portugal

\section{INTRODUCTION}

The supervised training can be costly and is not always a feature available in gyms. Not all members of gyms, health clubs and fitness centers use a Personal Trainer to achieve and meet their training objectives. The aim of this study was to compare the changes in muscle strength and self-selected load during strength training among individuals under the supervision of a personal trainer and those who trained without a personal trainer.

\section{METHODS}

Twenty-one individuals (men and women) completed two training sessions in the following order: (1) three sets of 10 reps on the leg press $45^{\circ}$, bench press, leg extension and biceps curl with selected case load, which 
consisted of usual training load, and (2) $1 \mathrm{RM}$ test.

\section{RESULTS}

The mean of training loads and 1RM was higher in the PT group. The effect size (ES) was small to medium for the difference in charges between the groups. The percentage of 1RM performed with ES medium to large for the legs and short ES for the upper limbs.

Table 1

1RM load percentage and the effect size.

\begin{tabular}{ccccc}
\hline & Leg Press & $\begin{array}{c}\text { Bench } \\
\text { Press }\end{array}$ & $\begin{array}{c}\text { Leg } \\
\text { Extension }\end{array}$ & $\begin{array}{c}\text { Bíceps } \\
\text { Curl }\end{array}$ \\
\cline { 1 - 3 } \cline { 5 - 6 } PT & $49.0 \%$ & $59.5 \%$ & $51.9 \%$ & $52.2 \%$ \\
WPT & $43.9 \%$ & $58.7 \%$ & $41.2 \%$ & $55.5 \%$ \\
\multirow{2}{*}{ ES } & 0.5 & -0.1 & 0.9 (high) & -0.3 \\
& (medium) & (small) & & (small) \\
\hline
\end{tabular}

Note: $P T=$ with Personal Trainer; $\mathrm{WPT}=$ without

Personal Trainer; ES = Effect size.

\section{CONCLUSIONS}

The resistance training supervised by a Personal Trainer appears to be advantageous for both men and for women, but the load percentage should be increased in order to meet the policy recommendations.

\begin{abstract}
Aknowledgments:
Macro-to-Nano Human Sensing: Towards Integrated Multimodal Health Monitoring and Analytics, n. ${ }^{\circ}$ da operação NORTE-01-0145-FEDER-000016, cofinanciado pelo Fundo Europeu de Desenvolvimento Regional (FEDER) através do NORTE 2020.
\end{abstract}

\section{REFERENCES}

Borg, G. A. (1982). Psychophysical bases of perceived exertion. Medicine and Science in Sports and Exercise, 14(5), 377-381.

Duncan, G. E., Anton, S. D., Sydeman, S. J., Newton, R. L., Corsica, J. A., Durning, P. E., ... Perri, M. G. (2005). Prescribing exercise at varied levels of intensity and frequency: a randomized trial. Archives of Internal Medicine, 165(20), 2362-2369. https://doi.org/10.1001/archinte.165.20.2362

\section{Variability, joint stability and risk of injury using non linear methods}

Orlando Fernandes ${ }^{1,2}$

1. Departamento de Desporto e Saúde, Escola de Ciência e Tecnologia, Universidade de Évora; orlandoj@uevora.pt; 2. Research Center in Sports Sciences, Health Sciences and Human Development, CIDESD, Vila Real, Portugal

\section{INTRODUCTION}

Joint Stability is the ability of the joint to resist a given perturbation. The sway variability during quiet standing reflect the strategies assumed by the control system to promote joint stability. To study these non-linear behaviors associated with the control it is necessary to use non-linear methods, which may give indications of how the nervous system controls the complexity of human movements. The variability associated with the system reflects the stability of the motor system and how the noise and how much noise makes the system stable and what is the commitment of the stability. The variability present in the neuro-motor control system is a function of deterministic processes, and error variability, is the result of a convolution of disorders of the neuromuscular control and Biomechanical variables. The present work attempts to establish a relation between high risk (stable) and low risk (unstable) of ankle sprain in a single stance position in athletes.

\section{METHODS}

Thirty two subjects were evaluated resulting 40 ankles (20 stable ankles (sa) and 20 unstables ankles (ua)). The task trial consisted in one leg stand (OLS) and measured the center of pressure 
(CoP) in both direction (AnteriorPosterior(AP) and Medio-Lateral (ML). The constitution of this sample was based on; a) greatest number of occurrences of injury - sprain ankle; b) greater severity of injury and c) time of inactivity. During the OLS, the reaction forces on the support and moments of force to the surface for the computation of CoP, were obtained on a Bertec force plate (Bertec 4060-10, Inc Columbus, $\mathrm{OH})$. The non-linear parameters for used in this work were, Lyapunov exponent (eLY) and Approximate Entropy (EnAp). All participants performed two repetitions trying to keep in OLS for 30 seconds, allowing some consistency in obtained data.

\section{RESULTS}

The results (parameter- mean $\pm \mathrm{sd}$ ); AP_eLy (sa)- 0.96 \pm 0.135 ; MLeLy (sa)$0.352 \pm 0.070$ AP $\operatorname{EnAp}(\mathrm{sa})-$ $0.424 \pm 0.081$ $0.351 \pm 0.097$
ML $\operatorname{EnAp}(\mathrm{sa})-$ AP_eLy(ua)-
$0.467 \pm 0.138$

ML_eLy(ua)-

$0.322 \pm 0.080$ AP_EnAp(ua)-

$0.410 \pm 0.111$ $\mathrm{ML}^{-} \operatorname{EnAp}(\mathrm{ua})$ $0.325 \pm 0.103$ and the statistics MANOVA was used with the following results (parameter- value, significance): AP_eLy - $\mathrm{F}_{(1,38)}=0.466,0.825$; ML_eLy $\mathrm{F}_{(1,38)}=1.578, \quad 0.217 ; \quad$ AP_EnAp $\mathrm{F}_{(1,38)}=0.189,0.666 ; \mathrm{ML}_{-} \mathrm{EnAp}-$ $F_{(1,38)}=0.697,0.409$.

\section{CONCLUSION}

The results allow us to conclude that is possible to analyze stability of the motor system using non-linear methods, but we must in conjunction with traditional measures of control of postural in addition to the information.

\section{REFERENCES}

Moorhouse, K. M., \& Granata, K. P. (2007). Role of Reflex Dynamics in Spinal Stability: Intrinsic Muscle Stiffness Alone is Insufficient for Stability. Journal of biomechanics, 40(5), 10581065. https://doi.org/10.1016/j.jbiomech.2006.04.01 8 


\title{
Changes in classical kinematics and non-linear parameters after a maximal 100-m front-crawl bout
}

\author{
Tiago M. Barbosa ${ }^{1,2,3}$, Jorge E. Morais ${ }^{2,3}$, Chen Simin1, Mario J. Costa ${ }^{3,4}$
}

1. Nanyang Technological University, Singapore; tiago.barbosa@nie.edu.sg; 2. Polytechnic Institute of Braganca, Portugal; 3. Research Centre in Sports, Health and Human Development, CIDESD, Portugal; 4. Polytechnic Institute of Guarda, Portugal

In a linear system there is proportionality between input and output. Under this framework it is expected that the amount of change in sports performance must be proportional to variations in the inputs. However, as far as elite performance goes, this is not a straightforward assumption. Sometimes the variables selected are not sensitive enough. Hence, there is the need of having non-linear concepts underpinning such analysis. The aim was to compare classical kinematics and non-linear parameters after a maximal 100-m front-crawl bout. Twenty four subjects (12 males and 12 females; $22.38 \pm 1.68$-y) were invited to perform a 100-m freestyle race at maximal pace. Before (pre-test, i.e. rested) and immediately after (post-test, i.e. under fatigue) the maximal bout, they performed two maximal $25 \mathrm{~m}$ swims at freestyle with push-off start. A speedo-meter cord (Swim speedo-meter, Swimsportec, Hildesheim, Germany) was attached to the swimmer's hip (Barbosa et al., 2015) in the two 25m trials collecting the instantaneous speed. It was computed the speed fluctuation (dv; Barbosa et al., 2015), approximate entropy (ApEn; Barbosa et al., 2015) and fractal dimension (FD; Higuchi, 1988). Repeated measures ANOVAs (pre-test vs. post-test; $\mathrm{P} \leq 0.05$ ), effect sizes (eta squared) and $95 \%$ of confidence intervals $(95 \mathrm{CI})$ were computed. The speed was $1.44 \pm 0.24$ and $1.28 \pm 0.23 \mathrm{~m} / \mathrm{s}$ in the pre- and post/test, respectively $(\mathrm{F}=55.136, \mathrm{P}<0.001)$. The $\mathrm{dv}$ increased from the pre- to the post-test with moderate effect sizes $\left(F=15.048, P<0.001, \eta^{2}=0.41\right)$. The $d v$ increased by $20.17 \%$, shifting the $95 \mathrm{CI}$ band from $0.116-0.134$ to $0.140-0.161$. The ApEn showed trivial variations between the pre- and post-test $\left(\mathrm{F}=0.037, \mathrm{P}=0.85, \eta^{2}<0.01\right)$. There was a trend for a decrease of the ApEn by $2.23 \%$ and the $95 \mathrm{CI}$ of pre- and post-test overlap (pre: $0.659-0.700$; post: $0.641-0.682$ ). The FD showed a significant effect due to the fatigue with a moderate effect size $\left(F=5.186, P=0.03, \eta^{2}=0.20\right)$. The $95 \mathrm{CI}$ band moved from 1.954-1.965 to 1.933-1.951. All 24 subjects increased the dv from pre- to posttest. 21 out of 24 swimmers decreased the FD from pre- to post-test and 16 decreased the ApEn. There was an increase in the dv and a decrease of both ApEn and FD. All in all, fatigue led to a higher speed fluctuation amid a more predictable and less complex motor behaviour.

References:

Barbosa, T. M., Morais, J. E., Marques, M. C., Silva, A. J., Marinho, D. A., \& Kee, Y. H. (2015). Hydrodynamic profile of young swimmers: changes over a competitive season. Scandinavian Journal of Medicine \& Science in Sports, 25(2), e184-196. https://doi.org/10.1111/sms.12281

Higuchi, T. (1988). Approach to an irregular time series on the basis of the fractal theory. Physica D: Nonlinear Phenomena, 31(2), $277-283$. https://doi.org/10.1016/0167-2789(88)90081-4

\section{Comparison of the fractal dimension among swimmers with different levels of expertise}

Tiago M. Barbosa1,2,3, Jorge E. Morais ${ }^{2,3}$, Raul Bartolomeu ${ }^{3}$, Mario J. Costa 3,4

1. Nanyang Technological University, Singapore; tiago.barbosa@nie.edu.sg; 2. Polytechnic Institute of Braganca, Portugal; 3. Research Centre in Sports, Health and Human Development, CIDESD, Portugal; 4. Polytechnic Institute of Guarda, Portugal

It is known that performance is strongly related to proportional changes in the inputs. The "marginal gains theory" in sports performance gained popularity a few years ago. It encompasses the assumption that small changes in the input (or the sum of several changes) may have a significant effect on the output. Yet, it is unclear if nonlinear parameters such as fractal dimension are able to distinguish subjects with different levels of expertise. The aim was to compare the fractal dimension in swimmers with different levels of swimming expertise. Seventy five subjects in accordance to their level of expertise (highly qualified experts, experts and non-experts) were invited to perform maximal $4 \times 25 \mathrm{~m}$ swims in each swim stroke after a pushoff start. A speedo-meter cord (Swim speedo-meter, Swimsportec, Hildesheim, Germany) was attached to the swimmer's hip (Barbosa et al., 2015) collecting the instantaneous speed. Upon that, the fractal dimension (FD; Higuchi, 1988) was computed. Two-way repeated-measures ANOVAs (group x swim stroke; P $\leq 0.05)$, effect size by the eta-squared $\left(\eta^{2}\right)$ plus Cohen's d (d) and $95 \%$ confidence interval $(95 \mathrm{CI})$ were computed. There was an expertise $\mathrm{x}$ swim stroke interaction $\left(\mathrm{F}_{6,72}=3.564 ; \mathrm{P}<0.001 ; \eta^{2}=0.13\right)$ in the swim speed. Front-crawl was the fastest stroke, followed by the Butterfly, Backstroke and Breaststroke $(P<0.001)$. As far as FD goes, there was a non-significant expertise $x$ stroke interaction $\left(P=0.13 ; \eta^{2}=0.03\right)$ albeit a moderate effect of the swim stroke $\left(\mathrm{P}<0.001 ; \eta^{2}=0.41\right)$ and a small effect of the expertise level $\left(\mathrm{P}=0.01 ; \mathrm{\eta}^{2}=0.12\right)$ was found. The FD was higher with large effect sizes in the group of non-experts than the other two (highly qualified experts: $\mathrm{P}=0.01,0.70 \leq \mathrm{d} \leq 1.0$; experts: $\mathrm{P}=0.05,0.52 \leq \mathrm{d} \leq 0.78$ ). The variable was different among all pair wises $(\mathrm{P}<0.001)$ but Front-crawl vs. Backstroke. Breaststroke showed 
the highest FD followed by Butterfly, Front-crawl and Backstroke. There was a shift of the 95CI to the left side (i.e. a decrease of the FD) comparing non-experts with competitive counterparts. E.g., in Front-crawl the $95 \mathrm{CI}$ was $1.86-1.91$ for non-experts and about $1.80-1.88$ for highly qualified experts and experts. The FD is prone to decrease with increasing expertise. Hence, the complexity level of the motor behaviour in swimming is dependent on the swimmer's expertise.

\title{
References:
}

Barbosa, T. M., Morais, J. E., Marques, M. C., Silva, A. J., Marinho, D. A., \& Kee, Y. H. (2015). Hydrodynamic profile of young swimmers: changes over a competitive season. Scandinavian Journal of Medicine E Science in Sports, 25(2), e184-196. https://doi.org/10.1111/sms.12281

Higuchi, T. (1988). Approach to an irregular time series on the basis of the fractal theory. Physica D: Nonlinear Phenomena, 31(2), 277-283. https://doi.org/10.1016/0167-2789(88)90081-4

\section{Relationships between Functional Movement Screen scores and physical performance variables in surf athletes}

\author{
Bruno Silva ${ }^{1}$, Filipe Manuel Clemente ${ }^{1,2}$ \\ 1. Instituto Politécnico de Viana do Castelo, Escola Superior de Desporto e Lazer, Portugal; 2. Instituto de Telecomunicações, \\ Delegação da Covilhã, Portugal
}

Functional Movement Screen (FMS) has been proposed as a battery test to simplify the assessment of movement patterns in daily sports practice. Besides the importance to predict the risk of injuries, FMS has been also associated with athletic performance. In a surf competition occurs a variety of condition that have a large effects on activity patterns (Mendez-Villanueva, Bishop, \& Hamer, 2006). Nevertheless, no association between patterns and performance has been tested. Thus, the aim of this study is to analyse the relationships between FMS and athletic performance. Eighteen surf athletes (11 male) participated in the study $(18.3 \pm 6.3 \mathrm{y} ; 60.0 \pm 9.6 \mathrm{~kg} ; 168.6 \pm 8.1 \mathrm{~cm})$ and were tested in FMS scores, anthropometrics (weight, \%visceral fat, bone mineral density, muscular mass and \%fat mass tested with DEXA), strength of lower (isometric knee extension) and upper limbs (isometric handgrip), power of lower limbs (squat and countermovement jumps) and ankle mobility (knee to wall). Significant and moderate-to-strong correlations tested with Kendall's tau-b were found in the pairs: deep squat*left and right ankle mobility $\left(T_{b}=0.47\right.$ and 0.62); right hurdle step*left and right handgrip $\left(T_{b}=0.54\right.$ and 0.55$)$, right hurdle step*left and right knee extension $\left(T_{b}=0.56\right.$ and 0.46$)$, right hurdle step*weight $\left(T_{b}=0.45\right)$, right hurdle step*bone mineral density $\left(T_{b}=0.51\right)$ and right hurdle step*muscular mass $\left(T_{b}=0.51\right)$; right inline lunge*right ankle mobility $\left(T_{b}=0.47\right)$; left shoulder mobility*visceral fat $\left(T_{b}=-0.39\right)$; trunk stability push up*squat jump $\left(T_{b}=0.60\right)$, trunk push up*countermovement jump $\left(T_{b}=0.57\right)$, trunk push up*right handgrip $\left(T_{b}=0.57\right)$, trunk push up*left handgrip $\left(T_{b}=0.58\right)$, trunk push up*right knee extension $\left(T_{b}=0.56\right)$, trunk push up*left knee extension $\left(T_{b}=0.43\right)$, trunk push up*fat mass $\left(T_{b}=-0.52\right)$, trunk push up*visceral fat $\left(T_{b}=\right.$ - 0.51) and trunk push up*muscular mass $\left(T_{b}=0.55\right)$; composite FMS score*right handgrip $\left(T_{b}=0.42\right)$, composite FMS score*left handgrip $\left(T_{b}=0.46\right)$, composite FMS score*bone mineral density $\left(T_{b}=0.36\right)$ and composite FMS score*muscular mass $\left(T_{b}=0.37\right)$. The trunk stability push-up it was the most correlated test with physical variables. It is also possible to suggest that individual FMS scores can be more useful than the composite score.

Acknowledgement

The authors thank the coaches from Surfing Viana High Performance Centre and participating athletes from Surf Club de Viana References:

Mendez-Villanueva, A., Bishop, D., \& Hamer, P. (2006). Activity profile of world-class professional surfers during competition: a case study. Journal of Strength and Conditioning Research, 20(3), 477-482.

\section{Cardiovascular effort in different head-out aquatic exercise routines: influence of limbs action and floating equipment.}

\author{
Lúcia Cruz ${ }^{1}$, Nuno Serra ${ }^{1}$, Ana Simão ${ }^{1}$, Carolina Vila-Chã ${ }^{1,3}$, Tiago M. Barbosa ${ }^{2,3}$, Mário J. \\ Costa 1,3 \\ 1. Polytechnic Institute of Guarda, Portugal; 2. Nanyang Technological University, Singapore; tiago.barbosa@nie.edu.sg; 3. \\ Research Centre in Sport Sciences, Health Sciences and Human Development, CIDESD, Portugal
}

Head-out aquatic exercise classes comprise limbs action with or without equipment to diversity and change the intensity of the session. Instructors use arms only, legs only action or full mode of exercise to induce different forms of effort. Although acute physiological response can be dependent from the number of limbs in action or by the inclusion of floating material (Costa et al., 2008), there is a need to stagger those routines for health and conditioning purposes. Ten young and healthy women $(22.2 \pm 2.6$ years, $59.3 \pm 12.5 \mathrm{~kg}$ of body mass and $1.63 \pm 0.08 \mathrm{~m}$ of height) were recruited to perform five head-out aquatic exercises: (i) 
horizontal arms abduction (Ab); (ii) horizontal arms abduction with dumbbells (AbDum); (iii) frontal kick (Fk); (iv) frontal kick with leggings (FkLeg), and; (v) aquatic skiing (Ski). Subjects were randomly assigned to each routine that was performed for three minutes at the cadence of $132 \mathrm{bpm}$. Cardiovascular response was assessed by heart rate, systolic blood pressure, double product and rating of perceived exertion. There were significant and strong variations in all variables according to the routine performed $(\mathrm{p}<0.01$, partial $\eta^{2}>0.64$ for all). The heart rate was higher in FkLeg $(140.40 \pm 25.50 \mathrm{bpm})$ compared to Ab $(110.30 \pm 23.75$ $\mathrm{bpm}, \mathrm{p}=0.03)$ and AbDum $(110.00 \pm 22.70 \mathrm{bpm}, \mathrm{p}=0.04)$. The systolic blood pressure showed higher values in $\mathrm{Fk}(120.60 \pm 15.20 \mathrm{mmHg})$ when compared to $\mathrm{Ab}(104.50 \pm 10.80 \mathrm{mmHg}, \mathrm{p}=0.05)$. The double product also showed higher values in Fk (15962.80) and FkLeg (16990.40) when compared to Ab (11608, $\mathrm{p}<0.01$ and $\mathrm{p}=0.01$, respectively). Interestingly, the rating of perceived exertion showed lower values in Ski (10.40) than AbDum (13.60, p = 0.01) and FkLeg (15.80, p < 0.01). It can be concluded that different head-out aquatic exercise routines, encompassing different limbs or with the aid of floating devices, induce different cardiovascular responses. Actions by the lower limbs are the most intense, while upper limbs elicit a lower exertion. Exercising the four limbs (e.g. aquatic skiing) seems to be less demanding than eliciting only two limbs with the aid of a floating device.

References:

Costa, G., Afonso, S., Bragada, J. A., Reis, V. M., \& Barbosa, T. M. (2008). Comparison of acute physiological adaptations between three variants of a basic head-out water exercise. Brazilian Journal of Kinanthropometry and Human Performance, 10(4), 323-329. https://doi.org/10.5007/1980-0037.2008v10n4p323

\title{
Artificial neural networks and performance prediction from low to severe swimming intensities
}

\author{
Kelly de Jesus ${ }^{1,2,3}$, Karla de Jesus $1,2,3$, Alexandre A. Medeiros ${ }^{4}$, Pedro Gonçalves ${ }^{2,3}$, Helon \\ Ayala $^{5}$, Leandro dos Santos Coelho ${ }^{5,6}$, João Paulo Vilas-Boas ${ }^{2,3}$, Ricardo J. Fernandes ${ }^{2,3}$ \\ 1. Faculty of Physical Education and Physiotherapy, Federal University of Amazonas, Amazonas, Manaus, Brazil; 2. Centre of \\ Research, Education, Innovation and Intervention in Sport, Faculty of Sport, University of Porto, Porto, Portugal; 3. Porto \\ Biomechanics Laboratory, University of Porto, Porto, Portugal; ricfer@fade.up.pt; 4. Centre of Biodynamic Human Movement \\ Research, Institute of Physical Education and Sport, Federal University of Ceará, Fortaleza, Ceará, Brazil; 5. Industrial and \\ Systems Engineering Graduate Program, Pontifical Catholic University of Paraná, Paraná, Brazil; 6. Electrical Engineering \\ Graduate Program, Federal University of Paraná, Paraná, Brazil
}

The non-linear modelling method is promising in the area of competitive swimming [1], being artificial neural networks considered potentially superior than linear approach for modelling, pattern recognition and time series forecasting with errors lower than $0.50 \mathrm{~s}$ for middle-distance events (Leondes, 2002; Pfeiffer \& Hohmann, 2012). We aimed to apply two artificial neural networks types (i.e. Multilayer Perceptron and Radial Basis Function) for horizontal center of mass swimming velocity (CM) prediction at low-moderate, heavy and severe training intensities during an incremental protocol using physiological and biomechanical data. We hypothesized that a satisfactory model-fit could be achieved with both artificial neural networks types implemented for performance prediction of different swimming training intensities. Ten well-trained front crawl male swimmers (mean $\pm \mathrm{s}$ : age $19.78 \pm 5.36 \mathrm{yrs}$, stature $1.78 \pm 0.06 \mathrm{~m}$, body mass $71.40 \pm$ $5.72 \mathrm{~kg}$ ) volunteered to participate. Swimmers completed an intermittent incremental protocol of $7 \times 200$ $\mathrm{m}$ crawl swims to exhaustion ( $0.05 \mathrm{~m} . \mathrm{s}-1$ increments and $30 \mathrm{~s}$ intervals), being measured expiratory gases and blood lactate concentrations. Two surface and four underwater digital cameras recorded independent images subsequently processed for tridimensional reconstruction of two front crawl cycles (25 and $175 \mathrm{~m}$ laps). Eight physiological and 12 biomechanical parameters were assumed as input to estimate CM horizontal velocity at low-moderate, heavy and severe swimming intensity. Multilayer Perceptron (MLP) was implemented with the Levenberg-Marquardt as training algorithm (feed forward with one hidden layer of six neurons) and the Radial Basis Function (RBF; Gaussian) was built using orthogonal least squares algorithm. MLP and RBF, can predict the CM horizontal velocity (validation error < 5\%) at low- moderate, heavy and severe swimming intensities based on physiological and biomechanical data (Table 1).

\begin{tabular}{|c|c|c|c|c|c|}
\hline Intensity & Model & Training (\%) & Validation (\%) & All models (\%) & Best Validation (\%) \\
\hline \multirow{2}{*}{ Low-moderate } & MLP & $5.51 \mathrm{E}-06 \pm 8.65 \mathrm{E}-06$ & $2.43 \pm 1.44$ & $0.49 \pm 0.29$ & 0.13 \\
\hline & $\mathrm{RBF}$ & $6.72 \mathrm{E}-02 \pm 4.54 \mathrm{E}-02$ & $1.85 \pm 1.16$ & $0.42 \pm 0.25$ & 0.15 \\
\hline \multirow{2}{*}{ Heavy } & MLP & $5.36 \mathrm{E}-06 \pm 8.56 \mathrm{E}-06$ & $2.45 \pm 1.61$ & $0.49 \pm 0.32$ & 0.63 \\
\hline & $\mathrm{RBF}$ & $1.28 \mathrm{E}-01 \pm 4.33 \mathrm{E}-02$ & $1.82 \pm 0.92$ & $0.47 \pm 0.17$ & 0.46 \\
\hline \multirow{2}{*}{ Severe } & MLP & $4.70 \mathrm{E}-06 \pm 8.34 \mathrm{E}-06$ & $3.89 \pm 1.78$ & $0.78 \pm 0.36$ & 0.51 \\
\hline & $\mathrm{RBF}$ & $9.53 \mathrm{E}-02 \pm 6.23 \mathrm{E}-02$ & $2.78 \pm 0.96$ & $0.63 \pm 0.20$ & 1.11 \\
\hline
\end{tabular}

This current study indicates that MLP and RBF can model and predict the CM horizontal swimming velocity at low-moderate, heavy and severe intensities using physiological and biomechanical data during a traditional training protocol. 
Acknowledgement

This study was supported by grants: Projects CAPES/543110-7/2011 and from PTDC/DES/101224/2008 - FCOMP-01-0124-FEDER-00957. References:

Leondes, C. T. (2002). Neural networks and expert systems. Em C. T. Leondes (Ed.), Intelligent Systems: Technology and Applications, Six Volume Set (pp. 2-45). Washington DC: CRC Press.

Pfeiffer, M., \& Hohmann, A. (2012). Applications of neural networks in training science. Human Movement Science, 31, $344-359$.

\section{CFD comparison of friction and pressure drag between road and time trial helmets for wheelchair racing.}

Pedro Forte ${ }^{1,2}$, Daniel A Marinho' ${ }^{1,2}$, Jorge E Morais ${ }^{2,3}$, Pedro Morouço ${ }^{4}$, Tiago M Barbosa 2,5

1. University of Beira Interior, Covilhã, Portugal; 2. Research Center in Sports, Health and Human Development, CIDESD, Portugal; 3. Polythecnic Institute of Bragança, Bragança, Portugal; 4. Polythecnic Institute of Leiria, CDRsp, Leiria, Portugal; 5. Nanyang Technological University, Singapure; tiago.barbosa@nie.edu.sg

Computer Fluid Dynamics has been used by sports scientists aiming to improve the athlete's performance in sprinting events. In wheelchair sprinting, the athlete's velocity can reach up to $7 \mathrm{~m} / \mathrm{s}$. The use of sport garments such as helmets may reduce the aerodynamic drag by $10 \%$. Therefore, the aim of this study was to compare the friction and pressure drag between road and time trial helmets. A wheelchair racer (category T-52), European medallist in sprinting events and world championships finalist was recruited for this research. The subject wore a road helmet (LAS, Istron) and a time-trial model (LAS, Cronometro). The geometries were obtained by a 3D scan (Artec-L, Artec Group, Inc., USA). Fluent (Fluent, Inc., USA, New York) code allowed to compute numerical simulations applying a mathematical model to the fluid flow, in a created domain with discretized expressions of the Navier-Stokes equations. It solves the equations with a finite volume approach. The domain, created by a 3D mesh of subdivided cells, represented the fluid flow around the head and helmets. Realizable k-epsilon turbulence model was applied. The 3D mesh had more than 6 million cells for booth helmets domains and helmets angles of attack was $0^{\circ}$. The fluid flow velocity was set in inlet portion of the dome surface at $2 \mathrm{~m} / \mathrm{s}$, with increments of $1.5 \mathrm{~m} / \mathrm{s}$ up to $6.5 \mathrm{~m} / \mathrm{s}$. Typically the wheelchair racer will reach these range of speeds over a short distance event. Pressure and friction drag increased with velocity (Fig. 1).

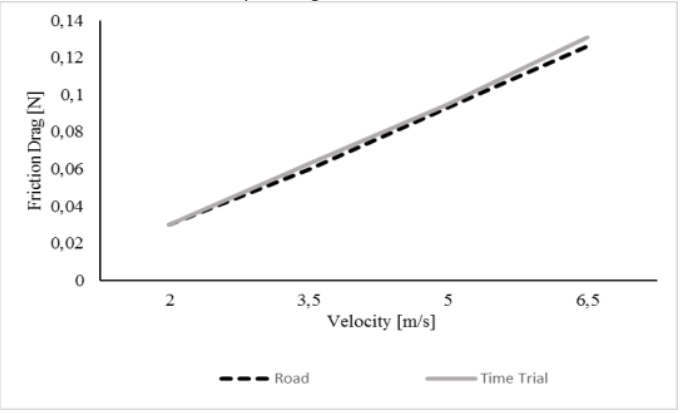

(a)

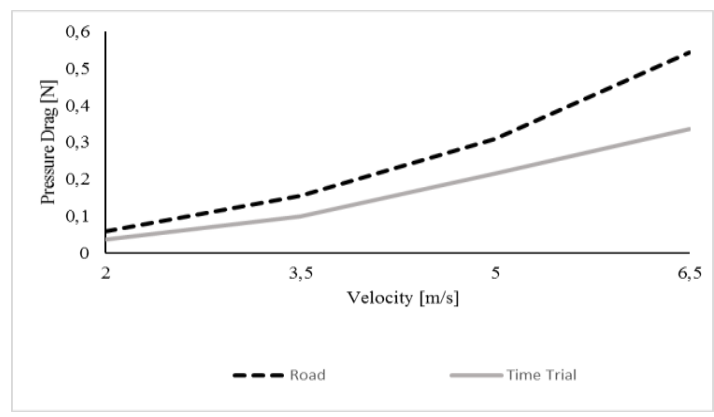

(b)

Figure 1. Friction (a) and Pressure (b) drag for road (dash line) and time trial (solid line) helmets at different speeds.

Pressure drag ranged from $0.059 \mathrm{~N}$ to $0.542 \mathrm{~N}$ and $0.036 \mathrm{~N}$ to $0.336 \mathrm{~N}$, for road and time trial helmets respectively. Pressure drag was lower wearing the time trial helmet than the road one at all selected velocities. As far as friction drag is concern, it ranged between $0.03 \mathrm{~N}$ and $0.126 \mathrm{~N}, 0.03 \mathrm{~N}$ and $0.131 \mathrm{~N}$, for road and time trial helmets respectively. The partial contribution of friction drag to total drag force ranged from $34-19 \%$ and $45-28 \%$, for road and time trial helmets, respectively. The partial contribution of pressure drag was $28-49 \%$ and $55-72 \%$ for road and time trial models, respectively. Aerodynamic drag increases with velocity. The road helmet presented a lower friction drag and the time trial a lower pressure drag. The pressure drag was the main contributor to total drag, inducing a time trial helmet usage.

\section{Applied biomechanics in competitive gymnastics: Brazilian scenario}

Karla de Jesus ${ }^{1}$, Kelly de Jesus Allen Graça ${ }^{1}$, Alexandre I.A. Medeiros ${ }^{2}$

1. Human Motor Behaviour Studies Laboratory, Faculty of Physical Education and Physiotherapy, Federal University of Amazonas, Amazonas, Manaus, Brazil; karladejesus@ufam.edu.br; 2. Research Group in Biodynamic Human Movement, Institute of Physical Education and Sport, Federal University of Ceará, Fortaleza, Ceará, Brazil.

Biomechanics has much to contribute to the continued progress of gymnastics. Its use may sharpen the understanding of the techniques, suggest new skills and lead to the achievement of advanced performances. 
It may also help identifying and controlling circumstances that lead to accidents (Irwin \& Kerwin, 2010). The aim of this study was to review the biomechanics studies conducted by Brazilian research groups concerning competitive gymnastics. The literature search was conducted using Pubmed, SciELO and Google Academic electronic databases. "Gymnastics" and "biomechanics" (English) and "ginástica" "e" "biomecânica" (Portuguese) were used as keywords. The identified reference lists in the articles, dissertations and thesis were considered. Searchers were also carried out from the Proceedings of the Scientific Conferences of the International Society of Biomechanics in Sports. Experimental biomechanical studies from 2000 to 2016 conducted by Brazilian research groups were included.

Table 1

Included rhythmic gymnastics studies with authors, main aim and variables.

\begin{tabular}{lll}
\hline \multicolumn{1}{c}{ Authors } & \multicolumn{1}{c}{ Main aim } & \multicolumn{1}{c}{ Variables } \\
\hline Szezerbaty et al. (2013) & $\begin{array}{l}\text { To verify the fatigue influence on the low back } \\
\text { muscles in postural stability }\end{array}$ & $\begin{array}{l}\text { Centre of postural oscillation, Anterior- } \\
\text { posterior velocity, } \\
\text { velocity }\end{array}$ \\
\hline Guiotte et al. (2012) & $\begin{array}{l}\text { To characterise the physic-functional profile related } \\
\text { to postural stability and the gymnastics injury history }\end{array}$ & $\begin{array}{l}\text { Centre of pressure oscillation mean } \\
\text { velocity }\end{array}$ \\
\hline Shigaki et al. (2013) & $\begin{array}{l}\text { To evaluate posture balance between the dominant } \\
\text { and contralateral lower limb during different balance } \\
\text { tasks }\end{array}$ & $\begin{array}{l}\text { Ellipse area of the centre of pressure, } \\
\text { mean velocity, mean frequency of the } \\
\text { centre of pressure oscillations }\end{array}$ \\
\hline
\end{tabular}

From the 18 included studies, $55.0 \%$ were conducted from 2010 to 2016, which might be related to the onward Brazilian gymnastics performance in elite level events. Most of the researches have considered only the artistic gymnastics (50.0\%). Rhythmic gymnastics corresponded to $33.33 \%$ of the included studies being three published in peer-reviewed journals (Table 1). One study has concerned about trampoline gymnastics. Kinematics and kinetics have been the two most common areas in the gymnastics biomechanics $(72.22 \%)$. Brazilian research groups have focused on artistic gymnastics for kinematic and kinetic characterisation, which might be due to the ascendant gymnastics performance in elite events.

References:

Guiotte, V. et al. (2012). Physical- functional evaluation of athlete's rhythmic gymnastics: a history of injuries and postural stability. Journal of Health Sciences, 14, 217-220

Irwin, K., Kerwin, D. (2010). Biomechanics and gymnastics. In. R. Jensen, W. Ebben, E. Petushek, C. Richter, K. Roemer (Eds.), XXIII International Conference on Biomechanics in Sports (pp. 104). Marquette, USA

Shigaki, L. et al. (2013). Comparative analysis of one-foot balance in rhythmic gymnastics athletes. Revista Brasileira de Medicina do Esporte, 19, 104107

Szezerbaty, S. et al. (2013). The influence of fatigue of lumbar muscle in stability postural athletes of rhythmic gymnastics. Manual Therapy, 11, $546-550$

\title{
Influence of Heat Stress in Mg and P metabolism during maximal effort test.
}

\author{
Ignacio Bartolomé ${ }^{1}$, Mario Iborra ${ }^{1}$, Jesús Siquier ${ }^{1}$, Mario Perez ${ }^{1}$, Francisco Llerena ${ }^{1}$, Marcus \\ Maynar $^{1}$
}

Faculty of sports Sciences. UNEX. Extremadura. Spain, ignbs.1991@gmail.com

Although the number of studies is reduced and some results are contradictory it seems clear that perform exercise in heat conditions results in a major tension of all exercise-dependent metabolisms, like the antioxidant or energetic. Consequently, the whole-body metabolization of trace elements during exercise can be affected in these situations. The aim of this work was to determine the concentrations of magnesium $(\mathrm{Mg})$ and phosphorus $(\mathrm{P})$ in sweat, serum and erythrocyte before and after a maximal effort test in room and heat conditions. Nineteen healthy adult males (age 22.58 \pm 1.05 years; height $178.32 \pm 5.93 \mathrm{~cm}$; weight $74.98 \pm 9.08 \mathrm{Kg}$; BMI $23.63 \pm 1.83$ ) performed two maximum incremental tests in cycloergometer separated by 48 hours. The first one was performed in normothermia $\left(22 \pm 2^{\circ} \mathrm{C}\right)$ and the second one in hyperthermic $\left(42 \pm 2^{\circ} \mathrm{C}\right)$ conditions using an environmental chamber. Blood and urine samples were obtained before (in rest conditions) and after each test. $\mathrm{Mg}$ and $\mathrm{P}$ concentrations in serum, urine and erythrocyte measurements were measured using inductively coupled plasma mass spectrometry (ICP-MS). The effect of a maximum effort test did not produce any significant change in $\mathrm{P}$ or $\mathrm{Mg}$ organic metabolism by itself. However, the heat stress suffered during a maximal effort test in an environmental chamber induced a diminution $(\mathrm{p}<0.01)$ in seric Mg. It is known that hyperthermia produce reductions in the organic availability of $\mathrm{O}_{2}$, this can lead to an increased metabolic tension that may affect several elements like Mg. However this stress did not induce any other change of this element in erythrocyte or urine. 
Table 1

Concentrations of magnesium and phosphorous in urine, serum and erythrocyte

\begin{tabular}{|c|c|c|c|c|c|c|c|}
\hline \multirow[t]{2}{*}{ Elements } & & \multicolumn{3}{|c|}{$\operatorname{Room}\left(22 \pm 1^{\circ} \mathrm{C}\right)$} & \multicolumn{3}{|c|}{ Heat $\left(42 \pm 1^{\circ} \mathrm{C}\right)$} \\
\hline & Unit & Before & After & Sig. & Before & After & Sig. \\
\hline Urinary $\mathrm{Mg}$ & & $72.47 \pm 39.83$ & $62.06 \pm 37.97$ & 0,078 & $75.15 \pm 83.04$ & $65.38 \pm 87.98$ & 0,573 \\
\hline Urinary P & & $620.30 \pm 478.17$ & $628.28 \pm 474.20$ & 0,679 & $615.36 \pm 600.63$ & $608.31 \pm 733.62$ & 0,904 \\
\hline Seric Mg & $(\mathrm{mg} / \mathrm{L})$ & $19.90 \pm 1.48$ & $19.40 \pm 2.27$ & 0,227 & $19.58 \pm 1.89$ & $18.31 \pm 1.67$ & $\underline{0,010}$ \\
\hline Seric $\mathrm{P}$ & & $149.31 \pm 18.77$ & $147.66 \pm 19.63$ & 0,334 & $136.34 \pm 19.63$ & $139.21 \pm 20.35$ & 0,616 \\
\hline Erythrocyte Mg & $(\mathrm{mg} / \mathrm{g}$ & $26.89 \pm 6.00$ & $25.19 \pm 4.95$ & 0,438 & $26.04 \pm 6.57$ & $26.35 \pm 8.55$ & 0,586 \\
\hline Erythrocyte P & $\mathrm{Hb})$ & $269.47 \pm 57.70$ & $260.67 \pm 48.02$ & 0.877 & $257.66 \pm 69.01$ & $268.16 \pm 80.45$ & 0.523 \\
\hline
\end{tabular}

It can be concluded that a maximum effort test in hyperthermic conditions $\left(42 \pm 2^{\circ} \mathrm{C}\right)$ lead to a diminution in the concentrations of seric $\mathrm{Mg}$ in comparison with the pre-test values of this element, suggesting an organic redistribution to, possibly, counteract the increased heat-induced demands.

References:

Clarkson, P. M., \& Haymes, E. M. (1995). Exercise and mineral status of athletes: calcium, magnesium, phosphorus, and iron. Medicine and science in sports and exercise, $27(6), 831-843$.

Grijota, F. (2016). Influencia del ejercicio físico en los niveles eritrocitarios de elementos minerales traza. Tesis Doctoral, Universidad de Extremadura, Cáceres.

Llerena F. (2011). Efectos del ejercicio físico en la eliminación urinaria de elementos traza. Tesis Doctoral, Universidad de Extremadura. Cáceres.

\title{
Variations of stroking parameters in young swimmers
}

Laura Freitas ${ }^{1,2}$, Nuno Batalha ${ }^{3}$, David B. Pyne ${ }^{4}$, Ricardo J. Fernandes ${ }^{1}$

1. Cifi2d at Faculty of Sport and Labiomep, University of Porto, Porto, Portugal; ricfer@fade.up.pt; 2. Leixões Sport Clube, Matosinhos, Portugal; 3. Departamento de Desporto e Saúde, Escola de Ciência e Tecnologia, Universidade de Évora, Évora, Portugal; Research Centre of Sports, Health and Human Development, CIDESD, STRONG Research Community; 4. Physiology, Australian Institute of Sport, Canberra, Australia

Technique is a highly determinant factor in swimming performance and should be assessed systematically during the training process, especially in young swimmers. The purpose of this study was to quantify the effect of a 15 week training macrocycle on swimming speed, stroke rate (SR) and stroke length (SL). Thirteen young swimmers (nine males and four females; $13.8 \pm 0.8 \mathrm{y} ; 1.67 \pm 0.10 \mathrm{~m} ; 60.0 \pm 11.3 \mathrm{Kg}$ ), with a weekly practice $\geq 6$ training units, performed the pool-based 7 x 50-m front crawl stroke mechanics (Pyne, Maw, \& Goldsmith, 2000), with increments of $5 \%$ of maximum speed (\%Vmax). Speed was assessed by a manual stopwatch, SR obtained by the number of cycles in $50 \mathrm{~m}$, and SL calculated through the ratio of speed and SR. A Student's T-Test for dependent samples was used to compare the pre and post-training responses, and an ANOVA to analyse change in the performance variables over the 15 weeks. We observed at both time points an increase of SR (more evident in the last two steps: 18\%) concurrently with increased swimming velocity. A decrease in SL was evident at each $10 \%$ increase of speed, after the 15 weeks. In addition, there was a tendency for an increase in maximum speed with the 15 weeks of training ( $1.61 \pm 0.15$ vs $1.64 \pm 0.15 \mathrm{~m} / \mathrm{s}, \mathrm{P}=0.086)$, although SR and SL remained stable in almost all the steps of the test. The exception was the intensity corresponding to $85 \%$ maximum speed $(\sim 1.38 \pm 0.11 \mathrm{~m} / \mathrm{s})$ where SR increased and SL decreased. The increase of maximum swimming speed was related to improvements in the underwater phase of the swimming starts and turns. The results suggests that SR is the technical parameter most closely related to swimming speed, and that a 15 week training macrocycle is not sufficient to elicit significant changes in all stroking parameters. The inability to invoke technical improvements is most likely related to inefficiency of the training program.

References:

Pyne, D., Maw, G., \& Goldsmith, W. (2000). Protocols for the Physiological Assessment of Swimmers: Australian Sports Commission. In H. Kinetics (Ed.), Physiological tests for elite athletes (Vol. 1). United States of America.

\section{Hyperthermia: acute effect on selenium and zinc trace minerals in erythrocytes, serum and urine.}

\author{
Jesús Siquier-Coll ${ }^{1}$, Carlos García-Gómez ${ }^{1}$, Ignacio Bartolomé ${ }^{1}$, Maria C. Robles, Francisco \\ Llenera ${ }^{1}$, Marcus Maynar ${ }^{1}$. \\ Laboratorio de Fisiología del Ejercicio. Facultad de Ciencias del Deporte. Universidad de Extremadura. \\ jsiquier@alumnos.unex.es
}

Selenium and Zinc are part of glutathione peroxidase and $\mathrm{Cu}-\mathrm{Zn}$ superoxide dismutase respectively, important enzymes in the antioxidant system (Underwood, 2012). The stress of exercise can cause changes in the concentrations (Grijota Pérez, 2016) of these and in turn being able to be compounded this event by 
thermal stress due to change in the homeostasis resulting heat stress(Keim, Guisto, \& Sullivan Jr, 2002). Nineteen adult males $(22.58 \pm 1.05$ age) did two maximum incremental stress tests in cycloergometer separated by 48 hours in normothermia $\left(22 \pm 2^{\circ} \mathrm{C}\right)$ and in hyperthermia $\left(42 \pm 2^{\circ} \mathrm{C}\right)$, respectively. Blood and urine samples were taken before and after each test. Serum, urine and erythrocyte analysis of trace metals was performed by inductively coupled plasma mass spectrometry (ICP-MS). Serum and erythrocyte concentrations were corrected by the formula of Dill and Costill (Dill \& Costill, 1974). No significant differences were found between before and after the test in normothermia or hyperthermia.

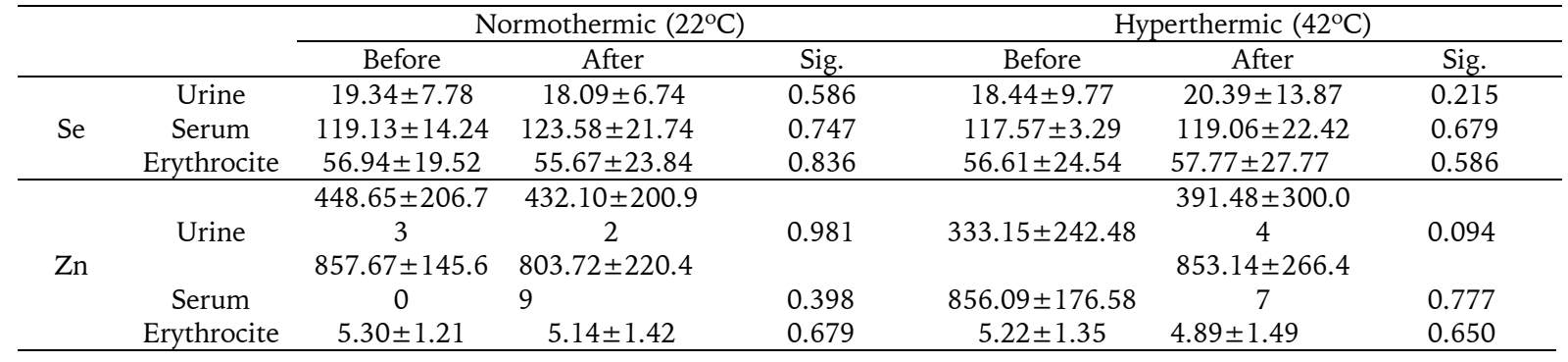

1. The concentrations, urinary, serum and erythrocyte remain unchanged as a result or test or hyperthermia.

2. Hyperthermia used did not make a cardiovascular displacement.

3. Hyperthermia used did not produce a decrease in performance test.

\title{
References:
}

Dill, D. B., \& Costill, D. L. (1974). Calculation of percentage changes in volumes of blood, plasma, and red-cells in dehydration. Journal of Applied Physiology, 37(2), 247-248.

Grijota, F. (2016). Influencia del ejercicio físico en los niveles eritrocitarios de elementos minerales traza. Tesis Doctoral, Universidad de Extremadura, Cáceres.

Keim, S. M., Guisto, J. A., \& Sullivan Jr, J. B. (2002). Environmental thermal stress. Annals of Agricultural and Environmental Medicine, 9 (1), 1-15. Underwood, E. (2012). Trace Elements in Human and Animal Nutrition. New York: Academic Press.

\section{Swimming performance and dry-land upper limbs strength in age group swimmers}

\author{
Nuno Amaro1, Daniel A. Marinho ${ }^{2,4}$, Mário C. Marques 2,4 , Nuno Batalha ${ }^{3,4}$, Pedro G. \\ Morouço ${ }^{1}$ \\ 1. Polythecnic Institute of Leiria, Leiria, Portugal; 2. University of Beira Interior, Covilhã, Portugal; 3. Departamento de Desporto \\ e Saúde, Escola de Ciência e Tecnologia, Universidade de Évora, Portugal; 4. Research Centre of Sports, Health and Human \\ Development, CIDESD, STRONG Research Community; pedro.morouco@ipleiria.pt
}

High values of dry-land strength and power, particularly in the upper-body, have been identified as a determinant factor to success in competitive swimming. Ball throwing is a common test used to assess dryland strength and power in age group swimmers. Therefore, the aim of this study was to determine the correlation between ball throwing measures and swimming performance. Twenty-one male prepubescent swimmers $(12.7 \pm 0.7$ years; $47.7 \pm 9.6 \mathrm{Kg} ; 1.56 \pm 0.78 \mathrm{~m})$ were recruited for this research. Experiments were conducted during the competitive period of the spring training, thus ensuring that the subjects were in a prime training period cycle. After a standard warm-up of articular mobilization and rope skipping of approximately 10 minutes, Ball throwing (BT) distances (in $\mathrm{m}$ ) were measured through maximal throwing velocity tests using a 1 and $3 \mathrm{~kg}$ medicine ball. Preceding the tests, each participant executed several random throws for warm-up, with both balls. Each participant executed three throws with 2 minutes rest between attempts. Three technical valid attempts were used to calculate the average for analysis. Swimming performance tests were executed after an 800 m moderate intensity warm-up in a $25 \mathrm{~m}$ indoor swimming pool. All subjects completed one maximal test of $50 \mathrm{~m}$ and 15 $\mathrm{m}$ (to exclude the influence of start) in front crawl in order to access their best time in each test ( $\mathrm{t} 50$ and $\mathrm{t} 15)$. Short distances were chosen due to the influence of force application over these distances. Spearman correlation coefficients were calculated between in water and dry land parameters assessed. Significance was accepted at the $\mathrm{p}<0.05$ level. Correlations obtained between ball throwing values and swimming performance were moderate to strong for both 1 and $3 \mathrm{Kg}$ balls throws (table 1$)$. Mean values ( \pm sd) obtained for ball throwing

\section{Table 1}

Correlation values $(\rho)$ between ball throwing values ( 1 and $3 \mathrm{~kg}$ ) and swimming performance (15 and 50 $m)$.

m).
\begin{tabular}{|r|c|c|}
\hline & BT_1kg & BT_3KG \\
\hline $\mathrm{t} 15$ & $-0.63^{*}$ & $-0.58^{*}$ \\
\hline $\mathrm{t} 50$ & $-0.60^{*}$ & $-0.64^{*}$ \\
\hline${ }^{*} \mathrm{p}<0.05$
\end{tabular}
were: $4.19 \pm 0.71 \mathrm{~m}(1 \mathrm{~kg})$ and $2.84 \pm 0.47 \mathrm{~m}(3 \mathrm{~kg})$. Swimming performance mean values $( \pm \mathrm{sd})$ were $10.63 \pm 0.51 \mathrm{~s}$ for $15 \mathrm{~m}$ trial and $33.70 \pm 2.46 \mathrm{~s}$ for $50 \mathrm{~m}$ trial. Results showed moderate to strong associations between variables, which may indicate that ball throwing can be a valid procedure to evaluate 
age group swimmers; however, it does not clearly explain performance variability. Lack of specificity of this dry-land test in relation to in-water tests can explain the results.

\title{
Can a Halliwick swimming program develop water competence, static and dynamic balance in disabled participants?
}

\author{
Andreia Maia1, Jean Amarante ${ }^{1}$, Nuno Serra ${ }^{1}$, Carolina Vila-Chã 1,3, Tiago M. Barbosa ${ }^{2,3}$ \\ Mário J. Costa 1,3 \\ 1. Polytechnic Institute of Guarda, Portugal; 2. Nanyang Technological University, Singapore; 3. Research Centre in Sport \\ Sciences, Health Sciences and Human Development, CIDESD, Portugal; mario.costa@ipg.pt
}

The Halliwick concept is an aquatic rehabilitation program aiming to enhance balance and core stability of disabled individuals. Previous studies focused on assessing the participants' satisfaction on Halliwick programs or the acquisition of water motor skills (Garcia et al., 2012).Yet, as far as our understanding goes there is not in the literature the assessment of the water independence or the transfer to land-based body balance and posture. Nine individuals ( $33 \pm 12.3$ years) diagnosed with cerebral palsy $(n=2)$, mental disability $(n=4)$ and trisomy $21(n=3)$ were took part in a Halliwick's 10-point programme. The programme had a duration of 15 weeks comprising one weekly session with one hour of duration. All sessions were planned and implemented by a trained therapist. In the beginning (W0) and in the end (W15) of the intervention programme it was assessed the water competence, static and dynamic balance. Water competence was assessed by the Water Orientation Test Align 2 (WOTA, in points) that is capped to 81 points (Tiroshi et al., 2008). Static balance was assessed by one-leg stance test (OST, in s) and functional reaching test (FRT, in $\mathrm{m}$ ) according to standard guidelines. The Time up \& go test (TUGT, in s) was selected as a measure of dynamic balance. Water competence measured by WOTA 2 showed significant improvements $\left(\right.$ WOTA $_{\mathrm{wo}}=$ $39 \pm 11$ vs $W O T A_{\mathrm{W} 15}=57 \pm 16$ points, $\left.\mathrm{p}<0.01\right)$ between the beginning and end of the programme. Static balance also improved. There was a significant change in the OST OST $_{\mathrm{W} 0}=15.56 \pm 12.88$ vs OST $_{\mathrm{W} 15}=$ $17.78 \pm 12.48 \mathrm{~s}, \mathrm{p}=0.04)$ and $\mathrm{FRT}\left(\mathrm{FRT}_{\mathrm{W} 0}=0.20 \pm 0.09\right.$ vs $\left.\mathrm{FRT}_{\mathrm{W} 15}=0.24 \pm 0.11 \mathrm{~m}, \mathrm{p}<0.01\right)$ performances. Dynamic balance also improved $\left(\mathrm{TUGT}_{\mathrm{W} 0}=9.12 \pm 2.61 \mathrm{vs} \mathrm{TUGT}_{\mathrm{W} 15}=7.74 \pm 2.52 \mathrm{~s}, \mathrm{p}=0.01\right.$ ) after the 15 th week. It can be concluded that 15 weeks of a well-designed Halliwick programme can improve water competence of disabled individuals. Concurrently, it was also noted a positive transfer of the skills acquired in water to on land body balance and posture. Hence, fitness and health practitioners should be aware of the water benefits to improve balance and core stability in disable populations.

References:

Garcia, M. K., Joares, E. C., Silva, M. A., Bissolotti, R. R., Oliveira, S., \& Battistella, L. R. (2012). The Halliwick Concept, inclusion and participation through aquatic functional activities. Acta fisiátrica, 19(3), 142-150.

Tiroshi, R., Katz-Leurer, M., \& Getz M. (2008). Halliwick-Based aquatic assessments: reliability and validity. International Journal of Aquatic Research and Education, 2, 224-236.

\section{Effect of strength training in hypoxia on body composition and muscle performance}

\author{
Ismael Martínez-Guardadoํㅡ, Marta Camacho-Cardenosa ${ }^{2}$, Alba Camacho-Cardenosa ${ }^{1}$, \\ Guillermo Olcina ${ }^{1}$, Rafael Timón ${ }^{1}$ \\ Sport Sciences Faculty. University of Extremadura. Caceres. wismi4@gmail.com
}

Resistance training is the best way to cause muscular adaptations. Current guidelines state that loads of $\geq 65 \% 1 \mathrm{RM}$ are necessary to elicit favorable increases in hypertrophy (Kraemer et al., 2002; Kraemer \& Ratamess, 2004). Besides this, the addition of hypoxic stimulus during resistance training is suggested to increase the metabolic responses, enhancing hypertrophy and muscle strength (Kon, Ikeda, Homma, \& Suzuki, 2012). To determine the adaptations caused by hypoxia resistance training on strength and body composition. Sixteen untrained subjects participated in the study (weight: $74.68 \pm 12.89 \mathrm{~kg}$; height: $1.75 \pm 0.08 \mathrm{~cm}$; BMI: $24.28 \pm 3.80 \mathrm{~kg} / \mathrm{m} 2$ ). A training period of 7 weeks in a hypoxia chamber under normobaric hypoxia conditions $\left(\mathrm{FiO}_{2}=13 \%\right)$ was performed. At the beginning, resistance training consisted of maximum repetitions to failure at $65 \% 1 \mathrm{RM}$, and then, every two weeks, intensity training increased to finish at $80 \% 1 \mathrm{RM}$. Initial and final measurements were taken. Body composition was determined through skin fold and muscle strength was evaluated with 1RM tests in the following exercises: bench press, bices curl, french press, rowing hip and half squat. A general linear model of repeated measures was performed to observe the differences in every variable. Increases were observed in muscle percentage, so the fat percentage decreased significantly. They also showed an increase in the perimeters of the arm, leg and thigh with respect 
to their initial values. Regarding the performance values, subjects also increased the number of $\mathrm{kg}$ raised in $1 \mathrm{RM}$ for all exercises. The significance level was set at $\mathrm{p} \leq 0.05$. In conclusion, resistance training of 7 weeks in hypoxia conditions increased strength and hypertrophy in untrained subjects.

Acknowledgement

This paper was supported by the Council of Extremadura (Aid for research groups GR 15020) for funding the research.

References:

Kon, Ikeda, T., Homma, T., \& Suzuki, Y. (2012). Effects of low-intensity resistance exercise under acute systematic hypoxia on hormonal responses. Journal of Strength \& Conditioning Research, 26(6), 1-7.

Kraemer, W. J., Adams, K., Cafarelli, E., Dudley, G. A., Dooly, C., Feigenbaum, M. S., Triplett-McBride, T. (2002). American College of Sports Medicine position stand. Progression models in resistance training for healthy adults. Medicine and Science in Sports and Exercise, 34 (2), 364380 .

Kraemer, W. J., \& Ratamess, N. A. (2004). Fundamentals of resistance training: progression and exercise prescription. Medicine and Science in Sports and Exercise, 36(4), 674-688.

\title{
Running capacity in a female rat ovariectomised model of obesity
}

\author{
Alex Soares Marreiros Ferraz ${ }^{1}$, Gabriella Caminha Bret de Aragão ${ }^{1}$, Hildiane Marinho Fontes \\ Sampaio ${ }^{1}$, Franciele Cristina Pereira de Oliveira ${ }^{1}$, Rodrigo Leite Furtado ${ }^{1}$, Vânia Marilande \\ Ceccatto $^{2}$
}

Institute of Physical Education and Sports, Federal University of Ceara; 2. Institute of Biomedical Sciences, State University of Ceara. ferrazalex@hotmail.com

The ovarian hormones privation, in experimental animals, induces increases in body weight, and adipose tissue differential gain, decrease in voluntary physical activity and a decrease in aerobic physical capacity is also suggested. The aim of this study is to investigate changes in physical capacity in models of ovariectomyinduced obesity in animals. We used 24 twelve-week old virgin, female Wistar rats, divided in eutrophic (sham surgery, $\mathrm{n}=6$ ) and obese (ovariectomy surgery, $\mathrm{n}=6$ ) treatments. After 8 weeks, running test in treadmill was performed, initial intensity $(0.4 \mathrm{~km} / \mathrm{h})$ was increased of $0.2 \mathrm{~km} / \mathrm{h}$ at 3 minutes until fatigue. Final speed it's determined, and power calculated as the product of, bodyweight $(\mathrm{kg})$, gravity $\left(\mathrm{m} / \mathrm{s}^{2}\right)$, speed $(\mathrm{m} / \mathrm{s})$. Animals were weights, euthanized with excess of anesthetic, visceral adipose tissue and muscles hind legs were collected and weighted. The results, media \pm standart deviation, showed that the groups gained weight during the experimental period, with the ovariectomised group presenting final average more than the eutrophic animals. The muscular and adipose tissue was also elevated in the obese group, mainly in body fat. However, no differences were found in the maximum speed and power among the experimental groups.

Table 1.

Weight of animals, weight the body tissue and physical capacity parameters in eutrophic and obese groups. $(*)=$ significant difference to eutrophic; $(\#)=$ significant difference to initial body weight $(p<0.05)$.

\begin{tabular}{ccc}
\hline & Eutrophic & Obese \\
\hline Initial Body Weight (g) & $157.3 \pm 9.7$ & $167.7 \pm 5.0$ \\
Final Body Weight (g) & $183.3 \pm 8.7^{\#}$ & $233.2 \pm 4.9^{\# *}$ \\
Muscular Weight (g) & $2.7 \pm 0.06$ & $3.2 \pm 0.12^{*}$ \\
Fat Weight (g) & $6.4 \pm 0.85$ & $11.9 \pm 1.15^{*}$ \\
Maximum Velocity (Km/h) & $1.97 \pm 0.15$ & $1.70 \pm 0.05$ \\
Power (Watts) & $0.98 \pm 0.10$ & $1.08 \pm 0.04$ \\
\hline
\end{tabular}

The similar capacity of the obese group can be justified by the muscular content increase that followed in part the body weight gain. Therefore, in sedentary experimental animals, seems to exist a plateau of maximum power race that is independent of the animal's condition obese.

References:

Khajuria, D. K., Razdan, R., \& Mahapatra, D. R. (2015). Additive effects of zoledronic acid and propranolol on bone density and biochemical markers of bone turnover in osteopenic ovariectomized rats. Revista brasileira de reumatologia, 55(2), 103-112. doi:10.1016/j.rbr.2014.09.006

Liu, T.W., Park, Y.M., Holscher, H.D., Padilla, J., Scroggins, R.J., Welly, R., ... Swanson, K.S. (2015). Physical Activity Differentially Affects the Cecal Microbiota of Ovariectomized Female Rats Selectively Bred for High and Low Aerobic Capacity. PLoS ONE, 10(8), e0136150. doi:10.1371/journal.pone.0136150.

\section{Short term recovery after an Olympic distance triathlon race}

\section{Guillermo Olcina ${ }^{1}$, Javier Brazo-Sayavera ${ }^{1}$, Marta Marcos-Serrano ${ }^{1}$, Alba Camacho- Cardeñosa ${ }^{1}$, Marta Camacho-Cardeñosa ${ }^{1}$, Carmen Crespo $^{1}$}

1. Sport Sciences Faculty. University of Extremadura. Cáceres. Spain. golcina@unex.es

Triathlon is an endurance sport which recently is getting more popular and the number of competitions is growing up. Some triathletes compete every week, but they do not truly know if they are full recovered. The aim of this study was to evaluate the short term recovery after the completion of an Olympic distance 
triathlon based on physiological and performance parameters. Fourteen triathletes, who raced in a triathlon qualifier for the National Spanish Championship, were recruited. Before, after, 24 hours and 48hours after the race, body composition, CMJ jump test and perceived exertion through the use of the BORG and VAS scales were assessed. As well, blood analysis were performed analysing the following parameters: Lactate $(\mathrm{mmol} / \mathrm{L})$, Haematocrit $(\%)$, Glucose $(\mathrm{mg} / \mathrm{dL})$, Total protein $(\mathrm{mg} / \mathrm{dL})$, Triglycerides $(\mathrm{mg} / \mathrm{dL})$, Bilirubin (mg/dL), GOT (IU/L), GPT (IU/L), LDH (IU/L), BUN (mg/dL), CPK (IU/L). RESULTS: The results showed a decrease of $5.7 \%$ in haematocrit after $24 \mathrm{~h}(\mathrm{p}<0.05)$ and $48 \mathrm{~h}(\mathrm{p}>0.01)$ as well as a decrease of $15.5 \%$ in total protein after 24 and $48 \mathrm{~h}(\mathrm{p}<0.001)$. CPK (IU/L) was heavily altered (PRE $128.92 \pm 50.85$ vs POST $275.62 \pm 59.20$ vs $24 \mathrm{~h} 535.62 \pm 461.61$ vs $48 \mathrm{~h} 488.38 \pm 545.47)(\mathrm{p}<0.01)$. The rest markers of metabolic stress and muscular damage return to normal values after a recovery period of $24-48 \mathrm{~h}$ as well as CMJ or body weight. A period of $48 \mathrm{~h}$ seems not to be enough for a full recovery after racing in an Olympic distance triathlon, especially regarding to muscular damage or plasma volume alterations.

\title{
Acknowledgement
}

This paper was supported by 226ERS (research agreement 179/15) and by the Council of Extremadura (Aid for research groups GR 15020) for funding the research.

References:

Bürger-Mendonça, M., Bielavsky, M., \& Barbosa, F. C. R. (2008). Liver overload in Brazilian triathletes after half-ironman competition is related muscle fatigue. Annals of Hepatology, 7(3), 245-248.

Del Coso, J., González-Millán, C., Salinero, J. J., Abián-Vicén, J., Soriano, L., Garde, S., \& Pérez-González, B. (2012). Muscle damage and its relationship with muscle fatigue during a half-iron triathlon. PloS One, 7(8), e43280. https://doi.org/10.1371/journal.pone.0043280

Meighan, V. (2012). Exertional rhabdomyolysis in female amateur triathletes. Critical Care, 16(Suppl 1), P459. https://doi.org/10.1186/cc11066

\section{Anthropometric changes after 3 months of training in endurance athletes.}

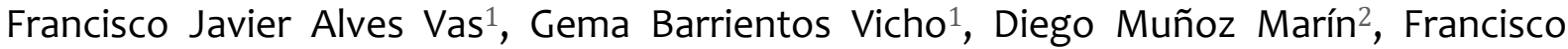 \\ Llerena Ruíz² ${ }^{2}$ Sergio López García ${ }^{1}$; Marcos Maynar Mariño ${ }^{2}$
}

1. Universidad Pontificia de Salamanca; fjalvesva@upsa.es 2. Universidad de Extremadura.

Researchers have indicated that performance in endurance athletes is related to specific physiological parameters (Joyner \& Coyle, 2008) as the maximal oxygen uptake $\left(\mathrm{VO}_{2}\right.$ max.) (Maldonado-Martin, Mujika \& Padilla, 2004) and anthropometric characteristics appropriate (Legaz-Arrese \& Eston, 2005). The aim of the study was to determine the changes induced in anthropometric parameters and $\mathrm{VO}_{2} \mathrm{max}$ in endurance runners after a period of training, and its possible relationship to performance. Before and after of three months of training, abdominal, subscapular, iliac crest, triceps, front thight and medial calf skindfolds were measured at twenty one middle and long distance runners highly trained (age $23 \pm 3$ years, weight $65.5 \pm 7.3$ $\mathrm{kg}$, height $177 \pm 0.05 \mathrm{~m}, \mathrm{VO} 2 \mathrm{max} .68 .1 \pm 4.6 \mathrm{ml} / \mathrm{min} / \mathrm{kg}$ ) all with at least 4 years of experience and a training volume $105.9 \pm 16.8 \mathrm{kms} /$ week; then the subjects performed an incremental test on a treadmill to determine VO2max. There was a significant increase $p<0.05$ in abdominal and iliac crest skinfold, and decrease $p$ $<0.01$ in the calf medium skindfold with training. In addition, the maximum speed reached by the subjects in the incremental test performance had a significant increase $\mathrm{p}<0.01$, while the $\mathrm{VO}_{2} \max$. had not significance.

Table 1.

Changes in $\mathrm{VO}_{2} \max$. and skinfold thicknesses after three months of training.

\begin{tabular}{cccc}
\hline & Beginning & 3 Month & NS \\
\hline $\mathrm{VO}_{2}$ max $(\mathrm{mL} / \mathrm{min} / \mathrm{kg})$ & $68,12 \pm 4,63$ & $67,53 \pm 9,54$ & $\mathrm{p}<0.05$ \\
\hline Abdominal skinfold $(\mathrm{mm})$ & $9,76 \pm 2,59$ & $10,39 \pm 3,39^{*}$ & $\mathrm{NS}$ \\
\hline Subscapular skinfold $(\mathrm{mm})$ & $8,23 \pm 1,49$ & $8,51 \pm 1,96$ & $\mathrm{p}<0.05$ \\
\hline Iliac crest skinfold $(\mathrm{mm})$ & $5,73 \pm 1,25$ & $6,74 \pm 1,52^{*}$ & $\mathrm{NS}$ \\
\hline Tricipital skinfold $(\mathrm{mm})$ & $6,33 \pm 1,59$ & $6,30 \pm 1,73$ & $\mathrm{NS}$ \\
\hline Front thight skinfold $(\mathrm{mm})$ & $8,50 \pm 3,04$ & $9,09 \pm 3,19$ & $\mathrm{p}<0,01$ \\
\hline Medium calf skinfold $(\mathrm{mm})$ & $8,24 \pm 3,07$ & $6,52 \pm 2,12^{*}$ & $\mathrm{NS}$ \\
\hline Sum of six skinfold $(\mathrm{mm})$ & $46,81 \pm 10,88$ & $47,57 \pm 10,68$ & \\
\hline
\end{tabular}

* Signicantly different from the initial measurement

Improvements in the performance of highly trained in endurance runners appear to be associated with loss fat weight in specific muscle groups in training.

References:

Joyner, M. J., \& Coyle, E. F. (2008). Endurance exercise performance: the physiology of champions. The Journal of Physiology, 586(Pt 1), 35-44. https://doi.org/10.1113/jphysiol.2007.143834

Legaz, A., \& Eston, R. (2005). Changes in performance, skinfold thicknesses, and fat patterning after three years of intense athletic conditioning in high level runners. British Journal of Sports Medicine, 39(11), 851-856. https://doi.org/10.1136/bjsm.2005.018960

Maldonado-Martin, S., Mujika, I., \& Padilla, S. (2004). Physiological variables to use in the gender comparison in highly trained runners. The Journal of Sports Medicine and Physical Fitness, 44(1), 8-14. 


\title{
World ranked swimmers: analysis of the finalists' ages between 2000 and 2016 Olympic games
}

\author{
Hugo Louro1,2, Bruno Dias ${ }^{1}$, António Silva2,3, Tiago M. Barbosa,2,4, Daniel A. Marinho 2,5, \\ Nuno Batalha ${ }^{2,6}$, Aldo Costa2,5, Mário Espada7,8, Ana Conceição ${ }^{1,2,9}$
}

1. Sport Sciences School of Rio Maior, Rio Maior, Portugal; hlouro@esdrm.ipsantarem.pt; 2. Research Center in Sports Sciences, Health and Human Development, CIDESD, Vila Real, Portugal; 3. University of Trás-os-Montes and Alto Douro, Vila Real, Portugal; 4 Nanyang Technological University, Singapura; 5. University of Beira Interior, Department of Sport Sciences, Covilhã, Portugal; 6. University of Évora, Évora, Portugal; 7. Polytechnic Institute of Setúbal, School of Education, Setúbal, Portugal; 8. Centro Interdisciplinar de Estudo da Performance Humana, CIPER, Portugal; 9. Life Quality Research Center, CIEQV, Santarém, Portugal

Swimming is a sport determined being the age beginning to compete at high-level a concern for a proper planning of the swimmer's career plan. There is an understanding that the career in swimming, sometimes considered does happen very early as far as biological age is concerned (Platonov, \& Fessenko, 1994). It was noted that swimmers reach the career peak earlier than other athletes (Silva et al., 2007). The aim of this study was to: (i) describe the decimal initial ages in the last five Olympic finals (2000 to 2016); and ii) compare the means of the decimal ages between genders, event distances and swimming strokes. It was analyzed 2080 entries corresponding to the classification of the 16 swimmers finalists and semifinalists in the following events: 50; 100; 200; 400; $800 \mathrm{~m}$ or 1500m freestyle for both genders, respectively; 100 and $200 \mathrm{~m}$ backstroke; 100 and $200 \mathrm{~m}$ breaststroke; 100 and $200 \mathrm{~m}$ butterfly and $400 \mathrm{~m}$ medley for both genders. The inclusion criteria was: i) competing at the Olympic Games Sydney 2000, Athens 2004, Beijing 2008, London 2012 and Rio 2016; ii) having qualified to the finals in at least one swimming events; iii) swimmers name and chronological age were available; iv) final classification in the event was also available. Afterwards, chronological age was converted into decimal age at the day of the event heats. The results showed that average age was between 20 to 25 years old in Olympic finals, being the in the sprinting events that it was found the oldest swimmers. We also found that in sprinting events the decimal ages are higher than in the middle- or long-distance events. The breaststroke and the medley events presented initial decimal ages lower for the female gender, with 15 and 16 years for the entrance to the finals. It can be concluded that there was a trend to an increase the average age of male and female swimmers in the finals of the Olympic Games, which suggests an increase in the duration of the sport career in swimming.

References:

Platonov, V., \& Fessenko, V. (1994). Os Sistemas de treinamento dos melhores nadadores do mundo. Barcelona: Paidotribo.

Silva, A. J., Marinho, D., Carvalhal, I. M., Durão, M., Reis, V., Carneiro, A., \& Aidar, F. (2007) Análise da evolução da carreira desportiva de nadadores do género feminino utilizando a modelação matemática. Revista Brasileira Medicina Esporte, 13, 175-180.

\section{Effects of endurance versus strength training programs in the lipid profile of sedentary young adults}

\section{André Freitas ${ }^{1}$, Ana Costa ${ }^{2}$, Catarina Pereira ${ }^{1,3}$, Nuno Batalha ${ }^{1,3}$}

1. Departamento de Desporto e Saúde, Escola de Ciência e Tecnologia, Universidade de Évora, Portugal; 2. Departamento de Química, Escola de Ciência e Tecnologia, Universidade de Évora, Portugal; 3. Research Centre of Sports, Health and Human Development, CIDESD, Portugal.

Cardiovascular diseases are a major cause of mortality in the world, and abnormal blood lipids are an important risk factors for these disease (Stampfer et al., 2000). Thus, controlling this risk factor, particularly cholesterol and triglycerides levels is essential (Curb et al., 2004). It is consensual that physical activity contributes to healthy lipidic levels (Haskell, 1984), however, it is not clear which type of exercise training is the best to this end. The present study aimed to analyze the effect of aerobic vs. strength training in total cholesterol (TC) and triglycerides (TGL) levels of young adults. The sample was randomly clustered into three groups: the aerobic training group $(\mathrm{N}=32)$, the strength training group $(\mathrm{N}=28)$ and the control group $(\mathrm{N}=21)$. All participants were sedentary college students (young adults) and were similar age and height. The aerobic and strength training programs comprised a period of 14 weeks, with three sessions/week for 1 hour. Three evaluations were performed (initial, 7weeks and 14weeks), in which body composition was measured and unstimulated whole saliva was collected using the drooling technique. Salivary cholesterol and triglyceride were assessed by colorimetric methods. Comparison evidenced that the strength group showed a decrease in TC over the 14 weeks. On the contrary, the control group showed an increase in TC $(\mathrm{p}=0.017)$. These contributed to the observed differences in TC between strength and control groups after the 14 weeks $(p=0.035)$. Regarding the TGL, there was a reduction in TGL of the aerobic group over the 14 weeks $(p=0,003)$. The TGL levels of the strength and the control groups did not changed significantly. Between groups, no significant differences in TGL were observed. Taking into account the young adults population 
and the training programs performed, our results seem to indicate that the strength training may be useful in $\mathrm{TC}$ reduction and the aerobic training in TGL reduction.

References:

Curb, J. D., Abbott, R. D., Rodriguez, B. L., Masaki, K., Chen, R., Sharp, D. S., \& Tall, A. R. (2004). A prospective study of HDL-C and cholesteryl ester transfer protein gene mutations and the risk of coronary heart disease in the elderly. Journal of Lipid Research, 45(5), 948-953. https://doi.org/10.1194/jlr.M300520-JLR200

Haskell, W. L. (1984). The influence of exercise on the concentrations of triglyceride and cholesterol in human plasma. Exercise and Sport Sciences Reviews, 12, 205-244.

Stampfer, M. J., Hu, F. B., Manson, J. E., Rimm, E. B., \& Willett, W. C. (2000). Primary prevention of coronary heart disease in women through diet and lifestyle. The New England Journal of Medicine, 343(1), 16-22. https://doi.org/10.1056/NEJM200007063430103

\title{
Relay start in swimming: a review
}

\author{
Andreia Fonseca1, Hugo Louro ${ }^{1,2}$, Aldo M. Costa $2,3,4$, Ana Conceição ${ }^{1,2,5}$ \\ 1. Sport Sciences School of Rio Maior, Rio Maior, Portugal; andreiaduartefonseca@gmail.com; 2. Research Center in Sports \\ Sciences, Health and Human Development, CIDESD, Vila Real, Portugal; 3. Universidade da Beira Interior, Departamento de \\ Ciências do Desporto, Covilhã, Portugal; 4. CICS-UBI, Health Sciences Investigation Center, University of Beira Interior, Covilhã, \\ Portugal; 5. CIEQV- Life Quality Research Center, Santarém, Portugal;
}

The literature is still scarce in studies on relay start in swimming (NPD). The reasons for this lack of research are considered to be based on the low number and public awareness of relay races in swimming events. FINA rules permit the second, the third, and the fourth swimmers to start their dives from the starting block before the incoming swimmer have finished their segments of the race. So, parts of the outgoing swimmer's foot must remain on the platform until the incoming swimmer has touched the wall. The aim of this study was to conduct a literature review regarding: i) the contribution of relay starts to overall swimming performance; ii) the effects of different starting techniques for evidence of relay. Using keywords ("swimming", "relay start", "relay"; "exchange time"), a comprehensive search was conducted on PubMed and Google Scholar databases. Only papers written in English and containing data about swimming relays with amateurs and/or elite swimmers (of all ages) were included. From the 6 studies found, some high variety methodologies in swimming relays were reported. With respect to swimming performance, the determination of the change over-time of the block output is the most studied topic of research, following by the final performance of the swimmers. The efficacy of different types of relay starts has also been studied but without consistent results, which seems to suggest that personal style is a key factor. Only one empirical study was found regarding the training intervention, suggesting a combination of verbal feedback and video analyses (with time) as relevant strategies to improve the relay exchange time, technique and team coordination. Recently Skorski, Etxebarria, and Thompson (2016) investigated if swimming performance is better in a relay race than in individual race, noting that highly trained swimmers do not swim faster in the relay events than the individual. The literature is consistent about the importance of the relay exchanges times during swimming events, but inconclusive about the optimal relay start technique and practice intervention strategies.

References:

Skorski, S., Etxebarria, N., \& Thompson, K. (2016). Breaking the Myth That Relay Swimming Is Faster Than Individual Swimming International. Journal of Sports Physiology and Performance, 11, $410-413$

\section{Effects of classic strength training versus eccentric-enhanced resistance training in people with Multiple Sclerosis}

\section{Claudia Eliza Patrocinio de Oliveira ${ }^{1,2}$, Osvaldo Costa Moreira1,2, José Antonio de Paz Fernández ${ }^{1}$}

1. Institute of Biomedicine, University of León, Spain; 2. Department of Physical Education, Federal University of Viçosa, Brazil; claudiapatrocinio@ymail.com

Despite looking like training with emphasis on eccentric actions it is safer and more efficient than the classical strength training to promote increases in strength, muscle mass and function (Roig et al., 2008; FernándezGonzalo et al., 2014), is not clear yet whether this training demonstrates the same benefits in people with Multiple Sclerosis (MS). To verify the effects of strength eccentric-enhanced resistance training (EERT) versus classic strength training (CST) in performance of functional testing and different manifestations of the strength of lower limbs in people with MS. Were evaluated 53 patients ( 20 men and 33 women) divided into two groups: the control group (GC) developed by the CST and the experimental group (GE) made EERT, both exercises are for lower limbs, with emphasis on the quadriceps. They were assessed before and after 13 weeks of training, through tests: get up and down (GUD), Timed Up and Go (TUG), maximal isometric strength (MIS) and maximal dynamic strength (1RM). Intragroup comparisons were made by Student $t$ test for related samples. Intergroup comparisons were performed using the percentage delta by Student test for independent samples. The effect size Cohen's $d$ was calculated. The significance level was $p<0.05$. No 
differences in the initial values for the various tests between the two groups were found. When compared the pre and post training values, the GC showed significant improvements in both functional tests and 1RM; GE showed significant improvements in all tests. In the comparison between groups, GE presented the best result for test GUD $(4.7 \pm 2.8 \%$ vs $1.9 \pm 2.8 \%$; $\mathrm{p}<0.01)$. The two types of workouts increase the lower limb strength and functional capacity in people with MS. Furthermore, the EERT seems to be more efficient in increasing the power of lower limbs.

Acknowledgement

Consejería de Sanidad-Junta de Castilla y León, Conselho Nacional de Desenvolvimento Científico e Tecnológico-CNPq and Coordenação de Aperfeiçoamento de Pessoal de Nivel Superior-CAPES

References:

Roig, M., Shadgan, B., \& Reid, W. D. (2008). Eccentric exercise in patients with chronic health conditions: a systematic review. Physiotherapy Canada, 60(2), 146-160.

Fernández-Gonzalo, R., Nissemark, C., Åslund, B., Tesch, P. A., \& Sojka, P. (2014). Chronic stroke patients show early and robust improvements in muscle and functional performance in response to eccentric-overload flywheel resistance training: a pilot study. Journal of NeuroEngineering and Rehabilitation, 11, 150-160.

\title{
Concurrent validity of a taekwondo specific aerobic test
}

Fernando Rocha1, ${ }^{1,2}$, Hugo Louro ${ }^{2,3}$, Ricardo Matias ${ }^{4}$, João Brito ${ }^{2,3}$, Aldo M. Costa ${ }^{1,2}$

1. Department of Sport Sciences, University of Beira Interior, Portugal; 2. Research Center for Sport, Health and Human Development (CIDESD), Portugal; 3. Sports Sciences School of Rio Maior, Polytechnic Institute of Santarém, Portugal; 4. School of Healthcare, Setúbal Polytechnic Institute, Portugal; mcosta.aldo@gmail.com

The literature refers to cycle ergometers or treadmills as laboratory test to assess $\mathrm{VO}_{2} \mathrm{max}$.None of these modes of exercise reproduce the taekwondo technical movements. We proposed to verify the possibility of determining the maximal oxygen uptake for taekwondo athletes through an incremental specific test. Seventeen male elite taekwondo athletes $(17.6 \pm 4.3$ years; $172 \mathrm{~cm} \pm 6.5 \mathrm{~cm}$ of height; $61.3 \mathrm{~kg} \pm 8.7 \mathrm{~kg}$ for weight) participated in this study. A two graded maximal exercise tests on different days was performed: the 20-meter multistage shuttle run test (SRT) and the incremental taekwondo specific test (TST). In both tests we recorded oxygen uptake $\left(\mathrm{VO}_{2} \mathrm{max}\right)$, ventilation (VE) heart rate (HR), and time to exhaustion. Differences were found between observed and estimated $\mathrm{VO}_{2} \max$ values $\left[\mathrm{F}_{(2,16)}=5.77, \mathrm{p}<0.01\right]$; posthoc subgroup analysis revealed the existence of significant differences $(\mathrm{p}=0.04)$ between the estimated $\mathrm{VO}_{2} \mathrm{max}$ value in the SRT and the observed value recorded in the TST $(58.4 \pm 6.4 \mathrm{ml} / \mathrm{kg} / \mathrm{min}$ and $52.11 \pm 6.9 \mathrm{ml} / \mathrm{kg} / \mathrm{min}$, respectively). Our analysis also revealed a moderate correlation between both testing protocols (SRT and TST) regarding the $\mathrm{VO}_{2} \max (r=0.62 ; \mathrm{p}=0.04)$, the test time $(\mathrm{r}=0.77 ; \mathrm{p}=0.02)$ and also the $\mathrm{VE}(\mathrm{r}=0.69$; $\mathrm{p}=0.03$ ), pointing to an acceptable concurrent validity. An equation/model to estimate $\mathrm{VO}_{2}$ max during the TST was produced based on the mean HR, TST_time, height, and weight, which explained $74.3 \%$ of the observed $\mathrm{VO}_{2} \max$ variability. A moderate correlation was found between observed and predicted $\mathrm{VO}_{2} \mathrm{max}$ values in the TST $(r=0.74, p=0.001)$. Our results suggest that an incremental specific test seems to estimate $\mathrm{VO}_{2}$ max of elite taekwondo athletes with satisfactory accuracy and reliability.

References:

Bridge, C. A., Santos J. F. S., Chaabène, H., Pieter, W., \& Franchini, E. (2014). Physical and physiological profiles of Taekwondo athletes, Review article. Sports Medicine, 44, 713-733.

Falcó, C., \& Estevan, I. (2014). Biomechanics in Taekwondo: practical applications. In M. Haddad (Ed.), Performance optimization in Taekwondo: from laboratory to field (pp. 1-23). Foster City, CA: OMICS Group eBooks.

Léger, L. A., \& Lambert, J. (1982). A maximal multistage 20-m shuttle run test to predict V02 max. European Journal of Applied Physiology, 49, 0112.

Sant 'Ana, J., Silva, J. F., \& Guglielmo, L. G. A. (2009). Variáveis fisiológicas identificadas em teste progressivo específico para Taekwondo. Motriz, Rio Claro, 15(3), 611-620.

\section{After school sports influence on $4^{\text {th }}$ graders dexterity performance}

\author{
Luís Coelho ${ }^{1,2}$, Ian Moirinho ${ }^{1,2}$, Carolina Ribeiro ${ }^{1,2}$, Nuno Amaro ${ }^{1,2}$, Nuno Santos ${ }^{1,2}$, Rogério \\ Salvador ${ }^{1,2}$, João Cruz $^{1,2}$, Rui Matos ${ }^{1,2}$
}

1. School of Education and Social Sciences - Polytechnic Institute of Leiria; coelho@ipleiria.pt; 2. Life Quality Research Centre

Manual ability and performance of dexterity tasks require both gross and fine hand motions and coordination (Golubović \& Slavković, 2014). Fine motor skills is still one of the specific components to be assessed when evaluating children's functional performance at home, in school and at play (Chui, Ng, Fong, Lin, \& Ng, 2007). Does children that are engaged on after school sports regularly have better dexterity? The main purpose of this work is to analyze after school sports association with dexterity performance (DP) in children. A sample of 53 4th graders was used (30 $\sigma^{\star}$ and 23\%, 38 play some type of after school sports and 15 doesn't). Dexterity assessment was performed by using the Placing Test from Minnesota Manual Dexterity Test, twice. First using dominant hand (DH) and second with the non-dominant hand (NDH). Bilateral dexterity symmetry (BDS) was calculated by its difference ( $\mathrm{DH}-\mathrm{NDH}=\mathrm{BDS})$. A very similar performance between both 
groups was found. This similarity was verified for both hands performance (DH: children that play after school sports $=73.4 \mathrm{~s} \pm 9.2$ and children that doesn't $=74.8 \mathrm{~s} \pm 7.0, \mathrm{p}>0.05$; NDH: children that play after school sports $=76.1 \mathrm{~s} \pm 8.1$ and children that doesn't $=80.1 \mathrm{~s} \pm 8.8, \mathrm{p}>0.05)$. We also didn't find any significant differences for BDS (children that play after school sports $=7.3 \mathrm{~s} \pm 4.4$ and children that doesn't $=7.2 \mathrm{~s} \pm 6.1$, $\mathrm{p}>0.05$ ). Results were also very similar between sexes for both hands and BDS. Sport type and week frequency wasn't controlled, so this is something that should be taken into consideration when analyzing these results, given the fact that it would be reasonable to expect some differences between groups. Other variables that may influence dexterity levels are such as playing video games, or even how kids spend their free time, but unfortunately, we weren't able to monitor it. A great percentage of 4th graders play some type of after school sports (72\%). Boys and girls have very similar dexterity performances at this age. Manual dexterity performance can't be associated only by engaging in some type of after school's sports.

References:

Chui, M. M. Y., Ng, A. M. Y., Fong, A. K. H., Lin, L. S. Y., \& Ng, M. W. F. (2007). Differences in the Fine Motor Performance of Children in Hong Kong and the United States on the Bruininks-Oseretsky Test of Motor Proficiency. Hong Kong Journal of Occupational Therapy, 17(1), 1-9. https://doi.org/10.1016/S1569-1861(07)70002-5

Golubović, Š., \& Slavković, S. (2014). Manual ability and manual dexterity in children with cerebral palsy. Hippokratia, 18(4), 310-314.

\title{
Influence of stretching in lower limbs muscle power
}

\author{
Rafael Oliveira ${ }^{1,2,3}$, Renata Silva ${ }^{1,2}$, João Moreira Brito ${ }^{1,2,4}$
}

1. Escola Superior de Desporto de Rio Maior, ESDRM, Rio Maior, Portugal; 2. Unidade de Investigação - Instituto Politécnico de Santarém; 3. Universidade Da Beira Interior, UBI, Covilhã, Portugal; rafaeloliveira@esdrm.ipsantarem.pt 4. CIEQV, Centro de Investigação e Qualidade de Vida

Nowadays, it is common to apply stretching methods before practice exercise training programs. They improve flexibility of skeletal muscles and increase the range of motion of joints. Stretching is also important in prevention of sport-related injuries and influences muscle strength and performance (Maeda et al., 2016). Therefore, the purpose of this study is to apply different stretching methods and analyse the lower limbs muscle power. Thirty subjects, 17 males (age, $18 \pm 1.87$ years) and 13 females (age, $18 \pm 1.22$ years) participated in the study. They were assessed three times in anthropometric assessment (body weight, height) and vertical jumps (squat and countermovement jumps). In first assessment, they did not apply any stretching exercises. In second assessment, they apply static stretching. In third assessment, they apply proprioceptive neuromuscular facilitation. It was used ANOVA-Friedman tests were used to compare different assessment moments. Results were significant in the interaction $(p \leq 0.05)$ and all data were analyzed using SPSS version 22.0 (SPSS Inc., Chicago, IL) for Windows statistical software package. The main results were in squat jumps where we found significant differences between squat height and fly time $(p=0.005$ and $p=0.005$, respectively) for man. However, there were no significant differences to woman in the other jump movements. These findings suggest the practice of regular stretching exercises can induce better jump results for fly time and height jump. That also means an increasing in lower limbs muscle power. We recommend applying a similar longitudinal study to verify what would be the results with a stretching training program.

References:

Maeda, N., Urabe, Y., Fujii, E., Moriyama, N., Iwata, S., \& Sasadai, J. (2016). The effect of different stretching techniques on ankle joint range of motion and dynamic postural stability after landing. The Journal of Sports Medicine and Physical Fitness, 56 (6), 692-698.

\section{Biomechanical characterization of swimmers with physical-motor disabilities}

\author{
Valdir Junior ${ }^{1,2}$, Alexandre Medeiros², Kelly de Jesus ${ }^{3}$, Rui Corredeira ${ }^{4}$, Daniel J. Daly ${ }^{5}$, \\ Ricardo J. Fernandes ${ }^{1}$ \\ 1. Cifi2d at Faculty of Sport and Labiomep, University of Porto, Porto, Portugal; ricfer@fade.up.pt; 2. Research Group in \\ Biodynamic Human Movement, Institute of Physical Education and Sport, Federal University of Ceara, Fortaleza, Ceará, Brazil; \\ 3. Human Performance Laboratory, Faculty of Physical Education and Physiotherapy, Federal University of Amazonas, \\ Amazonas, Manaus, Brazil; 4. Research Center on Physical Activity, Health and Leisure (CIAFEL), Faculty of Sport, University \\ of Porto, Porto, Portugal; 5. KULeuven, Faculty of Kinesiology and Rehabilitation Sciences, Leuven, Belgium
}

There are several studies evaluating biomechanical parameters in swimming (Figueiredo et al., 2014), but those involving swimmers with physical-motor disabilities are scarce. This study aimed to analyse and compare the kinematical parameters (Stroke Length - SL, Stroke Frequency - SF and Intracycle Velocity Variation - IVV) in front crawl swimming incremental protocol of $\mathrm{n} \times 200 \mathrm{~m}$ in the laps $100 \mathrm{~m}$ and $175 \mathrm{~m}$. The study included six male swimmers $(25.8 \pm 2.9$ years, $72.4 \pm 9.2$ weight, $1.79 \pm 0.11$ stature and spread $1.65 \pm 0.29)$ with physical-motor disabilities affiliated in Portuguese Swimming Federation. They are 
classified according to the International Paralympic Committee (IPC), on the following functional classes: S6 $(n=1)$, S8 $(n=1)$, S9 $(n=4)$. Standardized mean difference (SMD) and 95\% confidence intervals (CI) were used. Magnitude thresholds for difference in a mean were described using the following scale: 0-0.2 trivial, > 0.2-0.6 small, > 0.6-1.2 moderate, > 1.2-2.0 large, and > 2.0 very large (Hopkins, 2010). Table 1 shows the kinematical parameters in the laps $100 \mathrm{~m}$ and $175 \mathrm{~m}$ for each steps from crawl incremental protocol.

Table 1.

Means ( \pm standard deviation) of kinematical parameters in the laps $100 \mathrm{~m}$ and $175 \mathrm{~m}$ for each steps, standardized mean difference and 95\% CI, and effect size from comparisons between the $100 \mathrm{~m}$ and $175 \mathrm{~m}$ for each step of kinematical parameters.

\begin{tabular}{|c|c|c|c|c|c|}
\hline Variables & $\begin{array}{c}\text { Incremental } \\
\text { protocol } \\
(\mathrm{N} \times 200 \mathrm{~m})\end{array}$ & $\begin{array}{c}100 \mathrm{~m} \\
(\mathrm{M} \pm \mathrm{SD})\end{array}$ & $\begin{array}{c}175 \mathrm{~m} \\
(\mathrm{M} \pm \mathrm{SD})\end{array}$ & $\begin{array}{c}100 \mathrm{~m} \times 175 \mathrm{~m} \\
\text { SMD (IC) }\end{array}$ & Effect size \\
\hline SL & Step 1 & $1.76 \pm 0.27$ & $2.00 \pm 0.25$ & $0.68(-0.38,1.74)$ & Moderate \\
\hline SL & Step 2 & $1.68 \pm 0.28$ & $1.84 \pm 0.25$ & $0.43(-0.60,1.46)$ & Small \\
\hline SL & Step 3 & $1.62 \pm 0.33$ & $1.76 \pm 0.23$ & $0.33(-0.63,1.29)$ & Small \\
\hline SL & Step 4 & $1.60 \pm 0.34$ & $1.78 \pm 0.24$ & $0.39(-0.56,1.35)$ & Small \\
\hline SL & Step 5 & $1.56 \pm 0.35$ & $1.66 \pm 0.32$ & $0.23(-0.83,1.29)$ & Small \\
\hline SL & Step 6 & $1.48 \pm 0.36$ & $1.57 \pm 0.29$ & $0.19(-0.81,1.19)$ & Trivial \\
\hline SF & Step 1 & $0.47 \pm 0.11$ & $0.47 \pm 0.06$ & $0.02(-0.90,0.95)$ & Trivial \\
\hline SF & Step 2 & $0.51 \pm 0.09$ & $0.51 \pm 0.08$ & $0.00(-1.03,1.03)$ & Trivial \\
\hline SF & Step 3 & $0.54 \pm 0.10$ & $0.53 \pm 0.10$ & $0.00(-1.11,1.11)$ & Trivial \\
\hline SF & Step 4 & $0.58 \pm 0.08$ & $0.60 \pm 0.05$ & $0.18(-0.74,1.11)$ & Trivial \\
\hline SF & Step 5 & $0.61 \pm 0.09$ & $0.63 \pm 0.04$ & $0.17(-0.75,1.09)$ & Trivial \\
\hline SF & Step 6 & $0.65 \pm 0.10$ & $0.72 \pm 0.06$ & $0.47(-0.46,1.40)$ & Small \\
\hline IVV & Step 1 & $0.37 \pm 0.37$ & $0.40 \pm 0.53$ & $0.06(-1.34,1.45)$ & Trivial \\
\hline IVV & Step 2 & $0.35 \pm 0.41$ & $0.40 \pm 0.36$ & $0.08(-0.95,1.11)$ & Trivial \\
\hline IVV & Step 3 & $0.26 \pm 0.17$ & $0.42 \pm 0.60$ & $0.71(-2.47,3.89)$ & Moderate \\
\hline IVV & Step 4 & $0.27 \pm 0.22$ & $0.35 \pm 0.48$ & $0.31(-1.72,2.34)$ & Small \\
\hline IVV & Step 5 & $0.22 \pm 0.15$ & $0.32 \pm 0.44$ & $0.52(-2.08,3.13)$ & Small \\
\hline IVV & Step 6 & $0.21 \pm 0.08$ & $0.22 \pm 0.17$ & $0.14(-1.73,2.00)$ & Trivial \\
\hline
\end{tabular}

General swimming kinematical parameters (SL and SF) and efficiency estimators (IVV) remained stable in the 100 and $175 \mathrm{~m}$ laps independently of intensity changes. These indicators can be useful to a coach planning and monitoring training sets. Further experiments on the topic are encouraged, particularly to characterize the underlying mechanisms regarding 3D-kinematic data in other classes of physical-motor disabilities.

References:

Figueiredo, P., Nazario, R., Sousa, M., Pelarigo, J. G., Vilas-Boas, J. P., \& Fernandes, R. (2014). Kinematical analysis along maximal lactate steady state swimming intensity. Journal of Sports Science and Medicine, 13(3), 610-615.

Hopkins, W. (2010). Linear models and effect magnitudes for research, clinical and practical applications. Sport science, 14, 49-58.

\section{Effects of changes in handlebar height and bicycle frame length in muscular activity during cycling}

Ana Conceição ${ }^{1,2,3}$, Vítor Milheiro ${ }^{1}$, Pedro Sobreiro ${ }^{1}$, Hugo Louro ${ }^{1,2}$

1. Sport Sciences School of Rio Maior, Rio Maior, Portugal; conceicao.ana@gmail.com; 2. Research Center in Sports Sciences, Health and Human Development, CIDESD, Vila Real, Portugal; 3. CIEQV- Life Quality Research Center, Santarém, Portugal

Bicycling is a common mode of transportation adopted by many people around the world. So most of the adjustments in the bicycle are done to obtain a comfortable riding position and proper range of motion in lower extremities (Baino, 2011). Geometric factos like handlebar height and bicycle frame lenght are generaly adjusted to optimize the biking seating position. The aim of this study was to analyze the effects of muscular activity of different handlebar height and bicycle frame length during cycling. Nine male recreational cyclists (21.6 \pm 1.9 years; $75.3 \pm 5.8 \mathrm{~kg} ; 1.8 \pm 0.1 \mathrm{~m}$; crotch height: $9.5 \pm 26.1 \mathrm{~m}$; seat height: $0.7 \pm 0.0 \mathrm{~m}$; saddle distance from the handlebar_long: $0.6 \pm 0.0 \mathrm{~m}$; saddle distance from the handlebar short: $0.5 \pm 0.0 \mathrm{~m}$ ) took part in this study. Each subject performed: i) five minutes warm-up; ii) 30 seconds at maximal intensity; iii) 1 minute at 150 watts intensity; iv) 1 minute at 250 watts of intensity, and in a specifics conditions: a) handlebar height (high and low) and in a b) specific bicycle frame length(long and short), according the previous measures of each subjects. Using a wireless signal acquisition system (bioPlux research, Portugal), surface EMG was collected in 4 muscles deltoid anterior (DA), trapezius descendens (upper) (TD), gluteus maximus (GM) and latissimus dorsi (LD). EMG analysis were conducted with a MATLAB routine. Starting from the raw signal, DC components were removed and thereafter filtered with a fifth-order Butterworth band pass filter where the lower and upper cut-off frequencies were set to 10 and $500 \mathrm{~Hz}$. The average amplitude of EMG of each active phase was estimated using the average rectified value (ARV) and plotted as a function of time. The results showed differences with a $\mathrm{p}<0.05$ in short and long bicycle frame length in 4 muscles TD $(t=5.982)$, 
LD $(t=3.264), G M(t=4.077)$ and DA $(t=4.844)$. The 2 handled bar height positions with a short size frame showed differences $(\mathrm{p}<0.05)$ in GM $(\mathrm{t}=4.6)$ and DA $(\mathrm{t}=2.56)$. TD $(\mathrm{t}=1.78)$ and LD $(\mathrm{t}=0.586)$ revealed no significant differences. The handled with a long size frame presented differences $(p<0.05)$ in TD $(t=2.98)$ and GM $(t=3.11)$, and no differences in $L D(t=1.486)$ and DA $(t=1.47)$. This study revealed that consecutive changes handlebar height and bicycle frame length over time lead to increase in discomfort during cycling.

References:

Baino, F. (2011). Evaluation of the relationship between the body positioning and the postural comfort of non-professional cyclists: a new approach. The Journal of Sports Medicine and Physical Fitness, 51 (1):59-65.

\title{
Muscle activation levels during the push-up exercise on stable and unstable surfaces
}

\author{
Carolina Vila-Chã ${ }^{1,2}$, Luís Ribeiro ${ }^{1}$, Nuno Serra ${ }^{1}$, Mário Costa ${ }^{1,2}$, Filipe Conceição ${ }^{3}$, José \\ António De Paz ${ }^{4}$ \\ 1. Polytechnic Institute of Guarda, Guarda, Portugal; cvilacha@ipg.pt; 2. Research Center in Sports Sciences, Health and Human \\ Development, CIDESD, Vila Real, Portugal; 3. LABIOMEP - Universidade do Porto; 4. Institute of Biomedicine, Universidad de
} León

The push-up (PU) is one of the most common exercises used in the strength training programs for the upper body. Since it is limited to the body weight, fitness trainers use several exercise types (e.g. unstable surfaces) in order to increase the activity of the involved muscles (Freeman et al., 2006). This study aimed to analyze the changes in muscle activity pattern induced by either performing PU exercise on a stable surface (ground) or an unstable surface (BOSUß). Eleven voluntary male subjects (age, mean \pm SD: $21.9 \pm 4.2$ yrs.), familiarized with the push-up's exercises, have been recruited for this study. Subjects performed 5 repetitions of each push-up exercise (stable vs. unstable surfaces. Electromyographic activity (EMG) from the agonist muscles (clavicular, sternal and chondral portion of pectoral major, triceps brachii and anterior deltoid), antagonist muscles (latissimus dorsi and biceps brachii) and the stabilizer muscles (serratus anterior, superior trapezius, external oblique and erector spinae) has been collected with 11 wireless surface electrodes. The results showed that, from the agonist group, only the magnitude of activation of the triceps brachii has been affected by the exercise type $(\mathrm{p}<0.001)$. In the unstable PU the triceps brachii showed higher activation levels than in stable surface $(70.13 \pm 29.03 \%$ and $58.62 \pm 25.31 \%$, respectively). Regarding the antagonist group, the unstable PU exercise induced a higher activity of the brachial biceps and of the latissimus dorsi compared to the stable PU exercise ( $p<0.05$ for both muscles). In addition, for stabilizer muscles, it was observed that the upper trapezius activation was, on average, $37.79 \%$ higher than in the stable exercise $(p<0.01)$ during unstable PU. Instead, for the serratus anterior, the activation level was, on averaged, significantly higher in the unstable PU exercise than in the stable PU $(+14.71 \%, p=0.01)$. For the external oblique there were no differences between exercise types $(p=0.23)$. However, the activity of the erector spinae was significantly higher in unstable PU $(p=0.01)$. These results indicate that the push up exercise performed on an unstable surface (BOSU®) changes the pattern of activation of antagonist muscles, shoulder stabilizer muscles and agonist muscles, particularly the brachial triceps activation.

References:

Freeman, S., Karpowicz, A., Gray, J., \& McGill, S. (2006). Quantifying muscle patterns and spine load during various forms of the push-up. Medicine and Science in Sports and Exercise, 38(3), 570-577.

\section{EMG of trunk muscles compared with the pedaling power of and cyclist position: A case of study}

\author{
Vítor Milheiro ${ }^{1}$, Ana Conceição ${ }^{1,2,3}$, Hugo Louro ${ }^{1,2}$, Marco Branco ${ }^{1}$, Brito, João ${ }^{1,2}$ \\ 1. Sport Sciences School of Rio Maior, Rio Maior, Portugal; conceicao.ana@gmail.com; 2. Research Center in Sports Sciences, \\ Health and Human Development, CIDESD, Vila Real, Portugal; 3. CIEQV-Life Quality Research Center, Santarém, Portugal.
}

Over the past decades, have been published numerous biomechanical studies to optimize the performance and the prevention of cyclists' injury. Many of these studies have used electromyography (EMG) to analyze the effects of the cyclist position and bike geometry on kinematics, kinetics, muscle activation and energy expenditure. Most EMG studies in cycling has analyzed the lower limb (Hug, 2009), with few analyzing trunk and upper limbs EMG activity. The aim of this study was to analyze trunk muscles involvement in a recreational cyclist, as a result of bike fit and pedaling power., The sample consisted of one male recreational cyclist, 20 years old, $1.82 \mathrm{~m}$ and $76 \mathrm{~kg}$, which was shot while riding a bicycle supported on a roller equipped with a PowerTap potentiometer and allowed two handlebar positions and two frame lengths. Using a wireless signal acquisition system (bioPlux research, Portugal), surface electromyogram was collected in four muscles: deltoid anterior (DA), trapezius descendens (upper) (TD), gluteus maximus (GM) and latissimus dorsi (LD). 
Kinematic data were analyzed using the APAS software and the average amplitude of EMG of each active phase was estimated using the average rectified value (ARV) and plotted as a function of time. In kinematic analysis, we verified that trunk-horizontal angle $\left(53.0^{\circ} \pm 4.9^{\circ}\right)$ were slightly higher in the long-frame situation. By analyzing the variations of the trunk-horizontal angle with handlebar height, the results showed large differences between the handlebar high situation $\left(56.6^{\circ} \pm 3.7^{\circ}\right)$ and low $\left(49.3^{\circ} \pm 2.5^{\circ}\right)$. Regarding the trunk-upper limb angle $\left(77.8^{\circ} \pm 4.81^{\circ}\right)$, the results show always higher values in longer above situation. The elbow angle was always lower in high handlebar situation $\left(124.1^{\circ} \pm 17.9^{\circ}\right)$ compared to the low handlebar $\left(142.8^{\circ} \pm 9.7^{\circ}\right)$. In terms of electromyography ARV data, we found that GM values were higher in higher power cycling situation and in longer frame position. When analyzed ARV of DA muscle and frame size the data show higher values in higher power cycling situation and the short frame position. This study showed that the stroke pedal kinematics varies with bike geometry changes and is also very influenced by pedaling power. The great variability of EMG data only possible to analyze the gluteus maximus and deltoid muscles and the influence of kinematic parameters in the range of muscle activation.

References:

Hug, F., \& Dorel, S. (2009). Electromyographic analysis of pedaling: a review. Journal of Electromyography and Kinesiology: Official Journal of the International Society of Electrophysiological Kinesiology, 19(2), 182-198. https://doi.org/10.1016/j.jelekin.2007.10.010

\title{
Analysis of internal load in indoor cycling
}

Ana Margarida Lopes ${ }^{1}$, Pedro Bicó ${ }^{1}$, Orlando Fernandes ${ }^{2}$

1. Be in Shape, Ginásio, Évora; 2. Departamento de Desporto e Saúde, Escola de Ciência e Tecnologia, Universidade de Évora; fernandes.orlando@gmail.com

The analysis of the dynamics of external and internal load in cycle indoor (CIn) is very importance to guide the instruction during a cycling indoor class. To quantify the individual load carried by and the perception of this with the effort put in will allow you to tailor the response of cardiorespiratory and metabolic during the class. The internal load will be quantified by the heart rate (HR) and the forces applied over a force plate. These parameters will be used as objective parameters of the internal load, while in the exercise room, the reading of the HR is the most used, and in this sense, we will base the analysis of the internal load, essentially in the parameter of physiological HR and less in the load held in Newtons on the force plate. The aim of this work was to examine the response to the effort made by the participants of the CIn, based on internal and external load produced, relating to the perceived exertion (PSE). The PSE was the scale used to regulate the intensity used by the performer over the tests. Voluntarily participated in this study, 13 men $(33.7 \pm 7.3$ (years); $74.3 \pm 7.6(\mathrm{~kg}) ; 176 \pm 6.3(\mathrm{~cm})$ ) and 15 women's (31.5 \pm 6.3 (years); $59,7 \mathrm{~kg} \pm 6.7(\mathrm{~kg}) ; 166 \pm$ $4.5(\mathrm{~cm})$ ). The participants were divided into two distinct groups (randomly). One of the groups (A) was informed, during the first assessment, about the intensity and the way should regulate over the tests, as well as, should remain in future class respecting these intensities according to the different levels and according to the scale of perceived exertion. Nothing was said to the second group (NA), leaving to the discretion of the participants the load regulation during the tests and CIn class. The main result of this research was that the Group (A), differed significantly the different levels requested, on the contrary the Group (NA) was not able to differentiate the different intensity levels during the test. The lack of instruction on how to act and to keep a good PSE between the two assessments does not promote similar behaviour in the group, thus reinforcing the need to teaching the scale PSE during cycle class.

References:

Battista, R. A., Foster, C., Andrew, J., Wright, G., Lucia, A., \& Porcari, J. P. (2008). Physiologic responses during indoor cycling. Journal of Strength E Conditioning Research, $22(4), 1236-1241$.

Chen, M. J., Fan, X., \& Moe, S. T. (2002). Criterion-related validity of the Borg ratings of perceived exertion scale in healthy individuals: a metaanalysis. Journal of Sports Sciences, $20(11), 873-899$.

\section{Maximum and mean force relationship to body composition in swimmers}

\author{
Mário Espada1,2, Leandro Siqueira ${ }^{3}$, Astor Simionato ${ }^{3}$, Daniel Pestana ${ }^{4}$, André Barreto ${ }^{4}$, \\ Jorge Bombonatti ${ }^{4}$, Luis Imaizum ${ }^{4}$, Wesley Silva ${ }^{4}$, Leonardo Ishizava ${ }^{4}$, Ana Pereira ${ }^{2,5}$, Dalton \\ Pessôa-Filho 4 \\ 1. CIPER, Faculdade de Motricidade Humana, Lisboa, Portugal; 2. Instituto Politécnico Setúbal, Setúbal, Portugal; \\ mario.espada@ese.ips.pt; 3. Instituto de Biociências, PPG-DEHUTE - Unesp, Rio Claro, Brasil; 4. Faculdade de Ciências, \\ Educação Física - Unesp, Bauru, Brasil; 5. Research Centre of Sports, Health and Human Development, CIDESD, Vila Real, \\ Portugal
}

In swimmers, a low level of body fat and a high quantity of lean mass could generate an increase in higher energy expenditure and loss of performance, on the other hand, high levels of body fat increase the contact 
surface with the water, causing greater drag and loss of performance (Lowensteyn et al., 1994). The purpose of this study was to analyze the relationship between maximum and mean force determined from tethered swimming and body composition in swimmers. Eleven males $(18.0 \pm 4.0$ years of age, $180.2 \pm 6.8 \mathrm{~cm}$ in height and $71.8 \pm 9.5 \mathrm{~kg}$ in body weight) and five female swimmers $(16.8 \pm 3.6$ years of age, $166.2 \pm 5.5 \mathrm{~cm}$ in height and $61.1 \pm 9.8 \mathrm{~kg}$ in body weight) underwent a maximal tethered swimming force test (Fmaxtethered), which consisted of two 30 seconds maximal efforts in tethered apparatus (Cefise ${ }^{\circledR}$ ) with a 10 minutes rest interval to maximum and mean force determination (Fmax and Fmean) (Morouço, 2011). Body composition was assessed by dual-energy X-ray absorptiometry method (DXA), lean mass of the upper limb (LM_UL) and lower limb (LM_LL) and body fat percentage also of the lower and upper limb, (respectively, \%BF_UL and $\%$ BF LL) were determined. Upper and lower limb total mass was also assessed. Correlations were analyzed using Pearson's coefficient, $\rho \leq 0.05$ was adopted. Fmax $(19.0 \pm 4.7 \mathrm{~kg})$ was significantly correlated to LM_UL $(6741.9 \pm 1573.1 \mathrm{~g} ; \mathrm{r}=0.70, \mathrm{p}<0.01)$, LM_LL $(20146.5 \pm 3844.4 \mathrm{~g} ; \mathrm{r}=0.63, \mathrm{p}<0.01), \%$ BF_UL $(16.0 \pm 8.6 \%$ $\mathrm{r}=-0.69, \mathrm{p}<0.01)$ and \%BF_LL $(19.6 \pm 8.1 \% ; \mathrm{r}=-0.67, \mathrm{p}<0.01)$. Fmed $(17.7 \pm 4.3 \mathrm{~kg})$ was correlated to LM UL $(r=0.68, p<0.01)$, LM LL $(r=0.62, p<0.05)$, \%BF UL $(r=-0.72, p<0.01)$ and \%BF LL $(r=-0.71$, $\mathrm{p}<\overline{0.01)}$. No correlations were observed between Fmax and Fmed and total mass of lower and upper limb. Tethered swimming may represent a useful method for propulsive force and biomechanical proficiency analysis, as well as relationship with regional body composition, which seems to play an important role in swimming propulsive force, contrary to total mass. Upper limb body composition is more related to Fmax and Fmean, comparatively to lower limb and \%BF is negatively related to Fmax and Fmean, strengthening the relevance of body composition analysis in swimming.

References:

Lowensteyn, I., Signorile, J.F., \& Giltz, K. (1994). The Effect of Varying Body Composition on Swimming Performance. Journal of Strength E Conditioning Research, 8(3), 149-154.

Morouço, P., Keskinen, K. L., Vilas-Boas, J. P., \& Fernandes, R. J. (2011). Relationship between tethered forces and the four swimming techniques performance. Journal of Applied Biomechanics, 27(2), 161-169.

\title{
Development of an inertial sensor for the fencing hand analysis: correction on installation misalignments
}

\author{
Ana T. Campaniço ${ }^{1}$, António Valente ${ }^{1}$, Jorge Campaniço $^{2}$, Xavier Inglésias ${ }^{3}$, Rogério \\ Serôdio ${ }^{4}$ \\ 1. University of Trás-os-Montes e Alto Douro, School of Science and Technology, Engineering Department; 2. University Trás- \\ os-Montes e Alto Douro, School of Life Sciences and Environment, Laboratory Sport Observation; jorgecampanico@gmail.com; \\ 3. Universitat de Barcelona, Institut Nacional d'Educación Física de Catalunya, España; 4. University of Beira-Interior, Covilhã, \\ Mathematical Department
}

In sports the use of technology to help improve the athlete's performance has become integral. Video capture is a common method, but inefficient when dealing with obscured body parts. Inertial sensors allow to fill that gap by collecting the accelerations and rotations, but it's highly dependent of proper installation alignment in order to avoid measurement errors. This method proposes an inverse kinematics inspired quaternion rotation formula during the initial calibration, with the results being a highly reliable instrument, even under noise. The hardware used was an Arduino Due microcontroller and a GY-80 IMU, with an ADXL345 accelerometer. The experiment took place on top of a surface plate and the IMU was attached to a v-block for the static measurements. Twenty-two five second samples were recorded in a static position, while other six samples were recorded being statically held by a hand in the air, all in several orientations. The average of each sample was passed through the quaternion formula in order to calculate the vector's new position, as well as the norm for both vectors. The first error analysis checks how much the measured gravity deviates from the real gravity of the experiment location. The second checks if the measurement falls within the chosen range of precision. In all samples, the vector aligned perfectly with the direction of the Earth's gravity without any change in the vector's length. The error of the measured gravity was $\pm 1 \%$ at most, even in the semi-static samples. For the measurement error with a precision value of $99.9 \%$, only the semi-static samples fell outside of that range by $0.4 \%$ at most. This method can not only determine the rotation axis and align the sensor with the gravity perfectly, but it's highly precise and reliable, even in semi-static situations with no noise filtering applied. And the first step to create a tool that will allow to measure the movement of a single body part, in this case the fencing hand, with far more detail than video.

References:

Haake, S. J. (2009). The impact of technology on sporting performance in Olympic sports. Journal of sports sciences, 27 (13), $1421-1431$.

Chen, Y., Hu, W., Yang, Y., Hou, J., \& Wang, Z. (2014). A method to calibrate installation orientation errors of inertial sen sors for gait analysis. In 2014 IEEE International Conference on Information and Automation (ICIA) (pp. 598-603). https://doi.org/10.1109/ICInfA.2014.6932724 


\title{
The effects of warm-up in repeated 100m-sprint
}

\author{
Maria H. Gil11,2, Mário C. Marques ${ }^{1,2}$, Henrique P. Neiva1,2, Maris S. Cirilo-Sousa ${ }^{4,5}$, António \\ Sousa ${ }^{1,2}$, Nuno D. Garrido ${ }^{2,3}$, Simoni T. Bittar ${ }^{4,5}$, Adenilson T. Araújo Júnior 6 , Daniel A. \\ Marinho ${ }^{1,2}$
}

1. Department of Sport Sciences, University of Beira Interior, Covilhã, Portugal; 2. Research Center in Sports Sciences, Health and Human Development, CIDESD, Vila Real, Portugal; marinho.d@gmail.com; 3. University of Trás-os-Montes e Alto Douro, Vila Real, Portugal; 4. Department of Physical Education, Federal University of Paraíba, João Pessoa, Paraíba, Brazil; 5. Kinanthropometry and Human Development Laboratory, João Pessoa, Paraíba, Brazil; 6. Federal Institute of Paraíba, Campina Grande, Brazil

Byrne, Kenny and O'Rourke (2014) stated that the success of athletes in a multitude of sports that incorporate sprinting depends heavily on explosive power of the lower limbs. In addition to the specific skills of sports such as technique, tactics, strength, explosive strength, speed and endurance, repeated sprint ability has proved as an important factor for determining success in a multitude of sports (Fernandez-Fernandez, Zimek, Wiewelhove, \& Ferrauti, 2012). This study aimed to examine the potential effects of warm-up on repeated $100 \mathrm{~m}$-sprint performance. Methods: The sample consisted of 9 physically active females' subjects (age: $26.00 \pm 8.32$ years; height: $160.82 \pm 5.16 \mathrm{~cm}$; weight: $59.78 \pm 7.80 \mathrm{~kg}$ ). The subjects were submitted to two repeated sprint protocols: one without warm-up and the other with typical warm-up. The sprint times were recorded using Brower equipment (Wireless Sprint System, USA). Results: Results showed significant improvements from the first to the second sprint time when these were carried out without any preheating $(6.12 \%, p=0.015, d=0.42)$; this result was not observed in typical warm-up protocol $(p=0.886, d=$ 0.02). Conclusions: The first sprint may have worked not only as a warm-up for the unheated condition, but also as an enhancer of yield, increasing the neuromotor excitability that can optimize performance in a second $100 \mathrm{~m}$ sprint (Spencer, Bishop, Dawson \& Goodman, 2005). Our results suggest that when there is no possibility of carrying out a prior specific warm-up protocol, a sprint performed before may be as effective as a regular warm-up protocol, allowing overcoming the lack of a specific warm-up.

References:

Byrne, P, Kenny, J., \& O'Rourke, B. (2014). Acute potentiating effect of depth jumps on sprint performance. Journal of Strength and Conditioning Research, 28(3), 610-615.

Fernandez-Fernandez, J, Zimek, R, Wiewelhove, T., \& Ferrauti, A. (2012). High-intensity interval training vs. repeated-sprint training in tennis. Journal of Strength and Conditioning Research, 26(1), 53-62.

Spencer, M, Bishop, D, Dawson, B., \& Goodman, C. (2005). Physiological and metabolic responses of repeated-sprint activities: Specific to fieldbased team sports. Sports Medicine, 35(12), 1025-1044.

\section{Does emphasis on speeds of execution modify neuromuscular parameters?}

Sandro F. da Silva ${ }^{1}$, Cintia C. D. Rocha ${ }^{1,2}$, Claudia E. P. de Oliveira ${ }^{4,5}$, Osvaldo C. Moreira ${ }^{1,4,5}$

1. Grupo de Estudo e Pesquisa em Respostas Neuromusculares - GEPREN- Universidade Federal de Lavras - UFLA - Brasil; sandrofs@def.ufla.br; 2. Faculdade Presbiteriana GAMMON - FAGAMMON - Brasil; 3. Departamento de Educação Física Universidade Federal de Viçosa - UFV - Viçosa, MG, Brasil; 4. Instituto de Biomedicina - Universidad de León - ULe - León, España; 5. Instituto de Ciências Biológicas e da Saúde - Universidade Federal de Viçosa Campus Florestal - Florestal, MG, Brasil

It is well established in the scientific literature that such a cycle, when performed repeatedly, is responsible for causing muscle damage (Chapman et al., 2006), with some factors related to stretch-shortening cycle can interfere with the magnitude of this muscle damage, such as range of motion, the type of muscle action and the force generated during movement.(Libardi et al., 2013). The present study aimed to investigate the influence of different speeds of muscle actions on the volume of repetitions. The study included 9 women. At first, the volunteers performed the anthropometric measurements and evaluation of maximum dynamic strength through the 1RM test in the exercise squat. At second, the volunteers performed three sets with $60 \%$ of $1 \mathrm{RM}$ with the highest number of repetitions possible, emphasizing the concentric phase of the movement (CP); at third, the same exercise was executed with emphasis on the eccentric phase of the movement (EP); and at fourth, the same procedure was done without emphasis on any stage of the movement (CoP). At the end of each set and the three sets of execution of each protocol was added the maximum volume of repetitions (MVR). In the MVR in EP showed a smaller number of repetitions opposite the other protocols show in Table 1.

It was possible to conclude that the accomplishment of exercise protocols that emphasize the eccentric actions, causing losses in the parameters of strength training. 
Table 1.

Comparison of number of repetitions. maximum volume of repetitions in different protocols.

\begin{tabular}{|c|c|c|c|c|c|c|c|}
\hline Variables & $\mathrm{n}$ & \multicolumn{3}{|c|}{ Contraction } & \multicolumn{3}{|c|}{$p$} \\
\hline $\mathrm{MNR}_{\mathrm{s} 1}$ & & $14.55 \pm 2.31$ & $13.00 \pm 2.87$ & $15.88 \pm 3.58$ & 0.55 & 0.64 & 0.14 \\
\hline $\mathrm{MNR}_{\mathrm{s} 2}$ & 9 & $12.11 \pm 2.42$ & $11.44 \pm 2.60$ & $12.66 \pm 2.39$ & 0.85 & 0.89 & 0.58 \\
\hline $\mathrm{MNR}_{\mathrm{s} 3}$ & & $12.55 \pm 1.87$ & $10.33 \pm 2.44$ & $13.11 \pm 4.31$ & 0.32 & 0.92 & 0.17 \\
\hline
\end{tabular}

Acknowledgement

Fundação de Amparo à Pesquisa do Estado de Minas Gerais - FAPEMIG

References:

Chapman, D., Newton, M., Sacco, P., \& Nosaka, K. (2006). Greater muscle damage induced by fast versus slow velocity eccentric exercise. International Journal of Sports Medicine, 27(8), 591-598.

Libardi, C. A., Nogueira, F. R., Vechin, F. C., Conceição, M. S., Bonganha, V., \& Chacon-Mikahil, M. P. T. (2013). Acute hormonal responses following different velocities of eccentric exercise. Clinical Physiology Functional Imaging, 33 (6), 450-454.

\section{Time course expression of antioxidant enzymes after session of strenuous exercise in wistar rats}

Alex Soares Marreiros Ferraz¹, Juliana Osório Alves², Savio Victor Diogenes Mendes², Luiz Henrique Pontes dos Santos², Isabele da Silva Pereira², Vânia Marilande Ceccatto².

1. Institute of Physical Education and Sports, Federal University of Ceará. Fortaleza, Ceará, Brazil; ferrazalex@ hotmail.com; 2. Institute of Biomedical Sciences, State University of Ceará. Fortaleza, Ceará, Brazil.

Increases in the Production of Reactive Oxygen Species (ROS) resulting from exercise session, can cause cell and tissue risks due to the lipid peroxidation process. However, physical exercise also has an important role in signaling pathways antioxidant, as superoxide dismutase (SOD), catalase (CAT), and glutathione peroxidase (GPX). Our objective was to evaluate time course expression of these enzymes response after exhaustive exercise session. Thirty-six male albino Wistar rats were adapted to treadmill exercise, with 3 minute stages and increments of $0.2 \mathrm{~km} / \mathrm{h}$ until animal exhaustion, and divided into six groups: control (C) and times $0 \mathrm{~h} ; 6 \mathrm{~h} ; 12 \mathrm{~h} ; 24 \mathrm{~h}$ and $48 \mathrm{~h}$ after exercise. Samples of the gastrocnemius were dissected, weighed and frozen. Total RNA was extracted, quantitative real-time PCR performed in 96 CFX Realtime PCR System (Biorad, USA) for genes: PGC1 $\alpha$, SOD1, GPX1 CAT. The lipid peroxidation was determined by measuring the malondialdehyde concentration (MDA), in homogenates. Analysis of variance (ANOVA - One Way) and Tukey post test $(\mathrm{p}<0.05)$ were the statistical approaches. The marker of Lipid Peroxidation (MDA) increased in groups $0 \mathrm{~h}(2.2 \pm 0.23)$, $6 \mathrm{~h}(3.6 \pm 0.32)$ and $12 \mathrm{~h}(2.4 \pm 0.44)$ compared to control group $(0.9 \pm 0.20)$, returning to baseline after 24 hours $(1.1 \pm 0.04)$ and 48 hours $(0.7 \pm 0.17)$. Expression of CAT increased in groups $6 \mathrm{~h}(5.97 \pm 0.75), 12 \mathrm{~h}(7.4 \pm 0.99)$ and $24 \mathrm{~h}(5.8 \pm 0.86)$, whereas SOD1 increase in groups $24 \mathrm{~h}(1.4$ $\pm 0.15)$ and $48 \mathrm{~h}(1.0 \pm 0.06)$ compared with control group $(0.69 \pm 0.16)$, GPX1 showed similar increase expression in $24 \mathrm{~h}$ group $(2.38 \pm 0.31)$ and $48 \mathrm{~h}(1.0 \pm 0.31)$ compared control group $(1.01 \pm 0.14)$.
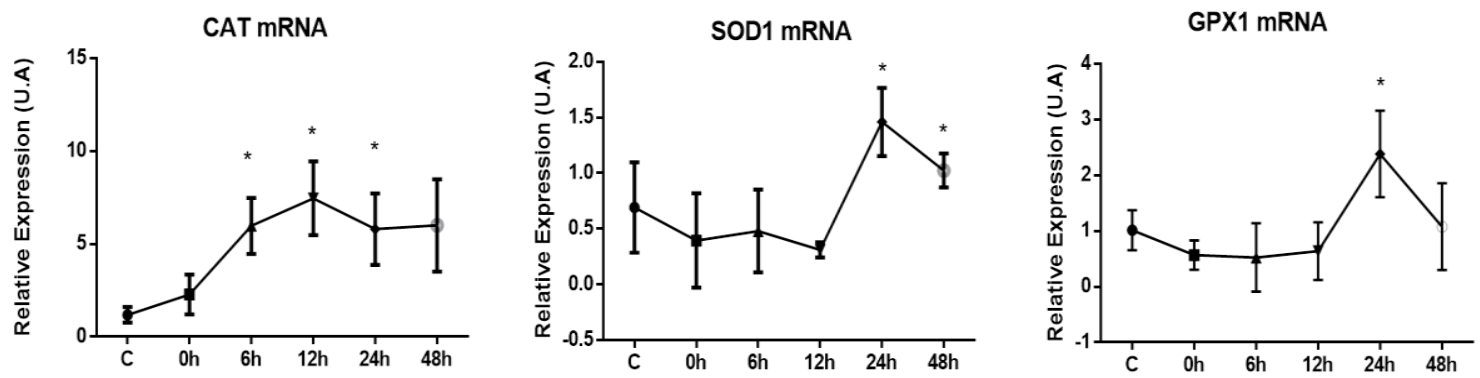

Figure 1. The mRNA levels of antioxidant enzymes: superoxide dismutase (SOD), ctalase (CAT) and glutathione peroxidase (GPx), quantitative real-time PCR, in the gastrocnemius of experimental groups. Values are normalized to the levesls of TATAbox ligase Protein mRNA. * $\mathrm{p}<0.05$. Date are expressed as mean $\pm \mathrm{SE}(\mathrm{n}=6)$

Our data showed the production of ROS increased by exercise and also, lipid peroxidation processes induced until 12 hours after the session. Balancing mechanisms possibly occurred by increased expression and activity of CAT like a first line defense, and SOD1, GPX1 in second line defense.

References:

Gomez-Cabrera, M. C., Borras, C., Pallardo, F. V., Sastre, J., Ji, L. L., \& Vina, J. (2015). Decreasing xanthine oxidase-mediated oxidative stress prevents useful cellular adaptations to exercise in rats. The Journal of Physiology, 567(1), 113-120. doi:10.1113/jphysiol.2004.080564

Powers, S.K., \& Jackson, M.J. (2008) Exercise-Induced Oxidative Stress: Cellular Mechanisms and Impact on Muscle Force Production. Physiological Reviews, 88(4), 1243-1276. doi:10.1152/physrev.00031.2007 


\title{
Analysis of the intention to be physically active in judo athletes
}

\author{
Alfredo Silva ${ }^{1}$ \\ 1. Sports Sciences School of Rio Maior, Research Unit of Polytechnic Institute of Santarém, Portugal; alfredosilva@esdrm.ipsantarem.pt
}

Beyond the sports performance of athletes in major competitions, sports system should be committed to preparing young people and adults to be physically active. The studies about intention to be physically active in the future after sports career, in the population of athletes are scarce. The intention expressed by the athletes to practice other sports or physical activity may be a good indicator of motivation to practice these activities, as well as a strong predictor of this behavior. The aims of this study were: i) determine the effect of the level of sport practice on the intention of the athletes being physically active after sports career) ii) create athletes' clusters according to the intention of being physically active. Questionnaires were collected from a total of 103 subjects ( $66 \%$ male and $34 \%$ female), with an average age of 30.6 years (SD $=13.6)$, and 16 years as an average of practice of judo $(\mathrm{SD}=11.2)$. To assess the intention of being physically active was used the modified scale "Measurement of Intention to be Physically Active - MIPA", proposed by Hein, V., Müür, M. \& Koka, A. (2004). Data were analyzed using SPSS 22., ANOVA one-way and correlation coefficient $r$ of Pearson. The cluster analysis was made by the hierarchical method Ward. The variables sporting level and sports volume were not individually significant predictors of intention to be physically active $(\beta=0.120$, $\mathrm{t}(101)=1.219, \mathrm{p}<0.226)$ and $(\beta=0.166, \mathrm{t}(101)=1.693, \mathrm{p}<0.094)$, respectively. Cluster analysis produced 3 clusters. Cluster 2 had the greatest number of individuals: includes $39 \%$ of the sample and includes athletes with a higher level of being physically active $(4,5)$. These are mostly female $(58 \%)$ and younger ( $90 \%$ between 15 and 24 years), with a higher sporting level (35\% took part in national and international competitions more than 4 times per year) and with a higher volume of sport $(55 \%$ practice more than 7 hours per week). The results regarding judo athletes did not confirm the conclusions taken in the study concerning basketball players who belong to the top league teams. The last ones showed higher levels of intention to be physically active in the future (Franco, Tejero, \& Arrizabalaga, 2013). Cluster analysis advises sports clubs to adopt specific segmentation strategies to different groups of athletes in order to maintain the link between clubs and athletes and increase sport participation after competitive career.

References:

Franco, E., Tejero, J. P., \& Arrizabalaga, A. (2013). Motivación e intención de ser físicamente activo en jugadores de baloncesto en formacion. Diferencias en función de la competición. Cuadernos de Psicología del Deporte, 12(1), 23-26

Hein, V., Müür, M., \& Koka, A. (2004). Intention to be physically active after school graduation and its relationship to three types of intrinsic motivation. European Physical Education Review, 10(1), 5-19.

\section{Predicting backstroke start performance based on artificial neural networks}

\author{
Karla de Jesus ${ }^{1,2,3^{*}}$, Kelly de Jesus ${ }^{1,2,3}$, Helon Ayala ${ }^{4}$, Leandro Coelho ${ }^{4,5}$, Alexandre \\ Medeiros $^{1,6}$, Ricardo Fernandes2,3, João Paulo Vilas-Boas ${ }^{2,3}$ \\ 1. Human Motor Behaviour Studies Laboratory, Faculty of Physical Education and Physiotherapy, Federal University of \\ Amazonas, Amazonas, Brazil; karladejesus@ufam.edu.br; 2. Centre of Research, Education, Innovation and Intervention in \\ Sport, Faculty of Sport, University of Porto, Portugal; 3. Porto Biomechanics Laboratory, University of Porto, Portugal; 4. \\ Industrial and Systems Engineering Graduate Program, Pontifical Catholic University of Paraná, Brazil; 5. Electrical Engineering \\ Graduate Program, Federal University of Paraná, Brazil; 6. Research Group in Biodynamic Human Movement, Institute of \\ Physical Education and Sport, Federal University of Ceará, Fortaleza, Brazil.
}

Studies have evaluated swimming start times using 5 to $15 \mathrm{~m}$ distances to differentiate variables that affect performance. From these, most researchers have applied linear models for performance prediction, which are considered unsuitable to explain movement complexity (Pfeiffer \& Hohmann, 2012). The current backstroke start technique has been gradually studied (de Jesus et al., 2016), although no attention has been given for start performance prediction. This study analysed the accuracy of artificial neural networks (ANN) for backstroke start performance prediction using kinematic and kinetic parameters. Ten backstrokers (age 21.1 \pm 5.36 yrs., stature $1.78 \pm 0.04 \mathrm{~m}$ and body mass $72.82 \pm 10.05 \mathrm{~kg}$ ) volunteered to participate. Swimmers performed four $15 \mathrm{~m}$ backstroke starts with hands on the highest horizontal handgrip and feet over the wedge. Swimmers were videotaped (surface and underwater) with two cameras (HDRCX160E, Sony Electronics Inc., Japan). Starts were performed on an instrumented block (FINA rules FR. 2.7 and 2.10) with four tri-axial force plates, two for upper and two for lower limbs independent measurements. Temporal, angular, velocity, force parameters were used as input for the development of an ANN called multilayer perceptron trained by Levenberg-Marquadt algorithm. Mean of absolute percentage error (MAPE) was calculated. MAPE identified an error of $\sim 0.004 \mathrm{~s}$ for $5 \mathrm{~m}$ backstroke start time prediction (Table 1). ANN evidenced precise backstroke start time prediction, being an important tool to solve complex training problems. 
Table 1

MAPE identified an error of $\sim 0.004 \mathrm{~s}$ for $5 \mathrm{~m}$ backstroke start time prediction

\begin{tabular}{c|c|c|c|c|c}
\hline Start Variant & Model type & Training (\%) & Validation (\%) & All data (\%) & Best Validation (\%) \\
\hline Horizontal & ANN & $8.78 E-07 \pm 1.99 E-06$ & $3.73 \pm 1.62$ & $0.43 \pm 0.19$ & 0.77 \\
\hline
\end{tabular}

Acknowledgement

Coordination for the Improvement of Higher Education Personnel and Foundation for Science and Technology (Edictal 039/2014).

References:

Pfeiffer, M., \& Hohmann, A. (2012). Applications of neural networks in training science. Human Movement Science, 31 (2), $344-359$.

de Jesus, K., de Jesus, K., Abraldes, J. A., Medeiros, A. I., Fernandes, R. J., \& Vilas-Boas, J. P. (2016). Are the new starting block facilities beneficial for backstroke start performance? Journal of Sports Sciences, 34(9), 871-877.

\section{Evolution of the ergoespirometric parameters along 6 months of training in runners from Extremadura of high level in middle and long distance}

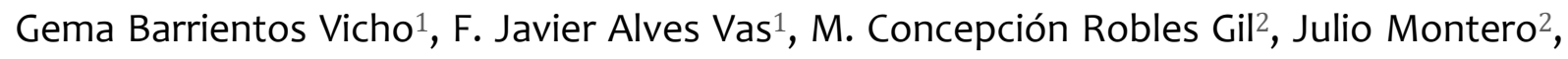
José Enrique Moral García ${ }^{1}$, Marcos Maynar Mariño²

1. Pontifical University of Salamanca; gbarrientosvi@upsa.es; 2. University of Extremadura.

Performance in middle- and long- distance running is influenced by variety of physiological factors (Coyle, 1999; Joyner \& Coyle, 2008). There are several ergoespirometric parameters that are changed with the training (Jones \& Carter, 2000) as are the pulmonary maximum ventilation (VE), the volume of oxygen in minute (VO2), the volume of carbon dioxide per minute (VCO2). The aim of the study was the evolution of these parameters during 6 months. To the start, in the half and at the end of season athletic winter is analyzed the ergoespirometric parameters of twenty- one runners of high level in middle and long distance (age $23 \pm 3$ years, weight $65.5 \pm 7.3 \mathrm{~kg}$, height $177 \pm 0.05 \mathrm{~m}$, VO2 máx. $68.1 \pm 4.6 \mathrm{ml} / \mathrm{min} / \mathrm{kg}$ ) with at least four years of experience and a volume of $80-110 \mathrm{~km} /$ week training. These data were measured both to the end of the effort as to them three minutes of recovery of a increased test on treadmill. In the VO2 máx. and in the VCO2 there is an increase of values at 3 months of training and a decrease at 6 months. The VO2 max in the anaerobic threshold is very near the end of test in the runners of high level. Ergoespirometric parameters changing during 6 months of training period in relation the competitions periods.

Table 1

Evolution of the ergoespirometric parameters absolute and relative to the start, in 3 months and 6 months of season athletic winter.

\begin{tabular}{|c|c|c|c|c|}
\hline & To the start & $3 \mathrm{M}$. & $6 \mathrm{M}$. & S. \\
\hline \multicolumn{5}{|l|}{$\mathrm{VE}(\mathrm{L} / \mathrm{min})$} \\
\hline T.E & $138.4 \pm 11.44$ & $137.0 \pm 48.36$ & $134.8 \pm 23.82$ & NS \\
\hline R. 3' & $40.36 \pm 14.36$ & $44.21 \pm 20.73$ & $46.76 \pm 25.62$ & NS \\
\hline \multicolumn{5}{|l|}{$\mathrm{VO}_{2}(\mathrm{~mL} / \mathrm{min})$} \\
\hline T.E. & $4240 \pm 0.71$ & $4660 \pm 1.57$ & $4390 \pm 0.89$ & NS \\
\hline R. 3' & $960 \pm 0.31$ & $1010 \pm 0.23$ & $1020 \pm 0.28$ & NS \\
\hline \multicolumn{5}{|l|}{$\mathrm{VCO}_{2}(\mathrm{~mL} / \mathrm{min})$} \\
\hline T.E. & $4600 \pm 0.47$ & $4820 \pm 1.43$ & $4520 \pm 0.91$ & NS \\
\hline R. 3' & $1140 \pm 0.33$ & $1270 \pm 0.50$ & $1190 \pm 0.40$ & NS \\
\hline \multicolumn{5}{|l|}{$\mathrm{VO}_{2}$ rel máx. $(\mathrm{mL} / \mathrm{min} / \mathrm{kg})$} \\
\hline T.E. & $68.12 \pm 4.63$ & $67.53 \pm 9.54$ & $68.55 \pm 6.97$ & NS \\
\hline R. $3^{\prime}$ & $16.01 \pm 4.68$ & $16.65 \pm 6.15$ & $13.45 \pm 5.88$ & NS \\
\hline $\begin{array}{r}\% \mathrm{VO}_{2} \text { máx. en UAN } \\
\text { T.E. }\end{array}$ & $91.02 \pm 2.43$ & $92.43 \pm 3.59$ & $91.02 \pm 3.08$ & NS \\
\hline
\end{tabular}

Note: $\mathrm{M}=$ Months; $\mathrm{S} .=$ Significance; $\mathrm{T} . \mathrm{E}=$ The End; $\mathrm{R}=$ Recovery; $\mathrm{NS}=$ Without significant variations.

\section{References:}

Coyle, E. F. (1999). Physiological determinants of endurance exercise performance. Journal of Science and Medicine in Sport, 2, 181-189.

Jones, A. M., \& Carter, H. (2000). The effect of endurance training on parameters of aerobic fitness. Sports Medicine, 29(6), 373-386. 


\title{
Effect of joint stiffness of the ankle joint stability in quiet standing posture
}

\author{
Orlando Fernandes ${ }^{1,2}$
}

1. Departamento de Desporto e Saúde, Escola de Ciência e Tecnologia, Universidade de Évora; fernandes.orlando@gmail.com;

2. Research Center in Sports Sciences, Health and Human Development, CIDESD, Vila Real, Portugal

Joint Stability is the ability of the joint to resist a given perturbation. Several studies have suggested that the number of falls, and injuries, are related to changes in the postural control system, mainly in the sensor and motor systems. The sway variability during quiet standing reflect the strategies assumed by the control system of the joint stability. The balance stabilization during quiet standing it's not only achieved by ankle muscle stiffness, but with a reflex component from changes of muscle activation. The purpose of this work is to contribute to the study and understanding of the mechanisms of joint stability at the ankle joint during a quasi-static posture. Using a stiffness model (Winter et al, 1998) for quiet standing. Methods: The patient studied was an Olympic athlete $(26$ years old; $1.74 \mathrm{~m} ; 71.1 \mathrm{~kg}$ ) who, for the past six months presented several sprains ankle on the left ankle. Although the sample is not representative of the ankle injury population, it is representative of the problem under study, being possible to analyze using procedures and means of collection of great accuracy. The present study case thus represents an approximation to the inductive behavior of a healthy ankle versus an injured ankle. The task trial consisted in the maintenance of the biped position and one leg stand position on the two platforms of forces plates for thirty seconds. Was asked to the subject to put the feet on the platform in the most comfortable position without any enforcement in relation to the support base. Results: The joint stiffness $(\mathrm{k})$, presented different values in the left ankle (l) compared to the right ankle (r) in medio-lateral (ML) component and the Antero-posterior (AP) component; kAPl = $1.275 \mathrm{Nm} / \mathrm{kg} /{ }^{\circ}, \mathrm{kAPr}=0.355 \mathrm{Nm} / \mathrm{kg} /{ }^{\circ}, \mathrm{kMLl}=-0.370 \mathrm{Nm} / \mathrm{kg} /{ }^{\circ}, \mathrm{kMLr}=-0.474 \mathrm{Nm} / \mathrm{kg} /{ }^{\circ}$. The obtained values of the ML component are presented in general lower values of ankle joint stiffness the exception is made when the position in one leg stand and with the introduction of noise (special perturbation). The results allow us to conclude that a) it is possible to describe the condition of Joint Stability through noninvasive processes; b) analyze the behavior of Joint Stability, as a consequence of quasi-static posture, either double or single stance, using joint stiffness as the primary tool.

References:

Alexandrov, A. V., Frolov, A. A., Horak, F. B., Carlson-Kuhta, P., \& Park, S. (2005). Feedback equilibrium control during human standing. Biological Cybernetics, 93(5), 309-322. https://doi.org/10.1007/s00422-005-0004-1

Allum, J., \& H. Budingen (1979). The influence of initial foot inclination and head movements on coupled stretch reflexes in ankle flexor and extensor muscles. Agressologie, 20, 143-144.

\section{Time-to-contact perception in relay swimming: a preliminary study with high-performance Portuguese swimmers.}

\author{
Lilian S. P. Ribeiro ${ }^{1}$, Mário Costa ${ }^{1,2,3}$, Hugo Louro ${ }^{2,4}$, Pedro Sobreiro ${ }^{4}$, Pedro Esteves ${ }^{2,5}$, Ana \\ Conceição 2,4 \\ 1. Department of Sports Science, Covilhã, Portugal; lili.ribeiro2000@gmail.com; 2. Research Center in Sports Sciences, Health \\ and Human Development, CIDESD, Vila Real, Portugal; 3. CICS-UBI Health Sciences Investigation Center, University of Beira \\ Interior, Covilhã, Portugal; 4. Sport Sciences School of Rio Maior, Rio Maior, Portugal; 5. Polytechnic institute of Guarda, Guarda, \\ Portugal
}

In competitive swimming, recent studies have highlighted the importance of optimal relay start strategies to improve the change-over time (Fisher, Braun, \& Kibele, 2017; Luedke \& Duoos, 2015), suggesting also that the technique used for diving off the block may be influenced by the perception of the time for the oncoming swimmer to touch the wall. Therefore, the aim of this study was to analyze the swimmers' perceptual judgements of a simulated time-to-contact corresponding to the $4 \times 100 \mathrm{~m}$ and $4 \times 200 \mathrm{~m}$ freestyle relays. The sample was composed of 31 national-level Portuguese swimmers $(n=18$ males, $17.22 \pm 1.95 \mathrm{yr} ; \mathrm{n}=13$ females, $14.61 \pm 0.76 \mathrm{yr}$ ). Prior to data collection, participants with the experimental task that consisted of the visualization of two videos of the performance of a swimmer approaching the wall in a simulated relay race of $4 \times 100 \mathrm{~m}$ and $4 \times 200 \mathrm{~m}$. These videos were presented with temporal occlusion correspondent to predetermined approaching distances $(7.5 \mathrm{~m}, 5.0 \mathrm{~m}$, and $2.5 \mathrm{~m})$. For each distance, were required to predict the time-to-contact of the approaching swimmer by pressing a switch. A pairwise t-test comparison was performed with a significance level of $5 \%$. The results showed that the time-to-contact predicted by the swimmers was smaller (between $3.8 \%$ and $39.8 \%$ ) than the real time in all the approaching distances. For the male participants, there were significant differences $(\mathrm{p}<0.05)$ between the predicted and the real time, in both videos, in all the approaching distances, with the exception of the $4 \times 200 \mathrm{~m}$ video in the distance of $7.5 \mathrm{~m}$ occlusion $(p=0.620)$. For the female participants, significant differences were found between the 
predicted and the real time in the shortest $(2.5 \mathrm{~m} ; \mathrm{p}=0.004$ and $\mathrm{p}=0.040$, for the $100 \mathrm{~m}$ and $200 \mathrm{~m}$ events, respectively) and in the longest approaching distances $(7.5 \mathrm{~m} ; \mathrm{p}=0.000$ and $\mathrm{p}=0.034$, for the $100 \mathrm{~m}$ and $200 \mathrm{~m}$ events, respectively). This study suggested that high-level swimmers seem to underestimate the time-tocontact when approaching the wall, in the context of a simulated relay race (video). Taken together, these results highlight the importance of the development of perceptual abilities in swimming to optimize the relay start technique and perception when diving off the block.

References:

Luedtke, D., \& Duoos, B. (2015). Comparison of for feedback methods used to help improve swimming relay exchanges: A pilot. International Journal of Aquatic Research and Education, 9 (2), 175-183.

Fischer, S., Braun, C., \& Kibele, A. (2017). Learning relay start strategies in swimming: What feedback is best? European Journal of Sport Science, 17(3), 257-263. https://doi.org/10.1080/17461391.2016.1221471

\title{
Neuromuscular activation in different technical elements of power jump between two groups
}

\author{
Pedro Bicó ${ }^{1}$, Ana Margarida Lopes ${ }^{1}$, Orlando Fernandes ${ }^{2}$
}

1. Be in Shape, Ginásio, Évora; 2. Departamento de Desporto e Saúde, Escola de Ciência e Tecnologia, Universidade de Évora; fernandes.orlando@gmail.com; 3. Research Center in Sports Sciences, Health and Human Development, CIDESD, Vila Real, Portugal

Introduction: Power Jump (PJ), created in Brazil, is a perfect example of indoor physical activity. The aim of this study was the comparison of neuromuscular activation, by evaluating electromyography (EMG) from different technical elements of Power Jump between two groups with difference levels of practice. Methods: Fourteen participants (random selection) were divided into two groups (intermediate level of practice - G1 and advanced level of practice - G2), conducted two technical elements (double scissors -DSs; double side DSd) of PJ at different levels of intensity (low- 1; medium- 2; high-3). Muscle activation of tibial anterior (TA) and rectum abdominal (RA) muscles were evaluated. The criteria for selecting the participants in different groups was based in video analysis, applying an observation grid from the critical technical components, set up for this purpose. Results: The results from both muscle, for the double scissors element

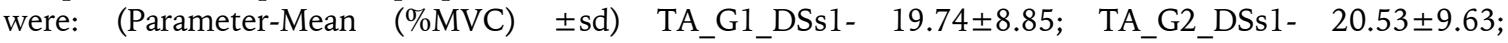
TA_G1_DSs2- 21.92 \pm 9.09 ; TA_G2_DSs2- 24.58 $\pm \overline{1} 1.32$; TA_G1_DSs3- $21 . \overline{4} 2 \pm \overline{1} 2.92$; TA_G2_DSs3-

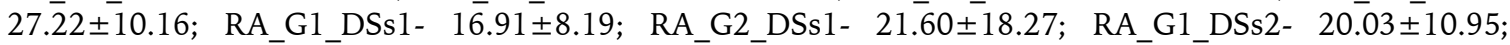

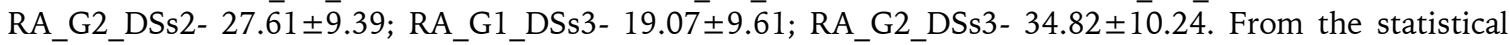
analyses, it was possible to find significances differences between muscle and groups specially in the high intensity exercise. The activation of the TA has statistically differences mainly in the early stages of the movement, and in the higher intensity levels. Muscle activation of RA was different in different levels of intensities and between technical elements. When comparing the Double Side between the groups in the same areas and levels of intensity you can see significant differences only in higher intensity levels. The results allow us to say that there is a progressive adaptation to contact surface as a function of increased intensity and execution of the different technical elements, recruiting more RA, a muscle important for stability in the execution. Conclusions: These changes are easier evident in higher intensity levels, where you need more control or less muscular adaptation in response to the supporting surface. When we compare the elements with each other we can find that, both the double side as the scissors are technical elements easy to learn but that require a large control of stabilizers, which most people can do because in the presence of the risk of a fall the centre of the body that is activated.

References:

Marquez, G., Aguado, X., Alegre, L. M., \& Fernandez-Del-Olmo, M. (2012). Neuromechanical adaptation induced by jumping on an elastic surface. Journal of Electromyography and Kinesiology, 23(1), 62-69.

\section{Environment perception and physical activity in Portuguese high school students}

Raúl Pereira ${ }^{1}$, Rute Santos ${ }^{1,2,3}$, Susana Póvoas ${ }^{1,4}$, Pedro Silva ${ }^{2}$

1. ISMAI, Maia, Portugal; spovoas@ismai.pt; 2. CIAFEL, Faculty of Sport, University of Porto, Porto, Portugal; 3. Early Start Research Institute, School of Education, Faculty of Social Sciences, University of Wollongong, Wollongong, Australia; 4. Research Center in Sports Sciences, Health and Human Development, CIDESD, Vila Real, Portugal

Promoting regular physical activity (PA) in youth has become a main public health goal. Thus, knowledge about the factors that may influence PA, namely environmental features, has gained increased interest. This study aimed at analysing the association between perceived environmental features and PA among adolescents of both genders. Participants were 866 (412 girls; 454 boys) 12-18-years-olds, from four 
Portuguese cities. Perceptions of environmental features were assessed by ALPHA questionnaire-adapted version (Spittaels et al. 2010). PA was assessed by a 5-item questionnaire that evaluated PA during leisure time (Telama et al, 1997). A total index (range: 5-20 points) was derived from this questionnaire and participants were assigned in the following categories: sedentary (5 points); low active (6-10 points); moderate active (11-15 points); and very active ( $>15$ points). Boys presented higher levels of structured PA, frequency and intensity of PA, and level of sport competition than girls $(\mathrm{p}<0.001)$. Distance to local facilities ( $\rho=-0.156$, girls; $\rho=-0.177$, boys) and home environment $(\rho=-0.142$, girls; $\rho=-0.175$, boys) were negatively associated with PA in both genders $(p \leq 0.015)$. Total infrastructures $(\rho=0.222)$, cycling infrastructures $(\rho=0.189)$ and walking infrastructure $(\rho=0.190)$, as well as cycling and walking network $(\rho=0.093)$ and connectivity $(\rho=0.99)$ showed a positive association with PA in boys $(p \leq 0.049)$. Analysis of variance showed significant differences between girls' levels of PA regarding aesthetics, study and home environment and whether it is pleasant or not $(\mathrm{p} \leq 0.023)$. Differences between boys' levels of PA were observed for distance to local facilities, total infrastructures, walking infrastructures, cycling infrastructures and home environment $(\mathrm{p} \leq 0.003)$. This study shows that some environmental features are associated with adolescents' PA, with relevant differences between genders. These gender differences must be taken into account, in order to increase levels of PA in young Portuguese people, especially in girls.

References:

Active Living Research (2012). Reference List by Year. from http://activelivingresearch.org/resourcesearch/referencelist

Committee on Environmental Health. (2009). The Built Environment: Designing Communities to Promote Physical Activity in Children. Pediatrics, 123(6), 1591-1598. https://doi.org/10.1542/peds.2009-0750

Spittaels, H., Foster, C., Oppert, J.-M., Rutter, H., Oja, P., Sjöström, M., \& De Bourdeaudhuij, I. (2009). Assessment of environmental correlates of physical activity: development of a European questionnaire. International Journal of Behavioral Nutrition and Physical Activity, 6, 39. https://doi.org/10.1186/1479-5868-6-39

Spittaels, H., Verloigne, M., Gidlow, C., Gloanec, J., Titze, S., Foster, C., ... De Bourdeaudhuij, I. (2010). Measuring physical activity-related environmental factors: reliability and predictive validity of the European environmental questionnaire ALPHA. International Journal of Behavioral Nutrition and Physical Activity, 7, 48. https://doi.org/10.1186/1479-5868-7-48

Telama, R., Yang, X., Laakso, L., \& Viikari, J. (1997). Physical activity in childhood and adolescence as predictor of physical activity in young adulthood. American Journal of Preventive Medicine, 13(4), 317-323.

\title{
Physiological load associated to different group fitness classes: a comparison between Zumba ${ }^{\circledR}$, PowerGym and Step
}

\author{
Bernardete Jorge ${ }^{1}$, Carolina Vila-Chã ${ }^{1,2}$, Natalina Casanova ${ }^{1}$
}

1. Polytechnic Institute of Guarda, Guarda, Portugal; bernardete@ipg.pt; 2. Research Center in Sports Sciences, Health Sciences \& Human Development, CIDESD, Vila Real, Portugal

Group fitness classes are very popular in gyms and health clubs. Regular participation in this type of classes has been found to improve cardiovascular fitness similar to those elicited by other endurance-type modes of exercise. However, this adaptation is dependent of other training variables, being training intensity one of the most important. This variable can be influenced by structure and choreography of different types fitness classes. Therefore, it matters to investigate the effects of the physiological load associated to different type of classes and, more importantly, if it allows the participants to reach intensities within adequate interval zones for cardiovascular adaptations and health benefits. Hence this study aims to investigate the physiological load associated to 3 different fitness classes: Zumba ${ }^{\circledR}$, PowerGym and Step. Ten young healthy women (age range 19-23-years-old), regular practitioners of group fitness classes, volunteered to participate in this study. Each subject participated in the 3 group fitness classes types (Zumba ${ }^{\circledR}$, PowerGym and Step). The sessions were performed at same time of the day, but with $48 \mathrm{~h}$ of rest between them. Physiological load was assessed through heart rate (HR) measurements (Zephyr BioHarness) and through Borg Rating of Perceived Exertion Scale (RPE). The mean HR in the Step, PowerGym and Zumba ${ }^{\circledR}$ classes was $150.5 \mathrm{bpm}$ $159.5 \mathrm{bpm}$ and $158.8 \mathrm{bpm}$, respectively. Regarding to the RPE, the highest values were achieved in the PowerGym (16.7 \pm 0.7$)$, followed by the Step $(14.3 \pm 1.2)$ and Zumba ${ }^{\circledR}(13.22 \pm 0.97)$, classes. The mean HR achieved in the Step, Zumba ${ }^{\circledR}$ and PowerGym represents $64 \%, 70.1 \%$ and $70.6 \%$ of the Heart Rate Reserve and de $75.5 \%, 79.7 \%$ and $80 \%$, of the maximum HR, respectively. According to ACSM (2011), these results indicate that during the step class the subjects are, in average, within an intensity interval considered moderate, while for the Zumba ${ }^{\circledR}$ and PowerGym, the intensity is considered vigorous. Therefore, these activities can be considered adequate to promote improvements in the cardiovascular fitness.

References

Delextrat, A., \& Neupert, E. (2016). Physiological load associated with a Zumba ${ }^{\circledR}$ fitness workout: a comparison pilot study between classes and a DVD. Journal of Sports Sciences, 34(1), 47-55. https://doi.org/10.1080/02640414.2015.1031162

American College of Sports Medicine. (2011). Quantity and quality of exercise for developing and maintaining cardiorespiratory, musculoskeletal, and neuromotor fitness in apparently healthy adults: guidance for prescribing exercise. Medicine and Science in Sports and Exercise, 43 (7), 1334-1359. https://doi.org/10.1249/MSS.0b013e318213fefb

Laukkanen, R. M., Kalaja, M. K., Kalaja, S. P., Holmala, E. B., Paavolainen, L. M., Tummavuori, M., ... Rusko, H. K. (2001). Heart rate during aerobics classes in women with different previous experience of aerobics. European Journal of Applied Physiology, 84(1-2), 64-68. https://doi.org/10.1007/s004210000338 


\title{
Foot rollover temporal parameters during walking and stepping over obstacles in postmenopausal women
}

\author{
David Silva ${ }^{1}$, Ronaldo Gabriel ${ }^{1,2}$, Maria Moreira ${ }^{1,3}$, João Abrantes ${ }^{4}$, Aurélio Fariaa, \\ 1. Sport Sciences, Exercise and Health, University of Trás-os-Montes and Alto Douro, UTAD, Vila Real, Portugal; \\ davidutad@gmail.com; 2. CITAB, UTAD, Vila Real, Portugal; 3. Research Center in Sports Sciences, Health Sciences and Human \\ Development, CIDESD, Vila Real, Portugal; 4. MovLab, CICANT, University Lusófona of Humanities and Technologies, Lisboa, \\ Portugal; (5) Sport Science Department, University of Beira Interior, UBI, Covilhã, Portugal
}

\section{INTRODUCTION}

Plantar pressure measurements supply important information about the structures of the foot during foot-ground interaction (Monteiro, Gabriel, Sousa, Castro, \& Moreira, 2010). Foot rollover temporal parameters during straightforward walking have been established for postmenopausal women (PW) (Monteiro et al., 2010), however, during daily activities stepping over obstacles occurs frequently, and poses greater demands (Austin, Garrett, \& Bohannon, 1999). The aim of this study was therefore to compare, the temporal characteristics of foot roll-over of PW between tasks: (T1) walking straightforward; and (T2) stepping over obstacles.

\section{METHODS}

Thirty-one PW participated in this study. Plantar pressure parameters were evaluated for the trailing limb by a Footscan platform using the two-step protocol. The initial contact, final contact and duration of contact was obtained for 10 foot areas. Paired-sample t-tests and Wilcoxon signed-rank tests were performed during statistical analysis.

\section{RESULTS}

When comparing both tasks, the data indicate that in the T2: the initial contact of the MF, M1M5, T2-5 and H1 occurred significantly earlier; the final contact of the M1-M5 occurred significantly later and the final contact of the HL and $\mathrm{H} 1$ occurred significantly earlier; the duration of contact of the M1-M5, T2-5 and H1 was significantly longer and the duration of contact of HL was significantly shorter.

\section{CONCLUSION}

Significant differences were found between tasks in some foot areas for the initial contact, final contact and duration of contact. Stepping over obstacles pose greatest demands and risks on the locomotor system, and the metatarsal and toe areas seem to play a major role in the initial break in the control of stability and on propulsion when compared to walking straightforward.

\section{REFERENCES}

Austin, Gary P., Garrett, Gladys E., \& Bohannon, Richard W. (1999). Kinematic analysis of obstacle clearance during locomotion. Gait $\mathcal{E}$ Posture, 10(2), 109-120. doi: http://dx.doi.org/10.1016/S09666362(99)00022-3

Monteiro, M., Gabriel, R., Sousa, M., Castro, M., \& Moreira, M. (2010). Temporal parameters of the foot roll-over during walking: influence of obesity and sarcopenic obesity on postmenopausal women. Maturitas, 67(2), 178185. doi: http://dx.doi.org/10.1016/j.maturitas.2010.06. 012 


\title{
A psychomotor rehabilitation intervention to improve health and well-being indicators of institutionalized older adults.
}

\author{
Catarina Pereira ${ }^{1,2}$, Marco Pereira ${ }^{1}$; Guida Veiga ${ }^{1,2}$
}

1. Departamento de Desporto e Saúde; Escola de Ciências e Tecnologia; Universidade de Évora; Portugal; clnp@uevora.pt; 2. Research Center in Sports Sciences, Health and Human Development, CIDESD, Portugal

\section{INTRODUCTION}

Institutionalization tends to exacerbate the usual fragility and disability associated with the ageing process (Heppenstall, Wilkinson, Hanger, Keeling, \& Pearson, 2011). In turn, poor health and well-being compromise older adults' quality of life.

\section{OBJECTIVE}

The aim of this study was to analyze the impact of a psychomotor rehabilitation program on health and well-being indicators of institutionalized older adults.

\section{METHODOLOGY}

A total of 42 nursing home residents (84 \pm 6.2 years) participated in the study: 21 were allocated to the experimental group (EG: engaged the rehabilitation program twice a week for $75 \mathrm{~min}$ ), and 21 were allocated to the control group (CG: maintained daily institution activities). The Mini Mental State Examination was used to screen severe cognitive impairment as an exclusion criteria. Mood states, pain, disability and self-rated health were assessed through the Profile of Mood States, the P4 Pain Scale, the Barthel Index, and the EuroQol visual analogue scale, respectively. After finishing the study, the CG attended the rehabilitation program.

\section{RESULTS}

Comparisons showed that: in terms of mood states, both groups showed improvements in tension, whereas only the EG demonstrated improvements in depression, anger, vigor, fatigue, and confusion (treatment effect: -0.23 to -2.60); the EG experienced a decrease in pain (treatment effect: 0.21 to 0.50 ), while the CG showed an increase; finally, in terms of the disability level and the self-rated health the EG experienced no changes, whereas these indicators worsened in the CG $(p<0.05)$.

\section{CONCLUSION}

The psychomotor program was able to revert the expected loss of health and well-being characteristic of older people, particularly the institutionalized ones. Specifically, the program was effective in improving the mood states and in decreasing pain of the nursing home residents, as well as in maintaining their disability level and health status. These findings suggest that the general adherence of nursing home residents to psychomotor rehabilitation programs may improve the quality of life of our oldest adults.

\section{REFERENCES}

Heppenstall, C. P., Wilkinson, T. J., Hanger, H. C., Keeling, S., \& Pearson, J. (2011). Factors related to care home admission in the year following hospitalisation in frail older adults. Age Ageing, 40 (4), 513-516. doi: afr045 [pii] 10.1093/ageing/afr045 


\section{Cutoffs for the metabolic syndrome risk factors in Danish children and adolescents}

Jorge Bravo ${ }^{1}$, Armando Raimundo ${ }^{1,2}$

1. Departamento de Desporto e Saúde, Escola de Ciência e Tecnologia, Universidade de Évora, Portugal; jorgebravo@uevora.pt; 2. Research Centre of Sports, Health and Human Development, CIDESD, GERON Research Community

\section{INTRODUCTION}

The International Diabetes Federation (IDF) developed a new definition to diagnose metabolic syndrome (MS) in children and adolescents aged 10-16 years old using modified adult criteria (Zimmet et al., 2007). Matching the consistent IDF cutoffs for adults (Alberti, Zimmet, \& Shaw, 2006) with the need for adjustment to youth, we aimed to develop age and gender-specific cutoffs for the MS risk factors in 10-15 years old Danish boys and girls, linking the youth to the adult criteria.

\section{METHODS}

Data included 1812 youth between 9.0-15.99 years old results from the Danish European Youth Heart Study (EYHS) frameworks I and II (Riddoch et al., 2005). Percentile curves were constructed, nationally weighted, and smoothed using the Cole's Lambda Mu Sigma method (Cole \& Green, 1992) and linked to the IDF cutoffs for adults at 16 years of age. Percentile curves included age and gender-specific cutoffs linked to the adult abnormal cutoff values for waist circumference (WC), triglycerides (TG), high-density lipoprotein cholesterol (HDL-C), systolic blood pressure (SBP), diastolic blood pressure (DBP), and fasting plasma glucose (GLU).

\section{RESULTS}

Growth curves for the MS risk factors were provided. The cutoffs for abnormal MS risk factors were equivalent to the $98^{\text {th }}$ (boys) and the $89^{\text {th }}$ (girls) percentile for $\mathrm{WC}$, to the $92^{\text {nd }}$ percentile for SBP in boys, to the $96^{\text {th }}$ (boys) and the $94^{\text {th }}$ (girls) percentile for TG, to the $16^{\text {th }}$ (boys) and the $6^{\text {th }}$ (girls) percentile for HDL-C and to the $84^{\text {th }}$ (boys) and the $95^{\text {th }}$ (girls) percentile for GLU. The DBP was suppressed in both genders because there were no subjects reaching the adult's cutoff ( $83 \mathrm{mmHg}$ ).

\section{CONCLUSIONS}

The curves represent waist and lipid percentiles and specific cutoffs for Danish children and adolescents, allowing both epidemiological and possibly clinical applications.

\section{REFERENCES:}

Alberti, K., Zimmet, P., \& Shaw, J. (2006). Metabolic syndrome, a new worldwide definition. A Consensus Statement from the International Diabetes Federation. Diabetic Medicine, 23(5), 469-480.

Cole, T. J., \& Green, P. J. (1992). Smoothing reference centile curves: the LMS method and penalized likelihood. Statistics in medicine, 11(10), 13051319.

Riddoch, C., Edwards, D., Page, A., Froberg, K., Anderssen, S. A., Wedderkopp, N., Harro, M. (2005). The European Youth Heart Study cardiovascular disease risk factors in children: rationale, aims, study design, and validation of methods. J Phys Act Health, 2(1), 115-129.

Zimmet, P., Alberti, K. G. M., Kaufman, F., Tajima, N., Silink, M., Arslanian, S., Caprio, S. (2007). The metabolic syndrome in children and adolescents - an IDF consensus report. Pediatric diabetes, 8(5), 299-306. 


\section{Burden, psychological symptoms and health-related quality of life in caregivers of patients with dementia}

Miguel Madruga Vicente ${ }^{1}, M^{a}$ de los Ángeles González González¹, Margarita Gozalo Delgado $^{1}$, Josué Prieto Prieto ${ }^{1}$, Narcís Gusi Fuertes ${ }^{1}$

1. Grupo de Investigación AFYCAV. Facultad de Ciencias del Deporte. Universidad de Extremadura; miguelmadruga@unex.es

\section{INTRODUCTION}

The most widely documented and described psychological symptoms in caregivers are anxiety and depression, however, other researches have referred that caregivers suffer as well from additional disturbances which cause serious effects on caregiver's burden and have negative consequences on their Health Related Quality of Life (HRQOL). Assessing the impact of these symptoms on caregivers may help to develop appropriate interventions to lessen the effect of caring in this population. The aim is to analyze the psychological symptoms experienced by primary informal caregivers and analyze the relationship among burden and HRQOL.

\section{METHOD}

This work is a cross-sectional community study to compare informal caregivers and noncaregivers. Sixty six caregivers and fifty six female non-caregivers of rural and urban areas in Extremadura were recruited. Psychological symptoms were assessed by the Symptom Check-List-90-Revised questionnaire and HRQOL by the EurQol-5D-3L questionnaire. Subjective burden was also assessed by the Spanish version of Zarit Burden Inteview.

\section{RESULTS}

Caregivers scored higher than non-caregivers in most dimensions of the SCL-90-R and also reported worse health and quality of life (EuroQol Group) than non-caregivers. Depression, Anxiety, Visual Analogic Scale and Health status correlated significantly with level of subjective burden in caregivers. Lower levels of health status are associated with higher level of burden, but psychological symptoms can be influential on that.

\section{CONCLUSION}

Caregivers suffer more psychological symptoms than non-caregivers, which were predictors of a poorer QOL and subjective burden. Thus, helpful interventions should be developed and assessed for their ability to mitigate multiple psychological symptoms and improve their quality of life.

\section{REFERENCES}

Fernandez de Larrinoa, P., Martinez, S., Ortiz, N., Carrasco, M., Solabarrieta, J., \& Gomez, I. (2011). Autopercepción del estado de salud en familiares cuidadores y su relación con el nivel de sobrecarga. Psicothema, 23(3), 388-393.

Delgado, E., Suárez, O., Del Valle, R., Valdespino, I., Sousa, Y., \& G., B. (2014). Características y factores relacionados con sobrecarga en una muestra de cuidadores principales de pacientes ancianos con demencia_. SEMERGEN, 40(2), 57-64.

Ho, S. C., Chan, A., Woo, J., Chong, P., \& Sham, A. (2009). Impact of caregiving on health and quality of life: a comparative population-based study of caregivers for elderly persons and noncaregivers. J Gerontol A Biol Sci Med Sci, 64(8), 873-879.

Pinquart, M., \& Sorensen, S. (2003). Differences between caregivers and noncaregivers in psychological health and physical health: a metaanalysis. Psychol Aging, 18(2), 250-267.

Vellone, E., Piras, G., Talucci, C., \& Cohen, M. Z. (2008). Quality of life for caregivers of people with Alzheimer's disease. J Adv Nurs, 61 (2), 222231. 


\title{
Food intake in middle-age and older patients with type 2 diabetes: Accomplishment of general dietary guidelines
}

\author{
Carlos Vasconcelos ${ }^{1,2}$, António Almeida ${ }^{1,3}$, Maria Cabral ${ }^{4}$, Elisabete Ramos ${ }^{4,5}$, Romeu \\ Mendes $1,3,6$ \\ 1. University of Trás-os-Montes e Alto Douro, UTAD, Vila Real, Portugal; cvasconcelos@esev.ipv.pt; 2. Polytechnic Institute of \\ Viseu, Portugal; 3. Research Center in Sports Sciences, Health Sciences and Human Development, CIDESD, Portugal; 4. ISPUP- \\ EPIUnit, Universidade do Porto; Portugal; 5. Faculdade de Medicina, Universidade do Porto, Portugal; 6. Public Health Unit, \\ ACES Douro I - Marão e Douro Norte, Vila Real, Portugal
}

\section{INTRODUCTION}

A healthy diet is one of the cornerstones of type 2 diabetes (T2D) treatment and control although there is not a one-size-fits-all eating pattern for these individuals. However general healthy eating recommendations should be addressed in public health messages and interventions for this population. This study aimed to evaluate food intake in middle-age and older patients with $\mathrm{T} 2 \mathrm{D}$ and to analyze the accomplishment of general dietary guidelines.

\section{METHODS}

Participants were 44 individuals with T2D (27 women and 17 men; $62.84 \pm 7.29$ years of age) enrolled in the project Diabetes em Movimento ${ }^{\circledR}, \quad$ a community-based lifestyle intervention program, combining physical activity and food education (Mendes et al., 2015; Vasconcelos, Almeida, Lopes, \& Mendes, 2016), developed in Vila Real (Portugal). Food intake was assessed using a 3-day food record and food consumption was converted into nutrients with the software Food Processor Plus ${ }^{\circledR}$. The accomplishment of general dietary guidelines was evaluated (yes or no) for: reduced fat intake (total fat intake $\leq 30 \%$ of total energy; saturated fat intake $<7 \%$ of total energy); protein intake up to $20 \%$ of total energy; at least $14 \mathrm{~g}$ of fiber consumption per $1000 \mathrm{kcal} /$ day.

\section{RESULTS}

Total energy intake was $1352.2 \pm 350.4$ $\mathrm{kcal} /$ day; total fat $434.9 \pm 148.8 \mathrm{kcal} /$ day; saturated fat $114.3 \pm 51.2 \mathrm{kcal} /$ day; protein $245.4 \pm 66.6 \mathrm{kcal} /$ day; fiber $13.7 \pm 5.7 \mathrm{~g} /$ day. The accomplishment of general dietary guidelines was observed in $38.6 \%$ of individuals for total fat intake; $27.3 \%$ for saturated fat intake; $68.2 \%$ for protein intake; and $13.6 \%$ for fiber consumption.

\section{CONCLUSIONS}

In general, a low prevalence of accomplishment with the guidelines was found. Dietary messages should be especially directed to this population, reinforcing the need to promote better interventions.

\section{REFERENCES}

Mendes, R., Sousa, N., Almeida, A., Subtil, P., GuedesMarques, F., Reis, V. M., \& Themudo-Barata, J. L. (2015). Lifestyle intervention in type 2 diabetes: Diabetes em Movimento ${ }^{\circledR}$ communitybased exercise program. Eur J Pub Health, 5(Suppl 3), 100. doi:10.1093/eurpub/ckv170.040

Vasconcelos, C., Almeida, A., Lopes, C., \& Mendes, R. (2016). Intervenção Nutricional na Diabetes Tipo 2: Proposta de um Protocolo de Educação Alimentar. Revista Portuguesa de Diabetes, 11 (Suppl 1), 55. 


\section{Eight weeks of classic strength training are able to revert the deleterious effects of aging on different muscle strength manifestations in physically active elderly}

Osvaldo Costa Moreira ${ }^{1,2}$, Claudia Eliza Patrocínio de Oliveira ${ }^{1,2}$, José Antonio de Paz ${ }^{1}$

1. Institute of Biomedicine, University of León, Spain; osvaldo.moreira@ufv.br; 2. Department of Physical Education, Federal University of Viçosa, Brazil

\section{INTRODUCTION}

Strength training (ST) is indicated as an alternative for the promotion and maintenance of muscle strength in elderly (ACSM, 2009). However, it isn't very well clarified whether ST can revert losses in various strength manifestations caused by aging, even in people trained. The objective of the present study was to evaluate the effect of aging on different strength manifestations in physically active elderly people, and determine the effect of eight weeks of classical ST on the muscle strength of these people.

\section{METHODS}

Were evaluated 18 elderly people, aged between 70 and 78 years, physically active. The muscle strength (isometric strength, dynamic force and power) was measured at three moments. At 2013, before start the investigation (EV0), at 2016 (EV1) and after a classic ST program of eight weeks (EV2), twice a week. Evaluations were made in the thigh through the knee extension exercise. Isometric strength (IS) was evaluated by a strain gauge, the dynamic strength (DS) by the 1RM test and the power (40, 50, 6070 and $80 \%$ of 1RM) through of a linear encoder. The ST program followed the ACSM (2009) recommendations. The Friedman test with Dunn's post hoc was used for comparisons of results between the different evaluations and the Cohen ' $d$ test for measure the effect size.

\section{RESULTS}

The comparison of results in the three evaluations is shown in the Table 1 .

Table 1

Comparison of various strength manifestations in the three evaluations.

\begin{tabular}{lcccccccc}
\hline & \multicolumn{3}{c}{ EV0 } & \multicolumn{3}{c}{ EV1 } & \multicolumn{3}{c}{ EV2 } \\
& Mean & SD & ES & Mean & SD & ES & Mean & SD \\
\hline IS (Kg) & 87.58 & $22.38^{\mathrm{c}}$ & 0.26 & 83.90 & $24.78^{\mathrm{c}}$ & 0.36 & 94.18 & 28.19 \\
DS (Kg) & 79.44 & $13.12^{\mathrm{c}}$ & 0.64 & 78.00 & $23.11^{\mathrm{c}}$ & 0.70 & 94.72 & 23.79 \\
POW40\% (w) & 299.67 & $67.27^{\mathrm{b}}$ & 0.51 & 265.56 & $71.37^{\mathrm{c}}$ & 0.49 & 302.94 & 76.87 \\
POW50\% (w) & 327.17 & $88.94^{\mathrm{b}}$ & 0.58 & 275.39 & $81.04^{\mathrm{c}}$ & 0.47 & 312.33 & 78.85 \\
POW60\% (w) & 330.83 & $84.77^{\mathrm{b}}$ & 0.65 & 275.33 & $67.61^{\mathrm{c}}$ & 0.49 & 317.56 & 85.56 \\
POW70\% (w) & 315.94 & $101.35^{\mathrm{b}}$ & 0.41 & 274.33 & $81.01^{\mathrm{c}}$ & 0.29 & 299.17 & 84.31 \\
POW80\% (w) & 286.39 & 94.78 & - & 257.38 & $98.48^{3}$ & - & 272.94 & 92.96 \\
\hline
\end{tabular}

b: $\mathrm{p}<0.05$ for comparison with EV1; c: $\mathrm{p}<0.05$ for comparison with Ev2.

\section{CONCLUSION}

Three years of aging have significant impact on muscle power. However, eight weeks of classic ST are able to revert the deleterious effects of aging on different muscle strength manifestations in physically active elderly.

Funding:

Supported by Plan Nacional I+D+I DEP2013-47659, Spain.

\begin{abstract}
Aknowledgments:
Coordenação de Aperfeiçoamento de Pessoal de Nivel Superior - CAPES

Conselho Nacional de Desenvolvimento Científico e Tecnológico - CNPq
\end{abstract}

\section{REFERENCES}

American College of Sports Medicine. (2009). American College of Sports Medicine position stand. Exercise and physical activity for older adults. Medicine and Science in Sports and Exercise, 41(7), 1510-1530. 


\section{A novel hybrid additive manufacturing system for cartilage regeneration}

Pedro Morouço ${ }^{1}$, Artur Mateus ${ }^{1}$, Nuno Alves ${ }^{1}$

1. Polytechnic Institute of Leiria, Centre for Rapid and Sustainable Product Development, Portugal; pedro.morouco@ipleiria.pt

\section{INTRODUCTION}

In the last years, the world has assisted an increase in the number of debilitating conditions and severe pain caused by cartilage defects. Due to accidental traumas or a disease prevalence, the scientific and clinical community are aware of the major problem that our society is facing. These diseases are on the top list concerns of WHO, being the breakdown of articular cartilage a major health matter to which there are few effective solutions.

\section{METHODS}

One utmost challenge in Tissue Engineering is the production of $3 \mathrm{D}$ constructs capable of mimicking the functional hierarchy of native tissues. This is well stated for osteochondral tissue due to the complex mechanical functional unit based on the junction of articular cartilage and bone. An integrated system was developed with 2 main features: (i) the printing of up to 3 distinct hydrogels; (ii) in coordination with the printing of a thermoplastic structural support. The hydrogel printing module was projected with a 'revolver-like' system, where the hydrogel selection was made by a rotating mechanism. The hydrogel deposition was then controlled by pressured air input. The use of specific components approved for medical use was incorporated in the material dispensing system (Nordson EDF Optimum ${ }^{\circledR}$ fluid dispensing system).

\section{RESULTS}

After testing and upgrades, a hydrogel modulus with 3 syringes ( $3 \mathrm{~cm}^{3}$ capacity each), with a pressure range of $0-2.5 \mathrm{bar}$, a rotational speed of 0-5rpm, and working with needles from $200-800 \mu \mathrm{m}$ was obtained. This modulus was successfully coupled to the extrusion system that presented a temperature up to $300^{\circ} \mathrm{C}$, a pressure range of 0-12bar, and working with nozzles from 200-500 $\mu \mathrm{m}$. Although there are distinct printing requirements for hydrogels and polymers, the novel system was able to develop hybrid scaffolds, combining the 2 modulus. The morphological analysis showed high reliability $(n=5)$ between the theoretical and obtained filament and pore size $(350 \mu \mathrm{m}$ and $300 \mu \mathrm{m}$ vs. $342 \pm 4 \mu \mathrm{m}$ and $302 \pm 3 \mu \mathrm{m}$, respectively, $p>0.05$ ) of the polymer; and multi-material $3 \mathrm{D}$ constructs were successfully obtained.

\section{CONCLUSIONS}

Human tissues present very distinct and complex structures regarding their mechanical properties, organization, composition and dimensions. For osteochondral regenerative medicine a multiphasic scaffold is required as subchondral bone and overlying cartilage must regenerate at the same time. The developed system may give a suitable solution to construct those hybrid scaffolds with enhanced properties. The present novel system is a step-forward regarding osteochondral tissue engineering due to its ability to generate layered mechanically stable implants through the double-printing of hydrogels with thermoplastics. 


\section{Volume of physical activity and neuropathy symptoms: Could we renounce to physical exercise in the management of type 2 diabetes?}

Santos Villafaina ${ }^{1}$, Juan Fuentes ${ }^{1}$, Isabel Domínguez-Vellarino ${ }^{2}$, Maria Giménez-Guervós ${ }^{1}$, and Ricardo De la Vega ${ }^{3}$

1. Faculty of Sport Science, University of Extremadura, Cáceres; svillafa@alumnos.unex.es; 2. Health centre of Jerez de los Caballeros, Servicio Extremeño de Salud; 3. Universidad Autónoma de Madrid, Spain

\section{INTRODUCTION}

The increase in Diabetes incidence, 371 million, aggravated by physical inactivity has become in one of the major problems in modern society (Whiting et al., 2011). One of the most common complication and consequence of diabetes is the peripheral neuropathy (Maser et al., 2003). Physical exercise could improve physical fitness, reduce inflammatory markers and increase the regenerative capacity of cutaneous axons, slowing or preventing neuropathy progression (Karstoft \& Pedersen, 2016; Singleton et al., 2015).

\section{OBJECTIVE}

The aim of this research was to evaluate the levels of physical activity in patients with type 2 diabetes (T2D) and its relation with body-mass index (BMI) neuropathy symptoms, glucose levels and C-reactive protein.

\section{METHODS}

BMI, blood sample, volume of physical activity (by International physical activity questionnaire, IPAQ) and neuropathy symptoms (by Neuropathy Symptom Score, NSS) was collected for a total of 40 T2D patients (69.53 \pm 12.33 ages).

\section{RESULTS}

Total volume of physical activity significantly correlate with NSS score $(\mathrm{r}=-.405, \mathrm{p}=.012)$. Thus, light and vigorous physical activity significantly correlate with NSS score $(r=-.396$, $\mathrm{p}=.014)$ and C-reactive protein $(\mathrm{r}=.368$, $\mathrm{p}=.035)$ respectively. Sitting time correlate with BMC ( $\mathrm{r}=.384, \mathrm{p}=.019)$ and glucose levels $(\mathrm{r}=.356, \mathrm{p}=.039)$.

Table 1

Results

\begin{tabular}{lcccccccccc}
\hline & \multicolumn{2}{c}{ Light Activity } & \multicolumn{2}{c}{ Moderate Activity } & \multicolumn{2}{c}{ Vigorous Activity } & \multicolumn{2}{c}{ Sitting Time } & \multicolumn{2}{c}{ Total IPAQ } \\
& $R$ & $p$ value & $R$ & $p$ value & $R$ & $p$ value & $R$ & $p$ value & $R$ & $p$ value \\
\hline BMI & .067 & .688 & -.015 & .929 & -.008 & .962 & $.384^{*}$ & .019 & .066 & .696 \\
Glucose & .042 & .810 & -.074 & .671 & -.166 & .341 & $.356^{*}$ & .039 & .018 & .317 \\
PCR & .189 & .293 & .110 & .543 & $-.368^{*}$ & .035 & -.024 & .894 & -.143 & .429 \\
NSS & $-.396^{*}$ & .014 & -.083 & .617 & -.154 & .350 & .216 & .198 & $-.405^{*}$ & .012 \\
\hline
\end{tabular}

\section{CONCLUSIONS}

The results supports that the physical activity should have an important place in the management of T2D, having a positive impact on the neuropathy symptoms; the greater volume of physical activity, the less neuropathy symptoms. Vigorous activity may be related to lower values of C-reactive protein, involved in the diabetic neuropathy inflammatory process. Thus, physical inactivity behaviors as sitting for prolonged periods are in relation with higher levels of BMI and glucose.

\section{REFERENCES}

Karstoft, K. \& Pedersen, K. (2016). Exercise and type 2 diabetes: focus on metabolism and inflammation. Immunology and Cell Biology, 94(2), 146-50.

Maser E., Mitchell D., Vinik I. \& Freeman R. (2003). The association between cardiovascular autonomic neuropathy and mortality in individuals with diabetes-A meta-analysis. Diabetes Care, 26(6), 1895-901.

Singleton, R., Marcus, L., Lessard, K., Jackson, E., \& Smith, G. (2015). Supervised Exercise Improves Cutaneous Reinnervation Capacity in Metabolic 
Syndrome Patients. Annals of Neurology, 77(1), 146-153.

Whiting, D. R., Guariguata, L., Weil, C., \& Shaw, J. (2011). IDF diabetes atlas: global estimates of the prevalence of diabetes for 2011 and 2030.
Diabetes Research and Clinical Practice, 94(3), 311321.

https://doi.org/10.1016/j.diabres.2011.10.029

\title{
Technology to monitoring physical exercise: State of the art and future developments
}

\author{
Filipe Matos ${ }^{1,2}$, Francisco Saavedra ${ }^{1,2}$
}

1. University of Trás-os-Montes and Alto Douro, UTAD, Vila Real, Portugal; fmatos@utad.pt; 2. Research Center for Sport, Health, and Human Development, CIDESD, Vila Real, Portugal

\section{INTRODUCTION}

The aims of this study were to analyze the state of art and future developments on the monitoring technology of physical exercise and provide an in-depth discussion of technologies and outcome measures utilized.

\section{METHOD}

The research process was conducted on the "Web of Science" databases. Fourteen studies were included in the analysis after a selection process according to the following inclusion criteria: 1) Original studies about technologies to monitoring physical exercise. 2) Studies must involve humans.

\section{RESULTS}

The fourteen reviewed studies were referred to Smart Apps, Home-based Interactive Training effectiveness, the interaction Human/Robot and the effectiveness of a heart rate monitoring devices. A total of 620 subjects were investigated, 134 male, 195 female and 291 nonidentified subjects. Investigations were performed on young and older healthy adults, however, the clinical condition was not specified in some studies. Accelerometers and inertial sensors were used to capture body movement patterns, postures, counting steps and repetitions. The heart rate was also evaluated, as well as, cognitive aspects related to motivation, memory and wellbeing. Most of the reviewed studies reported positive results with respect to improvements in physical activity parameters and cognitive aspects related to motivation, memory and wellbeing.

\section{CONCLUSION}

Most of the technologies in the literature evaluate physical activity parameters, but not physical exercise. The number of controlled studies examining technologies to exercise monitoring remains small. The computer-based multimedia approaches can create a relatively individualized learning session for a client. The challenge is to properly use and apply the technology for patient learning and that the patient-provider relationship should be enhanced, not replaced.

\section{Aknowledgments:}

Macro-to-Nano Human Sensing: Towards Integrated Multimodal Health Monitoring and Analytics, NORTE-01-0145-FEDER-000016.

\section{REFERENCES}

Bertolotti, G. M., Cristiani, A. M., Colagiorgio, P., Romano, F., Bassani, E., Caramia, N., \& Ramat, S. (2016). A Wearable and Modular Inertial Unit for Measuring Limb Movements and Balance Control Abilities. IEEE Sensors Journal, 16(3), 790-797. https://doi.org/10.1109/JSEN.2015.2489381

Bleser, G., Steffen, D., Weber, M., Hendeby, G., Stricker, D., Fradet, L., ... Carré, F. (2013). A personalized exercise trainer for the elderly. Journal of Ambient Intelligence and Smart Environments, 5(6), 547-562. 


\section{A gerontopsychomotor rehabilitation program can revert losses of motor and cognitive functioning on nursing home residents}

Hugo Rosado1, José Marmeleira ${ }^{1,2}$, Ana Cruz-Ferreira ${ }^{1,2}$, Catarina Pereira ${ }^{1,2}$

1. Departamento de Desporto e Saúde, Escola de Ciências e Tecnologia, Universidade de Évora, Évora, Portugal; hugo rosado9@hotmail.com; 2. Research Center for Sport, Health, and Human Development, CIDESD, Portugal

\section{INTRODUCTION}

European Union older adults number and old-age-dependency has increased (Eurostat, 2015). A frequent answer for their care needs is nursing home admission, although this solution tends to exacerbate older adults losses of cognitive and motor functioning (Frandin et al., 2016).

\section{OBJECTIVE}

To analyze the effect of a psychomotor intervention, accomplished by a multimodal exercise program alternating exercises mainly motor with exercises mainly cognitive, on executive and physical function of nursing homes residents.

\section{METHODS}

This study included 34 nursing home residents $(82.4 \pm 6.3 \mathrm{yrs}): 17$ were allocated to the experimental group (EG: engaged on a 10weeks multimodal exercise program), and 17 to a control group (maintained usual activities). Planning ability and selective attention were assessed by the Tower of London task and the attention Test $\mathrm{d} 2$, respectively. Physical function was assessed by the Senior Fitness Test and the Performance Oriented Mobility Assessment.

\section{RESULTS}

Comparison between groups evidenced that the EG improved planning ability variables from
$25 \%$ to $32 \%$, attention variables from $19 \%$ to $67 \%$, and physical function variables (aerobic endurance, lower body strength, agility, balance, gait, and mobility) from $11 \%$ to $41 \%(\mathrm{p}<0.05)$, corresponding to an effect size ranging from 0.29 to 1.11 .

\section{CONCLUSIONS}

The program induced improvements in the participants' executive functions (planning ability and attention) and physical functions, with a treatment effect from small to high. This shows that the psychomotor intervention was able to revert the usual loss of cognitive and motor functioning in old and very old institutionalized persons.

\section{REFERENCES}

Eurostat. (2015). Sustainable Development in the European Union. 2015 monitoring report of the EU Sustainable. Development Strategy. Retrieved from http://ec.europa.eu/eurostat/documents/32174 94/6975281/KS-GT-15-001-EN-

N.pdf/5a20c781-e6e4-4695-b33d-9f502a30383f

Frandin, K., Gronstedt, H., Helbostad, J. L., Bergland, A., Andresen, M., Puggaard, L. (2016). LongTerm Effects of Individually Tailored Physical Training and Activity on Physical Function, Well-Being and Cognition in Scandinavian Nursing Home Residents: A Randomized Controlled Trial. Gerontology, In Print. doi: 000443611 [pii] 10.1159/000443611 


\title{
Effects of Pilates-based exercises on immediate pain in older people with persistent non-specific low back pain
}

\author{
Pablo Tomas-Carus 1,2, Vanda Silva ${ }^{3,4}$, Iolanda Marques $^{3}$, José Parraca1,2, Armando \\ Raimundo ${ }^{1,2}$, Clarissa Biehl-Printes ${ }^{5}$ \\ 1. Departamento de Desporto e Saúde, Escola de Ciência e Tecnologia, Universidade de Évora, Évora, Portugal; ptc@uevora.pt; \\ 2. Research Centre in Sports Sciences, Health Sciences and Human Development, CIDESD, University of Évora, Evora, Portugal; \\ 3. Unidade de Saúde Familiar Quinta da Prata, Borba, Portugal; 4. Unidade de Saúde Familiar Lusitânia, Évora, Portugal; 5. \\ Instituto de Geriatria e Gerontologia, IGG, Pontifícia Universidade Católica do Rio Grande do Sul, PUCRS, Porto Alegre, Brasil.
}

\section{INTRODUCTION}

The low back pain is the most documented sort of vertebral column`s pain, it may affect almost $84 \%$ of the people at some point of their life (Airaksinen et al., 2006). This study aimed to determine the immediate changes of Pilatesbased exercises program on pain (before vs. after session) in older people with persistent nonspecific low back pain.

\section{METHODS}

Fifteen older people (age 65.5 \pm 3.5 years; body mass index $28.1 \pm 5.4 \mathrm{~kg} / \mathrm{m} 2$; specific pain drugs $1.1 \pm 1.0$ number) with persistent nonspecific low back pain were selected to participate in a 12 weeks (2sessions/week 60minutes/session) Pilates-based exercises program. The Portuguese version of The Keele Start Back Screening Tool (Raimundo et al., 2016) was used as inclusion criteria (medium and high risk were included). Pain was assessed with Visual Analogue Scale before and after each single session (i.e., 24 sessions).

\section{RESULTS}

Immediate benefits (pre-post session) were observed on pain with decrease $\approx 20 \%$ at $4^{\text {th }}, 6^{\text {th }}$, $7^{\text {th }}$, and $10^{\text {th }}$ sessions. No significant differences pre-post were showed before $4^{\text {th }}$ and after $11^{\text {th }}$ session. There were significant accumulative differences (pre session) on pain between $1^{\text {st }}$ session and all sessions after $8^{\text {th }}$ session.

\section{CONCLUSIONS}

Pilates-based exercises program (2 times/week) led to a positive immediate decrease in the level of pain in older people with persistent non-specific low back pain after the second week. From the second month of the intervention the pre session pain decreases compared with the pain on the first session. So, only from the second month the patients begin the practice without pain and the intervention goes to a maintenance stage.

\section{REFERENCES}

Airaksinen, O., Brox, J.I., Cedraschi, C., Hildebrandt, J., Klaber-Moffett, J., Kovacs, F.,...COST B13 Working Group on Guidelines for Chronic Low Back Pain. (2006). European guidelines for the management of chronic nonspecific low back pain. European Spine Journal, 15, S192-S300.

Raimundo, A., Parraça, J., Batalha, N., Tomas-Carus, P., Branco, J., Hill, J., \& Gusi, N. (2016). Portuguese translation, cross-cultural adaptation and reliability of the questionnaire "Start Back Screening Tool" (SBST) for evaluation and screening of low back pain. Acta Reumatológica Portuguesa, Aug 25, |Epub ahead of print|

\section{Mitochondria function in old institutionalized subjects with and without Alzheimer disease}

Maria Paula Mota ${ }^{1,2}$, Cecília Gabriel $^{1}$ e Vanessa Almeida ${ }^{1}$

1. Universidade de Trás-os-Montes e Alto Douro; mpmota@utad.pt; 2. Research Centre in Sports Sciences, Health Sciences and Human Development, CIDESD

\section{INTRODUCTION}

The longevity of the developed countries has increased and with it the frequency of degenerative diseases. Alzheimer's disease (AD) has a high incidence (60 to $70 \%$ ) and is characterized by a progressive deterioration of 
the brain associated with the accumulation of amyloid plaques and neurofibrillary tangles (Oddo, 2012). AD causes progressive and irreversible deterioration of various cognitive functions, including memory, attention, concentration, language, thinking and behaviour (Burns \& Iliffe, 2009). The loss of autonomy of the elderly is aggravated in the cases of $A D$, which often culminates in institutionalization. While the major risk factor for $\mathrm{AD}$ is age, the process is distinguished from normal aging. Although there are common changes and manifestations, probably supported by similar molecular and cellular changes, in $\mathrm{AD}$ brain aging process is aggravated. Literature have attributed an important role to oxidative stress and mitochondrial alterations either in the aging process or the AD. Thus, this study aims to understand the changes associated with normal aging process in mitochondria function and to identify some of the key differences in individuals with $\mathrm{AD}$.

\section{METHODS}

The sample was composed by 14 normal old subjects (80.5 \pm 7.7 years) and $11 \mathrm{AD}(83.2 \pm 7.7$ years) participated in this study. All the subjects were institutionalized and the diagnose of $\mathrm{AD}$ was in charge of a clinical Neurologist. After 9 hours of fasting condition, $10 \mathrm{ml}$ of of blood were collected by venous puncture into the vacuum $\mathrm{K}_{3}$ EDTA tubes and then centrifuged to separate serum, and to obtain lymphocytes. Mitochondria function [respiration in state 3 and state 4 , and respiratory control ratio $(\mathrm{RCR}=$ state $3 /$ state 4$)]$ were measured in lymphocytes cells in
OROBOROS, according to the equipment procedures. Malondialdehyde (MDA) was assayed in serum samples by spectrophotometic method. Protein content was determined by Biureto method. To compare average values of both groups, a t-test for independent samples was used. Significance level was set a 0.05.

\section{RESULTS}

The obtained results failed to found significant differences between groups in mitochondria respiration in states $3(1.77 \pm 0.67$ and $1.80 \pm 1.07$ for normal and $\mathrm{AD}$, respectively) and $4(0.56 \pm 0.33$ and $1.55 \pm 0.77$ for normal and AD subjects, respectively). Significant changes between groups were found in RCR $(3.76 \pm 1.54$ and $2.33 \pm 1.36$ for normal and $\mathrm{AD}$, respectively) $(\mathrm{t}=2.553 ; \mathrm{p}=0.017)$ and in serum MDA $(15.796 \pm 4.098$ and $11.169 \pm 4.459$ for normal and $A D$, respectively $(t=2.230 ; p=0.041)$.

\section{CONCLUSIONS}

These results revealed that comparatively with AD, normal aged subjects' evidence "healthy" mitochondria once they show high respiratory control (RCR). Nevertheless, the amount of oxidative stress damage (MDA) was higher in normal old subjects, possibly due to the influence of other unconsidered variables (medication, diet and daily physical activity).

\section{REFERENCES}

Burns, A. \& Iliffe, S. (2009). Alzheimer's disease. BMJ. 338: b158.

Oddo, S. (2012). The role of mTOR signaling in Alzheimer disease. Front Biosci (Schol Ed), 4: 94152 .

\section{2-Years of Physical Exercise and Hypertension}

Luis Leitão ${ }^{1}$, Ana Leitão ${ }^{2}$, Hugo Louro ${ }^{3}$

1. Superior School of Education of Setúbal, Portugal; luis.leitao@ese.ips.pt; 2. Faculty of Medicine of Masaryk University of Brno, Czech Republic; 3. Sport Sciences School of Rio Maior, Portugal

\section{INTRODUCTION}

Prevention of cardiovascular disease through physical exercise is very important on preventing disease and quality of life of older adults. The risk factors for this decease like high blood pressure, high cholesterol, overweight and obesity, diabetes mellitus, and physical inactivity can be changed through exercise (AHA, 2005; Castelli, 1984; Chodzko-Zajko et al., 2009). As main purpose of the study we intend to evaluate the effects of training and detraining during two 
years of an exercise program in blood pressure and resting heart rate of older adults.

\section{METHODS}

Fifty one women (70.2 \pm 6.4 years and $159.54 \pm 12,81 \mathrm{~cm}$ ) volunteered to participate in a 2-year exercise program with periods of nine months of physical exercise followed by a period of three months of detraining. The multicomponent program was prescribed according to ACSM (Chodzko-Zajko et al., 2009) and conducted by a specialist in older adults training. Each training period consisted in aerobic and muscle endurance group sessions held two days per week with forty-five minutes each session. All subjects were tested 5 times, before and after each training period and at the end of the detraining periods.

\section{RESULTS}

Blood pressure improved significantly only at the end of the program, besides resting heart rate improved right after the first period of exercise. Each detraining period resulted in deterioration of each variable. With the end of the program significant improvements were achieved in all variables of the study.

Table 1

Hemodynamic parameters in training and detraining periods

\begin{tabular}{lccccc}
\hline & E-01 & E-02 & E-03 & E-04 & E-05 \\
\hline Weight $(\mathrm{Kg})^{1.2}$ & $71.92 \pm 8.98$ & $70.78 \pm 8.86$ & $71.2 \pm 8.88$ & $69.28 \pm 8.7$ & $69.74 \pm 8.93$ \\
BMI $\left(\mathrm{m}^{2} / \mathrm{kg}\right)^{1.2}$ & $29.67 \pm 3.96$ & $29.50 \pm 3.90$ & $29.66 \pm 3.91$ & $28.6 \pm 3.87$ & $29.05 \pm 3.90$ \\
Systolic P $(\mathrm{mmHg})^{2}$ & $144 \pm 17.75$ & $139 \pm 14.13$ & $143 \pm 13.1$ & $137 \pm 12.19$ & $140 \pm 12.53$ \\
Diastolic P (mmH) $^{2}$ & $82 \pm 10.41$ & $76 \pm 8.46$ & $82 \pm 9.95$ & $75 \pm 9.31$ & $79 \pm 10.34$ \\
Resting HR (bpm) $^{1.2}$ & $77 \pm 7.69$ & $70 \pm 9.21$ & $74 \pm 8.13$ & $70 \pm 8.61$ & $74 \pm 8.62$ \\
\hline
\end{tabular}

${ }^{1}$ significant differences in the first year program ( $\left.\mathrm{p} \leq 0.05\right)$;

${ }^{2}$ significant differences between the beginning and the end of the program $(p \leq 0.05)$;

\section{CONCLUSIONS}

The results of this study shows that nine months of physical exercise weren't enough to improve blood pressure and three months reduce significantly the benefits achieved with training. This study reveal that physical exercise must be taken through the life span of the olders to maintain the benefits of exercise and reduce the impact of the risk factors of this decease.

\section{REFERENCES}

AHA. (2005). Recommendations for Blood Pressure Measurement in Humans and Experimental
Animals: Part 1: Blood Pressure Measurement in Humans. A Statement for Professionals from the Subcommittee of Professional and Public Education of the American Heart Association Council on High Blood Pressure Research, 45, 142-161.

Castelli, W. (1984). Epidemiology of coronary heart disease: the Framingham study. American Journal of Medicine, 27, 4-12.

Chodzko-Zajko, W.J., Proctor, D.N.,Fiatarone Singh, M.A.,Minson, C.T., Nigg, C.R., Salem, G.J., \& Skinner, J.S. (2009). American College of Sports Medicine position stand. Exercise and Physical Activity for Older Adults. Medicine $\mathcal{E}$ Science in Sports \& Exercise, 41(7), 1510-1530. doi. 10.1249/MSS.0b013e3181a0c95c.

\section{Impact of a psychomotor massage program on the quality of life of institucionalized elderly people}

Gisela Roque, ${ }^{1}$ Catarina Pereira ${ }^{1,2}$; Guida Veiga ${ }^{1,2}$

1. Departamento de Desporto e Saúde, Escola de Ciências e Tecnologia, Universidade de Évora, Portugal; gisela.cr.roque@gmail.com; 2. Research Center in Sports Sciences, Health and Human Development, CIDESD, Portugal

\section{INTRODUCTION}

The world's population is ageing (United Nations, 2015). Therefore the number of older people who are dependent on others, who have reduced mobility and physical and/or mental health problems, has been progressively increasing. These scenarios often lead to institutionalization, which has been associated with the loss of quality of life (Luppa, et al., 
2009). So, our objective was to analyze the effect of a therapeutic intervention based on psychomotor massage on quality of life indicators of institutionalized elderly people.

\section{METHODS}

The present study included 13 participants aged 63-94 years, without severe cognitive impairment, residing in a nursing home. First, participants (control group) maintained their daily life activities for 4 weeks. Second, participants (experimental group) attended the intervention, two days a week for a period of 8 weeks. The therapeutic intervention program was based on 30-minute sessions of psychomotor massage. Four weeks after the intervention, there was a follow-up. Physical mobility, pain, energy, emotional reactions, sleep and social isolation were assessed through the Nottingham Health Profile questionnaire.

\section{RESULTS}

Participants reported significant improvements in pain $(\mathrm{p}<.001)$, physical mobility $(p=.049)$, energy $(p=.012)$, emotional reactions $(p=.002)$, sleep $(p=.017)$, social isolation $(\mathrm{p}=.013)$, and health status $(\mathrm{p}=.001)$.

\section{CONCLUSIONS}

This study represents a first approach to the application of a psychomotor massage technique as a therapeutic intervention in nursing homes for the elderly. The method appears to be effective in enhancing health and quality of life of institutionalized elderly persons. This psychomotor technique could be considered as an option for achieving health benefits with a low cost for nursing homes, but further studies using this technique in larger samples are needed to confirm the trends observed in the present study.

\section{REFERENCES}

Luppa, M., Luck, T., Weyerer, S., König, H.-H., Brähler, E., \& Riedel-Heller, S. G. (2009). Prediction of institutionalization in the elderly. A systematic review. Age and Ageing, 1-8. doi:10.1093/ageing/afp202

United Nations. (Dezembro de 2015). World population ageing 2015 highlights. Obtido de https://shop.un.org/books/world-popuageing-2015-highlights-47737

\section{Effects of a multimodal exercise program on cognitive functioning and physical fitness of nursing home residents}

Luís Galhardas ${ }^{1}$, Armando Raimundo ${ }^{1,2}$, José Marmeleira ${ }^{1,2}$

1. Departamento de Desporto e Saúde, Escola de Ciências e Tecnologia, Universidade de Évora; galhardas.luis@hotmail.com; 2. Research Center in Sports Sciences, Health Sciences and Human Development, CIDESD

\section{INTRODUCTION}

Physical activity is an important strategy to promote successful aging, being associated with several health benefits and a reduction in risk of all-cause mortality. In recent years there has been a growing interest in the study of the effects of multimodal exercise in the functional capacity of older adults (e.g., Vaughan et al., 2014), but the investigation is still scarce. Therefore, the objective of this study was to investigate the effects of a multimodal exercise program on cognitive functioning and physical fitness of nursing home residents.

\section{METHOD}

Participants were selected by convenience among two nursing home residents. Twenty-one people (77-92 years old) of both genders participated. During the first 4 weeks of the study participants continued their normal daily life activities and were not engaged in the exercise program. After the control period, the group was engaged in a multimodal exercise program for 8 weeks ( 2 times per week). The exercise sessions alternated between periods of motor tasks and periods of motor-plus-cognitive tasks. To study the effects of the multimodal exercise program, data were collected at three different times: prior to the control period, after the control period (and before the beginning of 
intervention), and at the end of the intervention. A number of motor tests (physical fitness), cognitive tests and dual-tasks (motor-cognitive) were performed. All parameters were compared between the three evaluations using the nonparametric Friedman Test. Post-hoc comparisons were performed using the Wilcoxon Signed-Rank Test with Bonferroni adjustment to compensate for the multiple comparisons.

\section{RESULTS}

The analysis of the data collected in the three moments of evaluation, showed statistically significant effects of the exercise program in cognitive dimensions (information processing speed and attention) and functional physical fitness components (muscle resistance, cardiorespiratory fitness and dynamic balance).
In the tests carried out in dual-task conditions, the exercise program promoted significant improvements in the "timed up and go test" (with mental calculations).

\section{CONCLUSIONS}

The results of this study demonstrate that a multimodal exercise program can improve cognitive functioning and functional physical fitness in institutionalized older people. Thus, this type of intervention should be promoted among nursing home residents.

\section{REFERENCES}

Vaughan, S., Wallis, M., Polit, D., Stele, M., Shum, D. \& Morris, N. (2014). The effects of multimodal exercise on cognitive and physical functioning and brain-derived neurotrophic factor in older women: a randomized controlled trial. Age and Ageing 43, 623-629. doi: 10.1093/ageing/afu010

\section{The influence of physical fitness levels on BMI and obesity in students from 10 to 11 years old}

Júlio Martins ${ }^{1,2}$, João Cardoso ${ }^{1}$, Samuel Honório ${ }^{3}$

1. Sports Science Department, University of Beira Interior, Covilhã, Portugal; 2. Research Center in Sports Sciences, Health Sciences and Human Development, CIDESD; 3. Instituto Politécnico de Castelo Branco, RECI; samuelhonorio@hotmail.com

\section{INTRODUCTION}

The study purpose intends to verify the influence of levels of Physical Fitness, Body Mass Index (BMI) and obesity among 10-11 years old students. These students were divided into groups: students that only practise Physical Education ( $\mathrm{G} 1 ; \mathrm{n}=98)$, students that practise Physical Education and Sports in School (G2; $\mathrm{n}=94)$, and students that practise Physical Education and Federated Sports $(\mathrm{G} 3 ; \mathrm{n}=101)$.

\section{METHODS}

The sample had 293 students (113 female/180 male). The data was obtained from Physical Education teachers and Fitnessgram tests. The statistic procedures used were SPSS 20.0 with descriptive analysis using mean and standard deviation in each group. The nonparametric test of Mann-Whitney to compare groups between $G_{1}(P E), G_{2}(P E+S S)$ and $G_{3}$
$(\mathrm{PE}+\mathrm{FS})$, the Kruskal-Wallis and Wilcoxon tests for paired samples.

\section{RESULTS}

The results showed that boys revealed better physical fitness in the "Mile" test, "Abs" and "Arm extensions" tests, while girls revealed better in the flexibility tests. Both genders and groups, revealed an unsuccessful rate in "Abdominal" and "Arms Extensions" tests. The remaining tests showed some success, but not significant. $G_{3}$ students are those with better results, students of the $G_{2}$ are those with the highest failure rates. In body composition females presented their IMC average inside the "healthy zone", except for students of 10 years in $G_{3}$, the students aged 11 in $G_{1}$ and students of the $G_{2}$ at the same age, but only in the 2 nd data collection. All males practitioners showed values "Inside healthy zone" except in $G_{2}$ for students with 11 years in the $1^{\text {st }}$ data collection. Girls of 
the $G_{2}$ are the ones with the best results in all tests, unlike the students of $G_{1}$ and $G_{3}$. Boys of $G_{1}$ and $G_{3}$ were those who showed the best results in all tests.

\section{CONCLUSIONS}

Students who practice federated sports and Physical Education $\left(G_{3}\right)$, showed better results in the Fitnessgram test battery, in both genders.

\section{REFERENCES}

Bouchard, C. (2000). Physical Activity and Obesity. Champaign, IL: Human Kinetics Publishers.
Campbell, K.; Waters, E.; Ómeara, S., \& Summerbel, C. (2001): "Interventions for preventing obesity in childhood. A systematic review, in: Obesity Reviews, 2, 149-157; New York, USA.

Cole, T.; Bellizzi, M.; Flegal, K.; Dietz, W. (2000): "Establishing a Standard definition for children overweight and obesity wordwide: International Survez, in: BMJ Journal. 320, 120-1245

Rocha, A. \& Pereira, B. (2006). Avaliação da Aptidão Física e da Actividade Física Associada à Saúde em Crianças de 10 Anos de Idade. In: Pereira BO \& Carvalho GS (coordenadores), Educação física, saúde e lazer: a infância e estilos de vida saudáveis. Lisboa: Lidel; p. 165-176

\section{The effects of a multicomponent training on body composition and functional fitness in breast cancer women patients}

Raúl Bartolomeu ${ }^{1}$, Vanessa Barros ${ }^{2}$, Carla Peixoto ${ }^{2}$, António Miguel Monteiro ${ }^{2}$

1. University of Trás-os-Montes e Alto Douro, Vila Real, Portugal; rfbartolomeu@gmail.com; 2. Polytechnic Institute of Bragança, Bragança, Portugal

\section{INTRODUCTION}

Breast cancer is the most common cancer type between women (IARC \& WHO, 2015). Its treatment can lead to various changes in woman's body reducing their quality of life. Places that promote specific physical activity (PA) for this population are virtually nonexistent. Thus, the aims of this study were to assess the viability of a common PA program for women both healthy and whom suffered from breast cancer, and the effects of a multicomponent training in body composition (BC) and functional fitness (FF) of women with a recent episode of breast cancer.

\section{METHODS}

The sample consisted of 40 women, with between 59 and 65 years, 20 with a recent episode of breast cancer and 20 clinically healthy. The first 20 women were randomly assigned into two different groups, the breast cancer experimental group (BCEG) and breast cancer control group (BCCG). The second 20 women were recruited to two different groups, 10 to the healthy women experimental group (HEG) and 10 to the healthy woman control group (HCG). All 40 women were sedentary for the past 12 months. The multicomponent program was held twice a week for 15 weeks, with each training session having a duration of 60 minutes, divided into 30 minutes of aerobic training and 30 minutes of muscular strength training. FF was assessed using the Funtional Fitness Test (FFT) (Rikli \& Jones, 2001), and BC using a bioimpedance scale (TANITA BC-545).

\section{RESULTS}

In HEG, there have been significant improvements in the percentage of body fat $(\% \mathrm{BF}, \mathrm{p}=0,14)$, visceral fat $(\mathrm{p}=0,21)$ and bone mass $(p=0,008)$ and in all the six tests of FFT (arm curl, $\mathrm{p}=0,045 ; 2$-minutes step test, $\mathrm{p}=0,023$; seat and reach $\mathrm{p}=0,006$; up \& go, $\mathrm{p}=0,001$; chair stand, $\mathrm{p}=0,034$; back scratch, $\mathrm{p}=0,006)$. In $\mathrm{BCEG}$, there have been significant improvements in body mass ( $\mathrm{BdM}, \mathrm{p}=0,000)$ and \%BF $(p=0,000)$ and also in FFT's seat and reach $(p=0,000)$, up \& go $(p=0,005)$, chair stand $(p=0,000)$ and back scratch $(p=0,007)$ tests. Neither BCCG nor HCG shown any significant variation in $\mathrm{BC}$ or FFT values.

\section{CONCLUSION}

For both groups, BCEG and HEG, the multicomponent training program elicited improvements in body composition and functional fitness. Therefore, woman with recent history of breast cancer can engage the same 
fitness program of clinically healthy woman without jeopardize the improvements of any groups.

\section{REFERENCES}

International Agency for Research on Cancer, \& World Health Organization. (2015). Globocan
2012: Estimated Cancer Incidence, Mortality and Prevalence Worldwide in 2012. Retrieved September 30, 2016, from http://globocan.iarc.fr/Pages/fact_sheets_cance r.aspx

Rikli, R. \& Jones, C.. (2001). Senior fitness test manual. Champaign, IL: Human Kinetics

\title{
Physical Education curriculum, physical fitness and the promotion of an active life style
}

\author{
Fernando Vieira ${ }^{1,2}$, Francisco Carreiro da Costa ${ }^{3,4}$
}

1. Piaget Institute of Almada; Almada, Portugal; fernando.vieira@almada.ipiaget.pt; 2. Research in Education and Community Intervention, RECI; 3. Faculty of Physical Education and Sport, Lusofona University, Lisbon, Portugal; 4. Interdisciplinary Centre for the Study of Human Performance, CIPER, FMH-UL

\section{INTRODUCTION}

The curriculum approach and teachers' knowledge about Physical Fitness (PF) are two effective contributions to promote active students. The aim of this study was to understand the curriculum that is offered at the school in the PF concerns: (1) Planning; (2) Teaching and (3) Assessment.

\section{METHODS}

The OCEF-VS (Curricula Offer in Physical Education-Healthy Life) is a questionnaire that measures the operational curriculum in PE and the content of the development processes, evaluation and maintenance of PF. The OCEF-VS was applied in 79 secondary schools in Lisbon Area. The responses of 352 teachers was analysed in relation to PF. Teachers are aged between 22 and 59 years and $85.5 \%$ of them have more than 5 years of experience in teaching.

\section{RESULTS}

(1) $91.8 \%$ of teachers surveyed use the Fitnessgram as battery of tests for Physical Fitness. (2) A significant proportion of teachers of the sample (54.3\%) seems not to individualize the training of Physical Fitness. $46.6 \%$ does not implement 'progress contracts with the students' and $33.1 \%$ does not take into account the objectives of the latter. $54.3 \%$ does not use the results of tests of physical fitness to develop an individualized plan for Physical Activity. 34.1\% does not prescribe exercise in an individual way depending on the results of the Tests of Physical Fitness. (3) $39.7 \%$ of the teachers think there is enough time to implement a good program of development of Physical Fitness in Physical Education classes, while $60.2 \%$ think there isn't such time. (4) $87.8 \%$ of the teachers explain to their students the significance of the results obtained in the physical fitness test, although they do not share them with their parents (62.2\%). (5) Regarding the Educational Assessment of this area in the course of physical education, for $60.5 \%$ of the teacher's sample, values in the healthy zone of fitness physics are a reference in this assessment. There is a wide variety of criteria for the percentage allocated to this endpoint, ranging from $0 \%$ up to $75 \%$.

\section{CONCLUSIONS}

The Operational curriculum of physical fitness has proved to be much different among schools. Teachers value differently the area of PF and operationalize this goal in different ways.

\section{REFERENCES}

World Health Organization (2015). Physical activity strategy for the WHO European Region 20162025. Vilnius, Lithuania, $14-17$ September 2015.

Vieira, F. (2015). As Orientações Educacionais dos Professores, o Currículo e a Promoção de Estilos de Vida Ativos em Educação Física. Tese de Doutoramento. Universidade de Lisboa, FMH. 


\title{
The influence of extracurricular physical activities in cardiorespiratory fitness and body composition of $5^{\text {th }}$ grade students
}

\author{
Jéssica dos Santos Barbosa ${ }^{1}$, Fernando António Rodrigues Vieira ${ }^{1}$, Marta Sofia Dias e \\ Sousa ${ }^{1}$, Paulo Nuno Vieira ${ }^{2}$ \\ 1. Piaget Institute of Almada; Almada, Portugal; jessica.snts.barbosa@gmail.com; 2. Universidade Europeia, Lisboa.
}

\section{INTRODUCTION}

The World Health Organization recommends that physical activity should be practiced daily, mostly aerobics (WHO, 2010) and part of it should be practiced in schools (CNAPEF. 2013). However, studies have shown a sharp decline in the practice of physical activity. The participation of adolescents in popular sports have reduced as well and the operationalization of physical education classes have not had the attention and importance it really deserves (Matos et al. 2003 cited by Wang et al., 2006). The low level of physical activity is directly related to obesity, and it's being discussed nationally and internationally (cited by Wang et al., 2006). This fact require a greater curricular investment, but also extracurricular in order to complement the recommended daily practice.

\section{METHODS}

With the intent of understanding the influence of Extracurricular Physical Activity (ECPA) Practice in healthy students, more specifically, in cardiorespiratory fitness and body composition (BMI). Fifty one students of the fifth grade were selected as sample and were submitted to a few tests from the Fitnessgram battery tests. The data collection was performed at two different times, the beginning and the end of the school year.

\section{RESULTS}

Results showed that between students who practiced ECPA there were no statistical significant differences in both variables, genre and practice time. Statistical significance was reached in the frequency of practice and the variable practice or no practice of ECPA. The students that practiced ECPA obtained better results in both variables, cardiorespiratory fitness and BMI.

\section{CONCLUSIONS}

Physical education is part of the solution against physical inactivity, however extracurricular activities also play a role on the solution. This leads us to believe that the practice of extracurricular physical activity is a complement of the daily physical activity and it affects positively the health of students and promotes active and healthy habits.

\section{REFERENCES}

Wang, G., Pereira, B. \& Mota, J. (2006). A Atividade Física das crianças e a Condição física relacionada com a saúde: Um estudo de caso em Portugal. In B. Pereira \& G. S. Carvalho (Coord.) Educação Física, Saúde e Lazer: A infância e estilos de vida saudáveis (pp. 141-149). Lisboa: LIDEL Edições técnicas, Lda.

Organização Mundial de Saúde (2010). Global Recommendations on Physical Activity for Health. Geneva: WHO. Disponível a partir de: http://www.who.int/dietphysicalactivity/factsh eet_recommendations/en/

Costa, J. (2013). Estudo Norte-Americano reforça impacto da Educação Física e da Atividade Física. Conselho Nacional das Associações de Professores e Profissionais de Educação Física. Retrieved from https://cnapef.wordpress.com/2013/06/17/est udo-norte-americano-reforca-impacto-daeducacao-fisica-e-da-atividade-fisica/ 


\title{
Relationship between functional physical fitness, physical activity level and health related quality of life in sedentary older women
}

\author{
Carla Pires ${ }^{1}$; Luis Páez ${ }^{2}$; Borja Sañudo,2; Armando Raimundo, ${ }^{3,4}$; Catarina Pereira ${ }^{3,4}$
}

1. Instituto Superior Manuel Teixeira Gomes, Portugal; cpires74@gmail.com; 2. Universidad de Sevilla; 3. Departamento de Desporto e Saúde, Escola de Ciências e Tecnologia, Universidade de Évora, Évora, Portugal; 4. Research Center in Sports Sciences, Health and Human Development, CIDESD, Portugal

\section{INTRODUCTION}

Physical Activity (PA) and physical and functional fitness contribute to a better Health Related Quality of Life (HRQL) among older individuals (Physical Activity Guidelines Advisory, 2008). However, only precise field diagnosis will allow governmental institutions to take decisions about the implementation of physical exercise programs. Thus, this study aimed to characterize a representative sample of the Portuguese Algarvian west sedentary older women population, regarding functional physical fitness, PA and HRQL. Moreover, the study examine the associations between these variables in the studied population.

\section{METHOD}

This observational, descriptive, analytical and cross-sectional study included 422 sedentary older women (75.51 \pm 7.37 years old) living in the Algarvian west. Evaluations comprised body mass index (BMI), waist circumference (WC), levels of strength (dynamometry), aerobic fitness (6-minute walk test), PA level (modified Baecke questionnaire) and the HRQL ("Medical Outcomes Study 36 Item Short-Form Health Survey" questionnaire).

\section{RESULTS}

Significant differences were detected between individuals presenting normal weight versus overweight versus obese with respect to physical function $\left(\mathrm{p}=0.020 ; \eta^{2}=0.023\right)$, bodily pain $\left(p=0.000 ; \eta^{2}=0.051\right)$, general health $(p=0.007$; $\left.\eta^{2}=0.003\right)$, vitality $\left(p=0.002 ; \eta^{2}=0.034\right)$, and physical component $\left(p=0.001 ; \eta^{2}=0.002\right)$ of HRQL, in which the obese group showed the worst results, and the normal weight the best results. There were also differences between individuals presenting higher versus lower cardiovascular risk (CV) in physical performance $\left(\mathrm{p}=0.020 ; \mathrm{\eta}^{2}=0.011\right)$, bodily pain $(\mathrm{p}=0.000$; $\left.\eta^{2}=0.042\right)$, vitality $\left(p=0.003 ; \eta^{2}=0.021\right)$, social function $\left(\mathrm{p}=0.023 ; \mathrm{\eta}^{2}=0.017\right)$, and in physical $\left(\mathrm{p}=0.001 ; \mathrm{n}^{2}=0.001\right)$ and mental components $\left(p=0.010 ; \eta^{2}=0.000\right)$ of HRQL, with the lower $\mathrm{CV}$ group showing the best results. Correlations analysis showed significant associations between the studied variables for normal weight, overweight and obese groups, in which the strongest correlation was between aerobic fitness and the dimension physical function of HRQL in the obese group $(r=0.735)$.

\section{CONCLUSIONS}

Higher weight or a wider WC implies a worse HRQL, but obese individuals with better aerobic fitness, have fewer physical limitations in carrying out activities.

\section{REFERENCES}

Physical Activity Guidelines Advisory (2008). Physical Activity Guidelines Advisory Committee Report. Health (San Francisco). Washington, DC: U.S.: Department of Health and Human Services. 


\section{Comparison of different indirect methods for assessing body fat in children}

Sandro F. Silva ${ }^{1}$, Giancarla A. B. Santos ${ }^{1}$, Claudia E. P. Oliveira ${ }^{2,3}$, Osvaldo C. Moreira ${ }^{1,3,4}$

1. Grupo de Estudo e Pesquisa em Respostas Neuromusculares, GEPREN, Universidade Federal de Lavras, UFLA, Brasil; sandrofs@def.ufla.br; 2. Departamento de Educação Física, Universidade Federal de Viçosa, UFV, Viçosa, MG, Brasil; 3. Instituto de Biomedicina, Universidad de León, ULe, León, España; 4. Instituto de Ciências Biológicas e da Saúde, Universidade Federal de Viçosa Campus Florestal, Florestal, MG, Brasil

\section{INTRODUCTION}

Obesity is increasing in children and adolescents and that becomes a concern evident to the public health (Cerqueira et al., 2013). The aim is to compare 3 methods doubly indirect to detect the body fat in children and check what methods super or underestimate the body fat.

\section{METHODS}

Participated in the sample 90 children of both genders, being 33 males and 57 females, with an average age of $9.45 \pm 0.72$ years. The evaluations to estimate body fat were performed by 3 methods: 1) By The method of bioelectrical impedance analysis (BIA); 2) Methods of skinfolds (SM) calculated by the equation of Lohmman et al., (1987); and 3) by new method of the body adiposity index (BAI), was calculated as proposed by Bergman et al. (2011).

\section{RESULTS}

The BIA has shown an average of body fat of $20.35 \pm 8.90 \%$, the SM $23.51 \pm 11.27 \%$ and the BAI $24.70 \pm 4.47 \%$, which represented a significant difference between the BIA x SM and BIA $x$ BAI. The BIA underestimated body fat in relation to the other 2 methods in the sample assessed, which may represent a limitation of the instrument to assess children.

\section{CONCLUSION}

Thus, it's suggested that new studies are conducted considering the level of physical activity and the level of maturity of children on the anthropometric measures suggested, more specifically on the BAI and BIA., and can compare these methods with the analysis of the gold standard of body composition, Dual Energy X-ray (DEXA).

\section{Funding:}

Fundação de Amparo à Pesquisa do Estado de Minas Gerais - FAPEMIG

\section{REFERENCES}

Cerqueira, M., Amorim, P., Magalhães, F., Castro, E., Franco, F., Franceschini, S., Doimo, L. (2013). Validity of body adiposity index in predicting body fat in a sample of brazilian women. Obesity, 21(12), E696-E699.

Lohman T. (1987). The use of skinfold to estimate body fatness on children and youth. Journal of Physical Education, Recreation \& Dance, 58(9), 98103.

Bergman, R. N., Stefanovski, D., Buchanan, T. A., Sumner, A. E., Reynolds, J. C., Sebring, N. G., Watanabe, R. M. (2011). A better index of body adiposity. Obesity, 19(5), 1083-1089.

\section{Motivational variables and correlation between healthy lifestyles of students in Physical Education}

María Isabel Aspano Carrón ${ }^{1}$, Susana Lobato Muñoz ${ }^{1}$, Marco Batista², Marta Leyton Román ${ }^{1}$, Ruth Jiménez Castuera ${ }^{1}$

Universidad de Extremadura, Spain; Maribel-ac@hotmail.com 2. Escola Superior de Educação de Castelo Branco, Portugal.

\section{INTRODUCTION}

In our work we will focus on correlation between variables of lifestyle related to health and motivation ones, using the theoretical framework of Self-Determination Theory (Deci
\& Ryan, 1985). In this line, Ferriz, GonzálezCutre, Sicilia, and Hagger (2016) observed positive relations between satisfaction of basic psychological needs (BPN) and autonomous motivation, which contributed to an explanation 
of variance in healthy behaviors, such as physical activity and sport participation.

\section{METHOD.}

The sample consisted of 187 Spanish students in physical education classes (87 boys and 100 girls), belonging to three schools of Secondary Education of Badajoz, aged between 13 and 23 years, average age 15.5 years $(\mathrm{SD}=$ 1.70).

\section{Variables and Measuring Instruments}

Perceived Locus scale Causality in Physical Education (PLOC Scale), Scale measuring BPN (BPNES), Questionnaire Healthy Lifestyles (EVS), and the Scale of Measurement of Intentionality to be Physically Active (MIFA).

\section{RESULTS}

Our results show that autonomous motivation is related positively and significantly with satisfaction of BPN and intention to be physically active, and negatively and significantly with amotivation and alcohol consumption.

Table 1

Descriptive statistics, reliability analysis and correlation analysis.

\begin{tabular}{|c|c|c|c|c|c|c|c|c|c|c|c|c|c|c|c|c|}
\hline Variables & M & DT & $\alpha$ & (1) & (2) & (3) & (4) & (5) & (6) & (7) & (8) & (9) & (10) & (11) & (12) & (13) \\
\hline (1) AUTONOMOUS M. & 3.88 & .84 & .88 & - & & & & & & & & & & & & \\
\hline (2) INTROYECTED R. & 3.26 & 1.20 & .68 & $.37^{* *}$ & - & & & & & & & & & & & \\
\hline (3) EXTERNAL R. & 3.24 & 1.20 & .69 & -.07 & $.20^{* *}$ & - & & & & & & & & & & \\
\hline (4) AMOTIVATION & 1.97 & 1.04 & .78 & $-.29 * *$ & .12 & $.38^{* *}$ & - & & & & & & & & & \\
\hline (5) BPN. OF AUTONOMY & 3.31 & .85 & .74 & $.49^{* *}$ & $.27^{* *}$ & -.09 & -.13 & - & & & & & & & & \\
\hline $\begin{array}{l}\text { (6) BPN. OF } \\
\text { COMPETENCE }\end{array}$ & 3.89 & .76 & .79 & $.60^{* *}$ & $.25^{* *}$ & -.08 & $-.23^{* *}$ & $.56^{* *}$ & - & & & & & & & \\
\hline $\begin{array}{l}\text { (7) BPN. OF SOCIAL } \\
\text { RELATIONSHIPS }\end{array}$ & 4.31 & .68 & .80 & $.43^{* *}$ & $.18^{*}$ & -.05 & $-.20^{* *}$ & $.42^{* *}$ & $.44^{* *}$ & - & & & & & & \\
\hline (8) INTENTION & 3.88 & .93 & .81 & $.57^{* *}$ & $.18^{* *}$ & $-.16^{*}$ & $-.19^{* *}$ & $.43^{* *}$ & $.63^{* *}$ & $.35^{* *}$ & - & & & & & \\
\hline (9) ТОВАССО & 1.58 & .83 & .85 & -.00 & -.03 & -.07 & .04 & .04 & -.02 & .03 & -.05 & - & & & & \\
\hline (10) ALCOHOL & 1.51 & .83 & .80 & $-.18^{* *}$ & $-.16^{*}$ & -.03 & $.15^{*}$ & -.13 & -.05 & .05 & .00 & $.29 * *$ & - & & & \\
\hline (11) DRUGS & 3.66 & .90 & .78 & -.01 & -.02 & .02 & $.15^{*}$ & .02 & .11 & .06 & .11 & $.48^{* *}$ & $.46^{* *}$ & - & & \\
\hline (12) BALANCED DIET & 3.78 & .95 & .76 & .07 & $.16^{*}$ & .10 & .05 & .01 & .04 & .07 & .11 & .02 & -.09 & -.10 & - & \\
\hline (13) MEAL TIME & 3.59 & 1.14 & .96 & .09 & .06 & .05 & .03 & -.00 & .09 & -.06 & $.16^{*}$ & -.05 & -.11 & -.12 & $.47^{* *}$ & - \\
\hline
\end{tabular}

Note. M. = Motivation; R. = Regulation; BPN. = Basic Psychological Need.; ${ }^{*} p<.05 ;{ }^{* *} p<.01$.

\section{DISCUSSION}

We can explain these results because when students are more motivated to practice and improve tasks proposed by teacher, perceive greater competence and autonomy in their accomplishments, and their relationships with others, so his future intention of practice will be higher and they are more likely to avoid unhealthy habits, such as alcohol consumption. Some authors (Moreno-Murcia, González-Cutre, \& Cervelló, 2008) reported that consumption of tobacco and alcohol was negatively related to the self-determined motivation.

\section{CONCLUSIONS}

We propose solutions about achieving motivate and encourage satisfaction of BPN, especially, in order to promote health-enhancing behaviors.

\section{REFERENCES}

Deci, E. L., \& Ryan, R. M. (1985). Intrinsic motivation and Self-determination in human behavior. New York: Plenum.

Ferriz, R., González-Cutre, D., Sicilia, A., \& Hagger, M. S. (2016).Predicting healthy and unhealthy behaviors through physical education: A selfdetermination theory-based longitudinal approach. Scandinavian Journal of Medicine and Science in Sport, 26, 579-592.

Moreno, J. A., González-Cutre, D., \& Cervelló, E. (2008). Motivación y salud en la práctica físicodeportiva: diferencias según el consumo de alcohol y tabaco. International Journal of Clinical and Health Psychology, 8, 483-494. 


\section{Physical activity and functional fitness in older adults with cognitive impairment}

Soraia Ferreira ${ }^{1}$, José Marmeleira ${ }^{1,2}$

1. Universidade de Évora, Departamento de Desporto e Saúde, Escola de Ciência e Tecnologia; m11357@alunos.uevora.pt; 2. Research Center in Sports Sciences, Health Sciences and Human Development, CIDESD, Portugal

\section{INTRODUCTION}

The aging process leads to inevitable life changes, and is characterized by a progressive loss of psychological and physiological functions (Daroff \& Aminoff, 2003; Spirduso, 2005). Cognitive impairment is very common in the elderly, (Daroff \& Aminoff, 2003) and ranges from mild to severe (e.g., mild cognitive impairment and Alzheimer's disease). Unfortunately, the information available about the physical activity and sedentary behavior of people with cognitive impairment is scarce. Therefore, the main objective of this study was to examine physical activity levels and functional fitness of older adults with cognitive impairment.

\section{METHOD}

Eighty-one nursing home residents $(82.9 \pm$ 7.8 years) from both genders participated in this study; 53 participants have cognitive impairment according to the Mini Mental State Examination (Guerreiro et al, 1994). Physical activity data were collected through accelerometer and the study included the results from participants with at least 3 valid days (including 1 weekend day) and a minimum wear time of $8 \mathrm{hr}$ per day. Periods of at least 60 consecutive min of zero intensity counts were considered nonwear time. Functional fitness was evaluated by Berg Balance Scale, Functional Reach Test and some tests selected from the Senior Fitness Test. Simple reaction time was evaluated with the DearyLiewald reaction time task. Statistical analyses were conducted with the statistical software PASW Statistical for Windows with significance level set at $\mathrm{p}<0.05$.

\section{RESULTS}

The sample of this study have extremely lower levels of physical activity and high sedentary behavior. In participants with cognitive impairment, the mean time in sedentary behavior and moderate physical activity was $9 \mathrm{~h} 32 \mathrm{~min} /$ day and $1.1 \mathrm{~min} /$ day, respectively. The mean time spent in light physical activity was $88.8 \mathrm{~min} /$ day. Older adults without cognitive impairment (WCI) showed better results than the group with cognitive impairment (CI) in simple reaction time $(\mathrm{WCI}=869.4 \pm 439.2 \mathrm{~ms}, \mathrm{CI}=2185.0 \pm 3965.3 \mathrm{~ms}$, $\mathrm{p}=0.031$ ), arm curl (WCI $=11.6 \pm 4.9$ rep, $\mathrm{CI}=8.1 \pm 4.9$ rep, $\mathrm{p}<0.01$ ), and timed up and go test with dual task (WCI $=26.8 \pm 22.5 \mathrm{~s}$, $\mathrm{CI}=34.4 \pm 25.4 \mathrm{~s}, \mathrm{p}=0.046$ ), although physical activity and sedentary behavior were not statistically different. Most variables of functional fitness were related positively with the amount of physical activity performed.

\section{CONCLUSIONS}

Functional fitness and physical activity levels are very low in nursing home residents with cognitive impairment. Intervention programs are needed as decrease physical fitness and physical activity is associated with difficulties in daily life activities and normal functioning of the elderly.

\section{REFERENCES}

Daroff, R., \& Aminoff, M. (2003). Encyclopedia of the Neurological Sciences. New York: Academic Press. Guerreiro, M., Silva, A, Botelho, M, Leitão, O, CastroCaldas, A, \& Garcia, C. (1994). Adaptação à população portuguesa da tradução do Mini Mental State Examination (MMSE). Revista Portuguesa de Neurologia 1(9), 9-10.

Spirduso, W. (2005). Dimensões Físicas do Envelhecimento. Tamboré: Manole. 


\section{Comparing the performance of EQ-5D-5L, SF-6D, 15D and AQoL- 8D in Spanish women with Fibromyalgia}

Francisco Javier Dominguez-Muñoz ${ }^{1}$, Daniel Collado-Mateo ${ }^{1}$, Miguel Ângel Garcia-Gordillo¹, Álvaro Murillo-Garcia ${ }^{1}$, Miguel Ângel Hernandez-Mocholi ${ }^{1}$, Santos Villafaina ${ }^{1}$, José Parraca ${ }^{2,3}$

Facultad de Ciencias del Deporte, Universidad de Extremadura, Spain; fjdominguez@unex.es; 2. Universidade de Évora, Departamento de Desporto e Saúde, Escola de Ciência e Tecnologia; 3. Research Center in Sports Sciences, Health Sciences and Human Development, CIDESD, Portugal

\section{INTRODUCTION}

Fibromyalgia (FM) is a chronic syndrome that leads a large reduction in health-related quality of life (HRQoL). It is characterized by widespread pain and several associated symptoms, such as fatigue, stiffness, depression, poor physical fitness, non-restorative sleep, memory troubles, or muscle spasms. In Spain, FM is about 20 times more frequent among women compared with men, being the overall prevalence of FM in Spanish population $2.4 \%$. The main aim of the study was to compare the performance of EQ-5D-5L, SF-6D, 15D and AQoL-8D in Spanish women suffering from FM. Since there are no studies assessing HRQoL in FM patients using AQoL-8D, this paper also aims to establish reference values for this questionnaire in women with FM.

\section{METHODS}

Study design

A cross-sectional study was developed. Face to face interviews were conducted by a trained researcher between October 2014 and November 2015. A total of 192 women with FM participated in the study, the minimum age was 23 years old and the maximum was 83 .

Instruments

The four MAU instruments and the FIQR was used as disease specific instrument in order to evaluate the sensitivity of EQ-5D-5L, SF-6D, and $15 \mathrm{D}$ and AQoL-8D detecting relevant changes in women with FM.

\section{RESULTS}

The ability of the four MAU instruments to detect clinically relevant changes was tested in the Table. All four questionnaires presented high accuracy, but EQ-5D-5L showed highest relative efficiency.

\section{CONCLUSION}

The EQ-5D-5L, SF-6D, 15D and AQoL-8D are adequate instruments to assess HRQoL in Spanish women suffering from FM.

Table 1

Efficiency of EQ-5D-5L, 15D, SF-6D and AQoL-8D to detect clinically relevant differences in HRQoL.

\begin{tabular}{|c|c|c|c|c|c|c|c|c|}
\hline & & & & \multicolumn{3}{|c|}{$\mathrm{t}$-Test } & \multicolumn{2}{|c|}{ ROC curve } \\
\hline Measures & FIQR Total score $¥$ & $\mathrm{n}$ & Mean (SD) & t-statisitic & $p$-value & $\mathrm{RE} \dagger$ & AUC & $95 \% \mathrm{CI}$ \\
\hline EQ-5D-5L Utility & $<60.0$ & 92 & $0.67(0.16)$ & 12.19 & $<0.001$ & 1.40 & $0.86^{*}$ & (0.80 to 0.92$)$ \\
\hline & $\begin{array}{l}\geq 60.0 \\
<60.0\end{array}$ & $\begin{array}{l}99 \\
93\end{array}$ & $\begin{array}{l}0.31(0.22) \\
0.76(0.09)\end{array}$ & & & & & \\
\hline 15D Utility & $\geq 60.0$ & 99 & $0.61(0.10)$ & 10.28 & $<0.001$ & 1.00 & $0.82^{*}$ & (0.74 to 0.89 ) \\
\hline SF-6D Utility & $\begin{array}{l}<60.0 \\
\geq 60.0\end{array}$ & $\begin{array}{l}54 \\
87\end{array}$ & $\begin{array}{l}0.64(0.09) \\
0.50(0.07)\end{array}$ & 9.21 & $<0.001$ & 0.80 & $0.87^{*}$ & (0.80 to 0.93 ) \\
\hline AQoL-8D Utility & $\begin{array}{l}<60.0 \\
\geq 60.0\end{array}$ & $\begin{array}{l}90 \\
87\end{array}$ & $\begin{array}{l}0.56(0.16) \\
0.36(0.11)\end{array}$ & 9.42 & $<0.001$ & 0.83 & $0.85^{*}$ & (0.78 to 0.92 ) \\
\hline
\end{tabular}

AUC: Area under ROC curve; CI: Confidence interval; RE: Relative efficiency; ROC: Receiver operating characteristic; ¥ Severity of symptoms was classified as mild/moderate (lower than 60) or severe (equal or higher than 60); $\mathrm{p}<0.001$ indicates that AUC statistically significantly greater than 0.5 ; $†$ Reference was 15 Dutility

\section{REFERENCES}

Burckhardt C.S., Clark S.R., Bennett R.M. (1993) Fibromyalgia and quality of life: a comparative analysis. The Journal of rheumatology, 20(3), 475-9.
Wolfe, F. (2015). Editorial: the status of fibromyalgia criteria. Arthritis \& Rheumatology, 67(2), 330-333 Segura-Jiménez, V., Álvarez-Gallardo, I. C., CarbonellBaeza, A., Aparicio, V. A., Ortega, F. B., 
Casimiro, A. J., \& Delgado-Fernández, M. (2015, April). Fibromyalgia has a larger impact on physical health than on psychological health, yet both are markedly affected: the al-Ándalus project. Seminars in Arthritis and Rheumatism, 5(44), 563-570.
Mas, A. J., Carmona, L., Valverde, M., \& Ribas, B. (2008). Prevalence and impact of fibromyalgia on function and quality of life in individuals from the general population: results from a nationwide study in Spain. Clinical \& Experimental Rheumatology, 26(4), 519.

\section{Effects of an exercise program on social interaction and stereotypies of children with Autism Spectrum Disorders}

Chrystiane Vasconcelos Andrade Toscano ${ }^{1,2}$, Cyro Rego Cabral Júnior ${ }^{1}$, José Pedro Ferreira ${ }^{2}$

1. Federal University of Alagoas; Brazil; chrystoscano@gmail.com; University of Coimbra, CIDAF, Portugal

\section{INTRODUCTION}

Autism Spectrum Disorders (ASD) is a neurobiological disorder with impairment in social interaction, communication, restricted interests and stereotyped movements (Neely et al, 2014). The inclusion of children with ASD in exercise programs have been reported in the literature as one of the strategies to minimize the negative effects of the symptom (Lang et al., 2010). The purpose of this study was to investigate the effects of an exercise program on social interaction and stereotypic of children with ASD.

\section{METHODS}

An observational case-control study was used in this research. Sixteen children with ASD, with an age average of $8.0 \pm 3.0$ years old, without medication were assessed in a specialized care Center in Maceió-AL, Brazil. All participants were assessed twice, at baseline and after the exercise program using balance, strength and coordination variables and the Scale of Autistic Traits (ATA). The exercise program was a twice a week sixteen session training circuit with a total duration of 30 minutes per session. The statistical package R-Studio was used for data analysis. Wilcoxon Signed-Rank Test was used to compare the effects of exercise on eight different social interaction and stereotypies categories: 1) difficulty in social interaction, 2) environmental manipulation, 3) resistance to change, 4) strict order, 5) lack of eye contact, 6) lack of initiative, 7) mimic inexpressive and 8) stereotypies.

\section{RESULTS}

There was a significant decrease $(\mathrm{p}<0.05)$ in all variables from categories 1 to 6 . Although inexpressive mimic and stereotypies categories showed no significant differences, there was also a decrease in their global scores. The exercise program was defined according to the stereotypies profile of the children in the intervention group aiming to redefine their motor control profile and using the direct participation of their parents in the different tasks as a mediation strategy.

\section{CONCLUSION}

In spite of the exercise program short intervention period, that may have limited the effects of exercise on the categories requiring motor function reprogramming (mimic inexpressive and stereotypies), children with ASD showed good improvements on the other categories requiring social interaction with the environment.

\section{REFERENCES}

Lang, R., Koegel, L. K., Ashbaugh, K., Regester, A., Ence, W. \& Smith, W. (2010). Physical exercise and individuals with autism spectrum disorders: A systematic review. Research in Autism Spectrum Disorders, 4(4), 565-576.

Neely, L., Rispoli, M., Gerow, S., \& Ninci, J. (2014). Effects of Antecedent Exercise on Academic Engagement and Stereotypy. During Instruction. Behavior Modification, 39(1), 98-116. 


\title{
Effects of Whole Body Vibration Exercise on Muscle Strength and Dynamic Balance on Elderly People
}

\author{
Ivo Vieira ${ }^{1}$, Orlando Fernandes ${ }^{1,2}$, Armando Raimundo ${ }^{1,2}$, José Parraca ${ }^{1,2}$, Nuno Batalha1,2, \\ Pablo Tomas-Carus ${ }^{1,2}$ \\ 1. Departamento de Desporto e Saúde, Escola de Ciência e Tecnologia, Universidade de Évora, Évora, Portugal; \\ ivo.vieira.8@gmail.com; 2. Research Centre in Sports Sciences, Health Sciences and Human Development, CIDESD, University \\ of Évora, Évora, Portugal.
}

\section{INTRODUCTION}

One of the major causes that generate disabilities and even death among the elderly population are the falls, and as such, it's considered a major public health problem (Bogaerts, Delechulse, Boonen, Claessens, Milisen \& Verschueren, 2011). There are several studies that show that the Whole Body Vibration (WBV) can be a reliable alternative to many other types of training to reduce the risk of falls of the elderly, by improving the Muscle Strength (MS), balance capacity and mobility (Lam, Lau, Chung \& Pang, 2012). Therefore, the present study aims to find out what are the effects of the WBV on MS and Dynamic Balance (DB) in individuals over 65 years old.

\section{METHODS}

Thirty-one older people (age 70,2 $\pm 6,3$ years) were randomly assigned to an Experimental
Group (EG) ( $\mathrm{n}=16)$ or to a Control Group (CG) $(n=15)$. The EG performed 2 sessions per week for 16 weeks. Each session had a duration of 30 min constituted by a warm up ( 5 min bicycle and 5 min of 4 exercises) and 4 sets of $30 \mathrm{sec}$ of WBV with $60 \mathrm{sec}$ of rest between sets. Maximal isokinetic strength was measured at $60^{\circ} / \mathrm{s}$ in the knee extensors and flexors in concentric action. DB was evaluated using The Timed up and Go Test (Rikli \& Jones, 1999).

\section{RESULTS}

After 16 weeks of WBV exercise significant improvements occurred in concentric extensors strength at $60 \% \mathrm{~s}(\approx 17 \%)$ and in dynamic balance $(\mathrm{DB}) \quad(\approx 16 \%)$ (Table 1). Multivariate regression analyses indicated that gains in concentric knee extensors strength predicted improvements of $35 \%$ in postural balance [F (2, 17) $\left.\left.=17,410 ; \mathrm{R}^{2}=0,351 ; \mathrm{p}=0.026\right)\right]$

Table 1

Maximal isokinetic strength at $60 \%$ s in the knee extensors and flexors in concentric action and dynamic balance at baseline and after 16 weeks of whole body vibration

\begin{tabular}{|c|c|c|c|c|c|c|}
\hline & \multicolumn{2}{|c|}{ Baseline } & \multicolumn{2}{|c|}{16 weeks } & \multirow[t]{2}{*}{ Treatment effect } & \multirow[t]{2}{*}{$\mathrm{P} \dagger$} \\
\hline & EG $(n=11)$ & CG $(n=9)$ & EG $(n=11)$ & CG $(n=9)$ & & \\
\hline & Mean \pm S.D. & Mean \pm S.D. & Mean \pm S.D. & Mean \pm S.D. & Mean $(95 \% \mathrm{CI})$ & \\
\hline \multicolumn{7}{|l|}{ Rigth leg strength (N. m) } \\
\hline Extensors (cc) $60 \%$ & $91.8 \pm 27.4$ & $71.5 \pm 21.0$ & $108.4 \pm 33.3$ & $80.8 \pm 26.1$ & $16.72(5.11-28.32)$ & 0.007 \\
\hline Flexors (cc) $60 \% / \mathrm{s}$ & $50.0 \pm 19.6$ & $37.5 \pm 8.5$ & $50,9 \pm 19.9$ & $39.6 \pm 9.6$ & $-4,25(-19.52-11.12)$ & 0.569 \\
\hline \multicolumn{7}{|l|}{ Left leg strength (N . m) } \\
\hline Extensors (cc) $60 \%$ & $91.8 \pm 30.9$ & $75.7 \pm 18.2$ & $100.5 \pm 37.0$ & $80.6 \pm 18.0$ & $2,54(-7.27-12.36)$ & 0.592 \\
\hline Flexors (cc) $60 \%$ & $50.0 \pm 20.7$ & $37.5 \pm 13.1$ & $53.9 \pm 22.3$ & $38.1 \pm 12.7$ & $6.97(-4.76-18.70)$ & 0.228 \\
\hline Dynamic Balance - TUG (sec) & $6.19 \pm 0.69$ & $8.45 \pm 2.12$ & $6.58 \pm 1.00$ & $7.67 \pm 2.09$ & $15.78(7,03-24.54)$ & 0.001 \\
\hline
\end{tabular}

\section{CONCLUSIONS}

A WBV exercise produced relevant gains in DB and MS at low velocities of movements in extensors, some of which predicted improvements in DB which is important for daily activities such as, getting off a bus in time, to go to the bathroom or answer the phone.

\section{REFERENCES}

Bogaerts, A., Delecluse, C., Boonen, S., Claessens, 


\section{8 | International Congress CIDESD 2017}

A.L., Milisen, K., \& Verschueren, S.M. (2011). Changes in balance, functional performance and fall risk following whole body vibration training and vitamin $\mathrm{D}$ supplementation in institutionalized elderly women. A 6 month randomized controlled trial. Gait and Posture, 33(3), 466-472

Lam, F.M., Lau, R.W., Chung, R.C., \& Pang, M.Y.
(2012). The effect of whole body vibration on balance, mobility and falls in older adults: a systematic review and meta-analysis. Maturitas, 72(3), 206-213.

Rikli, R. \& Jones, J. (1999). Development and validation of a functional fitness test for community-residing older adults. Journal of Aging and Physical Activity, 7, 129-161. 


\title{
Validation of the Portuguese version of the Healthy Life Styles Questionnaire
}

\author{
Marco Batista1,3, Ruth Jimenéz Castuera², Marta Leyton Roman², Susana Lobato Muñoz², \\ Maria Isabel Aspano ${ }^{2}$ \\ 1. Instituto Politécnico de Castelo Branco, Portugal; marco.batista@ipcb.pt; 2. Facultad de Ciencias del Deporte, Universidad de \\ Extremadura, Spain; 3. RECI, Research, Education and Community Intervention
}

The aim of this study was the adaptation and validation the Portuguese version of Healthy Lifestyle Questionnaire, adapted of Wold (1995), using an exploratory and confirmatory factor analysis of the measurement model, with a sample of sports veterans. It was a) conducted a reverse translation; b) translated again by a translator unrelated to the research group to English, where he noted a great similarity with the original questionnaire also after retroversion process; c) evaluated by three experts in the field; d) administered the questionnaire to a small group of athletes with similar ages to the final sample to verify its correct understanding, not noticing any problems of reading comprehension; e) quiz application for approximate time of completion was about, fifteen minutes; f) data processing. The internal consistency of each factors resulting from the factor analysis (Cronbach's alpha) showed the following results: (.80) eating habits (.91) tobacco consumption, (.84) resting habits. The reliability coefficient should be above the .70 . There were also values of 0.861 on the KMO and Bartlett's test, where $56.24 \%$ of the variance is explained by three factors. After analysis, it was shown that the 20 items were grouped into three factors, respectively: eating habits (10 items), tobacco consumption (5 items) and resting habits (5 items). In a similar way, the standardized factor loads were all statistically significant $(\mathrm{p}<.01)$. The preliminary analysis of the data also indicated that the sample did not meet the criterion of normality, since the Mardia coefficient was high (62.43). For that reason, we used the robust estimation method of verisimilitude maximum. After a first analysis, the overall model results indicated a reasonable adjustment of the Healthy Lifestyles Questionnaire: $(\chi 2=172,117, \mathrm{p}=.000, \chi 2 / \mathrm{df}=4.190, \mathrm{CFI}=.966$, IFI $=.966$, MFI $=.909$, GFI $=.955$, AGFI $=.927, \mathrm{RMA}=.049, \mathrm{RMSEA}=.068, \mathrm{SRMR}=.043)$. Thus, we can conclude that the adaptation to Sports of the Portuguese version of the Healthy Lifestyles Questionnaire, can be used with confidence of validity and reliability in the evaluation of healthy lifestyles, underlying to the self-determination theory in sport context.

References.

Hu L, \& Bentler P. (1999). Cutoff criteria for fit indexes in covariance structure analysis: Conventional criteria versus new alternatives. Structural Equation Modeling, 6,1-55. http://dx. doi.org/10.1080/10705519909540118.

\section{Self-determination and healthy lifestyles: an exploratory study on veteran athletes}

\author{
Marco Batista1,3, Ruth Jimenéz Castuera², Samuel Honório1,3, Pedro Mendes ${ }^{1,3}$, Rui \\ Paulo ${ }^{1,3}$, Helena Mesquita ${ }^{1}$ \\ 1. Instituto Politécnico de Castelo Branco, Portugal; marco.batista@ipcb.pt; 2. Facultad de Deporte, Universidad de \\ Extremadura, Spain; 3. RECI, Research, Education and Community Intervention
}

The Theory of Self-determination relates to motivation and assumes the importance of meeting basic psychological needs in the appearance of self-determined behavior, as the future engagement with sports or exercise that leads to other healthy lifestyles habits. We intend to: i) characterize the motivation and satisfaction of basic psychological needs to practice sport ii) knowing the lifestyles iii) realize that selfdetermination variables influences the healthy lifestyles. Agreed to participate 684 veteran athletes of both sexes (age: $43.8 \pm 8.6$ years; mostly with 3 to 5 hours of weekly training, years of practice: $19.5 \pm 12.2$ ). We have applied the Portuguese versions of Basic Psychological Needs Scale Exercise (BPNES), the Behavioral Regulation in Sport Questionnaire (BRSQ) and Healthy Lifestyle Questionnaire, with the inclusion of sociodemographic data. We used SPSS software (IBM, Statistics 21.0) for processing data, with a focus on descriptive statistics, Pearson correlation coefficient and multiple linear regression. The level of significance was set at $\mathrm{p}<0.05$. The sample showed high levels in basic psychological needs and autonomous motivation, and lower values of controlled motivation and amotivation. In terms of lifestyles, revealed high levels of nutrition habits and rest, and lower values of tobacco consumption habits. Once 
correlated, the basic psychological needs showed positive and significant correlations with autonomous motivation levels, nutrition habits and rest. Levels of satisfaction with life showed significant and positive correlations with autonomous motivation levels and positive affect, and negative correlations with controlled motivation and amotivation. In regression analysis, nutrition habits and rest are predicted positively by autonomous motivation, as well as the basic psychological needs and negatively by controlled motivation. The results showed that veteran athletes have a good self-determination for sports practice, showing healthy lifestyles related to that same self-determination.

References

Deci, E. L., \& Ryan, R. M. (2002). Self-determination research: Reflections and future directions. En E. L. Deci \& R. M. Ryan (Eds), Handbook of selfdetermination research (pp. 431-44). Rochester, NY: University of Rochester Press.

\title{
Characterization of diabetics and non-diabetics in anthropometric parameters. A sample of Rio Maior city.
}

\author{
Rafael Oliveira1,2,3, João Moreira Brito ${ }^{1,2,4}$, Luis Cid ${ }^{1,5}$, João Moutão 1,2,4,5, Anabela Vitorino ${ }^{1,2}$, \\ Teresa Bento ${ }^{1,5}$, Diogo Monteiro ${ }^{1,5}$ \\ Escola Superior de Desporto de Rio Maior, Instituto Politécnico de Santarém, ESDRM-IPS; rafaeloliveira@esdrm.ipsantarem.pt; \\ 2. Unidade de Investigação, Instituto Politécnico de Santarém, UIIPS; 3. Universidade Da Beira Interior, UBI, Covilhã, Portugal; \\ 4. Centro de Investigação e Qualidade de Vida, CIEQV; 5. Centro de Investigação em Desporto, Saúde e Desenvolvimento \\ Humano, CIDESD
}

Portugal has $25 \%$ of population (60-79 years) with diabetes (SPD, 2015). Type 2 diabetes is strictly related with over body weight, obesity, metabolic, musculoskeletal and cardiovascular changes (Erdogan et al., 2011). The aim of the study was to characterize a sample of Rio Maior city by using some anthropometric parameters. The anthropometric parameters between diabetic type 2 or non-diabetics subjects were compared. Participated 109 subjects (age, 71.94 15.26 years) in the anthropometric assessment (body weight, height, body mass index and waist circumference) and diabetic parameters (level of glycemia). Subjects were divided in two groups: diabetics $\left(n=20, \sigma^{\top} 16\right.$ and 우 4$)$ and non-diabetics $\left(n=89, \delta^{\top} 31\right.$ and 우 58). The main results showed significant differences for weight $(\mathrm{p}<0.028)$, waist circumference $(\mathrm{p}<0.000)$ and glycemia $(\mathrm{p}<0.000)$ for both groups. Diabetics group had 78.65 $\pm 15.06 \mathrm{~kg}, 104.10 \pm 10.26$ $\mathrm{cm}, 158.70 \pm 49.96$, while non-diabetics group had $70.40 \pm 14.98 \mathrm{~kg}, 92.18 \pm 13.63 \mathrm{~cm}, 103.02 \pm 21.42$ for weight and waist circumference and glycemia, respectively. As expected diabetics group showed for body weight and waist circumference greater values than non-diabetics group. Our results indicated that the sample of Rio Maior had anthropometric values over the normal recommendations (ACSM, 2013), increasing risk criteria for diabetes. We suggest that a properly exercise training program would benefit the body weight and diabetes control, as well documented by Mendes et al. (2015).

References

American College of Sports Medicine, ACSM. (2013). ACSM's Guidelines for exercise testing and prescription (9th ed). Philadelphia: Lippincott Williams e Wilkins.

Erdogan, D., Akcay, S., Ersoy, I., Iclia, A., Yucela, H., Kutlucanc, A., ... Tamer, M. (2011). Cardiac determinants of impaired exercise performance in patients with type 2 diabetes mellitus. Int J Cardiol, 152, 143-6.

Mendes, R., Sousa, N., Almeida, A., Subtil, P., Guedes-Marques, F., Reis, V. \& Themudo-Barata, J. (2015). Exercise prescription for patients with type 2 diabetes - a synthesis of international recommendations: narrative review. Br J Sports Med, 0, 1-4, doi:10.1136/bjsports-2015-094895 Sociedade Portuguese de Diebetolgia, SPD. (2015). Diabetes: Factos e Números - O ano 2014 - Relatório Anual do Observatório Nacional da Diabetes. ISBN: 978-989-96663-2-0.

\section{Effect of eight weeks of classic strength training of short duration on functional capacity of elderly: a pilot study}

\section{Osvaldo Costa Moreira1,2, Claudia Eliza Patrocínio de Oliveira ${ }^{1,2}$, José António de Paz ${ }^{1}$}

Institute of Biomedicine, University of León, León, Spain; Osvaldo.moreira@ufv.br; Department of Physical Education, Federal University of Viçosa, Viçosa, Brazil

The exercise practice is a strategy to curb the deleterious effects of aging. Thus, strength training is indicated for the promotion of health and functional autonomy in elderly (ACSM, 2009). However, little is known about the effects of a classic strength training of short duration (CSTSD) on the functional capacity of these people. It was our objective to evaluate the effect of eight weeks of CSTSD on functional capacity of elderly. We evaluated 25 people between 70 and 78 years old, randomly divided into two groups, control group $(n=7)$ and training group $(n=18)$ through the functional tests battery of Rikli \& Jones (1999) before and after eight weeks of strength training. The training was designed as recommended by the ACSM 
(2009), being executed twice a week, with a maximum duration of 35 minutes/session. The statistical analysis realized was Wilcoxon test for comparisons of pre and post training results and the effect size calculation through Cohen' d test. The characteristics of the sample, pre and post training results and comparing these between groups are show in Table 1. Eight weeks of CSTSD are able to improve the performance of elderly in functional capacity tests.

Table 1.

Differences pre and post training in elderly performance during functional capacity tests.

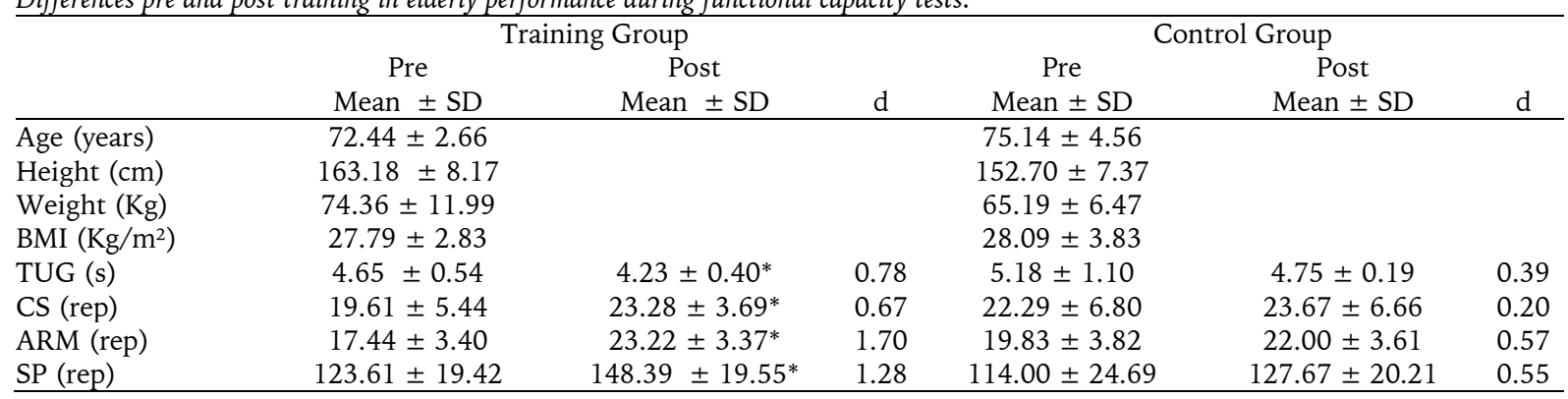

d:effect size; * $\mathrm{p}<0,05$ or pre and post comparison in the same variable; TUG: time up and go test; CS: Chair stand test; ARM: Arm curl test; SP: Step-in-place.

\section{Funding}

Supported by Plan Nacional I+D+I DEP2013-47659, Spain; Coordenação de Aperfeiçoamento de Pessoal de Nivel Superior - CAPES; Conselho Nacional de Desenvolvimento Científico e Tecnológico - CNPq

References:

Rikli, R. E., \& Jones, C. J. (1999). Development and validation of a functional fitness test for community-residing older adults. Journal of Aging and Physical Activity, 7, 129-161.

American College of Sports Medicine. (2009). American College of Sports Medicine position stand. Exercise and physical activity for older adults. Medicine and Science in Sports and Exercise, 41 (7), 1510-1530.

\section{Relationship of different perceived exertion scales in walking or running with self-selected and imposed intensity}

Marcelo Dias ${ }^{1}$, Roberto Simão2, Filipe Matos ${ }^{3,4}$, José Vilaça ${ }^{3,4}$, Francisco Saavedra ${ }^{3,4}$

1. Laboratory of Exercise Physiology and Morphofunctional Assessment, Granbery Methodist College, Juiz de Fora, Brazil; 2. School of Physical Education and Sports, Rio de Janeiro Federal University, Rio de Janeiro, Brazil; 3. University of Trás-os-Montes and Alto Douro (UTAD), Vila Real, Portugal; 4. Research Center for Sport, Health, and Human Development, University of Trás-os-Montes and Alto Douro (UTAD), Vila Real, Portugal; josevilaca@utad.pt

The aims of this study were to: (1) compare the Heart Rate (HR) and Rating Perceived Exertion (RPE) in training with self-selected and imposed loads, and (2) associate the OMNI-Walk/Run and Borg scales with self-selected and imposed loads, both on a treadmill. Ten trained men $(20.3 \pm 2.0$ years, $75.6 \pm 9.8 \mathrm{~kg}$, $175.1 \pm 5.1 \mathrm{~cm}$ ), participated in a training with self-selected load (time and speed individually preferred) and another with imposed load (even self-selected time and speed 10\% higher). The HR and RPE were measured, every minute of training, by the OMNI-Walk/Run and Borg scales. No significant differences were found in HR and RPE between training sessions. The correlation between the OMNI-Walk/Run and Borg scales showed a moderate association $(r=0.55)$ in training with self-selected load and a strong association in imposed load $(\mathrm{r}=0.79)$. In this study, self-selected load induced a suboptimal stimulus to elicit favorable organic adaptations. Moreover, high correlation of OMNI Walk/Run and Borg scales with the imposed load, showed that the greater the load of training the best are answers of RPE.

Acknowledgments

Macro-to-Nano Human Sensing: Towards Integrated Multimodal Health Monitoring and Analytics, n. ${ }^{\circ}$ da operação NORTE-01-0145-FEDER000016, cofinanciado pelo Fundo Europeu de Desenvolvimento Regional (FEDER) através do NORTE 2020. We would like to extend our thanks to the Granbery Methodist College.

References

Borg, G. A. (1982). Psychophysical bases of perceived exertion. Medicine and Science in Sports and Exercise, 14(5), $377-381$.

Glass, S. C., \& Chvala, A. M. (2001). Preferred exertion across three common modes of exercise training. Journal of Strength and Conditioning Research / National Strength \& Conditioning Association, 15(4), 474-479. 


\title{
Sedentary behavior and compensatory mechanisms in response to a weight loss program
}

\author{
Eliane A. Castro ${ }^{1}$, Pedro B. Júdice ${ }^{2}$, Analiza M. Silva², Pedro J. Teixeira², Pedro J. Benito ${ }^{1}$ on \\ behalf of the PRONAF Study Group \\ 1. LFE Research Group, Department of Health and Human Performance, Faculty of Physical Activity and Sport Sciences, \\ Technical University of Madrid, Madrid, Spain; lilicanep@hotmail.com; 2. Exercise and Health Laboratory, CIPER, Faculty of \\ Human Kinetics, University of Lisbon, Portugal.
}

Few studies have examined the patterns of physical activity, such as time spent sedentary and time spent in different activity intensity categories (Smith, Ekelund, \& Hamer, 2015), and limited data on compensatory behavior in response to exercise training are equivocal (Di Blasio et al., 2012; Kozey-Keadle et al., 2014; Turner, Markovitch, Betts, \& Thompson, 2010; Willis et al., 2014). Therefore, our objective was to examine compensatory changes in sedentary behavior (SB) and light-intensity physical activities (LIPA) in response to a 6-month exercise training program in overweight/obese adults. Eighty-nine overweight and obese individuals (48\% males), aged 18-50 years, were randomized into four intervention groups (strength, endurance, combined strength + endurance, and physical activity recommendations) with a 25-30\% caloric restriction diet for six months (Zapico et al., 2012). Energy expenditure was measured by accelerometry before, during and after the program. LIPA increased significantly $(p<0.001)$ after three months and at the end of intervention compared to baseline (pre: $281 \pm 9 ; 3$ months: $303 \pm 9$; post: $312 \pm 8 ; \mathrm{min})$. SB percentage decreased by $5.3 \%$ at the end of the intervention. No interactions were observed between groups or sex. There were no compensatory changes after a combined exercise and diet program; where LIPA increased and \%SB decreased after the program, without differences among exercise modes. Our data support previous results that demonstrate minor changes in sedentary time due to interventions solely with physical activity; and interventions which have a particular focus on reducing SB in order to generate significant clinical changes are required (Martin et al., 2015).

References:

Di Blasio, A., Ripari, P., Bucci, I., Di Donato, F., Izzicupo, P., D’Angelo, E., ... \& Napolitano, G. (2012). Walking training in postmenopause: effects on both spontaneous physical activity and training-induced body adaptations. Menopause, 19(1), $23-32$.

Kozey-Keadle, S., Staudenmayer, J., Libertine, A., Mavilia, M., Lyden, K., Braun, B., \& Freedson, P. (2014). Changes in sedentary time and physical activity in response to an exercise training and/or lifestyle intervention. Journal of physical activity $\mathcal{E}$ health, 11 (7).

Martin, A., Fitzsimons, C., Jepson, R., Saunders, D. H., van der Ploeg, H. P., Teixeira, P. J., ... \& Mutrie, N. (2015). Interventions with potential to reduce sedentary time in adults: systematic review and meta-analysis. British journal of sports medicine, bjsports-2014.

Smith, L., Ekelund, U., \& Hamer, M. (2015). The potential yield of non-exercise physical activity energy expenditure in public health. Sports Medicine, 45(4), 449-452.

Turner, J. E., Markovitch, D., Betts, J. A., \& Thompson, D. (2010). Nonprescribed physical activity energy expenditure is maintained with structured exercise and implicates a compensatory increase in energy intake. The American journal of clinical nutrition, 92 (5), $1009-1016$.

Willis, E. A., Herrmann, S. D., Honas, J. J., Lee, J., Donnelly, J. E., \& Washburn, R. A. (2014). Nonexercise energy expenditure and physical activity in the midwest exercise trial 2. Medicine and science in sports and exercise, 46 (12), 2286.

Zapico, A. G., Benito, P. J., González-Gross, M., Peinado, A. B., Morencos, E., Romero, B., ... \& Bermejo, M. (2012). Nutrition and physical activity programs for obesity treatment (PRONAF study): methodological approach of the project. BMC Public Health, 12 (1), 1.

\section{Resistance-training effects on daily living activities-related physical abilities of adult and elderly women}

Saulo Magalhães ${ }^{1}$, Alexandre Medeiros ${ }^{1}$, Maria Almeida ${ }^{1}$, Claudio Assumpção ${ }^{1}$

1. Research Group in Biodynamic Human Movement, Institute of Physical Education of Ceará, Fortaleza, Ceará, Brazil; saulochaves@hotmail.com

Resistance training (RT) is currently recommended for preventing and relieving many chronic and degenerative diseases. Furthermore, RT may trigger neuromuscular adaptations that can improve neuromuscular and physical fitness parameters related to daily living activities (DLA) (Radaelli et al, 2013). Thus, our study evaluated the effects of a RT program on variables such as dynamic balance, body stability, aerobic fitness, flexibility and muscle strength of active elderly and adult women. Twenty four healthy women (age $=58.9 \pm 6.42$; $\mathrm{BMI}=27.22 \pm$ ), physically active but without having ever participated in regular RT, were randomly divided in Experimental (EG; $n=12)$ and Control $(C G ; n=12)$ groups. EG underwent a 16-week RT ( 3 weekly sessions) program consisted of 6 exercises with intensity of 67 to $80 \%$ 1RM. CG kept their aerobic customary exercises exclusively. The same pre- and post-intervention assessments were applied for both groups: Push-ups (PU), Sittings to Standings Bench (SSB) and Jump (JT) tests for upper and lower limbs muscles strength; the AAHPERD Agility Test (AG) for dynamic balance and agility; Wells' 
Sit-and-reach test (SR) for flexibility; and the 1-mile Walking Test for relative $\mathrm{VO}_{2}$ max estimate. Multiple t-test was used, with statistical significance determined using the Holm-Sidak method, with alpha $=0.05$. Table 1 describes pre- and post-intervention assessments results

Table 1

Assessments results and pre- $v$ s. post-intervention comparison

\begin{tabular}{|c|c|c|c|c|}
\hline \multirow{2}{*}{ Variables } & \multicolumn{2}{|c|}{$\mathrm{CG}$} & \multicolumn{2}{|c|}{ EG } \\
\hline & Pre & Post & Pre & Post \\
\hline PU (rep) & $11.27 \pm 1.66$ & $11 \pm 1.42$ & $11.56 \pm 1.97$ & $25 \pm 3.75^{*}$ \\
\hline $\mathrm{SSB}(\mathrm{cm})$ & $11.30 \pm 1.02$ & $11.27 \pm 0.87$ & $11.30 \pm 0.40$ & $22.90 \pm 1.33^{* *}$ \\
\hline $\mathrm{JT}(\mathrm{cm})$ & $11.94 \pm 0.08$ & $11.06 \pm 0.39$ & $11.44 \pm 1.072$ & $13.95 \pm 1.41$ \\
\hline AG (sec) & $22.56 \pm 1.74$ & $22.34 \pm 1.22$ & $22.79 \pm 0.84$ & $20.14 \pm 0.64^{* * *}$ \\
\hline $\mathrm{SR}(\mathrm{cm})$ & $24.02 \pm 3.68$ & $23.63 \pm 3.3$ & $23.79 \pm 9.55$ & $24.7 \pm 10.38$ \\
\hline $\mathrm{VO}_{2 \max }\left(\mathrm{ml} \cdot \mathrm{kg}^{-1} \cdot \mathrm{min}^{-1}\right)$ & $24.3 \pm 1.49$ & $25.04 \pm 0.68$ & $24.7 \pm 1.67$ & $27.86 \pm 1.34^{* * *}$ \\
\hline
\end{tabular}

RT program was effective in transferring strength gains to other physical capacities in the studied population, denoting important functional-motor gains, which can bring benefits to the DLAs and potentially decreased risks in the physical dynamics of the daily life, such as risk of falls and willingness to daily tasks. In regards to flexibility, cofactors such as the regeneration process of muscle fiber and morphological individuality seem to influence the results.

References

Radaelli, R., Botton, C.E., Wilhelm, E.N., Bottaro, M., Lacerda, F., Gaya, A.,...Pinto, R.S. (2013). Low-and high-volume strength training induces similar neuromuscular improvements in muscle quality in elderly women. Experimental Gerontology, 48(8), 710-716.

\section{Assessment of the effects of an exercise program in breast cancer survivors - Pilot Study: Implementation of the MAMA_MOVE program}

\section{Pedro Antunes ${ }^{1}$; Dulce Esteves ${ }^{1}$; José Alberto-Moutinho²; Célia Nunes ${ }^{1}$}

1. Departamento de Ciências do Desporto, Universidade da Beira Interior, Covilhã, Portugal; pantunes 14@hotmail.com; 2. Faculdade de Ciências da Saúde, Universidade da Beira Interior, Covilhã, Portugal; 3. Departamento de Matemática e Centro de Matemática e Aplicações, Universidade da Beira Interior, Covilhã, Portugal

Breast cancer is the leading carcinoma among women. Due to the improved treatments the number of survivors has increased. However, the treatments administered to patients with cancer cause side effects like: fatigue, decreased aerobic capacity, muscle strength, quality of life and changes in body composition. Several studies report that exercise plays a key role in improving physical fitness (PA) and health related quality of life (HRQOL) (Oliveira, 2012) in breast cancer survivors (BCS). Speck et al. include in their review of 82 controlled trials related to physical activity interventions for cancer survivors, showing that physical exercise is well tolerated during and after treatment. Based on this hypothesis and with the objective of evaluate the effects of combined training in BCS was created MAMA_MOVE program. This research was designed as a cross-sectional study during 16 weeks, involving 19 women breast cancer survivors. Of these, 11 formed the intervention group (IG) and 8 the control group (CG). During the study, aerobic fitness was evaluated following the Balke modified protocol, the grip strength through a manual digital dynamometer, the strength of the lower limbs was indirectly assessed by Sit-stand test and HRQOL was performed by using the European Organization for Research and Treatment of Cancer Core Quality of Life Questionary C30. Regarding the exercise sessions patients were trained during 60 minutes, 3 times per week with progression in time and intensity during the intervention. After 16 weeks of training, significant improvements were observed in all variables of PA and the scales related to physical function, role function between the IG and CG $(\mathrm{p}<0.05)$. However, it was also determined a significant evolutionary trend related to Global health status/QOL and fatigue scale $(\mathrm{p}<0.1)$. In short, the results of this study highlight the importance of physical exercise to improve PA, HRQOL in BCS. Our findings are supported by other studies, suggesting that a specific exercise program as MAMA_MOVE should be recommended as co-adjuvant therapy for such patients.

References

Oliveira, E. (2012). Effects of supervised exercise intervention on cardiorespiratory fitness and health-related quality of life in breast cancer patients during treatment.

Speck, R. M., Courneya, K. S., Mâsse, L. C., Duval, S., \& Schmitz, K. H. (2010). An update of controlled physical activity trials in cancer survivors: A systematic review and meta-analysis. Journal of Cancer Survivorship, 4, 87-100. http://doi.org/10.1007/s11764-009-0110-5 


\section{Relationship between strength and body composition of university students}

Nilton Leite ${ }^{1}$, Nuno Batalha ${ }^{1,2}$, Armando Raimundo ${ }^{1,2}$

Dep. de Desporto e Saúde, Escola de Ciência e Tecnologia, Universidade de Évora, Évora, Portugal; 2. Research Centre of Sports, Health and Human Development, CIDESD; ammr@uevora.pt

Muscle strength and body composition are two components of physical fitness and subsequent, related to health and functional performance (Abdelmoula, et al, 2012). The aim of present study was to determine the relation between lower limb strength production and some body composition variables in university students. A total of 145 students of Sport Sciences at the University of Évora, (20.72 \pm 2.9 years old; 69.53 $\pm 12.91 \mathrm{~kg} ; 171.8 \pm 8.62 \mathrm{~cm}$ of height) were evaluated. To access the tight perimeter and skinfold a tape and caliper were used. Strength was evaluated by an isokinetic dynamometer (Biodex System 3 - Biodex Corp., Shirley, NY, USA) with concentric actions (3 repetitions) for knee extension and flexion at $90^{\circ}$ and $60^{\circ} / \mathrm{s}$ of angular speed. We conducted the analysis of the correlation by Person test to investigate the linear association between the evaluated parameters. For all statistical procedures, the confidence interval was 95\% ( $\mathrm{p}<0.05$ ). Significant directly proportional correlation were found between peak torque of the knee extension and flexion with the tight perimeter $(r=0.297 ; p=0.000$ and $r=0.209 ; p=0.01$ respectively) and inversely proportional correlation between the peak torque of flexion action with tight skinfold $(\mathrm{r}=$ $0.196, p=0.018)$. We concluded that depending on the size of the thigh, subjects will have more or less strength in extension and flexion of the dominant leg, while the leg strength on the flexion action decreased with increasing fat on the thigh of the dominant limb.

References

Abdelmoula, A., Martin, V., Bouchant, A., Walrand, S., Lavet, C., Taillardat, M., ... \& Ratel, S. (2012). Knee extension strength in obese and nonobese male adolescents. Applied Physiology, Nutrition, and Metabolism, 37(2), 269-275.

\section{Study of physical fitness for seniors on Alma Senior Project}

Álvaro Alves ${ }^{1}$, Paulo N. Vieira ${ }^{2}$, Fernando Vieira ${ }^{1}$

1. Piaget Institute of Almada; Almada, Portugal; alvaroalves41@gmail.com; 2 . Universidade Europeia, Lisboa.

Several studies have reported physical activity as an essential element for maintaining physical fitness, especially at older ages, as an aid to improve motor skills, injury prevention, improved quality of life, mainly with regard in daily tasks. According Spirduso (1995), exercise promotes the maintenance of balance by increasing strength levels and neuromuscular coordination, decrease the hypotensive posture and increases gait quality, even changing the values of body composition. Thus, the Municipality of Almada in partnership with the Parish Councils and other entities, developed the Alma Senior Project, in order to encourage older people to practice physical activity, using different forms and events as strategies. The aim of this research was to study the physical fitness of the participants, analysing the influence of number of activities, and comparing physical fitness in two moments, initial and final assessment. This study was designed from a sample of 110 participants, aged between 58 and 86 years, equivalent to an average age of 74 years, 48 males and 62 females. Participants are evaluated at the beginning and at the end of the sport season. In these evaluative moments three battery test "Fullerton Functional Fitness Test" Rikli and Jones (1999) are applied. Results showed that there is an improvement of physical fitness in some tests during the season. The results show a trend in physical fitness, where $p=0.098$ in the test of "strength of the lower limbs." There is also a level of significance, the "flexibility test" where $\mathrm{p}=0.046$, showing a progression of physical fitness. This project developed by the Municipality of Almada in order to promote physical activity in the county's elderly, help in improving the quality of life of older people, while also promoting human interaction, but mainly to improve physical fitness.

References

Jones, J.; Rikli, E.; Beam, W. C. (1999). A 30s Chair-Stand Test as a Measure of Lower Body Strength in Community-Residing Older Adults. Research Quartely for Exercise and Sport. 70(2), 113-119.

Jones, J.; Rikli, E. (2002). Measuring Functional Fitness for Older Adults. The Journal on Active Aging. 2, pp. 25-28.

Spirduso, W. (1995). Physical Dimension of Aging. Human Kinetics Publishers. Champaign, Illinois. 


\title{
Analysis of caloric intake and its relationship with body composition in university students
}

\author{
José Parraça1,2; José Marmeleira1,2; Jorge Bravo1; Armando Raimundo1,2; Nuno Batalha1,2; \\ Pablo Tomas-Carus ${ }^{1,2}$
}

1. Dep. de Desporto e Saúde, Escola de Ciência e Tecnologia, Universidade de Évora, Portugal; 2. Research Centre of Sports, Health and Human Development, CIDESD, Portugal; iparraca@uevora.pt

For there to be a good development of the components of body weight, it is necessary that the body is in good health and nutrition. The imbalance between food consumption and requirements, either deficit or excess, has implications for the development of body components. Several studies report differences in body composition related to the type of food; Overweight and obesity are characterized by excessive accumulation of body fat as a result of a higher caloric intake to energy expenditure. The composition of an organism reflects the accumulation of nutrients and other substrates acquired and retained by the body. The components ranging from elements to tissues and organs are the structures that make up the mass and function of all living beings. A group of 60 Students from University of Évora were evaluated. The variables obtained were assessed in the first day in the University at the time of registration, using a nutrition questionnaire and one bioelectrical impedance machine. The Spearman's Correlation was used to compare the results. We observed significant differences between men and women in total Kcal (male $2279.2 \pm$ 859.3 vs. female $2026.2 \pm 894.9 ; \mathrm{p}=0.044$ ); Cholesterol (male $455.1 \pm 213.1$ vs. female $382.7 \pm 340.8$; $\mathrm{p}=0.027$ ); Ethanol (male $9.4 \pm 17.5$ vs. female $2.4 \pm 2.9 ; \mathrm{p}=0.003$ ); Weight (male $68.7 \pm 10.9$ vs. female $56.3 \pm 10.1 ; \mathrm{p}=0.001$ ); Basal Metabolism (male $1720.1 \pm 183.8$ vs. Female1340.8 $\pm 147.4 ; \mathrm{p}=0.001$ ) and Visceral Index (male $1.95 \pm 1.42$ vs. female $1.30 \pm 0.72 ; \mathrm{p}=0.024$ ). We have also observed a statistically significant correlation between large part of the variables studied. We can conclude that the students before entering at the university have a good relationship between calorie intake and its direct relationship with body composition. However these data are predictors of a relatively high protein intake, a reduction of carbohydrates and an increase in cholesterol. The University stress associated with a poor diet, often resorting to fast food, can be a predictor of a decrease of good relationship: Nutrition and Body Composition

References

Aslam, M., Eckhauser, A. W., Dorminy, C. A., Dossett, C. M., Choi, L., \& Buchowski, M. S. (2009). Assessing body fat changes during moderate weight loss with anthropometry and bioelectrical impedance. Obesity Research and Clinical Practice, 3(4), 209-219. http://doi.org/10.1016/j.orcp.2009.03.005

Kyle, U. G., Genton, L., Gremion, G., Slosman, D. O., \& Pichard, C. (2004). Aging, physical activity and height-normalized body composition parameters. Clinical Nutrition, 23(1), 79-88. http://doi.org/10.1016/S0261-5614(03)00092-X

\section{The effects of strength training in the lower limbs and balance in the prevention of the risk of falls and cognitive function in elderly population}

Ana Pereira1,2, Pedro Silva ${ }^{3}$, Mário Espada ${ }^{1,4}$, Mário Marques ${ }^{2,3}$

1. Polytechnic Institute of Setubal, School of Education, Setúbal, Portugal; ana.pereira@ese.ips.pt ; 2. Research Center for Sports Sciences, Health and Human Development, Portugal; 3. University of Beira Interior, Covilhã, Portugal; 4. Interdisciplinary Centre for the Study of Human Performance, Lisbon, Portugal

The aim of this study was to examine the effects of strength training on lower limbs strength parameters and balance, in the risk of fall prevention and cognitive function in elderly population. Subjects were divided in two groups: experimental group ( $\mathrm{EG}, \mathrm{n}=8 ; 77.5 \pm 8.1$ years; $155.0 \pm 8.5 \mathrm{~cm} ; 66.1 \pm 10.2 \mathrm{Kg}$ and $26.9 \pm 2.8$ BMI) and a control group (CG, $n=8 ; 81.0 \pm 2.3$ years, $154.2 \pm 10.2 \mathrm{~cm} ; 66.8 \pm 9.5 \mathrm{Kg}$ and 27.1 $\pm 2.2 \mathrm{BMI})$. All subjects received home support from Association of Melhoramentos Pró-Outeiro in Oliveira of Azeméis. The EG performed an intervention program during 12 consecutive weeks with a frequency of two weekly sessions in non-consecutive days. The intervention program was based on a set of exercises to promote the strength of lower limbs, balance, and cognitive stimulation. The CG did not execute any physical activity. Both groups completed a pre-test, and after 12 weeks performed the post-test. Functional capacity was measured by the chair stand test (S30), foot up and go test (TUG) and 6-min walk test (MIN 6); the cognitive function was collected through the application of Mini-Mental State Examination (MMS) and balance assessed through Tinetti Scale (Lin et al. 2004). After 12 weeks of training, EG reduced the time to perform the test 
of coordination, agility and balance (TUG) by $2 \%$, increased the number of repetitions on S30 test by $4.1 \%$ and the number of meters from 216.4 to 246.8 (14.7\%, MIN 6) improving the aerobic capacity. Regarding to cognitive capacity (MMS) EG preserve the cognitive function comparatively to the CG [(EG: pre-test to post-test: 20.7-21.6 points (4.3\%) and in the CG: 20.03-19.65 points (-1.9\%)]. In balance performance EG showed a significant improvement after the program training $(\mathrm{P}=0.014)$ and also a significant increase compared to $C G(P=0.037)$. These data indicated that the effectiveness of the innovative training program applied during 12 weeks regarding to the prevention of the risk of falls seems to be positive in preserved physical independence and cognitive function mediated in part, by the effectiveness of program training particularly developed to institutionalised elderly people.

References

Lin, M., Hwang, H., Hu, M., Wu, H., Wang, Y., \& Huang, F. (2004). Psychometric Comparisons of the Timed Up and Go, One-Leg Stand, Functional Reach, and Tinetti Balance Measures in Community-Dwelling Older People. American Geriatrics Society, 52 (8):1343-8.

\section{Continuous metabolic syndrome risk score validity for Danish children and adolescents}

\section{Jorge Bravo ${ }^{1}$, Armando Raimundo ${ }^{1,2}$}

Departamento de Desporto e Saúde, Escola de Ciência e Tecnologia, Universidade de Évora, Portugal; 2. Research Centre of Sports, Health and Human Development, CIDESD; ammr@uevora.pt

A study performed in children (Eisenmann, Laurson, DuBose, Smith, \& Donnelly, 2010) showed that a continuous metabolic syndrome risk (cMSr) score, derived from principal component analysis (PCA), was higher in those with the metabolic syndrome (MS) and that the cMSr score raised progressively with the number of adverse risk factors, validating the cMSr score in 7-9 years old children. Their study suggests the application of such approach to validate a cMSr score for older youth. Our study aims to assess the validity of a cMSr score for Danish children and adolescents. Data included 1812 youth between 9.0-15.99 years old who participated in the European Youth Heart Study (EYHS) framework in Denmark (Riddoch et al., 2005). The cMSr was calculated based on the risk factors considered by the current International Diabetes Federation (IDF) definition for children and adolescents (Zimmet et al., 2007), involving three steps: a) all variables were normalized $(\log 10)$ because of their non-normal distribution; b) PCA with orthogonal (varimax) rotation was applied, and variables with a factor loading $\geq 0.4$, which share at least $15 \%$ of variance, were used. Analysis revealed three principal components with eigenvalue $\geq 1.0$ for girls and two principal components for boys; c) cMSr was computed by summing the individual principal component scores, each weighted for the relative contribution of the principal components to the explained variance. The cMSr score increased progressively with the number of adverse risk factors, being lowest in the group without risk factors $(-0.35 \pm 1.4)$, higher $(\mathrm{p}<0.001)$ in the group with one risk factor $(0.78 \pm 1.6)$, even higher $(\mathrm{p}<0.001)$ in the group with two risk factors $(1.98 \pm 1.2)$ and highest in those possessing the MS according to IDF criteria for youth $(3.17 \pm 1.5)$. Our results validate the application of the cMSr score for Danish children and adolescent.

References

Eisenmann, J. C., Laurson, K. R., DuBose, K. D., Smith, B. K., \& Donnelly, J. E. (2010). Construct validity of a continuous metabolic syndrome score in children. Diabetol Metab Syndr, 2, 8.

Riddoch, C., Edwards, D., Page, A., Froberg, K., Anderssen, S. A., Wedderkopp, N., Harro, M. (2005). The European Youth Heart Study cardiovascular disease risk factors in children: rationale, aims, study design, and validation of methods. J Phys Act Health, 2(1), 115-129.

Zimmet, P., Alberti, K. G. M., Kaufman, F., Tajima, N., Silink, M., Arslanian, S., Caprio, S. (2007). The metabolic syndrome in children and adolescents - an IDF consensus report. Pediatric diabetes, 8(5), 299-306.

\section{Effects of a functional rehabilitation program designed by the arronches care unit for a patient with stroke: a case report}

Ana Simeão ${ }^{1}$, Deolinda Pinto ${ }^{1}$, Andreia Miranda ${ }^{1}$, Catarina Pereira ${ }^{2}$

1. Arronches Care Unit of Mean Duration and Rehabilitation, Portugal; simeaorita@hotmail.com; 2. Departamento de Desporto e Saúde, Escola de Ciência e Tecnologia Universidade de Évora, CIDESD, Portugal

This study describes the effect of a Functional Rehabilitation Program (FR) designed for the recovery of stroke patients. A new FR approach for stroke patients was experienced obeying the internment protocol used in the Continuing Care Units Mean Duration and Rehabilitation. According to the law (DC 101/2006), the protocol includes the patient initial assessment and the design of an individual FR program of treatment developed until 90 days; moreover, suggests evaluations after 30 days of hospitalization and before day 90 
(Girão \& Guerreiro, 2011). Case Description: Patient aged 74 yrs, diagnosed with left capsular hematoma striatum due to ischemic stroke. Background: hypertension and alcoholism. In the initial evaluation, the patient was oriented in time and space, he showed left hemiparesis, hearing and visual acuity impairment, motor programming deficit, balance at setting position compromised, inability to walk, and high dependence in basic and instrumentals activities of daily living (BADLs and IADLs). Evolution prognosis: reserved. Intervention: The FR program (5 days/week) incorporated three areas: Rehabilitation Nursing $(\mathrm{RN})$, Physiotherapy (P), and Psychomotor Rehabilitation (PR).The RN performed BADLs relearning with a nurse; the $\mathrm{P}$ used the Bobath method; and the PR, as innovation, combined the traditional Brunnstrom method with sensorimotor stimulation targeting ontogenetic reliving. Evaluations were performed in the pre-intervention (PI), after 30 intervention days, and at the end of the program - before day 90. BADLs were accessed using the Barthel Index, and the IADLs using the Lawton Index. Global mobility was measured using Mobility Scale for the Elderly (EMI) and the six minutes walking test. The patient improved BADLs (Barthel, score: PI $=14 ; 30$ days $=37 ; 90$ days $=62$ ) and IADLs (Lawton score: PI $=0$; 30 days = 5; 90 day $=7$ ), as well as mobility (EMI score: PI $=0 ; 30$ days $=6$; 90 day $=11$ ), having reacquired the walking ability (walking test: $\mathrm{PI}=0 \mathrm{~m} ; 30$ days $=38 \mathrm{~m} ; 90$ day $=50 \mathrm{~m}$ ). The performed interdisciplinary intervention showed positive effects on the recovery of the stroke patient; specifically induced increases in his mobility and ability to perform BADLs and IADLs. These results suggest that interdisciplinary RF programs including ontogenetic reliving would be effective for the recovery of stroke patients with poor prognosis of evolution.

References

DC 101/2006 de 6 de Junho. Diário da República. N. ${ }^{\circ} 109$ - I S: A.

Girão, A. \& Guerreiro, I. (2011). Manual do Prestador - Recomendações para a Melhoria Contínua. Lisboa. UMCCI

\title{
Influence of the number of weekly resistance training sessions in health users of an exercise program in a corporate wellness center
}

\author{
Rhodes Serra ${ }^{1}$, Marcelo Dias $^{2}$, Roberto Simão ${ }^{1}$, Filipe Matos ${ }^{3,4}$, José Vilaça ${ }^{3,4}$, Francisco \\ Saavedra ${ }^{3,4}$ \\ 1. Escola de Educação Física e Desportos da Universidade Federal do Rio de Janeiro, Brasil; 2. Laboratório de Fisiologia do \\ Exercício da Faculdade Metodista Granbery, Juiz de Fora, MG, Brasil; 3. Universidade de Trás-os-Montes e Alto Douro (UTAD), \\ Vila Real, Portugal; 4. Centro de Investigação em Desporto, Saúde e Desenvolvimento Humano (CIDESD|UTAD), Vila Real, \\ Portugal; josevilaca@utad.pt
}

Resistance Training exercises (RT) have been shown to improve physical condition and health. However, very few is known about the influence of the number of weekly sessions in relation to RT practitioners in corporate wellness centers, designed to promote the health of workers. The aim of this study was to investigate the influence of number of weekly RT sessions on body composition (percentage of body fat, lean body mass and waist circumference), strength, flexibility and mental health of adults participating in wellness programs corporative. Sixty seven subjects (39 men and 28 women) aged between 30 and 45 years, were divided into three groups, according to the weekly frequency of training (2, 3 and 4 /week) and were submitted to the same RT methodology with 12 weeks. 10RM tests were performed for bench press, leg press and lat pulldown exercises, assessment of body composition and application of the General Health Questionnaire (GHQ 12) at baseline and after three months of training. All groups showed increases in loads of 10RM for all exercises after three months of training $(\mathrm{p}<0.05)$. The flexibility revealed a significant increase pre and post-training for all groups $(\mathrm{p}<0.05)$. In QHG 12, significant differences were observed $(\mathrm{p}<0.05)$ between the pre and post-intervention for all groups. Only in the group that trained four times a week there was a significant difference $(\mathrm{p}<0.05)$ in the percentage of fat, pre- and post-intervention. RT as a component of a corporate wellness program tends to improve strength, body composition, flexibility and psychological state of its practitioners. The number of weekly sessions had no significant impact on most of the variables.

\footnotetext{
Acknowledgement

Macro-to-Nano Human Sensing: Towards Integrated Multimodal Health Monitoring and Analytics, n. ${ }^{\circ}$ da operação NORTE-01-0145-FEDER000016, cofinanciado pelo Fundo Europeu de Desenvolvimento Regional (FEDER) através do NORTE 2020.

References:

Schoenfeld, BJ, Ratamess, NA, Peterson, MD, Contreras, B, and Tiryaki-Sonmez, G. (2015) Influence of resistance training frequency on muscular adaptations in well-trained men. J Strength Cond Res 29(7): 1821-1829
} 
Simão, R., de Salles, B. F., Figueiredo, T., Dias, I., \& Willardson, J. M. (2012). Exercise order in resistance training. Sports Medicine (Auckland, N.Z.), $42(3), 251-265$.

\title{
Prediction of intent to be active physically through the theory of self-determination
}

\author{
María Isabel Aspano Carrón¹, Susana Lobato Muñoz¹, Marco Batista², Marta Leyton \\ Román ${ }^{1}$, Ruth Jiménez Castuera ${ }^{1}$
}

1. Universidad de Extremadura; Maribel-ac@hotmail.com; 2. Escola Superior de Educação de Castelo Branco

The main objective of this study is to know motivational variables and healthy lifestyles which predict the intention to be physically active, using the Self-Determination Theory (Deci \& Ryan, 1985). Several authors (Fernández-Ozcorta, Almagro, \& Saenz-López, 2015) showed students who have satisfied their basic psychological needs (BPN) and more self-determined motivation will have a greater intention to remain physically assets in the future. The sample consisted of 187 Spanish students in physical education classes (87 boys and 100 girls), belonging to three schools of Secondary Education of Badajoz, aged between 13 and 23 years, average age 15.5 years $(S D=1.70)$. We used perceived Locus Scale Causality in Physical Education (PLOC Scale), Scale measuring basic psychological needs (BPNES), Questionnaire Healthy Lifestyles (EVS), and scale of measurement of intentionality to be physically active (MIFA). We used analysis of reliability or internal consistency of the items and a regression analysis using the method of introducing block.

Table 1

Descriptive statistics, reliability analysis and coefficients of regression analysis considering as dependent variable the intention to be physically active.

\begin{tabular}{|c|c|c|c|c|c|c|c|}
\hline Variable & $M$ & $D T$ & $\alpha$ & Beta & $R^{2}$ & $T$ & $p$ \\
\hline Block 1 & & & & & .42 & & \\
\hline BPN. of Autonomy & & & & .05 & & .71 & .47 \\
\hline BPN. of Competence & & & & .51 & & 7.04 & .00 \\
\hline BPN. of Social Relationships & & & & .05 & & .89 & .37 \\
\hline Block 2 & & & & & .49 & & \\
\hline BPN. of Autonomy & & & & .02 & & .30 & .76 \\
\hline BPN. of Competence & & & & .40 & & 5.38 & .00 \\
\hline BPN. of Social Relationships & & & & .02 & & .32 & .74 \\
\hline Autonomous M. & & & & .31 & & 3.97 & .00 \\
\hline Introyected R. & & & & -.07 & & -1.20 & .23 \\
\hline R.External R. & & & & -.12 & & -2.08 & .03 \\
\hline Demotivation & & & & .03 & & .57 & .56 \\
\hline Block 3 & & & & & .52 & & \\
\hline BPN. of Autonomy & 3.31 & .85 & .74 & .05 & & .81 & .41 \\
\hline BPN. of Competence & 3.89 & .76 & .79 & .35 & & 4.60 & .00 \\
\hline BPN. of Social Relationships & 4.31 & .68 & .80 & .00 & & .13 & .89 \\
\hline Autonomous M. & 3.88 & .84 & .88 & .32 & & 4.10 & .00 \\
\hline Introyected R. & 3.26 & 1.20 & .68 & -.07 & & -1.12 & .26 \\
\hline External R. & 3.24 & 1.20 & .69 & -.13 & & -2.29 & .02 \\
\hline Amotivation & 1.97 & 1.04 & .78 & .00 & & .13 & .89 \\
\hline Tobacco & 1.58 & .83 & .85 & -.12 & & -2.06 & .04 \\
\hline Alcohol & 1.51 & .83 & .80 & .07 & & 1.20 & .23 \\
\hline Drugs & 3.66 & .90 & .78 & .11 & & 1.68 & .09 \\
\hline Balanced diet & 3.78 & .95 & .76 & .07 & & 1.15 & .24 \\
\hline Meal time & 3.59 & 1.14 & .96 & .07 & & 1.24 & .21 \\
\hline
\end{tabular}

Note. M. = Motivation; R. = Regulation; BPN. = Basic Psychological Need.

These variables explain $42 \%$ of the variance in Block 1, Block 2 with $49 \%$ of the explained variance and eventually Block $3,52 \%$ of the variance. These results suggest that, in adolescence, intention to be physically active in the future by the subject could be associated to the promotion of cooperative learning, prioritization of effort and self-improvement, and consideration by the teacher that all class members of the group are important. Various authors (Fernández-Ozcorta, et al., 2015) have shown that intrinsic motivation significantly predicts intended to be physically active. Promoting the satisfaction of BPN of competence is crucial in physical education classes, explaining to students the purpose of the task at hand, proposing based on variety tasks, promoting the more self-determined motivation forms, which facilitate the effort and learning, making adaptive patterns are obtained, such as increasing intention of practicing physical exercise. 
Fernández-Ozcorta, E. J., Almagro, B. J., \& Sáenz-López, P. (2015). Predicción de la intención de seguir siendo físicamente activos en estudiantes universitarios. Cuadernos de Psicología del Deporte, 15(1), 275-284.

\title{
Hyperthermia: acute effect on copper and iron trace minerals in erythrocytes, serum and urine
}

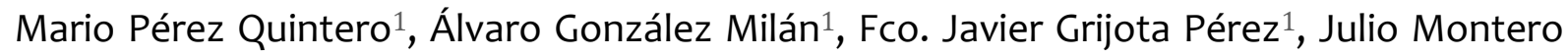 \\ Arroyo $^{1}$, Maria Concepción Robles $\mathrm{Gil}^{1}{ }^{1}$, Marcos Maynar Mariño ${ }^{1}$ \\ 1. Laboratorio de Fisiología del Ejercicio. Facultad de Ciencias del Deporte, Universidad de Extremadura. \\ Marioperezquintero10@gmail.com
}

Trace elements Iron $(\mathrm{Fe})$ and Copper $(\mathrm{Cu})$ are essential minerals involved in several exercise-related metabolisms, like the oxygen transport in the haemoglobin and myoglobin (Grijota Perez, 2016). Its organic concentrations may be affected by exercise-induced stress, which may impair optimal metabolism. When exercise is performed in hot environments the core temperature increases significantly and thermoregulatory responses are activated in order to maintain optimal organic conditions. This fact increases the whole-body biologic tension and, consequently, the antioxidant and energetic metabolic compounds can be severely affected, like $\mathrm{Fe}$ and $\mathrm{Cu}$. The aim of this work was to evaluate the effect of a maximal effort test in the organic concentrations of $\mathrm{Cu}$ and $\mathrm{Fe}$ in normothermia and hyperthermia conditions. Nineteen adult males $(22.58 \pm 1.05$ age; $178.32 \pm 5.93$ height $(\mathrm{cm}) ; 74.98 \pm 9.08$ weight $(\mathrm{kg})$ and $23.63 \pm 1.83 \mathrm{BMI})$ participated voluntarily in this survey. All of them performed two maximum incremental tests in cycloergometer separated by 48 hours. The first one was carried out in normothermic $\left(22 \pm 2^{\circ} \mathrm{C}\right)$ conditions and the second one in hyperthermic $\left(42 \pm 2^{\circ} \mathrm{C}\right)$ environment. Before and after each test blood and urine samples were obtained. Once obtained, blood samples were treated in order to separate serum and erythrocyte matrixes and conserved to biochemical analysis at $-80{ }^{\circ} \mathrm{C}$. The determination of $\mathrm{Cu}$ and $\mathrm{Fe}$ concentrations were carried out by mean of ICP-MS. Once determined the values were corrected (Dill \& Costill, 1974). As in can be observed in Table 1 the seric $\mathrm{Cu}$ concentrations augmented significantly after the effort test in normothermic $(p=0.01)$ and hyperthermic $(p=0.002)$ conditions.

\begin{tabular}{|c|c|c|c|c|c|c|c|}
\hline & & \multicolumn{3}{|c|}{ Normothermic $\left(22^{\circ} \mathrm{C}\right)$} & \multicolumn{3}{|c|}{ Hyperthermia $\left(42^{\circ} \mathrm{C}\right)$} \\
\hline & & Before & After & Sig. & Before & After & Sig. \\
\hline & Urine & $14.24 \pm 7.13$ & $11.41 \pm 4.98$ & 0.267 & $11.11 \pm 10.92$ & $12.31 \pm 12.73$ & 0.396 \\
\hline \multirow[t]{3}{*}{$\mathrm{Fe}$} & Serum & $1017.87 \pm 264.56$ & $1044.61 \pm 309.06$ & 0.687 & $1019.02 \pm 272.20$ & $1149.29 \pm 425.63$ & 0.145 \\
\hline & Erythrocite & $460.77 \pm 112.89$ & $444.44 \pm 134.37$ & 0.619 & $427.13 \pm 138.23$ & $469.56 \pm 133.04$ & 0.306 \\
\hline & Urine & $6.57 \pm 5.18$ & $7.15 \pm 4.33$ & 0.286 & $6.36 \pm 6.25$ & $7.46 \pm 6.78$ & 0.062 \\
\hline \multirow[t]{2}{*}{$\mathrm{Cu}$} & Serum & $762.96 \pm 132.22$ & $796.57 \pm 122.16$ & $\underline{0.010}$ & $724.59 \pm 138.13$ & $790.58 \pm 138.07$ & 0.002 \\
\hline & Erythrocite & $461.29 \pm 138.26$ & $427.78 \pm 130.87$ & 0.356 & $419.61 \pm 135.67$ & $456.15 \pm 148.67$ & 0.071 \\
\hline
\end{tabular}

It can be concluded that the performance of a maximal effort test induces an organic redistribution of $\mathrm{Cu}$ to overcome the increased metabolic stress, which becomes especially sensible in heat environments.

References

Dill, D. B., \& Costill, D.L. (1974). Calculation of percentage changes in volumes of blood, plasma, and red-cells in dehydration. Journal of Applied Physiology, 37(2), 247-248.

Grijota Pérez, F. J., (2016) Influencia del ejercicio físico en los niveles eritrocitarios de elementos minerales traza. Tesis Doctoral. Universidad de extremadura. Cáceres.

Kabata-Pendias, A., (1999). Biochemistry of trace elements. London: Taylor and Francis Group.

Williams, M. H. (2005). Introducción a la nutrición para la salud, condición física y deporte. Barcelona: McGraw Hil.

\section{Effects of Ballroom dancing in older adults: systematic review}

Diogo Gomes ${ }^{1}$, Catarina Pereira ${ }^{1,2}$, Ana Cruz-Ferreira ${ }^{1,2}$

1. Universidade de Évora, Departamento de Desporto e Saúde, Escola de Ciência e Tecnologia; 2. Research Centre in Sports Sciences, Health Sciences and Human Development (CIDESD); anacf@uevora.pt

The combination of scientific progress and improvement of public health status, housing and working conditions has led to a decrease in birth and death rates and an increase of the average life expectancy. As a result the world's population is aging (NIS - "Projections of resident population from 2012 to 2060."). This scenario urged the need to promote a healthy and active aging among the population through physical activity programs, for example cardiorespiratory, neuromotor, flexibility and endurance exercises. (Garber, et al. 2011). Ballroom dancing is an activity that combines cardiorespiratory, endurance, balance, 


\section{0 | International Congress CIDESD 2017}

coordination and flexibility training activities. Systematic revision is a very accurate way of summarising data and determining the methodologic quality of various research articles. Here we present the first systematic review of studies that investigated the effects of ballroom dancing on aging population. To assess the effectiveness of ballroom dancing in promoting healthy aging in the elderly. We searched 6 databases (Scielo, PEDro, Lilacs, PubMed, SportDiscus and Medline) for published research on the topic of ballroom dancing in the elderly using a selection of keywords: Dance, Ballroom, Elderly, Older adults, Age, Dança, Danças de Salão, Idoso e Sénior. The studies were selected according to the inclusion criterions and the quality and the strength of the evidence reported were assessed. Specifically, the methodological quality was assessed using the Physiotherapy Evidence Database (PEDro) and the strength of the evidence using an evidence synthesis grading system (Van Tulder, et al. 1997). Four articles were evaluated according to the PEDro scale, which obtained a mean score of 4.75 , i.e. a low methodological quality. The papers showed improvements in terms of balance (3 of 4 articles analysed), strength, overall fitness, cognitive function, autonomy or gait speed. This systematic review showed, although with limited evidence, that ballroom dancing promotes the improvement of several variables such as balance, overall physical condition and gait. It is clear that the effects of Ballroom Dancing as a promoter of healthy aging, although a very promising area of research given the current status of the developed world's population, is still in its infancy.

References:

Garber, C.,Blissmer, B., Deschenes, M., Franklin, B., Lamonte, M., Lee, I., Nieman, D., Swain, D. (2011) Quantity and Quality of Exercise for Developing and Maintaining Cardiorespiratory, Musculoskeletal, and Neuromotor Fitness in Apparently Healthy Adults: Guidance for Prescribing Exercise. Medicine \& Science in Sports \& Exercise 43(7), 1334-1359.

Van Tulder MW, Koes BW, Bouter LM. (1997) Conservative treatment of acute and chronic nonspecific low back pain: A systematic review of randomized controlled trials of the most common interventions. Spine. 22(18):2128-56.

National Institute of Statistics (NIS). (2014). "Projections of resident population from 2012 to 2060." Available in: http://www.ine.pt/xportal/xmain? xpid=INE\&xpgid=ine destaques\&DESTAQUESdest boui=208819970\&DESTAQUE $\underline{\text { Smodo }=2}$ 


\section{Basketball injury incidence in NBA: is there an impact of fixture congestion?}

Pedro T. Esteves ${ }^{1,2}$, Jorge Arede ${ }^{3}$, Nuno Leite ${ }^{2,3}$, Sara Santos ${ }^{2,3}$, Kazimierz Mikolajec 4

1. Polytechnic Institute of Guarda, Guarda, Portugal; ptesteves@gmail.com; 2. Research Centre in Sports Sciences, Health Sciences and Human Development, CIDESD, CreativeLab Research Community, Portugal; 3. Departamento de Ciências do Desporto Exercício e Saúde, Universidade de Trás-os- Montes e Alto Douro, Vila Real, Portugal; 4. Academy of Physical Education, Katowice, Poland

\section{INTRODUCTION}

The incidence of player injuries in basketball is surprisingly elevated and has generated increasing attention within the governing bodies and scientific community (Drakos et al., 2010; Talukder et al., 2016). To our knowledge, the link between fixture congestion and injury incidence has not been investigated yet in basketball. In this work we analysed the impact of fixture congestion on the number of injuries occurred in top-level basketball teams.

\section{METHODS}

Official statistics and injuries reports of 82 games of all teams participating in NBA 2014/2015 competition were retrieved from the official NBA website (http://www.nba.com (2016)). We considered the number of injuries occurring in three fixture cycles: (i) two consecutive games; (ii) one day interval between two games; and (iii) two or more days between two games.

\section{RESULTS}

The data analysis showed that injury incidence was not significantly correlated with fixture congestion $(r=-.00, p=.95)$. We also observed that injury incidence was not dependent on fixture congestion cycles $\left(\chi^{2}(6, \mathrm{~N}\right.$ $=1296)=3.48, \mathrm{p}=.75)$. Despite no significant differences were found, we noticed that a larger number of injuries occurred with one day of interval between games $(\mathrm{n}=137 ; 58.5 \%)$ than with no days of interval (i.e., two successive games) $(\mathrm{n}=55 ; 23.5 \%)$ and two-days interval between games of more $(n=42 ; 16.90 \%)$.

\section{CONCLUSIONS}

In contrary to our expectations, no relation was observed between fixture congestion cycles and injuries incidence. The results of this preliminary work may have been partially influenced by covariants such as the type of injury, match location, team standings, etc. Future research should further clarify this topic by considering the effect of a broader range of variables.

\section{REFERENCES}

Drakos, M. C., Domb, B., Starkey, C., Callahan, L., \& Allen, A. A. (2010). Injury in the National Basketball Association: A 17-year overview. Sports Health, 2(4), 284-290.

Talukder, H., Vincent, T., Foster, G., Hu, C., Huerta, J., Kumar, A., Malazarte, M., Saldana, D., \& Simpson, S. (2016). Preventing-in game injuries for NBA players. MIT Sloan Sports Analytics Conference. Boston, MA. 


\title{
Effects of soccer pitch area-restrictions on tactical behavior, physical and physiological performances in large-sided games
}

\author{
Bruno Gonçalves ${ }^{1,2}$, Pedro Esteves ${ }^{1,3}$, Hugo Folgado ${ }^{1,4}$, Angel Ric ${ }^{5}$, Carlota Torrents ${ }^{5}$, Jaime \\ Sampaio ${ }^{1,2}$ \\ 1. Research Center in Sports Sciences, Health Sciences and Human Development, CIDESD, CreativeLab Research Community, \\ Portugal; bgoncalves@utad.pt; 2. Sport Sciences Department, University of Trás-os-Montes e Alto Douro, Vila Real, Portugal; 3. \\ Polytechnique Institute of Guarda, Guarda, Portugal; 4. Departamento de Desporto e Saúde, Escola de Ciências e Tecnologia, \\ Universidade de Eワvora, Eワvora, Portugal; 5. National Institute of Physical Education of Catalonia (INEFC), University of Lleida, \\ Lleida, Spain
}

\section{INTRODUCTION}

The aim of this study was to identify how pitch area-restrictions affects the tactical behavior, the physical and the physiological performances of players during soccer largesided games.

\section{METHODS}

A 10 vs. 9 large-sided game was performed under three experimental conditions: (i) restricted-spacing, the pitch was divided into specific areas where players were assigned and they should not leave it; (ii) contiguous-spacing, the pitch was divided into specific areas where the players were only allowed to move to a neighboring one; (iii) free-spacing, the players had no restrictions in space occupation. The positional data were used to compute players' spatial exploration index and also the distance, coefficient of variation, approximate entropy and frequency of near-in-phase displacements synchronization of players' dyads formed by the outfield teammates. Players' physical and physiological performances were assessed by the distance covered at different speed categories, game pace and heart rate.

\section{RESULTS}

Most likely higher values were found in players' spatial exploration index under freespacing conditions. The synchronization between dyads' displacements showed higher values for contiguous-spacing and free-spacing conditions. Contrariwise, for the jogging and running intensity zones, restricted-spacing demanded a moderate effect and most likely decrease compared to other scenarios ( $20-50 \%$ to jogging and $\sim 60-90 \%$ to running).

\section{CONCLUSIONS}

Overall, the effects of limiting players' spatial exploration greatly impaired the co-adaptation between teammates' positioning while decreasing the physical and physiological performances. These results allow for a better understanding of players' decision-making process according to specific task rules and can be relevant to enrich practice task design, such that coaches acknowledge the differential effect by using specific pitch-position areas restrictions.

\section{Performance profiles in NBA playoffs: differences between the first and the last game of the series}

Nuno Mateus ${ }^{1}$, Bruno Gonçalves ${ }^{1}$, Eduardo Abade ${ }^{2}$, Nuno Leite ${ }^{1}$, Miguel Angel Gomez ${ }^{3}$, Jaime Sampaio ${ }^{1}$

1. Research Center in Sports Sciences, Health Sciences and Human Development, CIDESD, CreativeLab Research Community, Portugal; nuno mateus23@hotmail.com; 2. Research Center in Sports Sciences, Health Sciences and Human Development, CIDESD, CreativeLab Research Community, University Institute of Maia, ISMAI, Portugal; 3. Faculty of Physical Activity and Sport Sciences, Polytechnic University of Madrid, Spain

\section{INTRODUCTION}

The National Basketball Association (NBA) Playoffs games have unique characteristics that players rarely experienced during the first competitive phase of the season. Despite the literature suggested that players' performance 
changed along a playoff series, this topic is quite unexplored. Therefore, the aim of this study was to identify performance profiles in NBA playoffs and describe their differences between the first and the last game of the series.

\section{METHODS}

Archival data were obtained from official boxscore and player-tracking of 2014-2015 NBA Playoffs games. A total of 30 games were considered, in order to analyse only the first and the last game of each series. No games have been excluded, regardless the game outcome or the occurrence of additional periods. Data processing was carried out in two phases: first, a k-means cluster analysis used statistical records from both games to create and describe maximal different groups of game performance profiles; second, a descriptive discriminant analysis, was performed to all variables according to the obtained clusters, to identify which variables best discriminate them.

\section{RESULTS}

The results allowed discriminating different players' performances, differing in organizational, scoring and without the ball game-statistics. Players from a first-round loser team displayed less dominant performances, contrastingly players from the champion team were widely allocated in the clusters with a better offensive performance. Most players shooting more in the first game of the series. In the decisive game players make more outside shoots, performed more passes and touched the ball a greater number of times. Players committed more fouls and achieved a greater performance in some defensive actions, also in the last game.

\section{CONCLUSIONS}

The players performance was affected by the greater psychological load associated to the decisive game. In the last game, offensively teams played more collectively and defensively performed more cohesive and closed. Coaches should design specific training programs to prepare their players for playoffs special moments; and develop special tactics according to the game changes that occur throughout playoffs series.

\section{The effects of an enrichment training program in thinking, motor, and game creative behaviour in team sports}

Sara Santos ${ }^{1}$, Jaime Sampaio ${ }^{1}$, Nuno Leite ${ }^{1}$

1. Research Center in Sport Sciences, Health and Human Development, CreativeLab, University of Trás-os-Montes and Alto Douro, Vila Real, Portugal; sarasantos_8@hotmail.com

\section{INTRODUCTION}

Creativity in team sports inspires players to achieve remarkable behaviors that contribute to sports upgrade (Santos, Memmert, Sampaio \& Leite, 2016). This study's purpose was two-fold: first, it intended to examine the Enrichment Training Program effects in creative thinking, motor performance, and in-game creative behavior in team sports. Second, it aimed to investigate a relationship between creative thinking and in-game creativity.

\section{METHODS}

Forty children from primary school were allocated into control $(n=18$, age: $9.2 \pm 0.4)$ and experimental $(\mathrm{n}=22$, age: $9.5 \pm 0.7)$ groups.

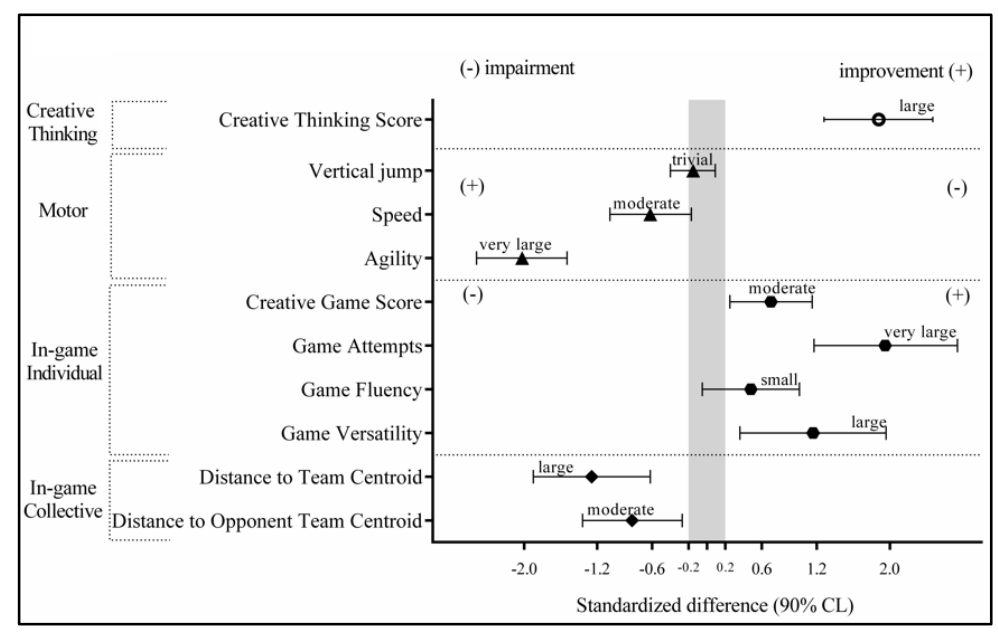

Experimental children participated in a fivemonth Creativity Program involving either creativity thinking, diversification, physical 
literacy, and nonlinear pedagogy including TGfU and differential learning approaches. Variables in the study included: a) creative thinking (divergent thinking); b) motor performance (vertical jump, speed, and agility); c) in-game individual creative behavior (attempts, fluency, and versatility); and d) in-game collective behavior (inter-player positional regularity).

\section{RESULTS}

The results suggest that the Enrichment Program fostered creative thinking, agility, and speed motor performance. Moreover, it stretched the individual exploratory behavior through the improvement of the attempts and versatility of the player's actions. Lastly, it nurtured a better learning of the tactical principles, whereas the children were more coordinated with their teammates' and opponents' positioning. Additionally, this study presents a positive correlation linking creative thinking and in-game creative performance.

\section{CONCLUSIONS}

These findings highlight that creativity is facilitated while players become more thinking and game-skilled and acquired a better capacity to explore their technical-tactical actions in field. Coaches may apply this enrichment environment to inspire children's disposition to move outside the box and trigger a creative spark in players. In fact, the team sports environment is ideally suited for fostering creative behavior, a higherorder disposition that will go on to differentiate the everyday life of a child.

Figure 1. Standardized differences in thinking, motor, in-game individual and in-game collective variables between pre-post test variations. The grey area represents trivial differences.

\section{REFERENCES}

Santos, S., Memmert, D., Sampaio, J. and Leite, N. (2016). The spawns of creative behavior in team sports: A creativity developmental framework. Frontiers in Psychology, 7(1282).

\title{
How players exploit variability and regularity of game actions in female volleyball teams
}

\author{
Ana Ramos ${ }^{1}$, Patrícia Coutinho ${ }^{1}$, Pedro Silva ${ }^{1}$, Keith Davids ${ }^{2}$, Isabel Mesquita ${ }^{1}$
}

1. CIFI2D, Faculty of Sport, University of Porto, Porto, Portugal; 111101083@fade.up.pt; 2. Centre for Sports Engineering Research, Sheffield Hallam University, Sheffield, UK

\section{INTRODUCTION}

Variability analysis has been used to understand how competitive constraints shape different behaviours in team sports. Specifically in volleyball, there is a general consensus on the importance of promoting adaptive variability in some game actions to avoid predictability and to help performers to exploit different solutions when competitive conditions change (Silva et al., 2015). Nevertheless, little is known about the role of adaptive variability on the emergence of tactical performance behaviours in volleyball teams at distinct expertise levels, and according to different game moments. In line with this, the purpose of this study was to analyse and to compare variability of tactical performance indices within complex I (setting conditions, attack zone, attack tempo and block opposition) at two different competitive levels (elite and national). It was also examined whether variability was influenced by set type (decisional and non-decisional) and period (initial and final).

\section{METHODS}

Eight matches from the 2012 Olympics competition (EL or elite level) and from the Portuguese national league (NL or national level) in the 2014-2015 season were analysed (60 sets -30 in each group; 1496 rallies). Variability of tactical performance indices was assessed using Shannon entropy measures. Magnitudebased inferences were used to analyse the practical significance of compared values of selected variables. 


\section{RESULTS}

Results showed differences between both levels for all variables especially when set type and periods were considered. EL exploited system stability in setting conditions and block opposition, but greater unpredictability in zone and tempo of attack. In decisional set, EL teams presented less variability in setting conditions and in attack variability (zone and tempo). In final set period EL showed less variability in setting conditions and attack zone, and higher variability in attack tempo.

\section{CONCLUSIONS}

The findings suggest that unpredictability in attacking actions was a key factor that could only be achieved with greater stability in setting conditions. Data revealed how EL displayed better resources to exploit adaptive and functional variability during critical game moments. Results reported may guide coaches to exploit processes of co-adaptation in teams by manipulating competitive constraints during training sessions.

\section{REFERENCES}

Silva, P., Esteves, P., Correia, V., Davids, K., Araujo, D., \& Garganta, J. (2015). Effects of manipulations of player numbers vs. field dimensions on inter-individual coordination during small-sided games in youth football. International Journal of Performance Analysis in Sport, 15, 641-659.

\section{Relative age effect on Olympic Beach Volleyball athletes according to final ranking in the competition}

Alexandre Medeiros ${ }^{1}$, Karla de Jesus ${ }^{2}$, Kelly de Jesus², Arthur Alencar ${ }^{1}$, José Afonso ${ }^{3}$, Antonio García de Alcaraz ${ }^{4}$, Cláudio Assumpção ${ }^{1}$, Rui Marcelino ${ }^{5}$, Isabel Mesquita ${ }^{3}$

1. Research Group in Biodynamic Human Movement, Institute of Physical Education and Sport, Federal University of Ceará, Fortaleza, Ceará, Brazil; alexandremedeiros@ufc.br; 2. Human Motor Behaviour Studies Laboratory, Faculty of Physical Education and Physiotherapy, Federal University of Amazonas, Amazonas, Manaus, Brazil; 3. Centre of Research, Education, Innovation and Intervention in Sport, Faculty of Sport, University of Porto, Porto, Portugal; 4. Faculty of Sport Sciences, Polytechnic University of Madrid, Spain; 5. Research Center in Sports Sciences, Health Sciences and Human Development, CIDESD, CreativeLab Research Community, Vila Real, Portugal

\section{INTRODUCTION}

Relative Age Effect (RAE) has been widely reported in literature (Wattie, Schorer, \& Baker, 2015), but to our knowledge this topic has not yet focused on Olympic Beach Volleyball (BV) players. This study aimed to examine the effects of the RAE in Olympic Games BV players' in the final rankings in those competitions.

Table 1

Birth-date distribution of the players by quartile according to gender and ranking in the tournament

\begin{tabular}{|c|c|c|c|c|c|c|c|c|}
\hline & Ranking & $\begin{array}{c}\text { Q1 } \\
\mathrm{N}(\%)\end{array}$ & $\begin{array}{c}\text { Q2 } \\
\mathrm{N}(\%)\end{array}$ & $\begin{array}{c}\text { Q3 } \\
\mathrm{N}(\%)\end{array}$ & $\begin{array}{c}\mathrm{Q} 4 \\
\mathrm{~N}(\%)\end{array}$ & $\mathrm{X}^{2}$ & $d f$ & $\mathrm{p}$ \\
\hline \multirow{4}{*}{ Male } & $1^{\circ}-8^{\circ}$ & $26(27.1)$ & $36(37.5)$ & $17(17.7)$ & $17(17.7)$ & \multirow{4}{*}{5.091} & \multirow{4}{*}{6} & \multirow{4}{*}{0.532} \\
\hline & $9^{\circ}-16^{\circ}$ & $21(22.6)$ & $30(32.3)$ & $27(29.0)$ & $15(16.1)$ & & & \\
\hline & $17^{\circ}-24^{\circ}$ & $23(23.7)$ & $28(28.9)$ & $29(29.9)$ & $17(17.5)$ & & & \\
\hline & Total & $70(24.5)$ & $94(32.9)$ & $73(25.5)$ & $49(17.1)$ & & & \\
\hline \multirow{4}{*}{ Female } & $1^{\circ}-8^{\circ}$ & $27(28.1)$ & $32(33.3)$ & $28(29.2)$ & $9(9.4)$ & \multirow{4}{*}{10.979} & \multirow{4}{*}{6} & \multirow{4}{*}{0.089} \\
\hline & $9^{\circ}-16^{\circ}$ & $33(35.5)$ & $21(22.6)$ & 18(19.4) & $21(22.6)$ & & & \\
\hline & $17^{\circ}-24^{\circ}$ & $22(26.5)$ & $23(27.7)$ & $20(24.1)$ & $18(21.7)$ & & & \\
\hline & Total & $82(30.1)$ & $76(27.9)$ & $66(24.3)$ & $48(17.6)$ & & & \\
\hline
\end{tabular}

Q1: first quarter - from January to March; Q2: second quarter - from April to June; Q3: third quarter - from July to September; Q4: fourth quarter - from October to December; $\mathrm{X}^{2}$ : chi-square; $d f$ : degrees of freedom

\section{METHODS}

All the BV players that participate in the Olympic Games from 1996 to 2016 were sampled [n=286 male (age: $29.1 \pm 5.2$ yrs, stature: $193.2 \pm 6.3 \mathrm{~cm}$, weight: $89.2 \pm 7.3 \mathrm{~kg}$ ); $\mathrm{n}=272$ female $(29.2 \pm 4.9 \mathrm{yrs}, 179.0 \pm 5.9 \mathrm{~cm}$, $67.7 \pm 5.2 \mathrm{~kg}$ ). Player birthdates were obtained through the Fédération Internationale of Volleyball, and were then ranked into four yearly quartiles. Chi-square analyses with adjusted 
residual values were used to compare differences between expected birth-date distributions across the quarters and the final ranking. Statistical significance was set at $\mathrm{p}<0.05$.

\section{RESULTS}

Table 1 shows the birth-date distribution of the players by quartile for each gender and result in the tournament.

\section{CONCLUSIONS}

RAE in BV are not associated with the final ranking in Olympic Game. However, there were more players born in the first two quartiles of the year when compared to the last two quartiles (164 vs. 122 in male; 158 vs. 114 in female).
Therefore, it seems that the RAE is more complex than previously thought. Specifically, although it conditions the likelihood of players born in each quartile into moving towards the highest levels of practice, it does not impair performance once you get there. Perhaps those born in the latter quartiles, even though initially in a disadvantageous situation, are forced into being increasingly better in order to overcome the RAE. Thus, when they do reach high level, RAE does not hinder the obtained results.

\section{REFERENCES}

Wattie, N., Schorer, J., \& Baker, J. (2015). The Relative Age Effect in Sport: A Developmental Systems Model. Sports Medicine, 45(1), 83-94. doi:10.1007/s40279014-0248-9

\section{When the context constraint futsal players' development}

\section{Bruno Travassos ${ }^{1,2}$, Tiago Lopes ${ }^{1}$, João Santos ${ }^{1}$}

1. Sports Science Department, University of Beira Interior, Covilhã, Portugal; bfrt@ubi.pt; 2. Research Center in Sport Sciences, Health and Human Development, CreativeLab, Vila Real, Portugal

\section{INTRODUCTION}

In this exploratory study, we assessed the influence of contextual factors on the development of youth futsal players' performance.

\section{METHODS}

Eighty five youth futsal players U13 (11.98 \pm 0.38 yr. old) from 6 Portuguese futsal teams participated on the study. Three teams were from rural contexts $(M=5234.67 \pm 3067.62$ inhabitants $)$ and three teams from an urban context (547733 inhabitants). Each team was divided into balanced teams that played 3 small-sided games $3 \mathrm{vs} 3$ (dimensions: $20 \mathrm{~m} \times 10 \mathrm{~m}$ ) of 5 min against other teams. The performance of teams was registered through a notational system using VideoObserver software. A questioner was used to assess information about formal and informal f players' practice. Differences on teams, from rural and urban contexts, were assessed independently via standardized differences with pooled variance, with $90 \%$ Confidence Intervals $(90 \% \mathrm{CI})$. Thresholds for effect sizes (ES) statistics were 0.2, trivial; 0.6, small; 1.2 , moderate; 2.0 , large; and $>2.0$, very large.
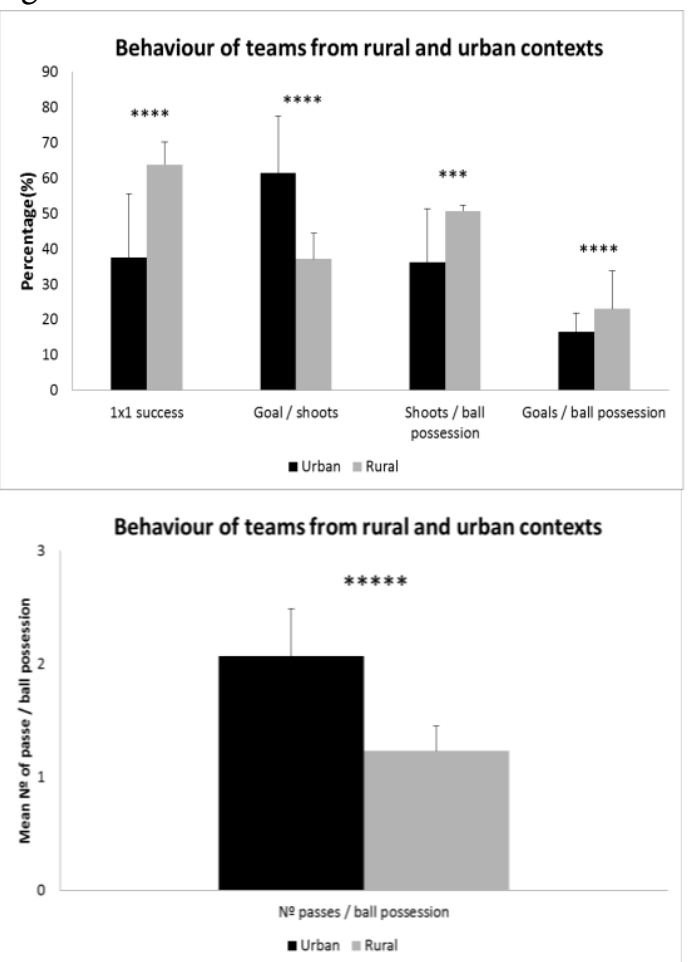

Figura 1. Mean value and standard deviation of players' performance. ${ }^{* * *}$ moderate effect size; ${ }^{* * * *}$ large effect size; ${ }^{* * * *}$ very large effect size. 


\section{RESULTS}

Players' performance revealed a very large effect on the number of passes per ball possession (2.57, [0.39, 3.91]), and a large effect on the percentage of goals per shoots $(1.95,[0.02,3.08])$ with higher values for urban than rural teams. In opposition, a large effect on successful $1 \times 1$ situations (1.94, [0.02, $3.08]$ ), on shoots per ball possession (1.35, $[0.36,2.52])$, and a moderate effect on goals per ball possession $(0.77,[0.76,1.99])$, with higher values for rural than urban teams were observed (see Figure 1). Results of formal practice didn't revealed differences on the number of practice sessions per week (2 per week), nor in the number of hours per session $(\approx 90 \mathrm{~h}$ for all). It was observed a very large effect on the percentage of players that practiced futsal for more than three years (2.51,
$[0.36,3.65])$, with higher values for urban $(55.56 \pm 19.25 \%)$ than rural teams $(20.56 \pm 4.19 \%)$. The results regarding the informal practice revealed a very large effect on the informal practice of futsal and other sport activities (9.36, [3.68, 11.26]), with higher percentage of players from rural $(70.37 \pm 6.45 \%)$ than urban teams $(14.44 \pm 5.5 \%)$.

\section{CONCLUSIONS}

Our results revealed differences on players' capabilities of rural and urban contexts to perform. While children from rural contexts have more opportunities of informal practice, children from urban contexts started earlier the practice of formal activities with consequences on the performance profiles of players.

\section{The effect of the number of passes in the final action outcome in top level handball matches}

Tiago Oliveira ${ }^{1}$, Bruno Gonçalves ${ }^{1}$, Jaime Sampaio ${ }^{1}$

\section{Research Center in Sports Sciences, Health Sciences and Human Development, CIDESD, CreativeLab Research Community, Portugal; ajaime@utad.pt}

\section{INTRODUCTION}

The Handball game suffered a great evolution in terms of speed in the last ten years, is much faster and the number of ball possesses of each team is certainly higher. Through the constant interaction of the players, the study of their role and importance in an offensive action sequence could provide relevant information in match analysis. In this sense, the aim of the study was to verify the effect of the number of passes per ball possession according to the final action outcome and to identify the influence of each player in the team-passing network.

\section{METHODS}

The sample consisted in the $\mathrm{KO}$ matches of the Velux EHF Champions League 2014-2015 and the variables considered were the number of passes per ball possession and the final action outcome. The video analysis was made with Longomatch by Fluendo and the ball movement were registered in CDartfish Easytag. Further analysis was made with Microsoft ${ }^{\circledR}$ Excel and the calculation of the number of passes per ball possession was made with MATLAB $\AA$. The network graphics were created with Cytoscape. According to the ball movement in attack, the backcourt players were more influent in the team-passing network, due to their positioning on the court.

\section{RESULTS}

According to the final action outcome, differences were found in $9 \mathrm{M}$ and $6 \mathrm{M}$ attempts. The number of passes was higher for $6 \mathrm{M}$ goal, comparing to $9 \mathrm{M}$ goal. Despite of the increased game pace, when compared the 6-meter line shots, the number of passes had influence in the final action outcome, since the players need to perform more passes to achieve success.

\section{CONCLUSION}

As predictable, according to the ball movement in attack, the backcourt players were 
more influent in the team-passing network, due to their positioning on the court.

The number of passes per ball possession was higher for $6 \mathrm{M}$ goal, comparing to $9 \mathrm{M}$ goal. Attacking and shooting from middle-range zones doesn't require so many passes between the players as situation of breakthrough does, forcing the defenders to commit errors.
Despite of the increased game pace, when compared the 6-meter line shots, the number of passes had influence in the final action outcome, since the players need to perform more passes to achieve success.

The results of the present study may suggest the importance of successive defensive tackles in order to break the offensive ball movement.

\section{The Influence of numerical relationship in defensive retreat - Analysis of the final phase of Men's European Championship 2014}

Duarte Sousa $^{1}$, Américo Cardoso ${ }^{1}$, João Vieira ${ }^{1}$, Ana Rodrigues ${ }^{1}$, Catarina Fernando ${ }^{1,2}$, Helder Lopes ${ }^{1,2}$, João Prudente ${ }^{1,2}$

1. Faculty of Social Sciences, Department of Physical Education and Sports, University of Madeira; duartesousaa@gmail.com; 2. Research Centre in Sports Sciences, Health Sciences and Human Development, CIDESD

\section{INTRODUCTION}

The evolution of Handball has turned offensive transitions very fast, promoting imbalances in defensive retreat, considered the first phase of the defense, making its approach important.

It aims to prevent or hinder, slowing the opponent counter attack, but also retrieve the ball through offensive actions over the attackers and pass lines with pressure made on the ball carrier, preventing its progression and delaying its decision trying to thereby recover more quickly the ball. As Picon regards (2005) teams should practice defensive retreat, working different aspects of it, to cover, for example, the fast transitions after goal, in order to guarantee the defensive balance, given the speed of the transitions of teams that better explore the counterattack. Constantini (1997) stated that this game sequence seems so simple that very few systematic reviews has it as an object, a situation that still remains.

With this study, we intend to analyse the defensive retreat in high-level handball in different numerical relationships, in order to detect patterns of behaviour during this attackdefense transition in final stage of Men's European Championship 2014 (EC 2014).

\section{METHODS}

For this study it was used observational methodology, and built, validated and subsequently used a mixed ad hoc instrument, field format with categories systems to collect the data. The prospective and retrospective sequential analysis and the polar coordinates technique were used for data analysis. The sample included all $(\mathrm{n}=724)$ defensive retreat game sequences, which occurred in 16 final matches of the EC 2014.

\section{RESULTS}

The results shows that there is significant probability of: 1) The numerical superiority activate an active retreat inhibiting passive retreat; 2 ) The inferiority inhibits passive retreat as well as ball recovery and activates stopping opponents counterattack, but using the sanctioned fault with exclusion; 3) The numerical equality enables the ball recovery and the passive retreat.

\section{CONCLUSIONS}

Given the results obtained it is possible to state that the numerical relationship influences the results and the behavior in defensive retreat: a numerical superiority promotes a more proactive attitude, while equality and inferiority promotes a more passive behavior.

\section{REFERENCES}

Constantini, D. (1997). Le repli défensif. In Handball. Cahiers des sports. Éditions "Revue EPS". Paris

Picon, G. (2005). Repliegue defensive. Paper presented in Internacionales. Days of Handball. 7 y 8 de julio. Malaga 


\section{Exploring the effects of mental and physical fatigue on soccer players' workload and collective behaviour during small-sided games}

Diogo Coutinho ${ }^{1}$, Bruno Gonçalves ${ }^{1}$, Dell Wong², Bruno Travassos ${ }^{2}$, Jaime Sampaio ${ }^{1}$

1. Research Centre in Sports Sciences, Health Sciences and Human Development, CIDESD, CreativeLab, University of Trás-osMontes and Alto Douro, Portugal; ajaime@utad.pt; 2. Sports Science Research Center, Shadong Sport University; 3. Research Centre in Sports Sciences, Health Sciences and Human Development, CIDESD, University of Beira Interior, Portugal

\section{INTRODUCTION}

In team sports, player's behaviour is shaped by the interaction between the performer, the task and the surrounding environment constraints. Although some research has been developed to understand how players adapt their behaviour to different tasks constraints, there is little information regarding to the effects of the manipulation of individual constraints. Thus, this study aimed to identify the effects of induced mental and physical fatigue on soccer players' workload and collective behaviour during smallsided games.

\section{METHODS}

Ten U15 players performed a $\mathrm{Gk}+5 \mathrm{v} 5+\mathrm{Gk}$ game under three conditions: a) control (CON), playing the game without any previous activity; b) physical fatigue (PHY), playing the game after performing a repeated change-of-direction exercise; c) mental fatigue (MEN), playing the game after completing a 30 minutes computerized version of the Stroop task. Players' positional data was used to compute timemotion variables and tactical-related.

\section{RESULTS}

On the time-motion analysis, the PHY showed a possible $\sim 38 \%$ decrease in the ratio of high distance covered and a likely $\sim 33 \%$ decrease in the number of high-intensity accelerations when compared with CON condition. The MEN showed a decrease in almost physical variables, with the exception of total distance comparatively with CON. From the tactical perspective, the PHY presented a very likely $\sim 6.9 \%$ decrease in the distance between dyads and a most likely $\sim 7 \%$ decrease in the team's stretch index in comparison with CON. The MEN showed a decrease in most of the tactical variables, mainly in the team coordination in relation to CON (likely $\sim 8 \%$ less).

\section{CONCLUSIONS}

The induced physical fatigue decreased the team dispersion and optimized the in-game physical performance. As players' behaviour is dependent on their interpersonal distance, it appears that closer distances require less demanding movements. The mental fatigue impaired the players' physical performance, possibly due to the increase perception of effort. Higher team coordination seems to emerge when the teams presented lower dispersion. Although the MEN presented lower team dispersion than CON, there was a decrease in the team coordination. This decrease may be pointed as a change in the players' ability to identify and use the environmental cues when mentally fatigued. Coaches may use both mental fatigue and physical fatigue conditions to promote variability in players' performances. 


\title{
Collective behaviour in football teams: A case study of a professional team against different opponents
}

\author{
Rui Marcelino ${ }^{1,2,3}$, Bruno Gonçalvesa², Jaime Sampaio ${ }^{1,2}$, lain Couzind ${ }^{5,6}$, Máté Nagye ${ }^{6,7}$ \\ 1. Research Center in Sports Sciences, Health Sciences and Human Development, CIDESD, Portugal; rmarcelino@utad.pt; 2. \\ University of Trás-os-Montes e Alto Douro; 3. University Institute of Maia, ISMAI; 4. Princeton University, Department of \\ Ecology \& Evolutionary Biology, Princeton, NJ 08544 USA; 5. Max Planck Institute for Ornithology, Department of Collective \\ Behaviour, Konstanz, Germany; 6. University of Konstanz, Chair of Biodiversity and Collective Behaviour, D-78457 Konstanz; \\ 7. MTA-ELTE Statistical and Biological Physics Research Group, Budapest, Hungary
}

\section{INTRODUCTION}

Team Sports refer to games played between two opposing teams. The players interact directly and concurrently to achieve an objective that involves teammates facilitating the movement of a ball, in order to score and to prevent the opposition from scoring. There are irreproducible multiinteractions of team and individual actions - a "coordination dynamics", according to Kelso (1995) - deeply intent on scoring more than the opponents. In this sense, sport teams are composed of different interacting individuals who develop cooperative relations to achieve successful performance outcomes (Sampaio \& Maçãs, 2012). This work aims to explore the interactions from the players of a particular team against two different opponents, in two consecutive matches.

\section{METHODS}

Two full matches from the German Bundesliga 2015-2016 season were analysed. The $\mathrm{X}$ and $\mathrm{Y}$ positional coordinates of all players (24 in total) and the ball were collected with TRACAB Image Tracking SystemTM sampling at $25 \mathrm{~Hz}$. For each intra- and inter-team pair, interactions were quantified based on highly correlated trajectory segments. Interactions in the match where calculated with directional correlation with time delay (Nagy, Akos, Biro, \& Vicsek, 2010) for each pair of teammates and opponents using a 6 -second-long time windows. The momentary interactions of each pair were summed for intervals in a range from a minute to the whole duration of the match.

\section{RESULTS}

Results reveal a consistent individual behaviour between matches with respect to opponents (see figure).

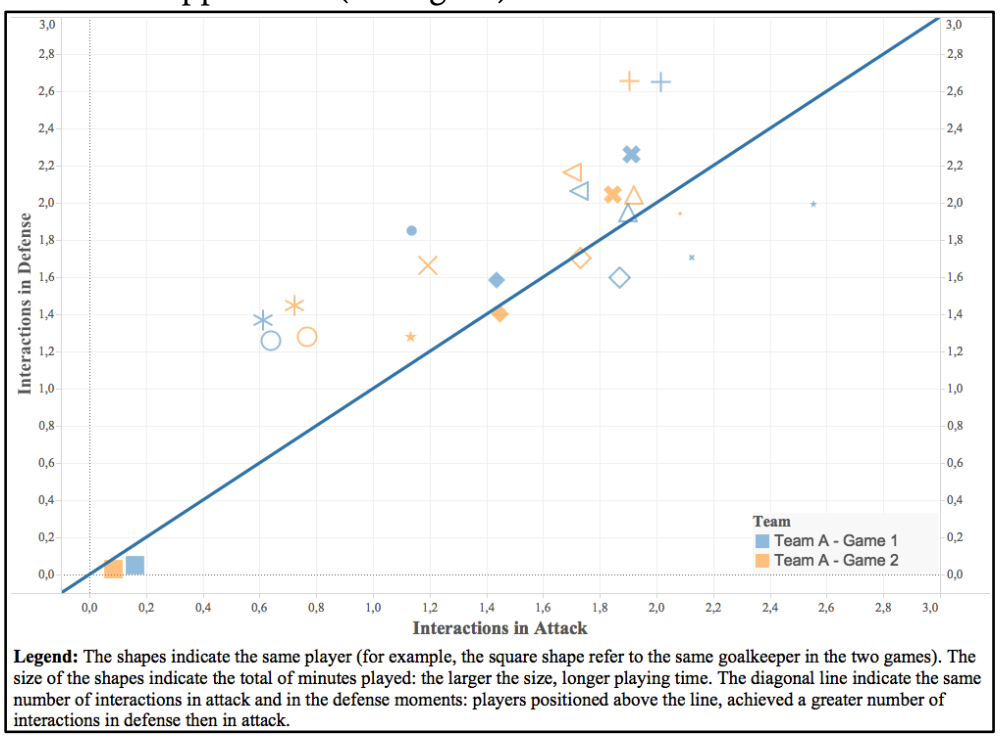

\section{CONCLUSION}

Football players assumed similar behaviour when interacting within both teammates and opponents in consecutive matches. Results shows that the method has the possibility to quantify characteristic behaviour of players and player's roles. This has potential application on players' (development, evaluation, etc.) and in teams' (tactical development, selecting team composition, etc.).

\section{REFERENCES}

Kelso, J. (1995). Dynamic Patterns: The Self-organization of Brain and Behavior. Cambridge, MA: Bradford Books/MIT Press.

Nagy, M., Akos, Z., Biro, D., \& Vicsek, T. (2010). Hierarchical group dynamics in pigeon flocks. Nature, 464(7290), 890-893

Sampaio, J., \& Maçãs, V. (2012). Measuring tactical behavior in Football. Int J Sports Med.(33), 1-7. 


\section{Effects of knowing the task duration on players' pacing patterns during soccer small-sided games}

Ricardo Ferraz1,2, Bruno Gonçalves², Roland van den Tillaar ${ }^{3}$, Jaime Sampaio², Mário Marques 1,2

1. University of Beira Interior, Department of Sport Sciences, Portugal; ricardo ferraz@hotmail.com; 2. Research Centre in Sport Sciences, Health Sciences and Human Development, CIDESD, Portugal; 3. Department of Teacher Education of Nord Trøndelag University College, Levanger, Norway

\section{INTRODUCTION}

The topic of fatigue in team sports have been updated recently, due to the possible effects of pacing (Waldron \& Highton, 2014). The knowledge of the duration is also known as a significant factor in the pacing pattern and it has been demonstrated to be a major factor in the allocation of physiological and psychological resources during continuous exercise, but also recently applicable and investigated in intermittent exercise (Waldron \& Highton, 2014). Despite advances on this topic, few studies examined the influence of pacing as an explanation of the work outputs changes in team sports. Therefore, the purpose of this study was to investigate the influence of prior knowledge of exercise duration on the pacing pattern employed during game-based activities in soccer.

\section{METHODS}

Twenty semi-professional male soccer players participated in this study. In the first game scenario, players were not informed how long they would be required to play the small-sided game and the activity was terminated after 20min (Unknown Condition). In the second game scenario, players were told that they would play the small-sided game for 10-min, but immediately after completing the 10-minute game they were asked to complete another 10min (Partially Condition). In the third game scenario, players were instructed that they would play the small-sided game for 20 minutes and then they completed the 20-min game (Known Condition).

\section{RESULTS}

The results presented a tendency of higher values in all performance variables in the [0'-10'] min compared with the [10'-20'] min. As the players' previous knowledge about the tasks duration increased, the performance between two moments tended to be similar. Considering the entire 20-min game duration, the Partially Condition of the exercise was the most demanding condition.

\section{CONCLUSION}

These results provides some evidence that during small-sided games in soccer, athletes alter their pacing patterns based on the knowledge of the exercise duration. The knowledge of a shorter duration seems to lead to an increase of exercise duration demand and longer exercise durations possibly tend to decrease differences between full knowledge and not knowing the exercise duration. Coaches should consider the potential and the possibilities of the manipulation of this variable in terms of the physical impact regulation in their training exercises.

\section{REFERENCES}

Waldron, M., \& Highton, J. (2014). Fatigue and Pacing in High-Intensity Intermittent Team Sport: An Update. Sports Medicine, 44, 1645-1658. 


\section{Classifying young basketball players by anthropometric characteristics and competition performances}

\section{Bruno Figueira ${ }^{1,2}$, Bruno Gonçalves ${ }^{1,2}$, Nerijus Masiulis ${ }^{3}$, Nuno Leite ${ }^{1,2}$, Jaime Sampaio ${ }^{1,2}$}

1. Research Center in Sports Sciences, Health Sciences and Human Development, CIDESD; benfigueira@hotmail.com; 2. Sport Sciences Department, University of Trás-os-Montes e Alto Douro, Vila Real. Portugal; 3. Faculty of Sports Biomedicine, Lithuanian Sports University

\section{INTRODUCTION}

The underlying determinants of success in sport performance has been thoroughly analysed by sports sciences. Consequently, the sport scientist position emerged as a natural support for sports organizations to improve knowledge about training and competitions. For example, science support can be determinant when accounting for specificity of performance profiles to group players not only by age criteria. Thus, the present study aimed to classify young Basketball players according to their sport performance profile during competition and provide to coaches an optimized control of players' responses to training.

\section{METHODS}

Thirty-three youth male players $(13.6 \pm 0.6)$ participated in the study. A k-means cluster analysis was computed to classify players into more homogeneous groups according to their anthropometric and performance profiles during competition. Also, a dissimilarity matrix was calculated to identify the most different players using simultaneously all variables.

\section{RESULTS}

The cluster analysis classified the players into three distinct groups accordingly to their anthropometric characteristics and physical/technical/tactical indicators during 6 competitive games. The Table 1 shows the distribution of players in each cluster considering the performance variables. Cluster 1 $(n=10)$ represents the players with highest values in the physical characteristics (Height $169.90 \pm 5.07$; Weight 57.40 \pm 12.33 . On the other hand, the players of cluster $3 \quad(n=16)$ presented better performance indicators (basketball motor skills 13.00 \pm 1.37 ; game knowledge 10.63 \pm 1.09 ).

Table1

Descriptive analysis for each cluster.

\begin{tabular}{|c|c|c|c|c|c|c|}
\hline \multirow{2}{*}{ Variables } & \multicolumn{2}{|c|}{ Cluster $1(n=10)$} & \multicolumn{2}{|c|}{ Cluster $2(n=7)$} & \multicolumn{2}{|c|}{ Cluster $3(n=16)$} \\
\hline & $\mathrm{M}$ & SD & $\mathrm{M}$ & SD & $\mathrm{M}$ & SD \\
\hline Age & 13.90 & 0.32 & 13.29 & 0.49 & 13.60 & 0.63 \\
\hline Height & 169.90 & 5.07 & 149.57 & 5.59 & 159.94 & 4.25 \\
\hline Weight & 57.40 & 12.33 & 32.57 & 6.33 & 43.00 & 5.01 \\
\hline High - Sit & 87.10 & 3.16 & 76.36 & 5.10 & 82.03 & 1.95 \\
\hline Wingspan & 170.80 & 5.85 & 146.71 & 7.87 & 157.44 & 5.05 \\
\hline Ranking & 53.90 & 13.59 & 54.14 & 11.31 & 60.50 & 60.50 \\
\hline General Motor Skills & 11.80 & 11.80 & 11.80 & 2.57 & 12.63 & 1.26 \\
\hline Basketball Motor Skills & 11.30 & 3.37 & 11.57 & 2.07 & 13.00 & 1.37 \\
\hline $1 \times 0 / 1 \times 1$ repertoire & 11.20 & 2.90 & 12.14 & 2.79 & 12.94 & 1.29 \\
\hline Game Knowledge & 9.60 & 2.46 & 9.29 & 1.98 & 10.63 & 1.09 \\
\hline Readiness/Aggression & 10.00 & 2.45 & 9.71 & 3.04 & 11.31 & 1.54 \\
\hline Future Height & 181.82 & 5.36 & 181.87 & 4.56 & 182.36 & 4.49 \\
\hline Distance to PHV (months) & 2.73 & 6.78 & -21.80 & 7.90 & -9.95 & 4.08 \\
\hline Age in PHV (years) & 13.35 & 0.41 & 14.51 & 0.96 & 13.85 & 0.43 \\
\hline
\end{tabular}

\section{CONCLUSIONS}

Classifying players based on performance profile similarities may contribute to optimizing adaptations the desired training stimulus, by using the clusters to improve confrontations in drills where coaches have to create groups.
Nevertheless, the limited number of players across clusters may be somehow insufficient to discriminate with precision the performance profile during the training process. However, these are the new challenges for the upcoming sports scientists. 


\section{Effects of a methodological-based program with coaches on the coaching competency and satisfaction with the coach}

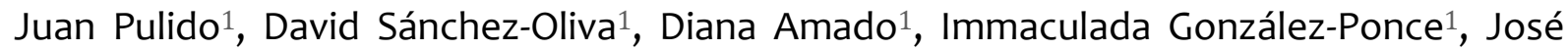
Chamorro $^{1}$

1. University of Extremadura, Spain; jipulido@unex.es

\section{INTRODUCTION}

Grounded on Self-Determination Theory (Deci \& Ryan, 2000), the coach can create a training environment in which the basic psychological needs (BPN) players are considered, or can adopt a thwarting behavioral depriving the innate development of participation of athletes. In the Spanish sports initiation, more and more administrative and political demands to play the role of coach young athletes, although not yet been extended and regulated in its entirety (Law of April 16th; 15/2015). For these reasons, a training program with coaches who had no academic or federative qualifications related to the function of training was developed, based on the promotion of methodological strategies to optimize their resources, aiming held to evaluate possible differences on a homogeneous group of coaches in the coaching competency and satisfaction with the head coach players' perception.

Table 1

Pre and post-test coaching competence and satisfaction with the coach variables.

\begin{tabular}{lcccc}
\hline \multirow{2}{*}{ Variables } & \multicolumn{4}{c}{ Fixed effects } \\
\cline { 2 - 5 } Motivation competence & Intercept & Group & Time & $G^{*} T$ \\
Game strategy competence & $4.08^{* *}$ & -.21 & -.10 & .27 \\
Technique competence & $3.97^{* *}$ & -.15 & $-.34^{* *}$ & $.34^{*}$ \\
Character building competence & $4.11^{* *}$ & $-.36^{*}$ & -.16 & $.33^{*}$ \\
Satisfaction with the coach & $4.29^{* *}$ & -.26 & $-.27^{*}$ & $.51^{* *}$ \\
\hline
\end{tabular}

\section{METHODS}

A total of eight male football coaches participated in this study, who were equitably divided taking into the professional experience in control group $(\mathrm{CG})(\mathrm{n}=4$; Mage $=32.5$; $\mathrm{SD}$ $=14.34)$ and experimental group (EG) $(\mathrm{n}=4$; Mage $=28.5 ; S D=13.67)$. Also, a 109 male football players participated (Rage $=11$ and 15 years) divided in control group $(n=56)$ and experimental group $(\mathrm{n}=53)$. Coaching Competency; the 15-item Spanish version of the Sport Athletes' Perceptions of Coaching Competency Scale II-High School Teams was used (Myers et al., 2010). Satisfaction with the coach; the 3-item of the Spanish version of the Satisfaction with the head coach was used (Myers et al., 2011).

\section{RESULTS}

As can be seen in Table 1, the values of the strategy competence and the character building showed a positively significant differences perceptions in the EG players in the final comparison of both groups, and a highly significant decrease was obtained in the perceptions of CG players. The technique competence factor showed significant differences in the initial measurement of both groups, and in the post-test measure it was obtained a significant increase in EG players' perceptions. Furthermore, satisfaction with the coach did not show significant differences.

\section{CONCLUSIONS}

A positive trend in the GE players' perceptions in all variables analyzed for the CG is shown. Hence, the effectiveness of methodological strategies applied in coaches without any qualification has been demonstrated.

Aknowledgments:
European Social Fund and Government of
Extremadura "(PD12112)"

\section{REFERENCES}

Deci, E. L., \& Ryan, R. M. (2000). The "what" and "why" of goal pursuits: Human needs and the self-determination of behavior. Psychological Inquiry, 11 (4), 227-268.

Myers, N. D., Chase, M. A., Beauchamp, M. R., \& Jackson, B. (2010). Athletes' Perception of Coaching Competency Scale II - High School Teams. Educational and Psychological Measurement, 70, 477-494.

Myers, N. D., Beauchamp, M. R., \& Chase, M. A. (2011). Coaching competency and satisfaction with the coach: A multilevel structural equation model. Journal of Sports Sciences, 29, 411-22. 


\section{Quantifying Sex differences Movement Demands in Elite Male and Female Beach Volleyball: A Positional Analysis on Portugal Championship 2015}

Paulo Vicente João ${ }^{1}$, Henrique Ortigão ${ }^{2}$, Mike Lee ${ }^{2}$, Maria Paula Mota ${ }^{1}$

1. University of Trás-os-Montes and Alto Douro / Research Center of Sports Science, Health and Human Development, CIDESD, Vila Real, Portugal; pvicente@utad.pt; 2. Catapult, Leeds, United Kingdom

\section{INTRODUCTION}

The aim of this study was to quantify the physical demands of beach volleyball (BV) competition, with reference to the specific sex differences in performance, during elite championship match play.

\section{METHODS}

160 professional female $\mathrm{n}=80$ and Male $\mathrm{n}=80 \quad \mathrm{BV}$ players were equipped with a commercially available $10 \mathrm{~Hz}$ GPS device containing an inertial measurement unit (Minimaxx S4, Catapult Sports, Australia). Data collection occurred over 52 official national championship matches, during a single competition, with a total of 120 sets used in the match average analysis. Distance covered (m), meterage per minute (m.min-1), Player Load (A.U), and both moderate $(20-40 \mathrm{~cm})$ and highintensity Jump volume $(>40 \mathrm{~cm}$ ) Meterage min (m) and Max velocity (m.min-1) were included in the analysis.

\section{RESULTS}

The results revealed positional differences in physical loading between Males and Females. Males and Females covered differences average distances $(940.7 \pm 424.3 \mathrm{~m}$ and $806.3 \pm 318.3$ $\mathrm{m}$ respectively, $\mathrm{p}>0.05)$, however Males did so at a greater relative intensity, $\mathrm{p}<0.05(36.6 \pm 4.1$ and $26.9 \pm 2.7$ m.min- 1 Males and females respectively). Player Load values were differences between sex, with Male having only slightly higher values than Females (123.3 \pm 56.1 and $102.8 \pm 44.1$ A.U. respectively $\mathrm{p}<0.05)$. However, Males analysis revealed highintensity jump volumes $(26.6 \pm 13.0$ and $12.0 \pm$ 6.5 respectively $\mathrm{p}<0.05)$ when compared with females $(16.5 \pm 11.9$ and $6.1 \pm 3.3$ moderate respectively, $\mathrm{p}<0.05)$. According Meterage min males revealed greater value $(36.8 \pm 4.08$ and $31.2 \pm 3.68 \mathrm{~m} . \mathrm{min}-1$ respectively, $\mathrm{p}<0.05)$ and the last variable, Max velocity, a moderate values $(12.5 \pm 1.95$ and $11.7 \pm 1.67 \mathrm{~m} / \mathrm{s}$ respectively, $\mathrm{p}<0.05)$.

\section{CONCLUSIONS}

Although the movement demands appear similar between sex differences, in elite female and Male BV, there appears to be a greater locomotive intensity demand for the males almost variables. In addition, there appears to be a significantly greater vertical loading component for males to which has implications for different approaches to physical preparation and recovery. Further analysis is necessary to better understand the physical demands associated with sex player role, however the current data may assist coaches in developing individualized programs that better meet the overall and positional specific demands in female and Male Beach Volleyball. 


\section{Influence of type of match on serve performance in men's volleyball}

Antonio García de Alcaraz ${ }^{1}$, José Palao ${ }^{2}$, Rui Marcelino $3,4,5$

1. Faculty of Physical Activity and Sport Sciences. Polytechnic University of Madrid; antonio.garciadealcaraz@upm.es; 2. University of Wisconsin-Parkside, United States; 3. Research Center in Sports Sciences, Health Sciences and Human Development, CIDESD, CreativeLab Research Community; 4. University of Trás-os-Montes and Alto Douro; 5. University Institute of Maia, ISMAI

\section{INTRODUCTION}

In performance analysis, the quality of opposition (QO) is a situational variable that may influence the match style and outcome. If the quality of teams is similar, there will be a balanced match (BM), whereas dissimilar qualities will lead to an unbalanced match (UM). Research in volleyball QO (Marcelino, Sampaio \& Mesquita, 2012) do not consider the initial stages of player developments. Thus, the aim of this study was to examine how players execute and perform serve actions throughout various agegroup categories in men's volleyball according to the type of match.

\section{METHOD}

The sample was composed of 8689 serves from 307 sets (except fifth set). The sample was randomly selected according to the type of match in different age groups categories: Spain's men national championship U14, U16, U19 and senior national first club league (season 2008/09), and Olympic Games (senior international, 2008). An observational design was used. The variables were: (a) age group, (b) frequency of use (FoU) and (c) coefficient of efficacy (CoE) of serve. Observer's reliability was over .93 -intra- and .83 -inter-. Team's quality was classified by a Kmeans cluster analysis (Schwartz's Bayesian) in stronger or weaker teams. Since this, BM were played by teams with the same quality, while UM were played by teams with dissimilar quality. Variables with fewer than 20 cases were excluded. The magnitude differences between BM and UM were assessed via standardized mean differences (SMD) at $90 \%$ of interval confidence.

\section{RESULTS}

Figure 1 shows the comparisons between BM and UM in terms of the FoU and the CoE in serve action. The variables that achieved at least a likely change ( $>75 \%)$ are marked in bold.

Figure 1. SMD \pm CI $(90 \%)$ related to the FoU and the $\mathrm{CoE}$ to the category of competition

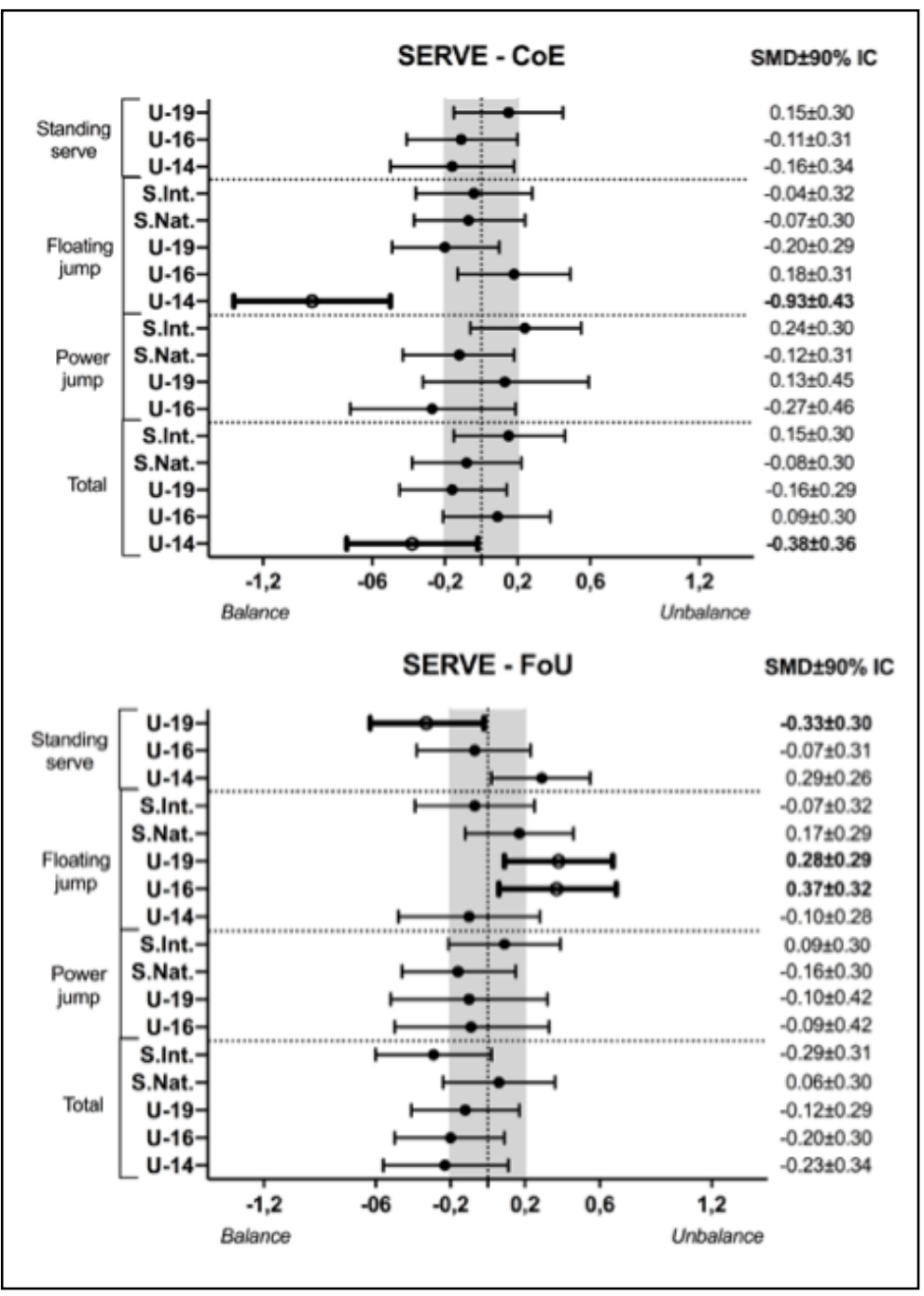




\section{CONCLUSIONS}

When the types of match are compared, serve performance changes during various stages of player development, especially in initial stages. The use of different types of serve in different types of match may be related to the risk taken by players. The greater FoU of floating jump serve (in UM at U16 and U19) is linked to the fact that players take more risks in matches with dissimilar quality, while U19 players adopt fewer risk strategies in $\mathrm{BM}$. Therefore, $\mathrm{QO}$ should be considered in order to adequately understand team performance in volleyball.

\section{REFERENCES}

Marcelino, R., Sampaio, J., \& Mesquita, I. (2012). Attack and serve performances according to the match period and quality of opposition in elite volleyball matches. Journal of Strength and Conditioning Research, 26(12), 3385-3391.

\section{Relationships between motivational variables and autotelic experience in competitors judokas.}

Silvia Pulido Pedrero ${ }^{1}$, Juan Pedro Fuentes García ${ }^{1}$,Ruth Jiménez Castuera ${ }^{1}$

1. University of Extremadura, Cáceres, Spain; silvyapulido@gmail.com

\section{INTRODUCTION}

Our reference in this work is Selfdetermination theory, by Deci \& Ryan, (1985). This theory explains how motivation works in human beings in social contexts.

Another determinant psychological variable in judokas performance is the flow. The most representative factor measuring the Flow is autotelic experience (Jackson \& Marsh, 1996).

The aim of this work was analysing the relationship stablished among types of intrinsic motivation, integrated regulation, identified regulation, introjected regulation, external regulation and amotivation, basic psychological needs (BPN) and dispositional flow in competitors judokas.

\section{METHOD}

\section{Participants}

The study sample consisted of a total of 148 competitors judokas, 47 women and 101 men, from Spain, aged between 12 and 64 years $(\mathrm{M}=$ $18.86, \mathrm{SD}=8.75)$.

\section{Quizzes}

Behavioral Regulation in Sport Questionnaire (BRSQ) validated the Spanish by MorenoMurcia, Marzo, Martínez, \& Conte (2011), Psychological Need Satisfaction in Exercise Scale (PNSE) validated to the Spanish by MorenoMurcia et all (2011) and Dispositional Flow Scale-2 validated to the Spanish by García, Jiménez, Santos-Rosa, Reina, \& Cervelló (2008).

Table 1.

Descriptive statistics, reliability and correlation analysis.

\begin{tabular}{|c|c|c|c|c|c|c|c|c|c|c|c|c|c|c|c|c|}
\hline Variable & $M$ & $S D$ & $\begin{array}{c}\text { Cronbach's } \\
\text { Alpha }\end{array}$ & 1 & 2 & 3 & 4 & 5 & 6 & 7 & 8 & 9 & 10 & 11 & 12 & 13 \\
\hline 1. IM. General & 6.74 & .51 & .76 & - & & & & & & & & & & & & \\
\hline 2. IM. Knowledge & 6.33 & .86 & .84 & $.52^{* *}$ & - & & & & & & & & & & & \\
\hline 3. IM. Stimulation & 6.30 & .85 & .78 & $.53^{* *}$ & $.52^{* *}$ & - & & & & & & & & & & \\
\hline 4. IM. Execution & 6.37 & .65 & .79 & $.52^{* *}$ & $.52^{* *}$ & $.59 * *$ & - & & & & & & & & & \\
\hline 5. R. Integrated & 5.98 & 1.12 & .81 & $.43^{* *}$ & $.43^{* *}$ & $.45^{* *}$ & $.67^{* *}$ & - & & & & & & & & \\
\hline 6. R. Identified & 6.07 & .94 & .74 & $.36^{* *}$ & $.47^{* *}$ & $.53^{* *}$ & $.61^{* *}$ & $.55^{* *}$ & - & & & & & & & \\
\hline 7. R. Introjected & 3.24 & 1.85 & .82 & .01 & .11 & .10 & $.17^{*}$ & $.24^{* *}$ & $.22^{* *}$ & - & & & & & & \\
\hline 8. R. External & 1.72 & 1.10 & .70 & $-.42 * *$ & $-.21^{*}$ & $-.17^{*}$ & $-.25^{* *}$ & -.15 & -.13 & $.29 * *$ & - & & & & & \\
\hline 9. Amotivation & 1.46 & .80 & .74 & $-.40^{* *}$ & $-.20^{*}$ & $-.20^{*}$ & $-.27^{* *}$ & $-.21^{*}$ & -.09 & .07 & $.41^{* *}$ & - & & & & \\
\hline 10. BPN. Competition & 5.27 & .85 & .92 & $.18^{*}$ & $.34^{* *}$ & $.40^{* *}$ & $.27^{* *}$ & $.17^{*}$ & .14 & -.02 & -.08 & -.12 & - & & & \\
\hline 11. BPN. Autonomy & 3.61 & 1.11 & .82 & .02 & .02 & $.27^{* *}$ & .09 & .01 & $.22^{* *}$ & -.07 & .07 & .02 & .15 & - & & \\
\hline $\begin{array}{l}\text { 12. BPN. Relationships } \\
\text { social }\end{array}$ & 5.48 & .57 & .63 & $.20^{*}$ & $.42^{* *}$ & $.50^{* *}$ & $.40^{* *}$ & $.28^{* *}$ & $.42^{* *}$ & .07 & -.09 & -.14 & $.41^{* *}$ & $.20^{*}$ & - & \\
\hline 13. E. Autotelic & 4.58 & .56 & .68 & $.36^{* *}$ & $.34^{* *}$ & $.57^{* *}$ & $.37^{* *}$ & $.26^{* *}$ & $.22^{* *}$ & .12 & $-.19 *$ & $-.23^{* *}$ & $.37^{* *}$ & $.16^{*}$ & $.44^{* *}$ & - \\
\hline
\end{tabular}

Note: IM: Intrinsic Motivation; R: Regulation; BPN: Basic Psychological Need; E: Experience; ${ }^{*} p<.05 ;{ }^{* *} p<.01$. 


\section{RESULTS}

The results extracted can be seen in the table 1. We found the data about the intrinsic motivation is positively and significantly related with it integrated, identified, regulation, basic psychological needs of competition and social relations and autotelic experience. Finally, there is a negative and significant relationship between intrinsic motivation and external regulation and amotivation.

\section{CONCLUSIONS}

To conclude, we consider of great importance the results obtained about motivational variable, since it plays a fundamental role in psychological training of the athletes. Given that the greater satisfaction of the BPN could increase levels of self-determined motivation and these could cause higher levels of autotelic experience in judokas.

\section{REFERENCES}

Deci, E. L., \& Ryan, R. M. (1985). Intrinsic motivation and selfdetermination in human behaviour. New York: Plenum Press.

García, T., Jiménez, R., Santos-Rosa, F., Reina, R., \& Cervelló, E. (2008). Psychometric properties of Spanish version of the flow state scale. The Spanish Journal of Psychology, 11 (2), 660-669.

Jackson, S. A., \& Marsh, H. (1996). Development and validation of a scale to measure optimal experience: The Flow State Scale. Journal of Sport \& Exercise Psychology, 18, 17-35.

Moreno-Murcia, J. A., Marzo, J. C., Martínez, C., \& Conte, L. (2011). Validación de la Escala de "Satisfacción de las Necesidades Psicológicas Básicas" y del Cuestionario de la "Regulación Conductual en el Deporte" al contexto español. Revista Internacional de Ciencias del Deporte, 26(7), 355-369.

\section{Soccer formations may influence the network centralities and properties of elite teams?}

Filipe Manuel Clemente ${ }^{1,2}$, Paulo Faria ${ }^{3}$, Diogo Peixoto ${ }^{1}$, Gabriel Veloso ${ }^{3}$, Rui Pereira ${ }^{1}$ Fernando Manuel Lourenço Martins ${ }^{2,4}$

1. Instituto Politécnico da Viana do Castelo, Escola Superior de Desporto e Lazer, Portugal; filipe.clemente5@gmail.com; 2. Instituto de Telecomunicações, Delegação da Covilhã, Portugal; 3. Universidade de Coimbra, Faculdade de Ciências do Desporto e Educação Física, Portugal; 4. Instituto Politécnico de Coimbra, Escola Superior de Educação, IIA, RoboCorp, UNICID, Portugal

\section{INTRODUCTION}

Soccer formation describes how the players in a team are positioned on the field. Despite of that, formation can be characterized as an important variable that may constrain the cooperation process of teammates (Clemente, Martins, Wong, Kalamaras, \& Mendes, 2015). Based on that, the aim of this study was to analyze the influence of different formations in the network properties of elite soccer teams and centralities of players during ball possession.

\section{METHODS}

One hundred and nine games from the 16 most successful soccer teams that participated in UEFA Champions League 2015-2016 were analyzed. The following formations were codified: i) 1-4-3-3; ii) 1-4-4-2; iii) 1-3-5-2; iv) 1 5-3-2; v) 1-4-4-2 diamond; vi) 1-4-2-3-1; vii) 14-5-1; viii) 1-3-4-3. Formations were codified in periods of 15 minutes by an expert analyst and crossing the information with the UEFA champions' league reports. Weighted adjacency matrices representing the passing interactions between teammates were used. General measures of total links and network density and the outdegree, indegree and betweenness centralities were tested. One-way ANOVA followed by Tukey post hoc was used to analyze the variance of network measures between formations. Effect size (Eta-squared) was also tested. Statistical procedures were made in the SPSS software for a $\mathrm{p}<0.05$.

\section{RESULTS}

Significant differences between formations were found in total links ( $p=0.009$; $E S=0.119)$ and network density $(\mathrm{p}=0.011 ; \mathrm{ES}=0.115)$. The 1-4-3-3 formation had greater total links $(\mathrm{p}=0.002)$ and network density $(\mathrm{p}=0.003)$ than the 1-4-4-2. Moreover, statistical differences were found in betweenness centrality $(p=0.001$; 
$\mathrm{ES}=0.027$, no effect) between the 1-4-3-3 and 1$4-4-2$ ( $\mathrm{p}=0.001 ; 2.39$ and 3.35 , respectively) and $1-4-2-3-1 \quad(\mathrm{p}=0.37 ; 2.39$ and 2.80 , respectively) and the 1-4-4-2 and 1-4-2-3-1 $(\mathrm{p}=0.19 ; 3.35$ and 2.80, respectively). No statistical differences in outdegree $(\mathrm{p}=1.000 ; \mathrm{ES}=0.001)$ and indegree $(p=1.00 ; E S=0.001)$ centralities were found.

\section{CONCLUSIONS}

The specific dynamics that emerge from the tactical missions in the formation may have constrained the network processes between teammates. Complementary metrics that measure dynamic of play should be used to cross with the social network variables.

\author{
Aknowledgments: \\ This work was supported by the FCT project PEst- \\ OE/EEI/LA0008/2013.
}

\section{REFERENCES}

Clemente, F. M., Martins, F. M. L., Wong, D. P., Kalamaras, D., \& Mendes, R. S. (2015). Midfielder as the prominent participant in the building attack: A network analysis of national teams in FIFA World Cup 2014. International Journal of Performance Analysis in Sport, 15(2), 704-722.

\section{Bullying in youth sport training}

Miguel Nery ${ }^{1}$, Carlos Neto ${ }^{1}$, António Rosado ${ }^{1}$, Peter K. Smith ${ }^{2}$

1. Faculty of Human Kinetics, University of Lisbon, Portugal; miguelnery@hotmail.com; 2. Goldsmiths College, University of London, UK

\section{INTRODUCTION}

There is a lack of research about bullying in sport (Evans, Adler, MacDonald \& Côté, 2015). Bullying consist in aggressive and anti-social peer behaviour, intentional and repetitive (Olweus, 2010).

Sport competitive nature may promote peer aggression. Bullying in sport has particular characteristics (Escury \& Dudink, 2010), there are risk factors for victimization (Vertommen, et. al. 2016), which may have severe consequences (Escury \& Dudink, 2010). The objective of this research was to describe and analyse bullying behaviours in different sports, in male youth sport training athletes.

\section{METHOD}

Sample

Male adolescent athletes $(n=1458)$, divided among 97 sport clubs, spread over Portugal, from nine sports: Team: volleyball $(n=144)$, football $(n=312)$, rugby $(n=424)$, handball $(n=236)$; Individual: gymnastics $(\mathrm{n}=58)$, swimming $(n=86)$, athletics $(n=66)$; Fight: judo $(n=83)$ and wrestling $(\mathrm{n}=49)$.

\section{Instrument}

Sport Violence Study and Prevention Questionnaire: Bullying in Sport, adapted from a questionnaire used in an EU-funded project for study bullying at school (Ortega, Mora-Mérchan, Lera, Singer, Smith, Pereira \& Menesini, 1999). The questionnaire collects data about types of bullying, the frequency and duration duration of bullying, location, activities in which bullying episodes occur, number of athletes involved, actors feelings, communication about bullying episodes, the bystanders reasons ascribed for bullying and reactions when involved in bullying episodes, victims coping strategies, and support sources, namely family, coach and peers.

\section{Data analysis}

Frequency distributions and Chi-Square tests were performed. Statistical significance was set at $\mathrm{p}<0.05$ level. Monte Carlo method and Holmes-Bonferroni correction were considered.

\section{General}

\section{RESULTS}

From the total sample, $10.0 \%$ of the athletes reported as being victims, $11.3 \%$ as bullies, $34.6 \%$ as bystanders and $44.0 \%$ respondents did not report bullying.

\section{Victims}

Chi square tests on victimization frequency differences found significantly more occasional victims reported training activity, while 
significantly more repeated victims reported multiple activities (training and competition) and high duration of episodes. Significantly more low duration victims reported training activity and sport club location for bullying to occur, while significantly more high duration victims reported multiple activities and multiples places (mainly inside club but also in competition) for victimization occurrence.

Chi square analysis on victimization also showed that athletes who used CFE strategies tended to maintain silence about victimization, while the athletes who used CFP strategies have talked with peers about bullying episodes.

\section{Bullies}

Chi Square tests on bullying frequency showed that significantly more occasional bullies reported verbal bullying, while significantly more repeated bullies reported multiple types of bullying, which consist mostly in the combination of verbal and social bullying.

Regarding the communication analysis, significantly more bullies who considered bullying to be individual reported peers' communication and significantly more bullies who considered group bullying reported that nobody has talked with them about bullying episodes.

\section{Bystanders}

Chi-square tests analysing bystanders' feelings towards bullying found that significantly more bystanders who consider bullying to be bullies accountability tended to express negative feelings towards it, while bystanders who consider bullying to be victims' accountability tended to express avoidance to bullying. The results also show that bystanders who expressed neutrality or avoidance, tended to observe without interfering, and bystanders who reported neutrality tended to join the bullying.
The bystanders who reported negative feelings tended to act on victims defence.

\section{CONCLUSION}

The increase of victimization frequency and duration leads to its generalization and leads to victims' progressive isolation. Coping focused on problem strategies are more efficient to deal with bullying because allow break silence and communication among peers is a key factor to fight bullying.

The increase of bullying frequency and number of peers involved in bullying episodes promotes social exclusion of victims.

There is a link between the bystanders' feelings and their reaction towards bullying, which should be considered in anti-bullying programs design.

\section{REFERENCES}

Escury, A. \& Dudink, A. Bullying beyond school: examinating the role of sports (P.235-248). In. S. Jimerson; S. Swearer \& D. Espelage (Eds.). Hanbook of bullying in school: an international perspective. New York: Routledge, 2010.

Evans, M. B., Adler, A., MacDonald, D. J., \& Côté, J. (2015). Bullying victimization and perpetration in adolescent sport teams. Pediatric Exercise Science. Advance Online Publication.

Olweus, D. (2010). Understanding and researching bullying: some critical issues (pp.9-33). In. S. Jimerson; S. Swearer \& D. Espelage (Eds.). Handbook of bullying in schools: an international perspective. New York: Routledge.

Ortega, R., Mora-Mérchan, J., Lera, A,, Singer, M., Smith, P.K., Pereira, B. \& Menesini, E. (1999). Final report of the working group on general survey questionnaires and nomination methods concerning bullying. Recovered from http://www.gold.ac.uk/tmr/reports/aim2_sevi lle1.html\#intro1

Vertommen, T., Veldhoven, N., Wouters, K., Kampen, J., Brackenridge, C., Rhind, D., Neels, K. \& Van Den Eede, F. (2016). Interpersonal violence against children in sport in the Netherlands and Belgium. Child Abuse \& Neglect, 51, 223-236. 


\section{Physical Kempo Test (PKT) - Development of a Graduation Scale for Kempo Athletes}

Samuel Honório ${ }^{1}$, Marco Batista ${ }^{1}$, Júlio Martins², Rui Paulo ${ }^{1}$, Pedro Mendes ${ }^{1}$, António Faustino $^{1}$, Pedro Rodrigues ${ }^{3}$, João Serrano ${ }^{4}$, João Petrica ${ }^{4}$

1. Instituto Politécnico de Castelo Branco, RECI; samuelhonorio@hotmail.com; 2. UBI, Covilhã; CIDESD; 3. Associação Kempo Koa do Entroncamento; 4. Instituto Politécnico de Castelo Branco, FCT and CI\&DETS (PEst- OE/CED/UI4016/2011)

\section{INTRODUCTION}

The main objective of this study is to propose a graduation scale to evaluate Kempo athletes. PKT intends to be a system analysis of physical condition, respecting the ecological dimension of kempo sport, developed in a time frame (duration of assaults) which includes strength training, speed, reaction and technique testing the athlete's endurance for combat., in "Light" fight, "Full" and "Knock-down", with three to five minutes in two rounds with a minute break between them (Franchini, 2001). PKT conception is based on the characteristics of this fighting sport, predicting a level of effort in a 3 minutes combat, of 2 rounds, with 1 minute of rest.

\section{METHODS}

PKT proposal consists of 3 exercises that should be performed in two rounds of 3 minutes each (same combat time), complying the following sequence: 1) Circular kick (reaction speed), 2) Kimura (resistance) and 3) Pushup and punch (strength) with a minute break between rounds, with a total of 6 minutes. The athlete must complete the sequence of the three exercises. The test has four levels: less than 15 repetitions (with no classification); level 1 Satisfactory (between 15 and 19 reps); Level 2 Good (between 20 and 24 reps); Level 3 - Very Good (between 25 and 29 reps); and Level 4 (Excellent (30 reps or more). Data analysis by
SPSS (20) using crosstabs, descriptive frequency, Mann-Whitney for genders, Kruskal-Wallis Test for athlete's levels and graduation colors. A convenience sample of 51 athletes aged between 13 and 48, female (9) and male (42), divided in four levels, "under 15" (22), "under 18" (14), "under 30" (9), and Masters (6).

\section{RESULTS}

We have registered a minimum of 8 repetitions and a maximum of 14 . Seven individuals achieved level 1 (13.7\%), in level 2 (52.9\%), and in level 3 (33.3\%), assuming values of very good level. The male gender has higher levels in PKT $(p=0.07)$, and as higher are the athletes graduation, higher are the values in PKT $(\mathrm{p}=0.135)$.

\section{CONCLUSIONS}

The PKT could be an important assessment tool for kempo athlete's evaluation, showing significant differences between genders, with higher levels in male. In terms of levels it was found that younger athletes have lower physical fitness compared to other age groups. Also, it has been found that as higher is the athlete graduation, better are the results.

\section{REFERENCES}

Borba, D. (2013). Teste de avaliação da performance em luta. Lisboa: Faculdade de Motricidade Humana. Franchini, E. (2001). Judô: Desempenho Competitivo. São Paulo: Manole. 


\section{How structured and unstructured sport activities aid the development of expertise in volleyball players}

Patrícia Coutinho ${ }^{1}$, Isabel Mesquita ${ }^{1}$, Keith Davids ${ }^{2}$, António M. Fonseca ${ }^{1}$, Jean Côté ${ }^{3}$

1. CIFI2D, Faculty of Sport, University of Porto; pcoutinho@fade.up.pt; 2. Centre for Sports Engineering Research, Sheffield Hallam University; 3. School of Kinesiology and Health Studies, Queen's University

\section{INTRODUCTION}

The role played by early developmental activities such as deliberate practice and deliberate play for skill acquisition and talent development has been a hot topic in the past decades. Nevertheless, empirical evidence has demonstrated that these may not be exclusive activities within talent development process, suggesting the important contribution of other types of activities in players' development (e.g. Coutinho et al, 2016). Therefore, this study sought to analyse self-reported perceptions of how the nature of sport activities undertaken by volleyball players aided their development.

\section{METHODS}

Based on a mixed method design, a retrospective interview was applied to thirty highly skilled and thirty less skilled volleyball players to identify the quantity and type of activities undertaken throughout the different stages of development. Quantitative data was examined used an analysis of variance with repeated measures. Qualitative data was analysed based on content analysis procedures.

\section{RESULTS}

Quantitative data showed (1) a significant effect for stage on the number of structured activities $\left(F(2,112)=22.938, p<.001, \eta^{2}=.291\right)$, with players participating in more structured activities during stage $1(3.0 \pm 1.8)$ and stage 2 $(2.3 \pm 1.4) ; \quad(2)$ a significant effect for stage
$\left(F_{(2,112)}=14.903, \quad p<.001, \quad \eta^{2}=.210\right) \quad$ and interaction between expertise level and gender $\left(F_{(6,112)}=5.289, p<.001, \eta^{2}=.221\right)$ on the number of hours spent in structured activities. Here, players accumulated more hours in stage 2 (1419.0 \pm 602.0$)$ and stage $3(1750.0 \pm 897.1)$, and highly skilled male and female players accumulated more hours than less skilled male players ( $p=.011$ and $p=.030$, respectively); (3) a significant effect for stage on the number of hours spent in unstructured activities $\left(F_{(2,112)}=21.214, p<.001, \eta^{2}=.275\right)$, with players accumulating more hours in stage 1 $(1773.0 \pm 766.2)$ and stage $2(1062.0 \pm 588.1)$. Qualitative data showed that highly skilled players were involved in structured and unstructured activities with older peers or teammates, and specific unstructured activities (street volleyball) was an important key activity to achieve expertise.

\section{CONCLUSION}

These findings suggest the need for future research to consider the validity of an additional talent development pathway to elite performance through a sophisticated mix of structured and unstructured play and practice activities.

\section{REFERENCES}

Coutinho, P., Mesquita, I., Davids, K., Fonseca, A.M., \& Côté, J. (2016). How structured and unstructured sport activities aid the development of expertise in volleyball players. Psychology of Sport \& Exercise, 25, 51-59. 


\section{Coach-athletes relationship: The perception of athletes about their coaches, considering gender, school level, competitive level and type of sport practiced}

Nuno Januário ${ }^{1}$, Vitor Ferreira ${ }^{1}$

1. Universidade de Lisboa, Faculdade de Motricidade Humana, Lisbon, Portugal; vferreira@fmh.ulisboa.pt

\section{INTRODUCTION}

The coach-athlete interaction has been an area of interests and research in the field of Sport Pedagogy and had been focus on several aspects as the effect of gender, type of sport and age, on the perception that athletes had about coach, the athletes' satisfaction about their coach and coach's leadership behavior perceived by the athletes.

The aim of present work is characterize the athletes' perceptions of their coaches considering athletes gender, school level, competitive level and type of sport practiced.

\section{METHODS}

The study involved 228 athletes (171 males, 57 females) aged between 13 and 28 years old, 120 provided from individual sports and 108 from the team sports. We used the Portuguese version of Player Coach Interaction Inventory (Medford \& Thorpe, 1986) developed by Leitão, Serpa and Bártolo (1995), composed by 23 items, on a Likert 7-points scale. We used the factorial structure referenced by Rosado, Palma, Mesquita, and Perla Moreno (2007). Data analysis was done using descriptive statistics, T-Student, Anova and Bonferroni tests.

\section{RESULTS}

Globally, athletes presents a very positive image of their coaches $(M=5.68 ; S D=0.66)$ and the most valued characteristics are sincere $(M=6.18)$, self-assured $(M=6.04)$ and honest $(M=6.00)$. The less referenced characteristics were to be a good sportsman $(M=4.78)$ and be careful $(M=5.25)$.

The most referenced factor was the personal qualities, followed by the leadership. The gender of athletes influenced the leadership factor $[t(226)=4.095, p \leq 0.001]$, having the female group a high average. Considering the type of sport significant differences were found to communication resources and interpersonal relationships $[t(226)=4.179, \quad p \leq 0.001]$ and personal qualities $[t(226)=3.830, p \leq 0.001]$. The athletes of individual sports referenced more the leadership and communication resources and interpersonal relationships were more indicated by athletes of team sports. Considering the athletes' competitive level significant differences were found in leadership $[t(226)=2.847$, $p=0.05]$, having the international group high values.

\section{CONCLUSIONS}

The athletes perception of about their coaches was influenced by independent variables studied, except athletes' school level.

\section{REFERENCES}

Leitão, J., Serpa, S., \& Bártolo, R. (1995). Liderança em contextos desportivos. A relação treinadoratleta numa selecção nacional de futebol (juniores B-sub16). Psicologia, 10 (1), 15-29.

Medford, P., \& Thorpe, J. (1986). An Inventory for measuring player-coach interaction. Perceptual and Motor Skills, 63, 267-270.

Rosado, A., Palma, N., Mesquita, I., \& Perla Moreno, M. (2007). Percepción de los jugadores de fútbol, de distinto nível, sobre sus entrenadores. Revista de Psicología del Deporte, 16 (2), 151-165. 


\section{Physical Fitness Profile of Competitive Young Soccer Players: Determination of Positional Differences}

Luís Branquinho 1, Mário C. Marques 1,2, Mikel Izquierdo 3, Tim J. Gabbett 4,5, Bruno Travassos 1,2 , Roland van den Tillaar 6

1. Department of Sport Sciences, University of Beira Interior, Covilhã, Portugal; luis.branquinho@ubi.pt; 2. Research Centre in Sports, Health and Human Development, CIDESD, Portugal; 3. Department of Health Sciences, Public University of Navarre, Navarre, Spain; 4. School of Exercise Science, Australian Catholic University, Brisbane, Australia; 5. School of Human Movement Studies, The University of Queensland, Brisbane, Australia; 6. Department of Teacher Education, Nord Trøndelag University College, Levanger, Norway

\section{INTRODUCTION}

Playing positions in team sports involve specific physical activity and technical skill demands to successfully compete. Recent studies have focused on the relationship between the anthropometric and physical characteristics, although comparisons between age groups have not been made (Mehdi Ben, Rym, \& Amri, 2013; Wong, Chamari, Dellal, \& Wisløff, 2011). To the best of our knowledge there are no studies that have assessed the anthropometric and physical qualities of the different playing positions among different age levels. The aim of this study was to compare the anthropometric and physical fitness characteristics of the different playing positions in adolescent soccer players.

\section{METHODS}

One hundred and sixty-seven young male national level soccer players (mean \pm SD age: $15.7 \pm 1.7 \quad$ years), were tested on anthropometric characteristics (height and body mass) and physical performance tests $(30 \mathrm{~m}$ sprint, ball kicking, overhead medicine ball throw and countermovement jump [CMJ]).

\section{RESULTS}

The results show differences in anthropometric characteristics between positions. Right defenders (RD) were significantly shorter $(\mathrm{p}<0.05)$ than all other positions except the left defenders. The RD were also significantly lighter $(p<0.05)$ than the forwards, central defenders and midfield players, while the left defenders were lighter and shorter than the central defenders. Differences were also found in the physical performance tests; forwards performed better in the throwing, CMJ and sprint tests than defenders. Midfielders demonstrated greater CMJ performances than RD.

\section{CONCLUSIONS}

Our results highlight that there is an influence of playing position on the anthropometric and physical qualities in adolescent players. This emphasizes the importance of evaluating the physical profile of players and their development according to playing age and playing position.

\section{REFERENCES}

Mehdi Ben, B., Rym, B., \& Amri, M. (2013). Anthropometric and Physical Characteristics of Tunisians Young Soccer Players. Advances in Physical Education, 3(03), 125.

Wong, P.-L., Chamari, K., Dellal, A., \& Wisløff, U. (2011). Relationship Between Anthropometric and Physiological Characteristics in Youth Soccer Players. The Journal of Strength \& Conditioning Research, 25(10), 1-2. 


\section{Spatial autocorrelation measures for soccer analysis: a pilot study}

Francisco Pires ${ }^{1}$, Filipe Manuel Clemente 2,3 , Paulo Morgado ${ }^{4}$

1. Instituto de Geografia e Ordenamento do Território, Universidade de Lisboa; fpires@campus.ul.pt; 2. Instituto Politécnico de Viana do Castelo, Escola Superior de Desporto e Lazer, Portugal; 3. Instituto de Telecomunicações, Delegação da Covilhã, Portugal; 4. Instituto de Geografia e Ordenamento do Território/Centro de Estudos Geográficos, Universidade de Lisboa

\section{INTRODUCTION}

In a soccer field, players share the space and associate their movements and actions with the teammates (Clemente, et al, 2014). This process leads to a spatial interaction that can be analyzed based on spatial autocorrelation methods employed in geography (Anselin \& Rey, 2012; Pires, 2015), and neglected for soccer games

\section{CONCLUSION}

Germany prefer her left wing for offensive dynamics, although much of the danger created was frontal in field last third (Figure 1). Argentina, rather favoured the inner part of the field for her strike plays although in the last third, dangerous plays could come from left, right or frontal zones. analysis. The aim of this study was to classify the spatiotemporal behaviour (teams strategy and tactics) of the FIFA World Cup 2014 finalists.

\section{METHODS}

Thirteen official matches of Germany and Argentina teams during WC 2014 were analysed. A total of 5,550 passes, 94 nonsuccessful shots and 17 goals scored that resulted from a

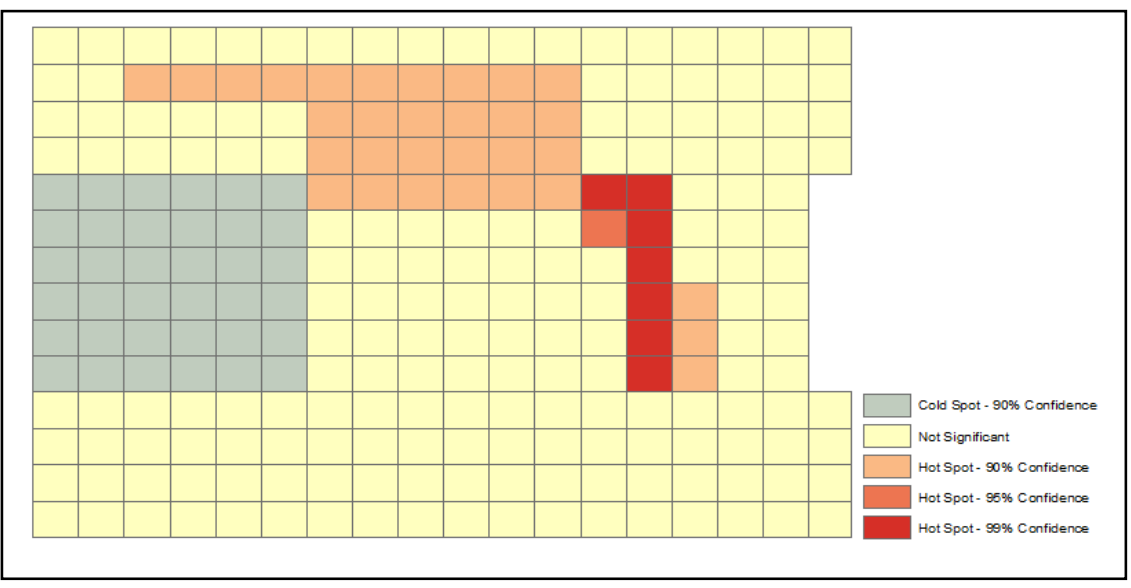
minimum sequence of 2 passes during regular time (excluding extra time) were analysed. Spatial autocorrelation analyse the organization and structuring of the phenomena, measuring if values are randomly distributed, or alternatively follow some regular structure eg. clustering.

\section{RESULTS}

Early results underline the usefulness of spatial autocorrelation methods for soccer games analysis. Both teams proven to be organized and tactics aren't random. Although Germany seems more conservative through time than Argentina, her cluster's don't change so much.

Figure 1. HeatMap of Germany team during the attacking process in their first game. Hotspots indicate an high concentration of passes received, while coldspots show areas where

\section{REFERENCES}

Anselin, L. and Rey, S. J. (2012). Perspectives on Spatial Data Analysis. Springer. Arizona. USA.

Clemente, F. M., Martins, F. M. L., Couceiro, M. S., Mendes, R. S., \& Figueiredo, A. J. (2014). Developing a Football Tactical Metric to Estimate the Sectorial Lines: A Case Study. In Murgante, Misra, Rocha, Torre, Falcão, Taniar, ... Gervasi (Eds.), Computational Science and Its Applications (pp. 743-753). Springer.

Pires, F. (2015). A Tática de uma equipa de Futebol. Modelação espacial para análise de redes. Dissertação para obtenção do grau de mestrado em Sistema de Informação Geográfica e Modelação Territorial Aplicado ao Ordenamento, Instituto de Geografia e Ordenamento do Território, Universidade de Lisboa. Lisboa. 


\section{Comparing time of practice with two different learning approaches in alpine skiing}

Sérgio Figueiredo ${ }^{1}$, Bruno Travassos ${ }^{1,2}$, Keith Davids ${ }^{3}$

1. Departament of Sport Sciences, University of Beira Interior, Covilhã, Portugal; sfigueiredo@ubi.pt; 2. Research Centre in Sports Sciences, Health Sciences and Human Development, CIDESD, CreativeLab, Portugal; 3. Centre for Sports Engineering Research, Sheffield Hallam University (UK)

\section{INTRODUCTION}

Making best use of practice time is directly related to skill acquisition in sport (Davids, Button \& Bennett, 2008). To assess how to improve quality of practice in Alpine skiing, we sought to introduce a constraints-led methodology in the practice context, changing traditional coaching approaches by introducing innovative practice task designs that were intended to upgrade the skill acquisition process in the same amount of time. The purpose of this study was to quantify and discuss the new practice task designs in alpine ski learning to make the most of time spent in training.

\section{METHODS}

Ten novice learners where randomly divided into two groups who experienced different learning designs: one group with a traditional approach and the other undergoing a constraints-led learning approach. Both groups had the same ski level (no previous experience) at the beginning of both practice programs.

The traditional approach (TA) follows the common ski learning process, using the explanation, demonstration and standard/analytic training exercises as basic resources for the development of the alpine skiing technique. The constraints led learning approach (CLLA) (Davids, et al., 2008) involved tasks designed to establish a progression of challenges and promote the constant adaptations of individuals to changing task constraints, for the development of skiing basic skills. Specific data were collected with a chronometer to register the different times time used for explaining, practising, and waiting. The percentage of the total time was calculated for each variable in each learning environment.

\section{RESULTS}

Results showed that the constraints-led approach proved to be more effective with regard to time spent in practice (TA $=22 \%$ and CLLA $=41 \%$ ), which is coherent with the evident diminution of time spent in explanation and demonstration $(\mathrm{TA}=27 \%$ and CLLA $=20 \%)$ and the time spent waiting for effective practice (TA $=51 \%$ and CLLA $=38 \%$ ), when compared with the traditional approach.

\section{CONCLUSIONS}

Although arriving the same level of skiing capacity, these findings helped us conclude that using a constraints-led methodology is valuable in terms of time, effort and expense compared to traditional approaches which were more costly in all these measures. These findings suggest the need to conduct more research comparing constraints-led and traditional learning approaches in adventure sports like alpine skiing to improve basic skills.

\section{REFERENCES}

Davids, K., Button, C., \& Bennett, S. (2008). Dynamics of skill acquisition: a constraints-led approach. Champaign: Human Kinetics Publishers. 


\title{
Relative age effect, final classification, MVP and time played in the U14 regional basketball tournament
}

\author{
Ricardo Stringfellow ${ }^{1}$, João Silva ${ }^{1}$, João Costa ${ }^{1}$, João Garcia ${ }^{1}$, Pedro Carvalho ${ }^{1}$, Nuno \\ Mateus $^{1}$, Nuno Leite ${ }^{1}$ \\ 1. Research Center in Sports Sciences, Health Sciences and Human Development, CIDESD, CreativeLab Research Community, \\ Portugal; nuno mateus23@hotmail.com
}

Relative age effect (RAE) has been widely studied in different sports. Portuguese team sports organizations commonly grouped children based on a gap of two-year birthdate, resulting in a difference of 24 months between the youngest and the oldest participants. This process results in important physical and cognitive discrepancies among athletes. In basketball the height is crucial, so that the presence of RAE in young categories would not be surprising (Arrieta, Torres-Unda, Gil \& Irazusta, 2016), however the relation between RAE and basketball game-performance is quite unexplored. Therefore, the aim of this study was to analyse the presence of RAE and its possible relation with performance in U14 Regional Basketball Tournament. The chronological age records of all U14 male participants $(n=210)$ in Regional Basketball Tournament were analysed. Game-data available in open-access official FPB box-scores were gathered. A Chi-Square test was used to cluster the players' birthdates according to the selection and quarter of the year. Therefore, a Kruskal-Wallis test for independent values were performed to analyse the relation between RAE and game-performance. The results suggested that more than half of the players born in the first quarters of both selection years (59.5\% of the cases). Players who born in the first year of selection played longer $(67.6 \%$ of players born in the first year of selection played more than twelve minutes per game, whereas only $45.5 \%$ of players born in the second year of selection played more than twelve minutes per game). The best classified teams were mostly composed by players that born in the first and second quarter of the first year of selection ( $55 \%$ of the players that born in the first year of selection and $45 \%$ of the study subjects, integrated the best nine classified teams). Players born in the first two quarters attained better Most Valuable Player (MVP) average stats (60\% of the participants) and MVP per minute $(60 \%$ of the participants). Overall, this study provided evidence that RAE was present in the birthdate distribution of U14 players. Coaches opted to select older players, especially those born in the first half of the year, due their greater maturational growth. Moreover, older athletes played more minutes per game as a consequence of better and consistent performances achieved during the tournament.

References

Arrieta, H., Torres-Unda, J., Gil, S. M., \& Irazusta, J. (2016). Relative age effect and performance in the U16, U18 and U20 European Basketball Championships. Journal of Sports Sciences, 34(16), 1530-1534. https://doi.org/10.1080/02640414.2015.1122204

\section{Risks in Adventure Sport Activity: Which risks are perceived by experienced canyoneers}

\author{
António Brandão ${ }^{1}$, Joel Pereira ${ }^{1}$, Francisco Gonçalves ${ }^{2}$, Susana Vale ${ }^{3}$, Luís Quaresma ${ }^{4}$
}

1. Escola Superior de Desporto e Lazer de Melgaço; 2. Centro de Estudos em Educação, Tecnologias e Saúde; 3. Escola Superior de Educação do Porto; 4. Universidade de Trás os Montes de Alto Douro; luisquar@utad.pt

The search for experiences in nature and adventure sports (NAS) is a growing reality, and canyoning is one of these sports to be experienced, thus contemporary society demands for new knowledge and sensations. After the first contact with the sport, many are looking for continuity, with a significant increase of practitioners in this sport at a training level or recreational. However, canyoning is considered a risky activity, as the practice sites are favorable for the occurrence of incidents / accidents. Its practice is carried out in sinuous, water and vertical spots, in which the risks are increased by the difficulties to reach this remote areas and to access the spots. In this study we have developed a risk identification process on canyoning, divided into two phases: first was to identify the state of the art; second phase consisted on the application of a questionnaire to experienced practitioners of two nationalities (Portuguese and Spanish). Participants were asked about their mental representation of risk that they have experienced on Canyoning, as athletes. According to literature, we observed that risk factors are divided into environmental and human factors, on which were identified 3 dimensions in environmental factors and 4 dimensions in human factors. The identification of risks by experienced athletes was carried out based in the theory of social representations applied to risks on canyoning, where 3 dimensions were identified in the environmental factors and 6 dimensions in human factors. This study aimed to strengthen and update the state of the art in this field through literature review and identification of risk factors using experienced canyoning athletes. With the information obtained would be useful to develop further research in order to improve the security and credibility of this sport. 


\title{
Shooting in Football: Play with the Opponent to Succeed
}

\author{
António Vicente ${ }^{1,3}$, Catarina Fernando 2,3 , Helder Lopes 2,3
}

1. University of Beira Interior, Covilhã, Portugal; vicente@ubi.pt; 2. University of Madeira, Funchal, Portugal; 3. Research Center in Sports Sciences, Health Sciences and Human Development, CIDESD, Portugal

Shooting in football is crucial to score more goals than the opponent. It is usual to believe that teams need to shoot several times in order to get the chance to score. And that the key to succeed in shooting is to play with the ball, master the ball to kick it at high speeds and with accuracy. However, studies that we have been developing (e.g. Vicente et al. 2016) showed that there is time relations with the opponents that players must not ignore to succeed and score. The aim of this study was to identify the effectiveness of shooting in major football competitions were the best players take part and verify whether a correlation exists between the success of shooting and the interactions between players (striker and goalkeeper). Five hundred shots from the FIFA World Cup 2014 matches, held in Brazil, were analyzed from TV footage. The ball trajectory was analyzed considering whether it was altered or not after (by another player touching any part of his body) being shot. We've also classified the situations from the results checking their effectiveness. The relationship between the shooter and the goalkeeper was also analyzed (measuring the goalkeeper initial movement (the hip or the feet first frame to move on the direction of the final displacement) regarding to the moment of the ball kick). Data was processed is SPSS using descriptive statistics and inferential statistics. The analyzed data showed a relatively low shot efficacy (29\%), being that $5 \%$ of the goals were achieved from fortuitous manners - the ball was deviated after the shot by another player. In $64.4 \%$ of the shots the goalkeepers started their movement after the ball being kick and in $27.5 \%$ before it. From the analyzed data we are led to conclude that the effectiveness of shooting in football is very low in major competitions were the best players take part as teams need to shoot several times to score. The fortuitous goals cannot be neglected what decreases the effectiveness of shooting. The findings also suggest that in shooting situations in football players are in permanent dialogue with opponents and must be prepared to take advantage over them being aware that they can influence their actions and response times to increase success chances.

References

Vicente A., Fernando C., \& Lopes H., (2016). Passing and shooting in football: playing with the ball... and the others. In Baca A., Wessner B., Diketmüller R., Tschan H., Hofmann M., Kornfeind P., \& Tsolakidis E. (Eds.), Crossing borders through sport science: Book of abstracts of the 21 st annual congress of the European College of Sport Science (pp. 514). Vienna, Austria. ISBN: 978-3-00-053383-9.

\section{Effects of a 10-weeks flexibility training program in Physical Education classes}

\author{
Rui Marcelino ${ }^{1,2,3}$, Eduardo Abade ${ }^{1,3}$, Alberto Alves ${ }^{1,3}$, Júlia Castro ${ }^{1,3}$, João Viana ${ }^{3}$ \\ 1. Research Center in Sports Sciences, Health Sciences and Human Development, CIDESD, Portugal; 2. University of Trás-os- \\ Montes e Alto Douro, UTAD, Vila Real; 3. University Institute of Maia, ISMAI, Maia rmarcelino@ismai.pt
}

Physical Education (PE) classes plays a role helping students acquire long-lasting habits of physical activity that will improve their overall health. Improving flexibility, namely through hamstring stretching (HF), will help execute and sustain students' daily life motor activities (Kallerud \& Gleeson, 2013). The objective of this study was to examine the effects of a dynamic stretching program on hamstring flexibility in PE

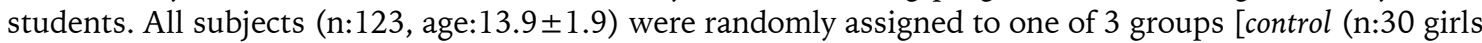

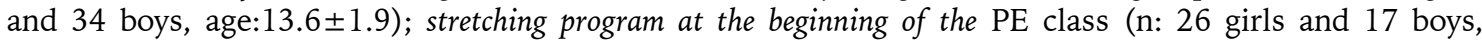

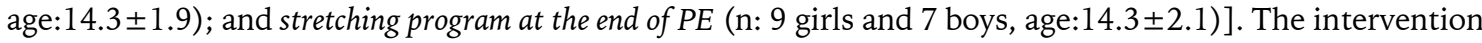
was conducted in 10 consecutive weeks, with 2 assessments (initial and final). Stretching protocols were administered to each subject in the regular PE classes. The subjects were asked to maintain their level of activity throughout the study and agreed not to stretch additionally during the 10-week research period. All subjects were evaluated in HF (Active knee extension). Progressive statistics (Unbiased Standardized Mean Differences and 95\% Confidence Intervals of parallel groups trial analysis) were applied to assess changes in HF between pre- and post- intervention for the two different training programs, compared with the control group. The subjects that have applied the stretching program at the beginning of PE (Initial assessment - Right led (RL): $156.8^{\circ} \pm 9.3^{\circ}$; left leg (LL): $156.4^{\circ} \pm 10.3^{\circ}$; Final assessment - RL: $157.0^{\circ} \pm 10.6^{\circ}$; LL: $155.4^{\circ} \pm 11.0^{\circ}$ ), as well as the one that have applied the stretching program at the end of the PE (Initial assessment - RL: $153.4^{\circ} \pm 10.0^{\circ}$; LL: $152.4^{\circ} \pm 10.4^{\circ}$; Final assessment - RL: $150.9^{\circ} \pm 9.7^{\circ}$; LL: $153.6^{\circ} \pm 8.8^{\circ}$ ) revealed benefits in hamstring flexibility compared with the control group (Initial assessment - RL: $158.7^{\circ} \pm 11.7^{\circ}$; LL: $156.8^{\circ} \pm 11.2^{\circ}$; Final assessment - RL: $153.5^{\circ} \pm 11.4^{\circ}$; LL: $\left.153.8^{\circ} \pm 12.9^{\circ}\right)$. The program was very likely beneficial in the RL flexibility at the beginning of PE $(0.49 \pm 0.22$, ES $\pm 95 \% \mathrm{IC})$, likely beneficial in $\mathrm{LL}$ at the end of PE $(0.41 \pm 0.40)$ and possible beneficial in LL at the beginning of PE $(0.21 \pm 0.25)$ and in 
$\mathrm{RL}$ at the end of PE $(0.23 \pm 0.26)$. The stretching programs applied, either at the beginning or at the end of PE classes were beneficial for the levels of HF, preventing its deterioration recorded in the control group and enabling improvements in some situations.

References

Kallerud, H., \& Gleeson, N. (2013). Effects of stretching on performances involving stretch-shortening cycles. Sports Medicine, 43(8), 733-750. https://doi.org/10.1007/s40279-013-0053-x

\section{The specificity of soccer drills and tactical positions may influence the acute responses of soccer players?}

Filipe Clemente ${ }^{1,2}$, Rui Mendes ${ }^{3}$

1. Instituto Politécnico de Viana do Castelo, Escola Superior de Desporto e Lazer, Portugal, filipe.clemente5@gmail.com

2. Instituto de Telecomunicações, Delegação da Covilhã, Portugal; 3. Instituto Politécnico de Coimbra, Escola Superior de Educação, IIA, RoboCorp, UNICID, Portugal

Some studies have revealed the variation of internal load during weekly microcycle (Brink, Nederhof, Visscher, Schmikli, \& Lemmink, 2010). Nevertheless, no study had analyzed the effects of activities and tactical positions in acute responses of amateur players, as far we know. Thus, the aim of this study was to analyze the variance of heart rate responses between different type of tasks/drills and tactical positions. Thirty-eight amateur soccer players from one male $(n=20 ; 20.4 \pm 3.12$ years old; $11.2 \pm 3.1$ years of practice; 193.2 \pm 6.4 HRmax) and one female $(n=18 ; 19.3 \pm 2.22$ years old; $7.6 \pm 2.8$ years of practice; $194.9 \pm 5.9$ HRmax) teams participated in this study. A 4-week period with 3 weekly training sessions was monitored with Polar Team App. Training session were also recorded with a single digital camera (GoPro Hero 2) to codify the type of activities prescribed by coaches. Two tasks were codified: i) conditioning tasks without game; and ii) ecological tasks based on the game. Players were also codified by their usual tactical positions (DF-defender; MF-midfielder; FW-forward). Training sessions were prescribed by coaches without any feedback from researchers. Manova did not revealed significant interactions between type of task and tactical positions $(\mathrm{p}=0.296 ; \mathrm{ES}=0.01)$ in the composite of heart rate. One-way ANOVA revealed significant differences between tactical positions in \%HRmax $(\mathrm{p}=0.001 ; \mathrm{ES}=0.04)$; and time spent between 7080\%HRmax $\quad(p=0.001 ; E S=0.02), \quad 81-90 \%$ HRmax $\quad(p=0.001 ; E S=0.02), \quad$ and $91-100 \%$ HRmax $(p=0.001 ; E S=0.02)$. Defenders had the greatest HR values with exception of time in $91-100 \%$ in which midfielders had the greatest percentage. Analysis of variance revealed that drill-based tasks had significant greater values of \%HRmax $(\mathrm{p}=0.001 ; \mathrm{ES}=0.08)$; and time between 70-80\%HRmax $(\mathrm{p}=0.001 ; \mathrm{ES}=0.03)$, 81-90\%HRmax $(p=0.001 ; E S=0.08)$, and 91-100\%HRmax $(p=0.001 ; E S=0.02)$. Drill-based activities had greater values of acute responses to exercise. Moreover, defenders had the greatest values of HR responses.

Acknowledgments

This work was supported by the FCT project PEst-OE/EEI/LA0008/2013. Authors would like to thank to Bento Cortesão, Catarina Vicente, Cláudio Santos, Sofia Silva, Miguel Almeida and Flávio Simões.

References

Brink, M. S., Nederhof, E., Visscher, C., Schmikli, S. L., \& Lemmink, K. a P. M. (2010). Monitoring load, recovery, and performance in young elite soccer players. Journal of Strength and Conditioning Research, 24(3), 597-603.

\section{Observational instrument for fencing: tactical actions characterization}

João José ${ }^{1}$, José Leitão ${ }^{1}$, Xavier Iglesias², Maria Anguera² ${ }^{2}$, Jorge Campaniço ${ }^{1}$

1. University Trás-os-Montes e Alto Douro, School of Life Sciences and Environment, Sport Observation Laboratory; jorgecampanico@gmail.ccom; 2. University of Barcelona, National Institute of Physical Education of Cataluña, Barcelona, Spain

The main purpose of this study was to create an observational instrument to characterize the tactical performance during fencing competition bouts, in a qualitative and sequential dimension, based on the observational methodology, we tried to create a tactical organization to identify existing T-Patterns of tactical interactions between the fencers. This study was divided in two phases. The first phase the focus it was in the reliability of the instrument based on one case study. In the second phase we study the existence of T-Patterns. The observational sample consisted observation of four games of the Men's FIE World Championship in Moscow (2015). To materialize the intended aims, an ad hoc instrument of observation was constructed, which associated the field formats and the systems of categories. The validation of the content of this instrument was carried out by fencing specialists, trainers (degree 3) of the Fencing Portuguese Federation and Modern Pentathlon Portuguese Federation and specialist coaches of Master Coach. The intra-observer reliability it was made by two observations of the same fencing competition bout, with two weeks between them. The inter-observer reliability was carried out by two coaches. We use the Cohen's Kappa coefficient to all categories and field formats. To collect data we use specific statistic tools 
as LINCE 1.4 and THÈME 5.0 (Magnusson et al., 2004) enable the study of the reliability of the data of this instrument and the T-Patterns. In the inter-observer test we verified a Cohen's Kappa coefficient of 0,878 with 2 field formats with variation between 0.60 and 0.65 . The intra-observer results for Cohen's Kappa coefficient was 1.0. 147 T-Patterns were identified, showing three complete standards and three incomplete standards with tactical meaning where we can represent a fencing tactical phrase. The results show us a high variability of environment situations that are expected at this collective sport level. The study of the incomplete standards made possible, in a phased way, to characterize the observed tactical actions. This instrument show that is possible the characterization of fencing tactical actions. Some errors occurred because of limitations in LINCE to select data and also problems with our instrument manual construction. More sampling is needed to determine complete standards. The preliminary data highlights the potential for T-pattern analysis to make a significant contribution to sport performance analysis in fencing.

\section{References}

Borrie, A., Jonsson, G. K., \& Magnusson, M. S. (2002). Temporal pattern analysis and its applicability in sport: an explanation and exemplar data. Journal of sports sciences, $20(10), 845-852$.

Magnusson, M. S. (1996). Hidden real-time patterns in intra-and inter-individual behavior: Description and detection. European Journal of Psychological Assessment, $12(2), 112$.

\section{Contributing factors to preseason repeated sprint ability in soccer players from first and second division}

\section{João Ribeiro ${ }^{1}$, Nuno Romano ${ }^{1}$, Vítor Moreira ${ }^{1}$, Francisco Miranda ${ }^{1}$, Samuel Amorim ${ }^{1}$}

\section{Gabinete de Otimização Desportiva, Sporting Clube de Braga SAD. Braga, Portugal}

The ability to produce repeated sprints efforts (RSA) is an important determinant of in-match soccer performance. This RSA seems to be a discriminating factor between soccer players from different standards but varies according to the season period (Rampinini et al., 2009). Our aim was to determine both the anthropometric and fitness parameters that best predict RSA in soccer players of two different competitive levels (First vs Second-division) at the preseason phase. Forty-five professional male soccer players of Portuguese League (First-division: $\mathrm{n}=22 ; 25.5 \pm 3.4 \mathrm{yrs}, 79.9 \pm 8.2 \mathrm{~kg}, 1.8 \pm 0.1 \mathrm{~m} v \mathrm{~s}$. Second-division: $\mathrm{n}=23$; $20.3 \pm 1.8 \mathrm{yrs}, 75.7 \pm 7.5 \mathrm{~kg}, 1.8 \pm 0.1 \mathrm{~m})$ were tested for anthropometrics (skinfolds and perimeters: body fat, lean body mass), Yo-Yo intermittent endurance test, countermovement jump (Ergojump, Globus, Italy), straight-line $30 \mathrm{~m}$ sprint and RSA test of $6 \times 35 \mathrm{~m}$ with $10 \mathrm{~s}$ passive recovery (Photocells, Brower Timing System, USA). Multiple linear regression models, with sprint decrement score (fatigue index) as the dependent variable, was used to determine

\section{Table 1}

Results of the Multiple Linear Regressions with sprint decrement score as dependent variable.

\begin{tabular}{ccccc}
\multicolumn{5}{c}{ dependent variable. } \\
\hline \multirow{2}{*}{ First } & Variables & Coefficient & Beta Weight & P value \\
Division & Constant & 18.50 & & $<0.01$ \\
& $\begin{array}{c}\text { Countermovement } \\
\text { Jump }\end{array}$ & -0.33 & -0.461 & 0.03 \\
\hline \multirow{2}{*}{ Second } & Constant & 53.32 & & \\
Division & 30 m sprint & -5.86 & -0.492 & $<0.01$ \\
& Yo-Yo & -0.20 & -0.356 & 0.04 \\
\hline
\end{tabular}
the most relevant factors contributing to RSA. The regression model included the countermovement jump $(r=0.59, P=0.04)$ for the First-division, and both the $30 \mathrm{~m}$ sprint and Yo-Yo test $(\mathrm{r}=0.66, P<0.01)$ for the Second-division, as the most relevant factors contributing to RSA (Table 1). For the First-division players the countermovement jump effect corroborated the importance of neuromuscular stimulus to determine RSA. Moreover, the $30 \mathrm{~m}$ sprint, which has been reported to be closely related with jump height (Nikolaidis, Dellal, Torres-Luque, \& Ingebrigtsen, 2015), partially explained the variability of RSA in the Second-division soccer players. This fact evidences that both competitive levels would benefit from an intensification of lower limb explosive power to enhance the preseason RSA. In addition, for Second-division soccer players, the aerobic fitness seems also to be an important influencing factor to the capacity to resist fatigue during repeated sprints. Although anthropometric factors did not assume an important role for RSA performance' contributing factor in both groups, they still need to be taken into account for general soccer performance purposes.

\section{References}

Nikolaidis, P. T., Dellal, A., Torres-Luque, G., \& Ingebrigtsen, J. (2015). Determinants of acceleration and maximum speed phase of repeated sprint ability in soccer players: A cross-sectional study. Sci Sports, 30(1), e7-e16.

Rampinini, E., Sassi, A., Morelli, A., Mazzoni, S., Fanchini, M., \& Coutts, A. J. (2009). Repeated-sprint ability in professional and amateur soccer players. Appl Physiol Nutr Metab, 34(6), 1048-1054. 


\title{
Profiling in olympic beach volleyball: the influence of player's role
}

\author{
Antonio García-de-Alcaraz ${ }^{1}$, Alexandre Medeiros ${ }^{2}$, Miguel Gómez-Ruano ${ }^{1}$
}

1. Faculty of Physical Activity and Sport Sciences. Polytechnic University of Madrid, Madrid, Spain; antonio.garciadealcaraz@upm.es 2. Research Group in Biodynamic Human Movement, Institute of Physical Education and Sport, Federal University of Ceara, Fortaleza, Ceará, Brazil

Sport performance analysis explores players/teams' behaviour during competition and provides objective and real information to improve the training process. The performance indicators studied should be classified according to some specific variables in order to enable a better methodological approach (Sampaio \& Leite, 2013). The player's role is a variable that may influence beach volleyball (BV) players' performance, and it is classified as blocker (i.e., playing close to the net) or digger (i.e., playing in the back court) in the defensive phase of play. These dissimilar functions may be associated with differences in players' characteristics. Therefore, the aim of this study was to analyse the anthropometric and technical-tactical performance profile in terms of players' role in Olympic BV. All the BV players $(n=96)$ participating in Rio 2016 Olympic Games were analysed. Only 44 men and 46 women that played a specific role (blocker or digger) were selected. The variables studied were: (a) gender (male and female); (b) technical-tactical (TT) actions performed by set (-b.1- total of attacks and serves performed, -b.2- total of points in attack, block and serve, and -b.3- efficacy of attack and serve); and (c) anthropometrical variables (AV) (height and weight).

Table 1

Descriptive results (mean \pm sd) and SMD at 90\% IC player's role in anthropometric and technical-tactical variables

\begin{tabular}{|c|c|c|c|c|c|c|}
\hline & \multicolumn{2}{|c|}{ Men $(n=44)$} & \multicolumn{4}{|c|}{ Women $(n=46)$} \\
\hline & $\begin{array}{l}\text { Blocker } \\
(\mathrm{n}=22)\end{array}$ & $\begin{array}{l}\text { Digger } \\
(\mathrm{n}=22)\end{array}$ & $\begin{array}{c}\text { SMD } \\
\text { (90\% IC) }\end{array}$ & $\begin{array}{l}\text { Blocker } \\
(\mathrm{n}=23)\end{array}$ & $\begin{array}{c}\text { Digger } \\
(\mathrm{n}=23)\end{array}$ & $\begin{array}{c}\text { SMD } \\
\text { (90\% IC) }\end{array}$ \\
\hline \multicolumn{7}{|l|}{ Anthropometric } \\
\hline Height & $198.95 \pm 6.31$ & $190.91 \pm 8.03$ & $-1.27 \pm 0.58^{* *}$ & $183.57 \pm 5.47$ & $176.52 \pm 5.88$ & $-1.27 \pm 0.51^{* *}$ \\
\hline Weight & $90.45 \pm 7.88$ & $83.82 \pm 8.76$ & $-0.88 \pm 0.57^{*}$ & $70.48 \pm 4.57$ & $66.35 \pm 4.20$ & $-0.88 \pm .047^{*}$ \\
\hline \multicolumn{7}{|l|}{ Technical-tactical } \\
\hline Attack (total) & $8.38 \pm 2.19$ & $11.41 \pm 2.31$ & $1.14 \pm 0.43^{*}$ & $10.45 \pm 1.87$ & $10.83 \pm 2.19$ & $0.16 \pm 0.54$ \\
\hline Attack Points & $4.82 \pm 1.21$ & $6.05 \pm 1.04$ & $0.92 \pm 0.42^{*}$ & $5.43 \pm 0.96$ & $5.45 \pm 1.32$ & $-0.08 \pm 0.62$ \\
\hline Attack Eff. & $58.03 \pm 6.33$ & $54.03 \pm 8.09$ & $-0.67 \pm 0.61^{*}$ & $52.53 \pm 8.09$ & $50.29 \pm 7.73$ & $-0.26 \pm 0.47$ \\
\hline Block Points & $1.48 \pm 0.59$ & $0.10 \pm 0.21$ & $-3.88 \pm 1.54^{* *}$ & $1.18 \pm 0.51$ & $0.05 \pm 0.08$ & $-3.78 \pm 0.65^{* *}$ \\
\hline Serve (total) & $21.11 \pm 10.79$ & $17.47 \pm 6.31$ & $-0.43 \pm 0.49$ & $16.22 \pm 4.87$ & $17.81 \pm 7.10$ & $0.22 \pm 0.53$ \\
\hline Serve Points & $1.28 \pm 1.25$ & $0.77 \pm 0.54$ & $-0.38 \pm 0.45$ & $1.03 \pm 0.61$ & $1.29 \pm 1.06$ & $0.18 \pm 0.59$ \\
\hline Serve Eff. & $5.55 \pm 3.46$ & $4.50 \pm 2.74$ & $-0.27 \pm 0.51$ & $6.43 \pm 2.97$ & $6.90 \pm 3.44$ & $0.06 \pm 0.54$ \\
\hline
\end{tabular}

Note: "Eff": Efficacy; * Moderate differences between player's role; ${ }^{* *}$ large (or more) differences between player's role. The negative symbol indicates a shift towards blocker

The data were obtained from the official website of the tournament. The magnitude differences assessed via standardized mean differences (SMD) at $90 \%$ of interval confidence (IC) were used to identify performance differences between player's roles. The magnitude of threshold was set as: 0-0.2 trivial, >0.20.6 small, $>0.6-1.2$ moderate, $>1.2-2$ large, and $>2$ very large. Results showed greater differences in AV and in block points between player's roles in both genders. Blockers were taller, heavier and displayed higher efficacy in block actions. Also, there were greater differences in attack between male player's roles. Diggers performed more attacks and scored more attack points than blockers, but the latter showed higher efficacy than diggers (Table 1). At BV Olympic level, there are great differences in AV and in block performance in terms of player's role both in male and female. In attack, there are great differences among male players in terms of role. These results may be useful for improving the training process in order to achieve top-level performance.

References

Sampaio, J., \& Leite, N. (2013). Performance indicators in game sport. In McGarry, T., O’Donoghue, P., \& Sampaio, J. (Eds.), The Routledge Handbook of Sports Performance Analysis (115-126). Oxon: Routledge. 


\title{
Performance analysis tool (PATO): Development and preliminary validation
}

\author{
Fernando Martins ${ }^{1,2}$, Filipe Clemente ${ }^{2,3}$, Frutuoso Silva ${ }^{2,4}$
}

1. Instituto Politécnico de Coimbra, Escola Superior de Educação, IIA, RoboCorp, UNICID, Portugal; fmlmartins@ubi.pt; 2. Instituto de Telecomunicações, Delegação da Covilhã, Portugal; 3. Instituto Politécnico da Viana do Castelo, Escola Superior de Desporto e Lazer, Portugal; 4. University of Beira Interior, Portugal

Social network analysis it has been recently used as notational technique to quantify the properties of soccer teams. In the majority of the cases the analysis has been made in traditionally notational software that can be unspecific or too much expensive to extend for the team sports community. Based on that reasons, the purpose of this study was to describe the development and preliminary validation of new assessment software for team sports. Validation had three phases (Cronbach, 1988): 1) content validity; 2) construct validity; and 3) reliability of observations. The Performance Analysis Tool (PATO) software was built with the aim to quickly codify relationships between players and built the adjacency matrices that can be used to test the network measures. From PATO it was possible to extract the adjacency matrices and use them in the SocNetV. PATO was analyzed by five expert coaches (soccer, basketball and handball) with a minimum of five years of experience in elite teams. After the clarification of doubts and improvement of procedures, three of the expert coaches have used the software to classify the centrality levels of players and compare with their own perception about the prominence of players (based on an order scale). After the preliminary test of association between coaches' perception and network measures, an inter- and intraobserver tests were performed. To do that, four novice observers with no previous experience in match analysis were trained during a course of 10 hours. These observers have collected data from three official matches (soccer, basketball and handball) in two periods with 20-day interval. Association values between the centrality levels (indegree and outdegree) had significant large positive correlations with the scale of prominence ordered by the coaches $(r=0.68$ and $r=0.74$, respectively). Values for the intra- and interreliability tests revealed very large positive correlations $(r=0.82$ and $r=0.73$, respectively). Values suggest that PATO is valid and reliable for assessment the network processes in team sports. Software must follow to an integrated platform that allow to directly compute network measures and use different sources of information.

Aknowledgments:

This work was supported by the FCT project PEst-OE/EEI/LA0008/2013.

References

Cronbach, L. J. (1988). Five perspectives on validity argument. In H. Wainer \& H. I. Braun (Eds.), Test validity (pp. 3-17). New Jersey: Lawrence Erlbaum Associates.

\section{National federations and sport participation in Portugal - Economic determinants and trend analysis from 2000 to 2014}

Félix Romero $^{1}$, Abel Santos ${ }^{1}$

1. ESDRM-Instituto Politécnico de Santarém; fromero@esdrm.ipsantarem.pt

Following European trends, sport participation in Portugal has grown in the last few years. An analysis of this growth by territorial areas, different types of sport practices, inequality between men and women, and the influence of economic determinants is critical to support decision-making. This is the main purpose of this research which will study the time frame between 2000 and 2014. Data regarding sport participation respects only to federate sports and was collected through Instituto Português do Desporto e da Juventude - IPDJ. Descriptive statistics were used to assess sport participation by district in 2014. Cluster analysis was used to define homogenous groups of districts and homogenous groups of different sports regarding their respective participations. A Cluster analysis of the different sports was also performed concerning the ratio women participants/total participants. A regression analysis was performed to explain the evolution in the number of participants from 2000 to 2014 using as independent variables: an indicator of the growth domestic product per capita of each district, the percentage of purchasing power of each district, and the relative momentum factor of each district which aims to reflect the changes of the purchasing power due to seasonality factors. In the year of $2014,4.7 \%$ of the total Portuguese Population engaged in some kind of federate sport activity. Regarding the total number of participants 4 homogenous groups of districts could be identified. A first group is formed by the districts of Lisbon and Porto, a second by Aveiro and Braga, a third by Açores Coimbra, Faro, Leiria, Santarém, Setúbal and Viseu and fourth by Beja, Bragança, Castelo Branco, Évora, Guarda, Madeira, Portalegre, Viana do Castelo and Vila Real. In what concerns to the sport being practiced, 3 clusters were identified: Football gathers $32.8 \%$ of all participants. Volleyball, Handball and Basketball represent $26.7 \%$ and all other sports account for $40.5 \%$ of participants. Women 
participation reaches $26.1 \%$, and 5 clusters of different sports were identified regarding this issue. The evolution in the number of sport participants from 2000 to 2014 was explained (adjusted $\mathrm{r}$ squared $=0.689$; $\left.\mathrm{F}_{(3,16)}=15.017, \mathrm{p}<0.001\right)$ by the percentage of purchasing power of each district $(\mathrm{B}=2117.2)$ and by the growth domestic product per capita $(B=-413.2)$ of each district but not by the relative momentum factor. In Portugal, sport participation at national sport federations is very heterogeneous across districts. Most participants are affiliated to few sports and most sports have few participants. Women's participation depends on the type of sport and is only relevant in a few sports. Sports participation growth from 2000 to 2014 is associated with the districts economic context namely the purchasing power.

References

Breuer, C., Hallmann, K., \& Wicker, P. (2011). Determinants of sport participation in different sports. Managing Leisure, 16(4), 269-286.

\title{
Preliminary validation of an observation instrument for analyzing verbal behavior in Spanish football coaches
}

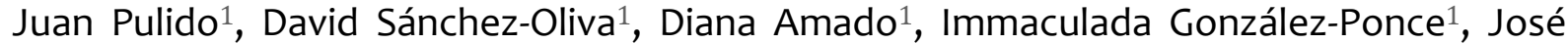 \\ Chamorro $^{1}$
}

1. University of Extremadura, Spain. jipulido@unex.es

The main aim of this study was to validate an observational instrument to analyze the coaches' behaviors, establishing a system configured categories based on the coaches' interpersonal styles and then check the reliability of the instrument level inter-observer and intra-observers. Firstly, a consultation of the literature was developed using different scientific databases to establish the criteria for observation. Moreover, the content or construct validity was established on a qualitative (degree of understanding, writing, proposed examples, levels granted and adequacy) and quantitative level (global assessment of each expert) through the agreement and consensus of ten experts reviewers on the topic of investigation. Secondly, the interobserver reliability and temporal reliability were examined by observing five minutes clips of different videos. The general assessments of the experts were positive and changes were minimal, while quantitatively valuations were above 8.35 out of 10 , except in the category entitled "Others", which after scores awarded by experts decided to eliminate. Regarding reliability, results showed scores above .75 both inter observer and the temporal reliability. A valid and reliable scale to analyze coach verbal behavior during the development of training and matches is presented.

\begin{tabular}{|c|c|c|c|c|c|c|c|c|c|c|c|}
\hline Categories/Reviewers & R1 & $\mathrm{R} 2$ & R3 & R4 & R5 & R6 & R7 & R8 & R9 & $\mathrm{R} 10$ & Global \\
\hline Initial Activity Information & 8 & 10 & 8 & 9 & 9 & 9.5 & 9 & 8 & 9 & 9 & 8.85 \\
\hline Adequacy category & Yes & Yes & Yes & Yes & Yes & Yes & Yes & Yes & Yes & Yes & Yes \\
\hline Redirecting Process & 10 & 9 & 8 & 10 & 8 & 9 & 9 & 9 & 10 & 9 & 9.1 \\
\hline Adequacy category & Yes & Yes & Yes & Yes & Yes & Yes & Yes & Yes & Yes & Yes & Yes \\
\hline Ego/Task Climate & 10 & 8 & 10 & 9 & 9 & 9 & 8 & 9 & 7 & 9 & 8.8 \\
\hline Adequacy category & Yes & Yes & Yes & No & Yes & Yes & Yes & Yes & No & Yes & Yes \\
\hline Team General Instr. & 8 & 9 & 7 & 7.5 & 9 & 10 & 10 & 7 & 10 & 7 & 8.45 \\
\hline Adequacy category & Yes & Yes & Yes & Yes & Yes & Yes & Yes & Yes & Yes & No & Yes \\
\hline Individual General Instr. & 8 & 9 & 7 & 7.5 & 9 & 10 & 10 & 7 & 10 & 7 & 8.45 \\
\hline Adequacy category & Yes & Yes & Yes & Yes & Yes & Yes & Yes & Yes & Yes & No & Yes \\
\hline Team Feedback & 8 & 9 & 6 & 9 & 9 & 10 & 10 & 6 & 8.5 & 8 & 8.35 \\
\hline Adequacy category & Yes & Yes & Yes & Yes & Yes & Yes & Yes & Yes & Yes & Yes & Yes \\
\hline Individual Feedback & 8 & 9 & 8 & 9 & 10 & 10 & 10 & 6 & 8.5 & 8 & 8.65 \\
\hline Adequacy category & Yes & Yes & Yes & Yes & Yes & Yes & Yes & Yes & Yes & Yes & Yes \\
\hline Social Team Climate & 10 & 9 & 9 & 8.5 & 9 & 9 & 10 & 8 & 10 & 9 & 9.15 \\
\hline Adequacy category & Yes & Yes & Yes & Yes & Yes & Yes & Yes & Yes & Yes & Yes & Yes \\
\hline Social Individual Climate & 10 & 9 & 7 & 9 & 9 & 9 & 10 & 8 & 10 & 7 & 8.8 \\
\hline Adequacy category & Yes & Yes & Yes & Yes & Yes & Yes & Yes & Yes & Yes & No & Yes \\
\hline Others & 10 & 9 & 0 & 4 & 8 & 9.5 & 10 & 7 & 5 & 7 & 6.95 \\
\hline Adequacy category & Yes & Yes & No & No & Yes & Yes & Yes & Yes & No & No & No \\
\hline
\end{tabular}

Note: Instr. = Instruction

Acknowledgements:

European Social Fund and Government of Extremadura "(PD12112)”.

References

Smith, R. E., Smoll, F. L., \& Hunt, E. (1977). A system for the behavioral assessment of athletic coaches. Research Quarterly, 48, $401-407$.

Smith, N., Tessier, D., Tzioumakis, Y., Quested, E., Appleton, P., Sarrazin, P., \& Duda, J. L. (2015). Development and validation of the multidimensional motivational climate observation system. Journal of Sport \& Exercise Psychology, 37(1), 4-22. 


\title{
Approach for the operationalization of the strategy in a medium- size sport club
}

\author{
Pedro Sobreiro $^{1}$, Eduardo Teixeira ${ }^{1}$, Hugo Louro ${ }^{1,2}$, Ana Conceição ${ }^{1,2,3}$
}

1. Sport Sciences School of Rio Maior, Rio Maior, Portugal; sobreiro@esdrm.ipsantarem.pt; 2. Research Centre in Sports Sciences, Health Sciences and Human Development, CIDESD, Portugal, Vila Real, Portugal; 3 CIEQV- Life Quality Research Center, Santarém, Portugal

Sport managers are in the business of uncertainty (Simon Chadwick, 2009), however is required a set of assumptions for the development of the organization, which facilitates the achievement of the organization goals (Slack \& Parent, 2006). The problem lies in the operationalization of the non-profit organization objectives (Thibault, Slack, \& Hinings, 1993). Considering the lack of research to operationalize the organization strategy, the aim of this study is the development of an approach to support their business objectives using Business Process Management (BPM) approach to support the operationalization of the strategy in a non-profit sport club. The research follows the case study approach using a single case study (Yin, 2003). The information was retrieved applying an interview with the sport club responsible framed in the BPM approach steps: (1) Mission and vision; (2) Identification of strategic objectives; (3) Assessment of business capabilities and (4) Assessment of stakeholder concerns and objectives. We documented our progress storing the information in a spreadsheet prepared to support the retrieved information. The results allowed the identification of six financial objectives, two objectives for the customers, one for human resources, and the local community. The assessment of stakeholders recognized the relevance of Practitioners, Sponsors, Small and Medium Enterprises, Parents, Volunteers, Club Member, Spectators, and Local Community. The identified business capabilities were "Get Practitioners", "Organize Activities and Events", "Fund Raising", "Manage Sport Activities" and "Support the Sport Activity". These capabilities reflect vital areas for the sport club existence. The stakeholders concerns assessment allowed the identification of Business Objectives related to "Practitioners Retention"; "Selling Merchandising" or "Sponsorship". The adopted approach allowed the development of the sport club strategy systematically. The clarification of the organization goals properly framed in a context simplifies the definition of the improvement actions to support the achievement of the organization objectives.

References

Simon Chadwick. (2009). From outside lane to inside track: sport management research in the twenty-first century. Management Decision, 47(1), 191-203. http://doi.org/10.1108/00251740910929786

Slack, T., \& Parent, M. M. (2006). Understanding Sport Organizations: The Application of Organization Theory. Human Kinetics.

Thibault, L., Slack, T., \& Hinings, B. (1993). A Framework for the Analysis of Strategy in Nonprofit Sport Organizations. Journal of Sport Management, $7(1), 25-43$.

Yin, R. K. (2003). Case study research: design and methods (3rd ed). Thousand Oaks, Calif: Sage Publications.

\section{Early sports involvement and improvements in reaction time: a specific training program approach}

Nuno Mateus ${ }^{1}$, Tautvydas Skrupskelis ${ }^{1}$, Nuno Leite ${ }^{1}$

1. Research Center in Sports Sciences, Health Sciences and Human Development, CIDESD, CreativeLab Research Community, Portugal; nuno_mateus23@hotmail.com

During youth occurred sensitive periods wherein the athletes are more susceptible to the training of motor skills. Reaction time can be improved different times during youth, in short periods of time. An early sport diversification could benefit players' performance in their main sport. The purpose of this study was to determine the effects of a specific training program in reaction time, taking into account the early sports involvement. Fifteen youth basketball players (age: $M=13.2, S D=0.5$; height: $M=163.9, S D=11.1 \mathrm{~cm}$; and mass: $\mathrm{M}=53.7 \mathrm{SD}=12.9 \mathrm{~kg}$ ) participated in this study. The intervention programme lasted five days and all players were involved in the same training regimen. For measured the improvements in reaction time two Batak-Pro tests were used. In the first test the users must strike out 25 targets at random as quickly as possible; in second test the number of targets doubles. The program effects were tested using Student's $t$ test for pairwise comparisons. Moreover, to ascertain the magnitude of the differences the Cohen's d Effect Sizes were calculated. All statistical tests were performed according to the years of experience in basketball practice and to the type of sporting activities performed throughout participants' sport careers. The results suggest improvements in reaction time regardless the previous experience in basketball practice and the sports career $\left(\mathrm{MD}_{25 \text { targets }}=-5.5 ; \mathrm{MD}_{50 \text { targets }}=-8.7\right)$. The early diversified practice participants revealed larger benefits $\left(\mathrm{MD}_{25 \text { targets }}=-4.4 ; \mathrm{MD}_{50 \text { targets }}=-8.1\right)$ comparatively to players who only had basketball experience $\left(\mathrm{MD}_{25 \text { targets }}=-6.3 ; \mathrm{MD}_{50 \text { targets }}=-9.2\right)$. Particularly in basketball, the participants with more years of practice showed better improvements than participants with less experience, in the 25 targets test $\left(\mathrm{MD}_{25 \text { targets }}=\right.$ $5.7 ; \mathrm{MD}_{25 \text { targets }}=-5.3$, respectively). Nonetheless, in the 50 targets test the opposite occurred, since the less 
experienced players accomplished a larger improvement comparatively the most experienced participants $\left(M D_{50 \text { targets }}=-9 ; \mathrm{MD}_{50 \text { targets }}=-8.4\right.$, respectively $)$. This study confirmed that reaction time may be improved trough short and intense training programs. Reaction time improvements were influenced by players' diversification practice and of the amount of previous years spent in basketball practice. The results of this study also confirmed that reaction time can be improved using simple drills performed during basketball training or warm-up. Finally, Batak-Pro confirmed to be a useful equipment to test, develop and assess reaction time in young basketball players.

\section{Who plays the most? The relation between physical capacities, relative age effect and playing time in young football players.}

Paulo Pereira ${ }^{1}$, Diogo Pacheco ${ }^{1}$, Bruno Leal ${ }^{1}$, Hugo Folgado ${ }^{1,2}$

1. Universidade de Évora, Escola de Ciências e Tecnologia, Departamento de Desporto e Saúde, Portugal; 2. CreativeLab, CIDESD, Portugal; hfolgado@uevora.pt

The relative age effect is a worldwide phenomenon, which refers to the chronological difference between subjects grouped into categories according to their year of birth (Schorer et al. 2009). Given this age difference it is not surprising that there is a systematic exclusion of younger and less mature players in youth football teams, leading to a higher representation of selected players born in the first quarters of the year. (Gravina et al., 2008). However, the relation between physical capacities and coaches' selection, represented by the amount of playing time, is still lacking in existing research, particularly focusing in different age groups. Thus, the aim of this study was to compare the playing time and physical capacities according to players' age group and quarter of birth. A total of 69 football players (age $=13.97 \pm 1.51)$ of EØvora region clubs participated in the study during the 2015/16 season. Players' physical capacities were evaluated trough a battery of physical tests, including speed (sprint 20 meters), agility (Illinois Test), strength (Hand Grip, Squat Jump and Counter Movement Jump) and endurance (Yo-Yo test). Players were grouped according to their age group (U13 to U17), trimester of Table 1
Comparison between physical capacities, playing time and trimester of birth, according to
players grouping. Players distribution by playing time revealed that players with higher
playing time tended to born in the early part of the year.

\begin{tabular}{|c|c|c|c|c|c|c|c|c|c|c|}
\hline \multirow{2}{*}{ Comparasion } & \multirow{2}{*}{ Variable } & \multirow{2}{*}{$n$} & \multicolumn{7}{|c|}{ Mean } & \multirow{2}{*}{ Post-Hoc } \\
\hline & & & s) (s) & $\mathrm{CM} /(\mathrm{s})$ & HGr(KE) & HGI(Kg) & $20 \mathrm{~m}(\mathrm{~s})$ & IIIInols (s) & Yo-Yo Test (m) & \\
\hline \multirow{3}{*}{$\begin{array}{l}\text { Phisical tests vs } \\
\text { Age group }\end{array}$} & Under-13 (AG1) & 31 & 0.42 & 0.49 & 18.97 & 18.78 & 4.32 & 19.04 & 1219 & \multirow{3}{*}{ 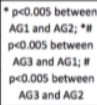 } \\
\hline & Under-15 (AG2) & 25 & $0.48^{\circ}$ & 0.50 & 30.38* & $28.22^{\circ}$ & 4.31 & 19.02 & 1416 & \\
\hline & Under-17 (AG3) & 14 & 0.49 & 0.51 & $39.84^{*}$ & $36.41 * \|$ & $4.04 * \pi$ & $17.90^{\circ} \|$ & 2188" & \\
\hline \multirow{4}{*}{$\begin{array}{l}\text { Phisical tests vs } \\
\text { Quarter }\end{array}$} & 1st Quarter (Q1) & 16 & 0.48 & 0.51 & 30.98 & 28.68 & 4.08 & 18.22 & 1685 & \multirow{4}{*}{ 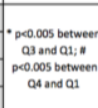 } \\
\hline & 2nd Quarter (Q2) & 18 & 0.46 & 0.51 & 30.14 & 28.81 & 4.17 & 18.48 & 1582 & \\
\hline & 3rd Quarter (03) & 20 & 0.45 & 0.48 & 25.30 & 24.05 & $4.39^{*}$ & $19.29^{\circ}$ & 1235 & \\
\hline & Ath Quarter (14) & 16 & 0.42 & 0.49 & 22.58 & 21.20 & 4.384 & 19.15 & 1482 & \\
\hline \multirow{4}{*}{ 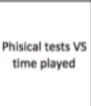 } & SA9X (G1) & 17 & 0.44 & 0.47 & 25.77 & 24.34 & $4.488^{*} \cdot 15$ & $19.83 * 45$ & 1254 & \multirow{4}{*}{ 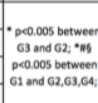 } \\
\hline & $50-74 \times(62)$ & 20 & 0.41 & 0.49 & 24.89 & 23.98 & 4.34 & 18.91 & 1126 & \\
\hline & $75-89 \%(63)$ & 27 & $0.48^{*}$ & 0.53 & 29.75 & 27.64 & 4.12 & 18.26 & $1774^{*}$ & \\
\hline & $290 \%(64)$ & 6 & 0.50 & 0.50 & 27.73 & 26.34 & 4.04 & 18.01 & 2020 & \\
\hline \multirow{6}{*}{\begin{tabular}{c|c}
$\begin{array}{c}\text { Time played Vs } \\
\text { Quarter U13 }\end{array}$ \\
\end{tabular}} & & & \multirow{2}{*}{\multicolumn{2}{|c|}{ Xolayers born in the 1 st }} & \multirow{2}{*}{\multicolumn{2}{|c|}{ 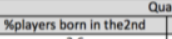 }} & \multicolumn{2}{|c|}{ Ef } & \multirow{2}{*}{\multicolumn{2}{|c|}{ Xplayers born in the 4th }} \\
\hline & S496(G1) & 5 & & & & & \multirow{2}{*}{\multicolumn{2}{|c|}{$\begin{array}{l}3.6 \\
71\end{array}$}} & & \\
\hline & $50.74 \times(62)$ & 13 & \multicolumn{2}{|c|}{3.6} & \multicolumn{2}{|c|}{$\frac{3.6}{17.9}$} & & & \multicolumn{2}{|c|}{$\begin{array}{c}10.7 \\
179\end{array}$} \\
\hline & $75-89 \times(63)$ & 8 & \multirow{2}{*}{\multicolumn{2}{|c|}{$\frac{10.7}{7.1}$}} & \multirow{2}{*}{\multicolumn{2}{|c|}{$\frac{7.1}{3.6}$}} & \multicolumn{2}{|c|}{$\frac{3.6}{0.0}$} & \multirow{2}{*}{\multicolumn{2}{|c|}{$\begin{array}{l}3.6 \\
0.0\end{array}$}} \\
\hline & $290 \times(64)$ & 3 & & & & & & & & \\
\hline & TOTAL & 28 & \multirow{2}{*}{\multicolumn{2}{|c|}{8.0}} & \multirow{2}{*}{\multicolumn{2}{|c|}{8.0}} & \multirow{2}{*}{\multicolumn{2}{|c|}{24.0}} & \multirow{2}{*}{\multicolumn{2}{|c|}{4.0}} \\
\hline \multirow{4}{*}{$\begin{array}{c}\text { Time played VS } \\
\text { Quarter U15 } \\
\end{array}$} & s499x (61) & 11 & & & & & & & & \\
\hline & $50-74 \times(62)$ & 2 & \multirow{2}{*}{\multicolumn{2}{|c|}{$\frac{4.0}{12.0}$}} & & & & & & 0.0 \\
\hline & $\begin{array}{l}75-89 \times(63) \\
2900(64)\end{array}$ & 9 & & & & & & & & 4.0 \\
\hline & $\begin{array}{l}\mid 2900 \text { (G4) } \\
\text { TOTAL }\end{array}$ & $\frac{3}{25}$ & & & & & & & & \\
\hline & s49\%(G1) & 1 & & & & & & & & 0.0 \\
\hline Time played VS & $50-74 \times(62)$ & 4 & & & & & & & & 0.0 \\
\hline Quarter U17 & $75-89 \times(63)$ & 9 & & & & & & & & 1.4 \\
\hline & $290 \times(64)$ & 0 & & & & & & & & 0.0 \\
\hline & TOTAL & 14 & & & & & & & & \\
\hline
\end{tabular}
birth (1st quarter from

January to March; 2nd from April to June; 3rd from July to September and 4th from October to December) and according to their relative playing time: G1 ( $\leq 49 \%)$, G2 (50\% to $74 \%)$, G3 (75\% to $89 \%)$ and G4 $(\geq 90 \%)$. One-way ANOVA was used to compare physical capacities per different groups. In short, young football players who born in the early part of the year are more developed and have better physical capabilities. These factors influence the selection of coaches, resulting into more playing opportunities. This effect is more present in the U13 and U15 age groups.

References

Gravina, L., Gil, S. M., Ruiz, F., Zubero, J., Gil, J., \& Irazusta, J. (2008). Anthropometric and physiological differences between first team and reserve soccer players aged 10-14 years at the beginning and end of the season. The Journal of Strength E Conditioning Research, 22(4), 13081314.

Schorer, J., Baker, J., Büsch, D., Wilhelm, A., \& Pabst, J. (2009). Relative age, talent identification and youth skill development: Do relatively younger athletes have superior technical skills. Talent Development and Excellence, 1 (1), 45-56. 


\title{
Physical qualities of a group of junior elite soccer athletes
}

\author{
Francisco Tavares ${ }^{1,2}$, Mário Simões ${ }^{3,4}$, Paulo Roriz ${ }^{5,6,7}$, Filipe Clemente ${ }^{3}$, Bruno Silva ${ }^{3}$, Pedro \\ Bezerra $^{3,7}$, Miguel Camões ${ }^{3}$ \\ 1. University of Waikato, Hamilton, New Zealand; 2. Chiefs Super Rugby, Hamilton, New Zealand; 3. Instituto Politécnico de \\ Viana do Castelo, Escola Superior de Desporto e Lazer; 4. Instituto Politécnico da Maia - Grupo de Investigação para o Desporto, \\ Educação e Saúde, GIDES; 5. Institute University of Maia, ISMAI, Maia, Portugal; 6. Porto Biomechanics Laboratory, LABIOMEP, \\ Porto, Portugal; 7. Research Center in Sports Sciences, Health and Human Development, CIDESD
}

\begin{abstract}
Physical qualities are known to play an important role in football. Differences were previously reported between different competitive levels, age-groups, gender and to a much lesser extent, starters and nonstarters (Gravina et al., 2008). The aim of this study is to compare body composition, strength and power between starters and non-starters. Twenty-six elite junior football athletes from the same club exposed to the same training, were divided into two groups: starters $(n=14 ; 17.2 \pm 0.6$ years; $173.3 \pm 5.9 \mathrm{~cm} ; 70.2 \pm$ $5.3 \mathrm{~kg})$ and non-starters $(\mathrm{n}=12 ; 17.3 \pm 0.5$ years; $176.6 \pm 6.1 \mathrm{~cm} ; 69.3 \pm 5.3 \mathrm{~kg})$ according to selection for start in one of 5 games. Starters played significantly $(\mathrm{p}<0.05)$ more time $(295.6 \pm 197.3$ vs $128.5 \pm$ 129.4) in comparison to non-starters, in the first 5 games of the season. Objective measures of body composition, strength and power, were collected by trained technicians. Body composition was assessed using Dual-energy X-ray absorptiometry (DXA) (Hologic Inc.). The net peak force was assessed for the Isometric Mid-Thigh Pull (IMTP) using a force plate (Kistler, Type 9260AA). Extension (PText) and flexion peak torque (PTflex) was evaluated with a load cell (Vertek VZ101BH 1ton), with the subjects seated on a custom-built chair with the hip and knee joint angle of approximately $90^{\circ}$. Jump performance was assessed trough squat jump (SJ), counter-movement jump (CMJ) and depth-jump (DJ) tests (Chronojump Boscosystem). Generalized linear models were used to evaluate the associations between number of minutes played (NMP) strength and power variables. The effect sizes (ES) analysis reported, small effect sizes $(\mathrm{d}=.20)$ for CMJ $(40 \pm 0.4$ and $38 \pm 0.4 \mathrm{~cm}$, starters and non-starters respectively) , DJ $(38 \pm 0.5 \mathrm{~cm}$ and $31 \pm 0.5 \mathrm{~cm})$, PText $(49.0 \pm 13.1$ and $41.9 \pm 9.3 \mathrm{Nm})$, PTflex $(25.9 \pm 6.7$ and $25.6 \pm$ $5.9 \mathrm{Nm})$ and medium effect sizes $(\mathrm{d}=.50)$ were found for SJ $(35 \pm 0.3$ and $33 \pm 0.3 \mathrm{~cm}$, starters and nonstarters respectively), DXA fat\% (13.7 \pm 1.4 and $15.0 \pm 2.0 \%)$, DXA lean mass $(86.4 \pm 1.4$ and $85.0 \pm$ $2.0 \%)$, and IMTP $(1217.3 \pm 205.3$ and $1172.0 \pm 126.8 \mathrm{~N})$; in favour of the starters. When adjusted for height and weight, PTflex was positively associated with NMP $(\beta=17,95 \% \mathrm{CI} 2.7 ; 31.4)$. Moderate effects were observed between strength, power and body composition and the selection of elite junior athletes. This data suggest the importance of developing such characteristics in elite junior footballers.
\end{abstract}

References

Gravina, L., Gil, S. M., Ruiz, F., Zubero, J., Gil, J., \& Irazusta, J. (2008). Anthropometric and physiological differences between first team and reserve soccer players aged 10-14 years at the beginning and end of the season. Journal of Strength and Conditioning Research, 22(4), 13081314. http://doi.org/10.1519/JSC.0b013e31816a5c8e

\section{Block constrain to the setter in volleyball during the side-out}

\section{João Prudente ${ }^{1,2}$, Ricardo Nunes ${ }^{1}$}

1. Faculty of Social Sciences, Department of Physical Education and Sports, University of Madeira; prudente@uma.pt

2. Research Center in Sports Sciences, Health Sciences and Human Development, CIDESD, Portugal

In volleyball the setter has among others a major role in managing the offensive capabilities of his team in the various complexes of the game (Afonso \& Mesquita, 2005), namely in side-out. The way the setter handles the opponent first defensive line: the block and its movements is crucial for maintaining the numerical advantage and initiative in the confrontation between spikers and blockers. The study aims to analyse how elite setters manage during side-out this constraint, understood here as an opportunity to act. For this study it was used observational methodology, and built, validated and subsequently used a mixed ad hoc instrument, field format with categories systems to collect the data (Anguera \& Blanco, 2001). Descriptive statistic and the prospective and retrospective sequential analysis was used for data analysis. The sample included all $(n=1120)$ side-out game sequences, which occurred in 12 games of the quarterfinals of the Italian Championship Volleyball A1 - 2010. For observation and recording of data from each sequence, seventeen categories were defined, between them: Number of Spikers in First Line, Start Position of the Block, Distribution Zone, Reception Quality, Middle Spiker Approach, Block Movements, Attack Organization, Shot Zone, Shot Tempo, Block Opposition. The main results shows that: (1) The action developed by the setter, produces $66 \%$ of spiking situations with block opposition less than 2 composed elements; (2) Tempo 2 (T_2) is the most used in the spike; (3) Most used attack zone, is the position 4 (ZR_5) with 31\%; (4) The sum of the areas used by fast attacks (ZR_7, ZR_1, ZR_2) totalized $31 \%$; (5) Sequential analysis allows us to state that: there is a significant probability (values $>1,96$; $p-0.05$ ) that the use of central distribution zones simultaneously with different block movements make the setter 
activate different attack zones. They were detected different patterns of behaviour and it was found that the factors of distribution location and block movements are constraints on action of the setter. Setter uses the information generated by the block, their positions and movements prior of the set to attack in order to maintain the initiative advantage. This situation creates more favourable conditions for their spikers complete the attack actions in side-out. This is more likely to occur if set is made in the central area of 3 meters.

References

Afonso, J., \& Mesquita, I. (2005). The Relationship Between Spike Tempo and Zone on the Number of Blockers in a Variety of Men's National Team Game Phases. International journal of Volleyball Research, 8, 19-23.

Angera, M. T., \& Blanco-Villaseñor, A. (2001). Registro y Codificación del Comportamiento Deportivo. Em A. Hernández-Mendo (Ed.), Psicología del Deporte: Metodologia (Vol. II, pp. 6-34). Buenos Aires: Túlio Guterman.

\section{A Pedagogical project for football coaching education}

Jorge Baptista ${ }^{1.2}$, Bruno Travassos ${ }^{1.3}$, Júlia Castro ${ }^{1.2}$

1. Research Center in Sports Sciences, Health Sciences and Human Development, CIDESD, Portugal; 2. University Institute of Maia, ISMAI, Maia, Portugal; 3. University of Beira Interior, UBI, Covilhã, Portugal; brunotravassos@hotmail.com

It is a common belief in coaching education that coaches do not value academic and formal knowledge as much as experiences in context environments such as peers' observation, expert coaches' observation, and knowledge sharing (Gilbert, Côté, \& Mallet, 2006). In Portugal, research has shown that coaches give more importance to guided sources, while emphasizing experiential sources through work with expert coaches (Mesquita, Isidro, \& Rosado, 2010). Despite the relevance of these findings, studies addressing critical evaluation of learning models and programs are lacking (Erikson et al., 2008). Therefore, we aimed to present and discuss: 1) a model for coaching training that proposes a set of interactive learning experiences, based on real coaching practice that would emerge from the conceptualizations of students' previous ideas of their "ideal game model" and guided by expert coaches; 2) method and preliminary results of a study of student $s$ perceptions of the program efficacy. Fifty-five $(n=35)$ male students (Mage: $25 \pm 1$ years) participated in this program. All participants had experience as football practitioners and short-term experience as football coaches. To evaluate the effectiveness of the model for coaching training, a questionnaire with 5 dimensions distributed in 12 questions was developed and applied to all the students that participated in the program. Also, twelve students were randomly selected to participate in a focus group interview. The preliminary results revealed an increase in participants' perception of confidence to work as coaches after the program in comparison with previous the program $(\mathrm{p}<.05$ for all the variables). The preliminary results of this study revealed that the proposal model for coaching training that promotes interactive learning experiences, based on real coaching practice, could be a valid method to be used on coaches' formation.

References

Erikson, K., Bruner, MacDonald, D., \& Côté, J. (2008). Gaining Insight into Actual and Preferred Sources of Coaching Knowledge. International Journal of Sport Science \& Coaching, 3(4), 527-538.

Gilbert, W., Côté, J., \& Mallet, C. (2006). Development Pathways and Activities of Successful Sport Coaches. International Journal of Sport Science E Coaching, $1(1)$, 69-76.

Mesquita, I., Isidro, S., \& Rosado, A. (2010). Portuguese coaches perception of and preferences for knowledge sources related to their professional background. Journal of Sports, Science and Medicine, 9, 480-498.

\section{Ethics and Olympic Movement in the graduation of football coaches in Portugal}

Teresa Rocha ${ }^{1}$, Xesus Peña ${ }^{1}$, Maria Martinez-Patiño ${ }^{1}$

1. Pontevedra University, Pontevedra, Spain; olympicteresa@gmail.com

Generally, sports are assumed, released and understood as a school of values for life. In this context, the coach must work as an agent, promoter of values and attitudes, which dignify his intervention, to the athlete and the practice of sports, through the example and model, the essential rules of sportsmanship. In recent years we have witnessed that the behaviours of some coaches have been deteriorating, in other words, the use of inappropriate language in sports grounds, a lack of respect for the referees and or the remaining technical teams. At the present the prestige of winning an Olympic medal by an athlete/team is the image of the coach that is of utmost importance for the valorisation of the coach/athlete in the Olympic environment. Are the coaches aware and sensitive to the Olympic Education, in transmitting Olympic Values to their athletes? The aim of this study is to present a set of issues related to ethic, Olympic Movement and to verify which values guide the career of a football coach. This study also aims: - to know if the coach transmits to their athletes the values and in which situation; - to identify which knowledge they have about the Olympic Movement and which sports values they have in their training as coaches. A 
questionnaire was submitted to coaches from both sexes in Portugal, a total of 103 . For $25.24 \%$ of the coaches Olympism is a Humanist Ideal, only $6.79 \%$ said it was a philosophy of life as described in the Olympic Charter. 53.39\% of the coaches don't know other Olympic ideals other than Fair Play, those who answered yes in a total of $46.60 \%$ only $8.73 \%$ point out friendship and respect. In terms of the Olympic Spirit only $21.14 \%$ replied that he/she had already heard the term Olympic Spirit, defining it as the union and joy among nations. For these coaches $54.36 \%$, don't give great importance to the fact that their sporting discipline is an Olympic sport, only $10.67 \%$ mentioned that it confers a certain prestige on a person. With regard to the transmission of values only $41.74 \%$ of the coaches do it just before training situation. $23.24 \%$ didn't care if one of his players doped himself to win an Olympic Medal. The participation in an Olympic Game is merely a cultural enrichment and not a valorisation of their sporting careers. Excellence is pointed out as a value associated with the Olympic Games. Associating the questions if they know the Olympic Ideals and the great values associated with the Olympic Games; on one hand they don't know other Olympic Ideal than the Fair Play but they point out Excellence as a more representative value. Only $9.7 \%$ said that in the training courses of coaches was addressed the topic of Ethics and Olympism.

References

Olympic Charter, Edition IPDJ-PNED - Portuguese Institute of Sports and Youth, available at: http://www.ipdj.pt/

\title{
The influence of extracurricular activities in muscular fitness of students of the 5 th year of the 2 nd cycle of basic education
}

\author{
Marta Sousa ${ }^{1}$, Fernando Vieira ${ }^{1}$,Jéssica Barbosa ${ }^{1}$
}

1. Piaget Institute, Almada; fernando.vieira@almada.ipiaget.pt

In the progress of the various components of physical fitness in children and young people is related to the processes of growth and maturation, in particular those that occur in the phase of further development, moment in which the young person has an abrupt increase in their body structures. It is in this way that the school is a privileged place in education for health, in the improvement of physical fitness, (Haywood, 1991; McKenzie, Alcaraz, Sallis, \& Faucette, 1998). Present study has as main objective to understand the influence of extracurricular activities in muscle fitness of pupils of $2^{\text {nd }}$ cycle of Basic Education. This work aims to understand the extent to which the practice of physical activity and extracurricular activities can influence on muscle fitness of students, evaluated through the battery of tests of Fitnessgram. We used a group of $5^{\text {th }}$ year of children, students of the $2^{\text {nd }}$ cycle of Basic School Carlos Gargate, which conducted a questionnaire and some of Fitnessgram battery tests. Given that the study is correlational and pure experimental, students involved were divided into two groups, one control it is made up of students not practicing Extracurricular Physical Activities and the other group for practicing students in AFE's. We proceeded to the analysis of the results at different times of the school year, including one at the beginning of the school year and another at the beginning of the $3 \mathrm{rd}$ period, so comparing results on two occasions. According to the figures in the table in significant amounts in relation to the abdominal test at the time 1 $(p=0.011)$. There trends in different tests: extension arms at the time $1(p=0.080)$; extension of the trunk when two $(p=0.098)$. In addition to realize that the average in all muscular fitness tests is higher compared to the group who does not work, the value of BMI is lower and there is no evolution. The results of this study are consistent with the literature review written throughout the work, confirming the importance of physical activity but also promote activities outside of school, because although physical education help develop healthy motor skills each child has the ideal frequency for the end. With this, the extracurricular activities are essential to the good development of all children as it is still an essential factor for a good muscle fitness and above all in maintaining a healthy weight according to their body mass.

References

Haywood, K. M. (1991). The role of physical education in the development of active lifestyles. Research Quarterly for Exercise and Sport, 62 (2), 151156. https://doi.org/10.1080/02701367.1991.10608705

McKenzie, T. L., Alcaraz, J. E., Sallis, J. F., \& Faucette, F. N. (1998). Effects of a Physical Education Program on Children's Manipulative Skills. Journal of Teaching in Physical Education, 17(3), 327-341. https://doi.org/10.1123/jtpe.17.3.327 


\section{Wearable Technology and aquatic activities: a review}

Henrique P. Neiva ${ }^{1,2}$, Mário C. Marques ${ }^{1,2}$, Bruno F. Travassos ${ }^{1,2}$, Daniel A. Marinho ${ }^{1,2}$

1. University of Beira Interior, Department of Sport Sciences, Covilhã, Portugal; henriquepn@gmail.com; 2. Research Centre in Sport Sciences, Health Sciences and Human Development, CIDESD, Portugal

\section{INTRODUCTION}

Health and fitness monitoring is nowadays one of the most highlighted markets for general people, professionals and researchers. The development of wearable technology able to record in real time a wide variety of physiological and biomechanical parameters provides a great opportunity to improve physical health (Chan et al., 2012). Several studies have described their use to detect movement patterns, daily activity, and sleep patterns and the progresses attained (Chambers et al., 2015). However, some physical activities, due to its context, may have restrictions that hinder the use of those devices. For example, in-water activities are always conditioned by the interference of water. Therefore, our purpose was to examine the current research about the utilization of wearable technology in aquatic activities and provide perspectives for future research.

\section{METHODS}

The SPORTDiscus, Pubmed, and Web of Science databases were searched for studies published from 2007 to 2016. This review included studies about the use of wearable sensors, technological devices, commercially available in aquatic exercitation, which were identified using the following key-terms, individually and/or combined: wearable sensors, devices, technology, physical activity, aquatic activity, water sports, monitoring, and health. Studies must be written in English, published in a peer-reviewed journal, and containing research questions on this subject with human participants.

\section{RESULTS}

In the initial search, 603 studies were identified. A total of 112 original research studies focused on physical activity and from these, only 13 focused on water sports and were included in our final analysis. From these, all of them were on swimming and most of them focused on performance and biomechanical analysis. Sensors provided acute methods of measuring stroke and kick rate, and swimming velocity.

\section{CONCLUSIONS}

The wearable technology can be effectively used to detect movements and offers an alternative for monitoring physical activities. However, there are few studies about their influence on aquatic exercitation other than swimming. Future research is required to determine movement patterns and physiological variables, to develop user-friendly technology to be efficient for improving physical health.

Acknowledgments:

NanoSTIMA: Macro-to-Nano Human Sensing: Towards Integrated Multimodal Health Monitoring and Analytics, NORTE-01-0145-FEDER-000016.

\section{REFERENCES}

Chambers, R., Gabbett, T. J., Cole, M. H., \& Beard, A. (2015). The use of wearable microsensors to quantify sport-specific movements. Sports Medicine, 45(7), 1065-1081.

Chan, M., Estève, D., Fourniols, J. Y., Escriba, C., \& Campo, E. (2012). Smart wearable systems: Current status and future challenges. Artificial intelligence in medicine, 56(3), 137-156. 


\title{
Physical activity evaluation with wearable technology in school age children's and adolescents: an update
}

\author{
António C. Sousa ${ }^{1,2}$, Bruno Travassos ${ }^{1,2}$, Daniel A. Marinho ${ }^{1,2}$, Mário C. Marques ${ }^{1,2}$ \\ 1. University of Beira Interior, Department of Sport Sciences, Covilhã, Portugal; mariomarques@mariomarques.com; 2. Research \\ Centre in Sport Sciences, Health Sciences and Human Development, CIDESD, Portugal
}

\section{INTRODUCTION}

In recent years, physical activity (PA) assessment has increasingly relied on wearable monitors (Prince et al, 2008).As a result, there has been a rapid increase in the PA assessment instruments, which are commercially available to researchers, practitioners, and consumers (Yang \& Hsu, 2010).Unfortunately, the literature is still scarce about the use of these wearables technology in schools context. Therefore, our purpose was to examine the use of wearable technology in the evaluation of physical activities and provide perspectives for future research in school age children's and adolescents.

\section{METHODS}

This work was based on articles indexed in several databases as ISI Web of Knowledge, PubMed, and ScienceDirect. For the analysis the following keywords we included individually and / or combined: portable sensors, devices, technology, physical activity, children, adolescent, evaluation, monitoring and health.

\section{RESULTS}

The most used wearable gadgets to provide a precise assessment of $\mathrm{PA}$ are: heart rate monitors (which provide an indication of exercise intensity), accelerometers (which provide an indication of the motion count), pedometers and the global positioning system (GPS).The heart rate monitors were usually used to quantify power consumption associated with different movement speeds of children in school. The accelerometers are motion sensors, sensitive to changes in the acceleration of the body in different axes, allowing to measure the frequency, intensity and duration of a PA. The pedometers registers the number of steps based on the detection of changes in body acceleration. The GPS determines the location, direction and speed of the activity performed.

\section{CONCLUSIONS}

In brief, wearable technology can actually be a very important instrument/tool to monitor PA in children and adolescents. Despite of the benefits of the use of these instruments to evaluate the physical condition and PA in schools, few studies were observed with the aforementioned goals. Consequently, it appears to be necessary more studies using these tools to improve training quality and children and adolescent overall physical performance.

\section{Acknowledgments: \\ NanoSTIMA: Macro-to-Nano Human Sensing: Towards Integrated Multimodal Health Monitoring and Analytics, NORTE-01-0145-FEDER-000016.}

\section{REFERENCES}

Prince, S.A., Adamo, K.B., Hamel, M.E., Hardt, J., Connor Gorber, S. \& Tremblay, M. (2008). A comparison of direct versus self-report measures for assessing physical activity in adults: a systematic review. The international journal of behavioral nutrition and physical activity, 5, 56.

Yang, C.C. \& Hsu, Y.L. (2010). A review of accelerometrybased wearable motion detectors for physical activity monitoring. Sensors, 10(8), 7772-7788. 


\section{Team sports in special groups and the use of technology: a review}

Nuno Mateus ${ }^{1}$, Nuno Leite ${ }^{1}$, Jaime Sampaio ${ }^{1}$

1. Research Center in Sports Sciences, Health Sciences and Human Development, CIDESD, CreativeLab Research Community, Portugal; ajaime@utad.pt

\section{INTRODUCTION}

In the last decade, physical activity in special populations has been widely studied. Swimming, aerobic exercises and resistance training are among the physical activities vulgarly recommended and used in clinical trials. Although less frequent, the health impact of team sports has also been studied and compared to traditional programmes. However, to date there are not know studies about the effects of wearables in team sports training programs to critical populations. The aim of this study was to review the effects of team sports protocols applied in special populations and emphasized the importance that technology can accomplish.

\section{METHODS}

B-On, PubMed, ISI Web of Science and ResearchGate were searched using the combined keywords "team sports", "elderly", "special populations" and "wearables". The inclusion criteria were: (1) team sports intervention programmes; (2) special populations of all ages, regardless of gender, physical activity level, health status and training experience. The exclusion criteria were: (1) papers with no team sports intervention programmes; (2) team sports activities applied in normal people.

\section{RESULTS}

From 36 studies found, a high variety of team sports methodologies were reported. Regarding team sports activities, the football training is the most studied with 35 studies published, followed by rugby with 1 study. The results showed that recreational football and rugby small-sided games are an effective physical activity for both children and adults, regardless of age, gender, physical activity level, health status and training experience. The only wearables used in the reviewed studies were heart rate belts and GPS devices as a way to monitoring the exercise.

\section{CONCLUSIONS}

Team sports had significant health promoting effects in elderly, overweight children and special populations (patients suffering from hypertension, type 2 diabetes and cancer). Moreover, football programs promoted psychological and social interactions that raise the social relations of participants and motivate for adherence to a long-term physically active lifestyle. Wearables could be a real asset, because in some studies the authors mentioned the occurrence of injuries that could be avoided in the presence of real-time feedback of the physical condition of the participants.

\section{Acknowledgments: \\ NanoSTIMA: Macro-to-Nano Human Sensing: Towards Integrated Multimodal Health Monitoring and Analytics, NORTE-01-0145-FEDER-000016.}

\section{REFERENCES}

Krustrup, P., Dvorak, J., Junge, A., \& Bangsbo, J. (2010). Executive summary: The health and fitness benefits of regular participation in small-sided football games. Scandinavian journal of medicine $\&$ science in sports, 20(s1), 132-135.

Mendes, J., Vieira, M., Pires, M., \& Stevan, S. (2016). Sensor Fusion and Smart Sensor in Sports and Biomedical Applications. Sensors, 16(10), 1569. 


\section{Exercise Monitoring in Persons with Peripheral Artery Disease}

Isabel Machado ${ }^{1}$, Joana Ferreira ${ }^{2}$, Catarina Abrantes ${ }^{1}$

1. Universidade de Trás- os- Montes e Alto Douro, DCDES, CIDESD, Vila Real; abrantes@utad.pt; 2. Centro Hospitalar de Trásos- Montes e Alto Douro/EPE, Serviço de Angiologia e Cirurgia Vascular, Vila Real

\section{INTRODUCTION}

Peripheral artery disease is an occlusive atherosclerotic disease of the arteries in lower limbs that affects millions of people all over the world. And, the major symptoms are related to intermittent claudication (Gardner, Parker, Montgomery, \& Blevins, 2014). The discomfort associated with intermittent claudication contributes to a sedentary lifestyle, increasing cardiovascular risk factors and decreasing physical fitness.

Exercise is a non-pharmacological strategy used to prevent and treat peripheral artery disease by its action in improving perfusion of the muscular-skeletal (Hamburg, \& Balady, 2011), being walking the most advantageous exercise mode (AMA, 2009).

The aim of this paper is to present the current state of knowledge on benefits of monitoring exercise in peripheral artery disease.

\section{METHODS}

Literature research of the exercise monitoring performed during exercise in people with peripheral artery disease.

\section{RESULTS}

Presentation of the most relevant results related to the effects of exercise on peripheral artery disease. And, the relevance of exercise monitoring to maximizing physiological adaptations to exercise and to decrease the symptoms of the disease.

\section{CONCLUSIONS}

The results of this research allow to conclude that exercise promotes benefits on symptomatology of the disease, however the information concerning the type of monitoring performed and their impact on physiological adaptations is scarce or inaccurate.

\section{Acknowledgments:}

NanoSTIMA: Macro-to-Nano Human Sensing: Towards Integrated Multimodal Health Monitoring and Analytics, NORTE-01-0145-FEDER-000016.

\section{REFERENCES}

Gardner, A. W., Parker, D. E., Montgomery, P. S., \& Blevins, S. M. (2014). Step-Monitored Home Exercise Improves Ambulation, Vascular Function, and Inflammation in Symptomatic Patients with Peripheral Artery Disease: A Randomized Controlled Trial. J Am Heart Assoc, 3(5), 1-11.

Hamburg, N., \& Balady, G. (2011). Exercise rehabilitation in peripheral artery disease: functional impact and mechanisms of benefits. Circulation, 123, 87-97.

AMA - American Medical Association (2009). Treadmill exercise and resistance training in patients with peripheral arterial disease with and without intermittent claudication. JAMA, 301 (2), 165-174

\section{Potential of non-invasive strategies for physiological evaluations in active ageing}

Eduardo Teixeira ${ }^{1}$, Sara Morais ${ }^{1}$, Catarina Garcia ${ }^{1}$, Carla Sá1,2, Luís Carvalho ${ }^{1}$, Alberto Carvalho $^{1,2}$, Alberto Alves ${ }^{1}$, João Viana ${ }^{1,2}$.

1. Research Center in Sports Sciences, Health Sciences and Human Development, CIDESD; 2. University Institute of Maia, ISMAI. Eduardo.teixeira@ismai.pt

\section{INTRODUCTION}

The interaction between the so-called personalized digital medicine (Kvedar, Fogel, Elenko, \& Zohar, 2016) and the constant evolution on wearable sensor technologies
(Bandodkar \& Wang, 2014; Kim et al., 2011) sets the stage for a new working paradigm regarding the evaluation of the physiological impact both in sports and exercise medicine. Therefore, scrutinizing non-invasive strategies 
of collection and analysis of biomarkers, accurately providing information regarding the acute and chronic physiological effects promoted by exercise is mandatory, particularly in the ageing population. Despite their own limitations, when compared to invasive methods such as blood collection and muscle biopsies, many advances have been made when using sweat, tears, urine and saliva (Gao et al., 2016; Imani et al., 2016; Lindsay \& Costello, 2016) to precisely monitor physiological alterations and health status in sports and exercise medicine. Important biomarkers that characterise health status and sport-related adaptations (e.g., muscle damage, inflammation, cardiovascular stress, oxidative stress, immune response and hydration state) are present in both urine and saliva (Lindsay \& Costello, 2016). Moreover, physiological alterations of skin temperature and sweat constituents are highly valuable to understand an individual physiological state and can be used as a diagnosis for common pathological situations and sport-related effects, e.g., hyponatremia, hypokalemia, dehydration, glucose monitoring, pressure ischemia (lactate in sweat) and pressure ulcers (temperature) (Gao et al., 2016). Finally, electronic sensors that can accurately record electrophysiological signs (EPs) from the skin are also of great potential. Either EPs from the heart [electrocardiograms (ECGs)] or muscle tissue [electromyograms (EMGs)] can now be obtained through biocompatible materials (without the use of conductive gels or penetrating needles) that do not degrade or cause skin irritation when used more than $24 \mathrm{~h}$ (Kim et al., 2011). These sensors, besides the use in clinical settings, may be particularly important to monitor elderly individuals with higher risk of cardiovascular pathologies such as myocardial infarction, arrhythmias and hypertension (Michard, 2016). Moreover, insight from the EMGs may be valuable to analyse fall situations and help to prevent their occurrence. The integration and scientific validation of these technologies in the sports and exercise medicine field is mandatory.

\section{Acknowledgments:}

NanoSTIMA: Macro-to-Nano Human Sensing: Towards Integrated Multimodal Health Monitoring and Analytics, NORTE-01-0145-FEDER-000016.

\section{REFERENCES}

Bandodkar, A. J., \& Wang, J. (2014). Non-invasive wearable electrochemical sensors: a review. Trends in Biotechnology, 32(7), 363-371. doi:10.1016/j.tibtech.2014.04.005

Gao, W., Emaminejad, S., Nyein, H. Y., Challa, S., Chen, K., Peck, A., .. . Javey, A. (2016). Fully integrated wearable sensor arrays for multiplexed in situ perspiration analysis. Nature, 529(7587), 509514. doi:10.1038/nature16521

Imani, S., Bandodkar, A. J., Mohan, A. M., Kumar, R., Yu, S., Wang, J., \& Mercier, P. P. (2016). A wearable chemical-electrophysiological hybrid biosensing system for real-time health and fitness monitoring. Nat Commun, 7, 11650. doi:10.1038/ncomms11650

Kim, D. H., Lu, N., Ma, R., Kim, Y. S., Kim, R. H., Wang, S., . . . Rogers, J. A. (2011). Epidermal electronics. Science, 333(6044), 838-843. doi:10.1126/science.1206157

Kvedar, J. C., Fogel, A. L., Elenko, E., \& Zohar, D. (2016). Digital medicine's march on chronic disease. Nature Biotechnology, 34(3), 239-246. doi:10.1038/nbt.3495

Lindsay, A., \& Costello, J. T. (2016). Realising the Potential of Urine and Saliva as Diagnostic Tools in Sport and Exercise Medicine. Sports Medicine. doi:10.1007/s40279-016-0558-1

Michard, F. (2016). Hemodynamic monitoring in the era of digital health. Ann Intensive Care, 6(1), 15. doi:10.1186/s13613-016-0119-7

\section{Development of a questionnaire about the use of wearable technology to monitor exercise/physical activity}

Carla Sá1,2, Luis Paulo Rodrigues ${ }^{1,3}$, Alberto Alves ${ }^{1,2}$, João Viana,1,2, Vitor Lopes ${ }^{1,4}$

Research Center in Sports Sciences, Health Sciences and Human Development, CIDESD; 2. University Institute of Maia - ISMAI; 3. Polytechnic Institute of Viana do Castelo; 4. Polytechnic Institute of Bragança. carla.sa@ismai.pt

\section{INTRODUCTION}

Modern technological advancements have radically altered the way we live our lives.
Personal wearable systems that enable people to monitor their physical activity include pedometers, accelerometers, smartphone 
applications and heart rate monitors (Pantelopoulos \& Bourbakis, 2008). Evidence to support the reliability of wearable technology in monitoring physical activity is emerging (Pantelopoulos \& Bourbakis, 2008; Sanders et al., 2016). But despite the potential and the wide range of wearables available, little is known about the interest, usage and preferences for using wearables (Stephanie Alley \& Mitch J Duncan, 2016). Therefore, we aimed to develop a questionnaire about the use of wearable technology that captures how often people use it and how they use it to monitor exercise/physical activity.

\section{METHODS}

Based on a review of the literature we included 24 questions in the questionnaire. The answers to the questions use a multiple-choice format. The format and the content of the questions were tested informally in a sample of 69 volunteers, with a mean age of $35 \pm 14.8$ years old. Some questions were reformulated afterwards according to the suggestions and uncertainties presented by the participants while filling out the questionnaire. After this process, we intend to estimate the test re-test reliability of the questionnaire, stratified by age and sex, using a sample of 120 subjects from 20 to 65 years of age of both sexes.

\section{CONCLUSION}

We expect that the use of this instrument will help us to understand how people use wearable technology and if its utilization has any influence on physical activity levels.

Acknowledgments:
NanoSTIMA: Macro-to-Nano Human Sensing:
Towards Integrated Multimodal Health Monitoring
and Analytics, NORTE-01-0145-FEDER-000016.

\section{REFERENCES}

Pantelopoulos, A., \& Bourbakis, N. (2008). A survey on wearable biosensor systems for health monitoring. Conf Proc IEEE Eng Med Biol Soc, 2008 , 4887-4890. doi:10.1109/IEMBS.2008.4650309

Sanders, J. P., Loveday, A., Pearson, N., Edwardson, C., Yates, T., Biddle, S. J., \& Esliger, D. W. (2016). Devices for Self-Monitoring Sedentary Time or Physical Activity: A Scoping Review. J Med Internet Res, 18(5), e90. doi:10.2196/jmir.5373

Stephanie Alley, S. S., Diana Guertler, Cally Jennings,, \& Mitch J Duncan, C. V. (2016). Interest and preferences for using advanced physical activity tracking devices: results of a national crosssectional survey. BMJ Open, 6.

\section{ExTra4Health - integrating technology in monitoring exercise and its impact in health parameters in elderly people}

Sara Morais, S.T., Garcia, C., Teixeira, E., Sá, C., Carvalho, L., Carvalho, A., Alves, A., Viana, J.L.

Research Center in Sports Sciences, Health and Human Development, CIDESD; 2. University Institute of Maia, ISMAI. smorais@ismai.pt

\section{INTRODUCTION}

According to the 2011 Portuguese census, elderly people represent $19 \%$ of the population, with over 2 million individuals aged $65+$. Guaranteeing quality of life in ageing is of utter importance for society and it includes providing good healthcare and assuring elderly maintain the capacity of performing daily routine tasks independently for the longest period possible. A set of skills is required for this so-called Active Ageing, such as strength, balance, coordination, flexibility, resistance, mental health and motor control, which are all improved by physical activity. Exercise also helps preventing falls, which are the major cause for incapacity in elderly population (DGS, 2006).

A strong potential for the use of technology in monitoring of exercise and health-related outcomes has been identified, mainly in the field of information and communication technologies (ICT) (Sarasohn-Kahn, 2013). Moreover, the use of ICT promotes the engagement of participants in exercise and 
encourages the development of selfmanagement and autonomy abilities. The increasing concern in providing quality of life for elderly people and the heterogeneity related to their health conditions, make it urgent to develop customized exercise programs. Health status information arises as a primary indicator to personalize exercise plans and using technologies can simplify that. Thus, it is important to introduce ICT in exercise programs on a perspective of empowerment and making elderly more responsible for their own health.

ExTra4Health - Exercise Training for Health is a community-based exercise program for sedentary elderly people ( $\geq 65$ years old) without any contraindications for exercise. This evidence-based exercise intervention involves the combination of resisted, aerobic and agility exercises, accumulating a total of 180 minutes per week. It is expected a gradual introduction of ICT in the monitoring of the exercise program, whilst promoting the execution of the tasks in a home-based environment, with continuous follow-up and routine adaptation by the research team.

\begin{tabular}{l} 
Acknowledgments: \\
NanoSTIMA: Macro-to-Nano Human Sensing: \\
Towards Integrated Multimodal Health Monitoring \\
and Analytics, NORTE-01-0145-FEDER-000016. \\
\hline
\end{tabular}

\section{REFERENCES}

Instituto Nacional de Estatística, I. P. (2012). Censos 2011 Resultados Definitivos - Portugal. Lisboa.

Direcção-Geral da Saúde (DGS) (2006). A actividade física e o desporto: um meio para melhorar a saúde e o bem-estar. Lisboa.

Sarasohn-Kahn, J. (2013). Making Sense of Sensors: How New Technologies Can Change Patient Care. California Health Care Foundation.

\section{Sedentary behaviour and physical activity in older adults: systematic review}

Soraia Ferreira1, 2 , José Marmeleira1, 2, Armando Raimundo ${ }^{1,2}$

1. Universidade de Évora, Departamento de Desporto e Saúde, Escola de Ciência e Tecnologia; 2. Research Center in Sports Sciences, Health Sciences and Human Development (CIDESD). ammr@uevora.pt

\section{INTRODUCTION:}

The regular practice of physical activity (PA) is associated with several health benefits as decrease of blood pressure; improved cholesterol levels; decrease the risk of developing some forms of cancer, coronary heart diseases, type 2 diabetes, stroke, (WHO, 2008 ), cognitive decline and dementia (Marmeleira, Godinho \& Fernandes, 2009). Sedentary behavior is a risk factor for the development of some diseases described above. (Katzmarzyk, 2010). This behavior is defined by low energy expenditure in leisure activities ( $<1.5$ METs) (Matthews et al, 2008). Therefore, it is important to understand the physical activity levels of older people, to be possible, in the future, to prescribe adequate physical activity programs.

\section{OBJECTIVES}

The aim of this study was collect and analyze published literature relating to physical activity and sedentary behaviour levels in older adults.

\section{METHODOLOGY}

Using the following keywords: older adults, elderly, physical activity, sedentary behaviour, sedentary behaviour, levels, patterns, habits, prevalence, questionnaire, accelerom*, self report and diary we searched 6 databases; PubMed, SportDiscus, ScienceDirect, CINAHL, MedicLatina and Medline.

Studies were included if they written in the English, Spanish or Portuguese language, included key study outcomes, healthy older adults 65 years or over.

\section{RESULTS}

Ninety-two records were screened, and sixteen articles met the inclusion criteria.

Fifteen studies used objective measures (accelerometer) and a research used subjective measures (International Physical Activity Questionnaire).

The studies with accelerometry showed that 
$59 \%$ of older adults do not do the recommended physical activity recommendations. The sedentary behaviour is very high in this type of population. In included studies, the time spent in physical activity decreases as age increases.

\section{CONCLUSIONS}

This systematic review showed that the physical activity levels in older adults are low. It is important to implement health promotion strategies for prevent the increase of the daily PA in older people.

\author{
Acknowledgments: \\ NanoSTIMA: Macro-to-Nano Human Sensing: \\ Towards Integrated Multimodal Health Monitoring \\ and Analytics, NORTE-01-0145-FEDER-000016.
}

\section{REFERENCES:}

Katzmarzyk, P. (2010). Physical activity, sedentary behavior, and health: Paradigm paralysis or paradigm shift? Diabetes. 59, 2717-2725.

Marmeleira, J., Godinho, M., \& Fernandes, O. (2009). The effects of an exercise program on several abilities associated with driving performance in older adults. Accident Analysis \& Prevention, 41, 90-97.

Matthews, C., Chen, K., Freedson, P., et al. (2008) Amount of time spent in sedentary behaviors in the United States, 2003-2004. Am J Epidemiol. 167(7):875-81.

World Health Organization (WHO). 2008. Global Recommendations on Physical Activity for Health. http://apps.who.int/iris/bitstream/10665/44399/1/ 9789241599979_eng.pdf

\section{Technology to Monitoring Physical Exercise: State of the Art and Future Developments}

Filipe Matos ${ }^{1,2}$, Francisco Saavedra ${ }^{1,2}$

1. University of Trás-os-Montes and Alto Douro (UTAD), Vila Real, Portugal; fjfsaave@utad.pt; 2. Research Center for Sport,
Health, and Human Development, University of Trás-os-Montes and Alto Douro (UTAD), Vila Real, Portugal.

INTRODUCTION

The aims of this study were to analyze the state of art and future developments on the monitoring technology of physical exercise and provide an in-depth discussion of technologies and outcome measures utilized.

\section{METHOD}

The research process was conducted on the "Web of Science" databases. Fourteen studies were included in the analysis after a selection process according to the following inclusion criteria: 1) Original studies about technologies to monitoring physical exercise. 2) Studies must involve humans.

\section{RESULTS}

The fourteen reviewed studies were referred to Smart Apps, Home-based Interactive Training effectiveness, the interaction Human/Robot and the effectiveness of a heart rate monitoring devices. A total of 620 subjects were investigated, 134 male, 195 female and 291 non-identified subjects. Investigations were performed on young and older healthy adults, however, the clinical condition was not specified in some studies. Accelerometers and inertial sensors were used to capture body movement patterns, postures, counting steps and repetitions. The heart rate was also evaluated, as well as, cognitive aspects related to motivation, memory and wellbeing. Most of the reviewed studies reported positive results with respect to improvements in physical activity parameters and cognitive aspects related to motivation, memory and wellbeing.

\section{CONCLUSION}

Most of the technologies in the literature evaluate physical activity parameters, but not physical exercise. The number of controlled studies examining technologies to exercise monitoring remains small. The computerbased multimedia approaches can create a relatively individualized learning session for a client. The challenge is to properly use and apply the technology for patient learning and that the patient-provider relationship should be enhanced, not replaced. 


\author{
Acknowledgments: \\ NanoSTIMA: Macro-to-Nano Human Sensing: \\ Towards Integrated Multimodal Health Monitoring \\ and Analytics, NORTE-01-0145-FEDER-000016.
}

\section{REFERENCES}

Bertolotti, G. M., Cristiani, A. M., Colagiorgio, P., Romano, F., Bassani, E., Caramia, N., \& Ramat, S. (2016). A Wearable and Modular Inertial Unit for Measuring Limb Movements and Balance Control Abilities. IEEE Sensors Journal, 16(3), 790-797. https://doi.org/10.1109/JSEN.2015.2489381

Bleser, G., Steffen, D., Weber, M., Hendeby, G., Stricker, D., Fradet, L., ... Carré, F. (2013). A personalized exercise trainer for the elderly. Journal of Ambient Intelligence and Smart Environments, 5(6), 547-562. 